MATHEMATICAL MODELING OF SEDIMENT DEPOSITION IN RESERVOIRS

by

Jose Luis Lopez S.

July 1978

HYDROLOGY PAPERS

COLORADO STATE UNIVERSITY

Fort Collins, Colorado 


\section{MATHEMATICAL MODELING OF SEDIMENT DEPOSITION IN RESERVOIRS}

by

Jose Luis Lopez S.

HYDROLOGY PAPERS

COLORADO STATE UNIVERSITY

FORT COLLINS, COLORADO 80523 
1.1 Statement of the Problem.

1.2 Approach to the Problem.

1.3 Objectives and Scope.

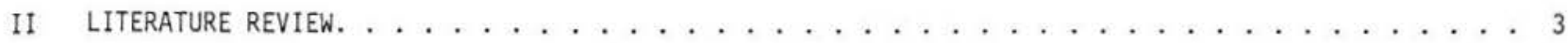

2.1 Historical Evidence of Reservoir Sedimentation. . . . . . . . . . . . . . . . . . . 3

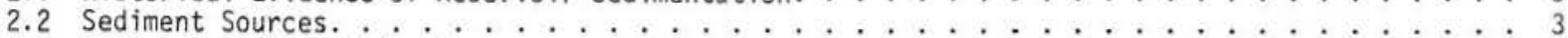

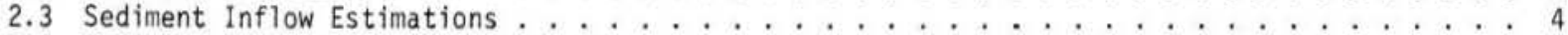

2.4 Sediment Retained in the Reservoir. . . . . . . . . . . . . . . . . . . . . . . . . 4

2.5 Specific Weight of Sediment Deposits. . . . . . . . . . . . . . . . . . . . . 6

2.6 Distribution of Sediment Deposits . . . . . . . . . . . . . . . . . . . . 7

2.6.1 Backwater Deposits . . . . . . . . . . . . . . . . 7

2.6.2 Delta Formation. . . . . . . . . . . . . . . . . . . . . . . . 8

2.6.3 Bottom Deposits. . . . . . . . . . . . . . . . . . . 8

2.6.4 Density Currents . . . . . . . . . . . . . . . . . . . . . . . 8

2.7 Control of Reservoir Sedimentation. . . . . . . . . . . . . . . . . . . . . 8

2.8 Mathematical Models in Reservoir Sedimentation. . . . . . . . . . . . . . . . 10

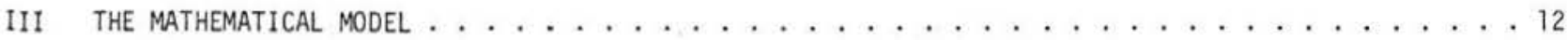

3.1 Introductory Remarks. ................................12

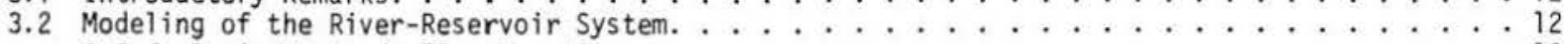

3.2.1 Basic Unsteady Flow Equations. . . . . . . . . . . . . . . . . . . . . . 13

3.2.2 Jet Flow Theory. . . . . . . . . . . . . . . . . . . . . . . . . 15

3.2.3 Compound Flow Theory. . . . . . . . . . . . . . . . . . . . . 17

3.3 Method of Solution. . . . . . . . . . . . . . . . . . . . . . . 17

3.3.1 Flow Routing . . . . . . . . . . . . . . . . . . . . . . . . . . . 17

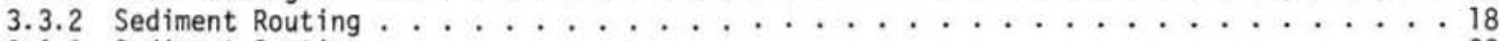

3.3.3 Sediment Sorting . . . . . . . . . . . . . . . . . . . . . . . . . . 20

3.3.4 Model Flow Chart and Data Requirements . . . . . . . . . . . . . . . . . . 21

3.4 Limitations of the Model. . . . . . . . . . . . . . . . . . . . 21

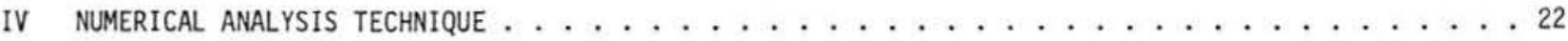

4.1 Finite Difference Scheme. . . . . . . . . . . . . . . . . . . . . . . . . . . 22

4.2 Discretization of the Flow Continuity Equation. . . . . . . . . . . . . . . . 23

4.3 Discretization of the Flow Momentum Equation. . . . . . . . . . . . . . . . . 23

4.4 Discretization of the Sediment Continuity Equation. . . . . . . . . . . . . . . . 26

4.5 Solution Algorithm. . . . . . . . . . . . . . . . . . . . . 27

4.6 Boundary Conditions . . . . . . . . . . . . . . . . . . . . . . . . . . . . .

4.7 Stability and Accuracy. . . . . . . . . . . . . . . . . . . . . . . . 29

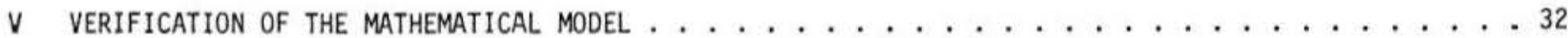

5.1 Introductory Remarks. . . . . . . . . . . . . . . . . . . . . . . 32

5.2 Flume Study. . . . . . . . . . . . . . . . . . . . . . . 32

5.2.1 Experimentai Equipment and Procedure . . . . . . . . . . . . . . . . 32

5.2.2 Model Evaluation ..............................33

5.2 .3 Discussion of Results. . . . . . . . . . . . . . . . . . . . . . . 35

5.3 Colorado River Study. . . . . . . . . . . . . . . . . . . . . . . . . 35

5.3.1 General. .............................. . . . . . . . . . . . . . . . . . . .

5.3 .2 Available Data ............................ . . . . . . . . . . . . . . . . .

5.3.3 Computer Model . . . . . . . . . . . . . . . . . . . . . . . . . . . . . 39

5.3 .4 Model Calibration. . . . . . . . . . . . . . . . . . . . . . 47

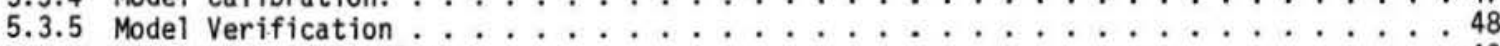

5.3 .6 Discussion of Results. . . . . . . . . . . . . . . . . . . . 49

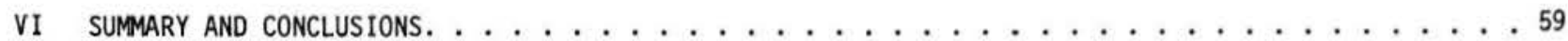

6.1 Summary and Discussion. . . . . . . . . . . . . . . . . . . . . 59

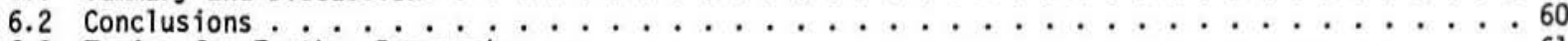

6.3 Topics for Further Research . . . . . . . . . . . . . . . . . . . 61

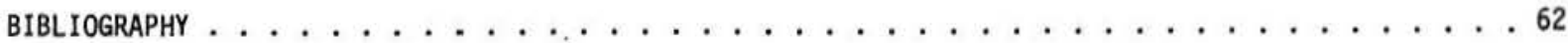




\section{ACKNOWLEDGMENT}

The writer wishes to express his deep gratitude to his Advisor and Major Professor, Dr. E. V. Richardson, Professor of Civil Engineering, for his help during the writer's graduate work. Special thanks are given to Or. Y. H. Chen, Assistant Professor of Civil Engineering, for his valuable suggestions and for the many hours spent in stimulating discussions. Dr. G. V. Skogerboe, Dr. V. M. Ponce, Dr. J. W. Andrew, and Dr. K. Mahmood served on the graduate committee. Sincere thanks are extended to them for their help in the author's Ph.D. program. In addition, a special thanks goes to Mrs. Dorothy A. Rein for her invaluable help during the author's graduate studies.

The financial support received during the writer's doctoral studies from CONICIT, an agency of the Venezuelan Government, is gratefully recognized.

The writer would like to acknowledge also the cooperation provided by the U.S. Bureau of Reclamation in Denver, Colorado, and Boulder City, Nevada, in obtaining the Colorado River data used in this study.

Part of the research leading to this dissertation has been financially supported by the Colorado State University Experiment Station. The aid is acknowledged. Acknowledgment is also given to the Technical Typing and Drafting sections of the Engineering Research Center at Colorado State University for their assistance in preparing the final draft of this dissertation.

Finally, the deepest gratitude is expressed to his wife, 01 impia, for her sacrifice in giving up her studies for the benefit of the writer's graduate studies.

\section{ABSTRACT}

When a dam is constructed across a river basin to form a reservoir the velocity of the flow in the reservoir is reduced and the sediment transported by the river is deposited. These deposits accumulate to form deltas. Estimation of the sedimentation rates and the amount and location of sediment accumulations are required by engineers in the design of reservoirs because of the sediment effect on active storage capacity, outlet elevations, recreational facilities and backwater upstream.

Prediction of the sediment distribution patterns in reservoirs is a complex task because of numerous interrelated factors involved in the process, such as size and gradation of the sediment particles, seasonal variations in river and sediment flow, size and shape of the reservoir and reservoir operating schedule.

A mathematical model for the prediction of the extent, locations and gradation of the sediment deposits in reservoirs is developed. The model considers the reservoir as a set of multiple channels and uses a compound stream model approach together with a two-dimensional jet theory to route the flow of water and sediment. Upstream from the reservoir a one-dimensional single channel approach is used to simulate the river flow.

Validation of the mathematical model is carried out in two steps. Initially, the sediment deposition pattern in a sudden expansion is studied by means of a physical model built in a laboratory flume, and secondly, available data from the Lower Colorado River above Imperial Dam is used to compare with generated bed profiles from the mathematical model. The flume study shows the importance of considering the jet model when studying the deposition pattern of wide basins. The extent and the distribution of the sediment deposits above the Imperial Dam appear to be in reasonable agreement with the observed data. The model can also effectively account for sediment sorting and for change in gradation of bed material with time.

The mathematical model provides a method for better and more accurate estimations of trap efficiencies in reservoirs. It can also be used as a predictive tool for design considerations in reservoirs by enabling a more precise determination of capacity curves and outlet elevations. 


\section{Chapter 1 INTRODUCTION}

\subsection{Statement of the Problem}

Reservoirs are constructed for one or more purposes which include source of water supply, source of irrigation water, source of power, flood prevention and recreation. In other words, reservoirs form part of a basic commodity for the economy and well-being of our society. All reservoirs formed by dams on natural water courses are subject to some degree of sedimentation. The problem confronting the hydraulic engineer is to estimate the rate of sedimentation and the period of time before the sediment will interfere with the useful functions of the reservoir.

In general, the construction of a hydraulic structure such as a dam alters the natural equilibrium of the stream by changing the characteristics of discharge and the sediment transport capability. Under these conditions a natural stream is usually classified into four different phases (Fig. 1.1). The first phase occurs upstream in the watershed where soil erosion and degradation takes place. This phase usually originates most of the sediment transported by the stream. The second phase is that part of the river where aggradation and/or degradation is taking place. This part of the system can be considered to be in dynamic equilibrium until changes induced by nature or man's activities alter the natural conditions. The third phase occurs in the reservoir itself where sediment deposition or aggradation takes place. That part of the stream downstream from the dam is further designated as the fourth phase where mostly degradation takes place.

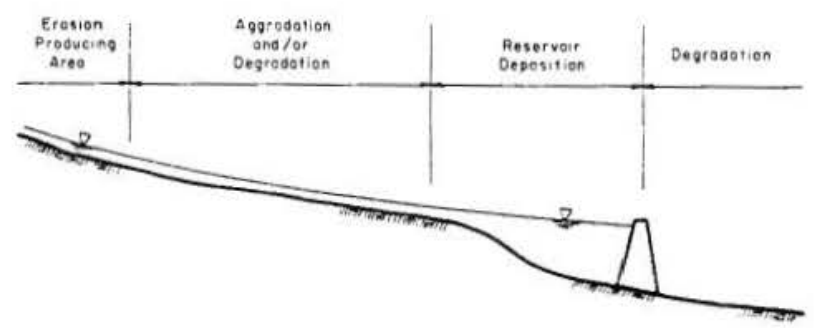

Fig. 1.1 - Four Regimes Associated with Aggradation and Degradation in a Natural Stream

In the design of the reservoir there are four areas of concern with respect to the sediment. These are: 1) sedimentation in the reservoir; 2) river response upstream of the reservoir; 3) river response downstream of the reservoir; and 4) handling the river during construction.

When a dam is constructed across a stream to form a reservoir, the velocity of the flow will be reduced and the major part, or all, of the sediment transported into the reach will be deposited in the reach of backwater influence and in the reservoir. These deposits accumulate to form deltas increasing the stream bed elevation at the upstream end of the reservoir. The increase in elevation can be significant and can increase the backwater effects of the reservoir a considerable distance upstream. Thus, the upstream river response will be the aggradation of tributary channels which is actually an extension of the reservoir sedimentation process which may adversely affect drainage conditions and aggravate flooding problems on adjacent lands. Downstream of the dam, water is usually released with a reduced sediment load and a consequential increase in available energy for sediment erosion takes place. The river response is then to degrade the bed until the river is again in balance with the new flow characteristics.

Estimation of the reservoir sedimentation rates and the amount and location of sediment accumulations is required by engineers in the design of dams because of the effect on active storage capacity, location of outlet structures and recreational facilities. Among other aspects affected by silting of reservoirs are sedimentation of navigable channels and harbors; aggradation of flood channels, causing increased frequency of flooding; silting of arable lands and destruction of fertility; increased cost of operating irrigation systems, due to the necessity of frequent dredging or provision of desilting works; increased cost of water supply treatment; damage to mechanical equipment by wear of gates, valves, turbines, etc.

It is therefore evident that estimating only the amount of sediment deposition in the reservoir is not sufficient; it is also necessary to predict how and where this sediment will be deposited.

\subsection{Approach to the Problem}

The accumulation of sediment deposits in reservoirs is dependent on many interrelated factors such as size and texture of the sediment particles, seasonal variations in river and sediment flow, size and shape of the reservoir and reservoir operation schedule. Prediction of the sediment distribution pattern is a complex task because of the interaction between these variables. Numerous approaches have been made to establish this distribution, but to a large extent have been based upon empirical field observations.

Recent technological advances in analyzing complicated physical problems have stimulated great interest in hydraulics to solve river problems by the use of mathematical models. The natural riverine environment has been studied extensively in an attempt to determine the interaction between sediment and water movement, bed formation in alluvial channels, and key parameter determination for sediment movement in general. From these studies numerous mathematical models have been developed and are currently being applied for the estimation of bed aggradation and degradation.

In reservoir sedimentation studies, hydraulic engineers are interested in the information on the amount and location of the sediments that will accumulate in a reservoir after a certain period of time. In the conventional approach to determine sedimentation rates, the whole river-reservoir system is considered as a lumped system and field data are used and analyzed statistically to relate the important variables. Thus, the complicated process of the interaction between these variables is ignored.

If the flow of water and sediment and the boundary conditions in the river-reservoir system can 
be described by analytical equations, a mathematical model of the system can be formulated. The mechanics of water and sediment movement in alluvial channels can be expressed by a set of partial differential equations: 1) the equation of continuity for the liquid and solid phases based on the principle of conservation of mass; and 2) the equation of motion based on the principle of conservation of momentum. Supplementary relations for the complete formulation of the problem should include equations describing the flow resistance properties, sediment transport capacity relationships, boundary conditions, geometry of the system, water and sediment properties, etc. This complete set of governing equations constitutes a mathematical model. It is clear that the interaction between these equations is so complex that one has to resort to numerical approximations and digital computers to find a solution.

By formulating a model about the river system, simulation experiments can be carried out in the computer and useful information can be obtained. Rather than starting with field data from which statistical interrelationships are derived and inferences drawn regarding the process, the mathematical model approach uses the process itself as the starting point. The mathematical model affords the engineer a technique to explore the interrelationship between the important variables of the process and it also offers a unique opportunity to study long-term system responses.

\subsection{Objectives and Scope}

Current mathematical models to predict sediment distribution patterns in reservoirs have not, to the best of the author's knowledge, considered all the major factors affecting the process of sediment deposition. Several major factors, such as nonuniform flow conditions in the transversal flow direction, delta development and specific weight of deposits with time need to be incorporated in a mathematical model not only to obtain a more realistic assessment, but also to study the effect of these items on conditions in and upstream from reservoirs.

The objectives of this study are to formulate a mathematical model to predict the location and extent of the sediment deposition in reservoirs, and to verify the mathematical model by using laboratory and field data.

In accordance with the above objectives, Chapter II reviews some important aspects related to the reservoir sedimentation problem. In Chapter III the theoretical basis is discussed and the mathematical model is formulated. Chapter IV deals with the numerical analysis technique and algorithms to solve the governing equations. Chapter $V$ uses data available from the Colorado River, upstream of the Imperial Dam, to validate the model and Chapter VI discusses the results and suggests some potential applications and/or design recommendations of the mathematical model. 


\section{Chapici 2 \\ UרRAIURL RLVILW'}

In order to explain and understand the phenomena of sediment deposition in reservoirs some of the important aspects related to the problem are reviewed in this chapter.

The problem of reservoir sedimentation and $i$ ts solution are inextricably united with that of erosion. Basically all of the sediment transported to a reservoir by a stream is derived from erosion of the land. The determination of the volume of sediment expected to accumulate in a reservoir is a problem which occurs in the planning of all reservoirs. Where the expected sediment volume is large, it becomes necessary to set aside a reasonable amount of space for sediment storage, so that the purpose for which the reservoir is intended can be served without undue shortages during the useful economic life of the structure.

Estimates of the magnitude and location of the sediment accumulation in reservoirs consists basically of the following parts:

1. Estimate of sediment inflow to the reservoir;

2. Estimate of sediment inflow that is retained in the reservoir;

3. Conversion of retained sediment from a basis of weight to volume; and

4. Estimate of distribution of sediment deposits.

The current methods of approach to each one of these parts are briefly reviewed here including some comments about the origin and nature of sediment and remedies for reservoir silting.

\subsection{Historical Evidence of Reservoir Sedimentation}

Sedimentation of canals and reservoirs is a common problem in every part of the world that reduces the efficiency of irrigation systems and absorbs funds and labor for maintenance that are solely needed for activities to increase production. The accelerated silting of reservoirs, cutting their effectiveness for hydroelectric-power generation, flood control, and irrigation, has huge annual worldwide costs that have never been totaled.

In the early history of reservoir development in the United States, little attention was given to sedimentation as a factor in design. Reservoirs built below watersheds with low rates of erosion did not suffer appreciable damage because of sediment accumulation. But in humid agricultural areas where erosion rates are relatively higher, serious depositio:is of sediment in reservoirs have occurred. A review of the annual rates of deposition in reservoirs built prior to 1935 in these problem areas, as reported by the Sedimentation Committee, Water Resources Council (United States Department of Agriculture, 1973), indicates that 33 percent have lost from one-fourth to one-half of their original capacity; about 14 percent have lost from one-half to three-quarters of their original capacity; and approximately 10 percent have had their capacity reduced to run-of-river conditions with all usable storage completely depleted.

Siltation is especially dramatic in reservoirs that are small in relation to the river feeding them, such as the Mangla and Tarbela Reservoirs in Pakistan. The water-holding capacity of the Tarbela Reservoir is only about one-seventh the annual flow of the soil-laden Indus, ensuring a short life. Lake Mead on the Colorado River, by contrast, holds more than twice as much water as the Colorado carries in a year, and will remain useful for centuries, despite the river's high sediment load.

The threat of siltation is frequently underestimated by dam builders, resulting in unhappy surprises later on for governments and farmers. The Anchicaya Dam in Colombia is a good example of this problem in which the potential sedimentation of the reservoir was underestimated, even though the inflow of farmers and roads to the surrounding slopes was beginning at the time of its construction. The rate of sedimentation was so fast that in 1957, only twenty-one months after the dam was completed, nearly a fourth of the reservoir capacity had been lost to sediment (Eckholm, 1976).

Preliminary calculations for Taiwan's Shihmen Reservoir suggested a useful life of seventy-one years, but in one five-year period, from 1963 to 1968 , 45. percent of its capacity was lost, provoking a new government program to halt unauthorized forest clearing and the rapid spread of farming onto steep slopes upstream. The Philippines' Ambuklao Dam, built to last sixty-two years, will be useful for only thirty-two years, mainly because of excess logging in the Upper Agno River watershed.

A sample survey in 1941 indicated that 39 percent of the reservoirs in the United States had a useful life of less than fifty years. The total economic loss from reservoir sedimentation in the United States was estimated at fifty million dollars per year as of 1962. As pointed out by Eckholm, a good reservoir site is, in a sense, a non-renewable resource. Once exploited and then destroyed by silt, it can be replaced only at increased expense, and sometimes it is irreplaceable.

\subsection{Sediment Sources}

Basically all the sediment transported to a reservoir by a stream originates in sheet erosion on the watershed or in the various types of bank erosion on the river channel. In regions where erosion is negligible, silting of reservoirs may not be serious; and, where erosion is normally excessive, or has been accelerated by man's activities, reservoir silting can be rapid. However, this is not always true. The ratio of reservoir volume to mean annual water flow is a good index for a quick estimate. When this ratio is low, say less than 1.0, then trouble in the reservoir can be expected.

Witzig (1943) groups the factors influencing the erosion cycle in two broad classes. "Eroding and transporting forces" include rate of runoff, turbulence of flow, fluid shear at boundaries and in eddies, fluid and particle impacts, surface and channel slopes, roughness, and sediment concentration. "Resisting and depositing forces" include gravity, adhesion, protective cover, impermeability, decrease in turbulence, penetrable surface cover and flocculation. Theoretical attempts to evaluate more than two of these factors at a time is very difficult. The quantitative, empirical approach by way of field survey or reconnaissance gives probably the best data on erosion for engineering usage.

Robert Horton (1941) states that, of the total erosion in the evolution of a humid drainage basin, 
probably 1 percent was initially bank erosion, and 99 percent sheet erosion. In some instances the major immediate source of sediment may be erosion of the bed and banks or headcutting in a degrading channel. The watershed characteristics most patently affecting sediment production and hence the rate of sediment delivery to a reservoir are: 1) degree of erosion; 2) relative extent and distribution of kinds of erosion (sheet, bank, gully, highway, etc.); 3) soil type (size of particles); 4) amount of runoff and character of discharge; and 5) topographic form.

\subsection{Sediment Inflow Estimations}

The sediment produced by erosion finds its way to the reservoir through the river by movement in suspension and movement as bed load. The former accounts for transport of most of the finer sediment, whereas the coarser sands and gravels, and boulders, are moved by rolling and jumping along the bed of the stream.

In genera1, sediment inflow estimations are made by using one or more of the following methods or approaches.

1. The sediment-rating curve-flow duration method requires concurrent field measurement of streamflow and sediment to establish an average relationship between parameters of streamflow and sediment quantity. Corrections for the unmeasured portion of the sediment load have to be made. These corrections can be made by using one of the several bed load or total-load formulas available. The Modified Einstein Procedure is most commonly used for estimating total load when channel-hydraulic and suspended-sediment data are available. Total load computations are made for several discharges and the sediment-rating curve is then adjusted for the quantity of unmeasured load over its entire range.

2. The reservoir sediment-deposition survey method involves measurement by field survey of the volume of sediment accumulated in a reservoir. The measured volumes are converted into weights, adjusted for reservoir trap efficiency, and expressed as rates of accumulation according to the age of the reservoir or the time interval between surveys. Deposition surveys on a number of reservoirs in a land resource area, watershed or river basin are often compiled and summarized to show relationships between sediment yields and size of drainage area. This approach gives general useful information of the magnitude and variation of the sediment yield in the region of interest but has limited value for forecasting sediment yield from an individual watershed where no measurements have been obtained.

3. The sediment-delivery ratio method requires a factor expressing the percentage relationship between sediment yield from a watershed and gross erosion in the watershed in the same time period. Sedimentdelivery ratios are developed from the sediment yields obtained by reservoir surveys or measurements at suspended-load stations in comparison with erosion in the watershed. The erosion quantities for sloping uplands are computed by erosion prediction equations and are estimated by various procedures for gullies, stream channels, and other sources.

4. Sediment transport relationships make use of mathematical equations developed for calculating the rate and quantity of movement of sediment materials. There are a variety of other methods in this classification but the most common is the Bedload Function of Einstein, with one of its many modifications or the more recent Toffaleti procedure. The equations often give widely different results for the same conditions.

5. Estimate of the sediment yield can be made on the basis of field inspections of the watershed and by comparison with other areas. By using reservoir resurvey information or long-term sampling data from watersheds having similar climatic, topographic, and geologic properties it is possible to construct sediment yield rate curves with drainage basin size as the independent variable. Obviously the reliability of this method depends upon the skill of the sedimentologist doing the reconnaissance study; it is best applied to preliminary planning studies and has its greatest reliability when the yield rate can be correlated with a measured sediment yield from an adjacent basin or sub-basin.

\subsection{Sediment Retained in the Reservoir}

The actual accumulation of sediment in a reservoir will depend on the proportion of the inflowing sediment that will be retained in the reservoir. The trap efficiency of a reservoir is defined as the ratio of the quantity of deposited sediment to the total sediment inflow and is dependent primarily upon the sediment particle fall velocity and the rate of flow through the reservoir. Particle fall velocity may be influenced by size and shape of the particle, viscosity of the water, and chemical composition of the water. Another factor which also affects trap efficiency is size and age of the reservoir, type of outlets and operation of the reservoir.

The Task Committee (Vanoni, 1975) says that in large reservoirs, possibly those with 10,000 acre-ft or more of storage capacity, it may be assumed that the trap efficiency will be 100 percent; i.e., all the sediment entering the reservoir will remain there. There may be some sediment moved through the pool in density flows or during periods of very high discharge, but, considering the basic approximations involved in most estimates of the sediment quantities to be anticipated it is best to ignore this factor. In small dry reservoirs, sometimes most of the inflowing sediment may be transported through the pool. This may also occur during high inflow periods when a reservoir discharges over the spillway and there is an appreciable velocity of flow through the reservoir. Fine sediments (the silt and clay sizes) may remain in suspension long enough to pass through the reservoir. Sand sizes will not.

Methods for estimating reservoir trap efficiency are empirically based upon measured sediment deposits in a large number of reservoirs.

Brune (1953) presented an empirical relationship based on the records of 44 normally ponded reservoirs. His curves, relating trap efficienty and the ratio between reservoir capacity and mean annual water inflow, both in acre-ft, are shown in Fig. 2.1.

Churchill (1947) presented a relationship based on Tennessee Valley Authority reservoirs. His method relates the percentage of incoming sediment passing through a reservoir and the sedimentation index of the reservoir, i.e., the period of retention (capacity, in cubic feet, at mean operating pool level divided by average daily inflow rate, in cubic feet per second) divided by velocity (mean velocity, in feet per second, obtained by dividing average cross-sectional area, in square feet, into the inflow). The average 
cross-sectional area in this case is computed by dividing capacity, in cubic feet, by length, in feet. Churchill's curve is shown in Fig. 2.2.

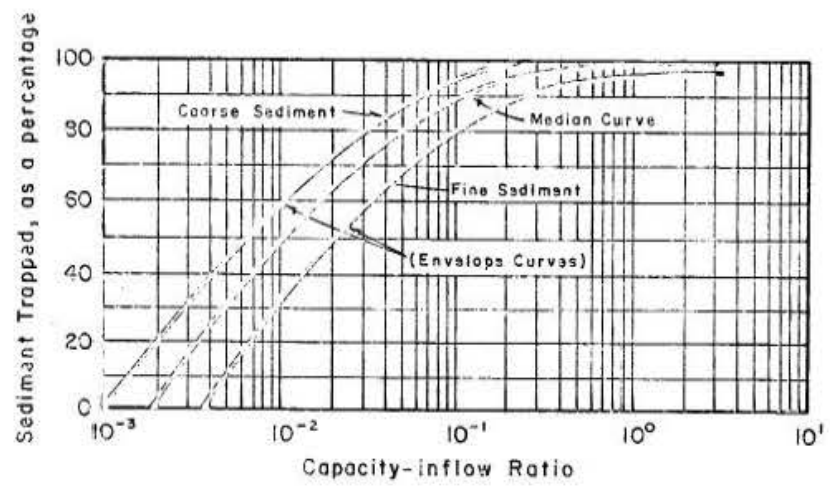

Fig. 2.1 - Reservoir Trap Efficiency Curve; Brune (1953)

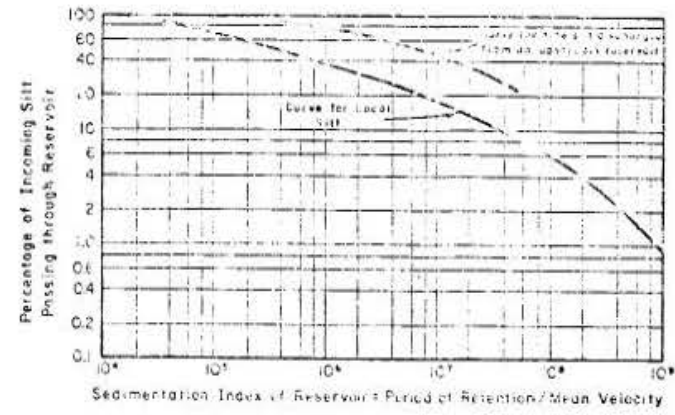

Fig. 2.2 - Reservoir Trap Efficiency Curve; Churchill (1947)

Borland (1971) verified Churchill's method with reasonable accuracy by applying known data from a number of sources, including reservoirs with a capacity of several hundred thousand acre-feet and concluded that Churchill's method gave better results than the Brune curves.

Karaushev, A. V. (1966) derived an analytical equation for calculation of the trap efficiency in small reservoirs.

$$
t_{e}=1-(1-\omega) e^{\frac{-\phi \omega}{1-\omega}}
$$

where $t_{e}=$ trap efficiency

$\omega=$ capacity inflow-ratio

$\phi=\frac{U_{T} S}{H_{\text {res }}}$

$U=$ the mean fall velocity of the transported sediment

$H_{\text {res }}$ = mean value of the depth of the reservoir

$T_{S}=$ duration of the spill-over period in seconds.

The Lasic calculation relation is presented in the form of a series of graphs relating the relative sedinent-retaining capacity of a body of water to its relative capacity (Fiq. 2.3). The parameter of this relationship is a variable which depends on the characteristic of the flovi, the body of water and the transported sediment. Karaushev pointed out that when = constant this cquation corresponds to
Brune's empirical graph and the deviation of a variable parameter $d$ reveals the inadequacy of Brune's empirical generalization. The best agreement between Brune's graph and the above equation is obtained for $\phi=30$, although points from the graph corresponding to specific reservoirs and sometimes exhibiting considerable deviations from the curve yield values of $\phi$ lying on an average between 20 and 40 . For the point most distant from the curve an even more significant deviation of $\$$ from the mean is obtained. It is evident that the actual data given in Brune's paper should be generalized not by a single curve, but by a family of curves, and that each curve of this family corresponds to a specific value of $\phi$.

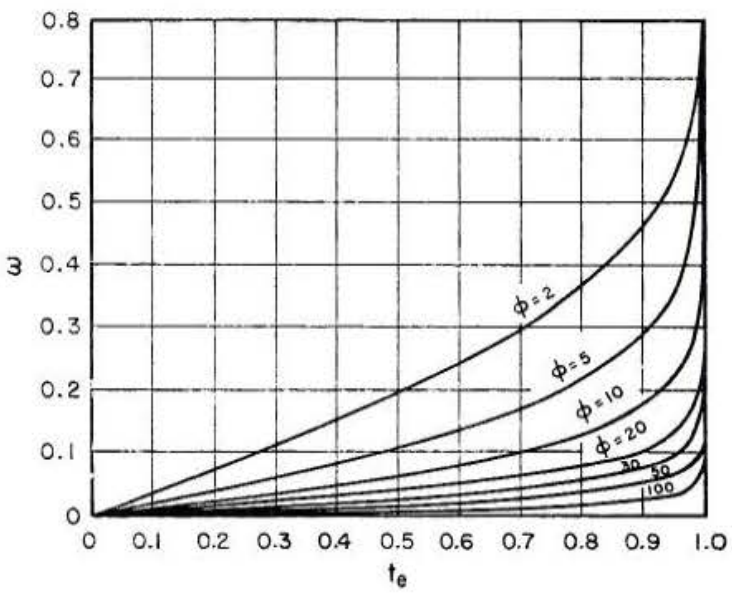

Fig. 2.3 - Reservoir Trap Efficiency Curve; Karaushev (1966)

Karaushev's equation can be applied to specific size categories of sediments accordingly with the proportions obtained from actual samples. The agreement of the expression theoretically derived with empirical observations gives good basis to accept its applicability even though the derivation of the expression for the parameter $\phi$ is not included in the paper.

Borland (1971) developed a procedure for computing the trap efficiency of a settling basin by applying the results obtained by Einstein (1965).

$$
t_{e}=1-e^{-\frac{1.055 \ell V_{s}}{V d}}
$$

where $t_{e}=$ fraction of material deposited over total settling basin length in percent

$\ell=$ settling basin in length in miles

$V=$ average flow velocity in feet per second

$\mathrm{d}=$ water depth in feet

$V_{\mathrm{s}}=$ fall velocity in feet per second.

This is the equation used in computing the quantities of sediment deposited within given particle size ranges. The sum of these quantities gives the total volume of sediment deposited in acre-ft. The trap efficiency is computed by dividing the total sediment inflow by the total sediment deposited expressed in percent. Borland pointed out that, when the estimated sediment volume accumulation is a substantial percentage of the reservoir capacity, it may be necessary to analyze the trap efficiency for some incremental periods of the reservoir life. Theoretically, the reservoir trap efficiency will progressively decrease once storage is begun. However, it is 
generally not practical to analyze the trap efficiency by increments of less than 10 years. The variation in annual sediment inflow rates may introduce anomalies in the analysis when shorter periods are used.

\subsection{Specific Weight of Sediment Deposits}

Sediment discharge data are normally reported in terms of weight, i.e., tons per day or per year. In order to utilize these data to estimate storage loss in reservoirs, it is necessary to convert the weight values into volumes. This is a very inexact procedure, because the volume of a given weight of sediment, when deposited in a reservoir, will vary with the proportions of sand, silt, and clay-size materials, the depth of the deposits, the mineralogical and chemical characteristics of the clay sediments and water, and variations of the pool level that might expose the deposits to alternate wetting and drying.

The Task Committee (1975) reports that the average overall weight of sediment deposits, based on samples and on reservoir sediment surveys, will vary in different reservoirs from as low as 30 pcf (dry' weight) to $100 \mathrm{pcf}$ (dry weight). The dry weight of sand in place in several delta deposits was about 85 pcf; however, a more commonly used value is 95 pcf. The term specific weight of a sediment deposit, as used herein, is defined as the dry weight of the sedimentary material within a unit volume, which in the foot-pound system of units is expressed in pounds per cubic feet. Because there are voids between the grains of sediment, the specific weight of the deposit is always less than that of the grains themselves.

On the above-mentioned factors affecting the weight of deposited sediments, probably the most influential is that of reservoir operation. Sediments depositing in a reservoir that is drawn down for considerable periods are subjected to exposure. The sediments consequently dessicate and become more dense, thus increasing the unit weight. On the other hand, reservoirs normally operating with a full pool would cause the unit weights to be lower, the deposited sediments not being exposed (Lara and Pemberton, 1963).

The size of the incoming sediment particles has a significant effect upon unit weights. Sediment composed largely of silts and sands would have higher unit weights than those in which clay predominates.

Compaction or consolidation rates are also of importance in affecting the unit weights of deposited sediments. The unit weight will increase each year sediment deposits remain in the reservoir.

Lane and Koelzer (1943), based on measurements of the weights of reservoir sediments, presented a relation for estimating the specific weight of deposits in reservoirs, taking into account the grain size of the sediment, the method of operating the reservoir and time:

$$
\gamma_{d}=\gamma_{d i}+k \log T
$$

in which $\gamma_{d}=$ the specific weight of a deposit with an age of $T$ years, in pounds per cubic foot

$\gamma_{d i}=$ its initial weight, usually taken to be the value after one year of consolidation

$K=$ constant with dimensions of pounds per cubic foot.
Both $Y_{d i}$ and $K$ are functions of sediment

size and method of operating the reservoir and are given in the paper. The equation gives the specific weight of material that has consolidated for a period of $T$ years after having reached its initial specific weight, in a short period of about one year. However, part of the sediment will deposit in the reservoir in each of the $T$ years of operation and each year's deposits will have a different compaction time.

Miller (1953), by integration of the above equation with respect to time, obtained the average specific weight of the sediments in a reservoir after $T$ years of operation during which deposits accumulated at a uniform rate:

$$
\gamma_{d a}=\gamma_{d i}+0.434 k\left[\frac{T}{T-1}\left(\log _{e} T\right)-1\right]
$$

Lara and Pemberton (1963) updated the procedure developed by Lane and Koelzer by using 1,316 samples for the determination of the initial unit weight of the sediment deposits. The basis of the development is correlation and regression techniques for computing the parameters involved in the formulas. Some of these formulas were taken from basic soil mechanics theories. Basically, the method consists of using parameters given in Table 2.1 and the following equation:

$$
\gamma_{d i}=W c P c+W m P m+W s P s
$$

in which $d i=$ initial unit weight in pounds per cubic foot

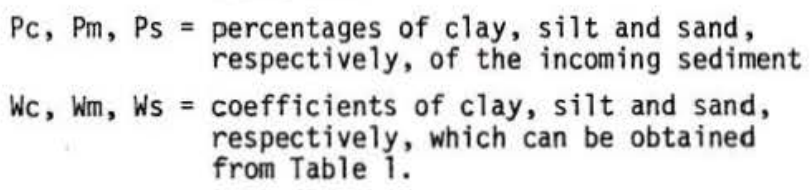

\begin{tabular}{|c|c|c|c|c|c|c|}
\hline \multirow{2}{*}{ Reservoir Operation } & \multicolumn{2}{|c|}{ Clay } & \multicolumn{2}{|c|}{ Silt } & \multicolumn{2}{|c|}{ Sand } \\
\hline & WC & K & $W_{m}$ & 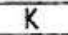 & WS & K \\
\hline \multicolumn{7}{|l|}{ Type } \\
\hline $\begin{array}{l}1 \text { Sediment always } \\
\text { submerged or } \\
\text { nearly submerged }\end{array}$ & 26 & 16.0 & 70 & 5.7 & 97 & 0 \\
\hline $\begin{array}{l}2 \text { Normally moderate } \\
\text { to considerable } \\
\text { reservoir drawdown }\end{array}$ & 35 & 8.4 & 71 & 1.8 & 97 & 0 \\
\hline $\begin{array}{l}3 \text { Reservoir normally } \\
\text { empty }\end{array}$ & 40 & 0 & 72 & 0 & 97 & 0 \\
\hline 4 Riverbed sediments & 60 & - & 73 & - & 97 & - \\
\hline
\end{tabular}

Table 2.1 Coefficients for the Computation of Specific Weight of Sediment Deposits (after U.S. Bureau of Reclamation, 1973)

The classification of sediment according to size as proposed by the American Geophysical Union is the most commonly used in sedimentation engineering:

Table 2.2 Classification of Sediment Sizes According to the American Geophysical Union

\begin{tabular}{cc}
\hline Sediment Type & $\begin{array}{c}\text { Size Range } \\
\text { (millimeters) }\end{array}$ \\
\hline clay & less than 0.004 \\
silt & 0.004 to 0.625 \\
sand & 0.0625 to 2.0 \\
\hline
\end{tabular}




\subsection{Distribution of Sediment Deposits}

When the flow of a stream enters the head of the backwater reach above a reservoir, the flow velocity will immediately begin to decline, and the coarsest sediments in transport will begin to be deposited. This process continues until, at some distance within the reservoir, the flow velocity has been sufficiently reduced so that all the sediments of sand size or larger have been deposited while the silt and claysize sediments are transported further into the pool. Thus, the deposit in general will consist of a backwater deposit, a sand and gravel delta and a bottom deposit of silt and clay materials.

According to Borland (1971) factors that influence the mode of deposition include: 1) size and texture of the sediment particles; 2) size and shape of the reservoir; 3) reservoir inflow-outflow relations; and 4) reservoir operating rules.

In order to compute how the sediments will distribute in a reservoir, the most accepted method seems to be the Empirical Area-Reduction Method developed by Borland and Miller (1958) and revised by Lara (1962). Briefly, this method was developed by analyzing data gathered from resurveys of 30 reservoirs. The data indicated that definite relationships between percent of total reservoir depth to percent of total reservoir sediment volume existed for each of four different reservoir types based on physical shape. The type of reservoir is found by plotting the reservoir depth (ordinate) against capacity (abcissa) on logarithmic coordinates. Usually this plots in a straight line, although some reservoirs have a physical shape resulting in two straight lines. The reciprocal of the slope of the line or lines indicates the reservoir type.

Table 2.3 Classification of Reservoirs (after U.S. Bureau of Reclamation, 1973)

\begin{tabular}{ccc}
\hline Reservoir Type & Classification & $M$ \\
\hline I & Lake & $3.5-4.5$ \\
II & Floodplain foothill & $2.5-3.5$ \\
III & Hill & $1.5-2.5$ \\
IV & Gorge & $1.0-1.5$ \\
\hline
\end{tabular}

in which $M=$ the reciprocal of the slope of the depth versus capacity plot on logarithmic paper.

Curves showing a rapid increase in capacity with depth indicate large basin-type reservoirs whereas a small increase indicates gorge-type reservoirs. Borland emphasizes that other kinds of conditions such as anticipated reservoir operation or size of the inflowing sediments may override the classification made on shape. As an example of these conditions, assuming that a reservoir has been classified as a hill type but the operation schedule shows the reservoir will be substantially drawn at frequent intervals, or assuming the inflowing sediments are predcminantly of the clay size, the reservoir should then be classified instead as a gorge-type.

The resurvey data for 30 reservoirs have been used to develop four standard type curves of percent sediment deposit versus percent reservoir depth (Fig. 2.4).

When the reservoir has been appropriately classified, the second main step is to make a trial and error type computation using the average end area or prismoidal formulas until the capacity computed equals the predetermined capacity. The sediment distribution computations proceed in an orderly manner as outlined in the report by Lara (1962).

Borland and Miller (1958) pointed out that still a procedure is needed which considers all the major factors affecting sediment deposition. Several major factors, such as density currents, delta development and specific weight of deposits with time need additional study and evaluation to develop procedures for predicting the effect of these items on conditions in and upstream from reservoirs.

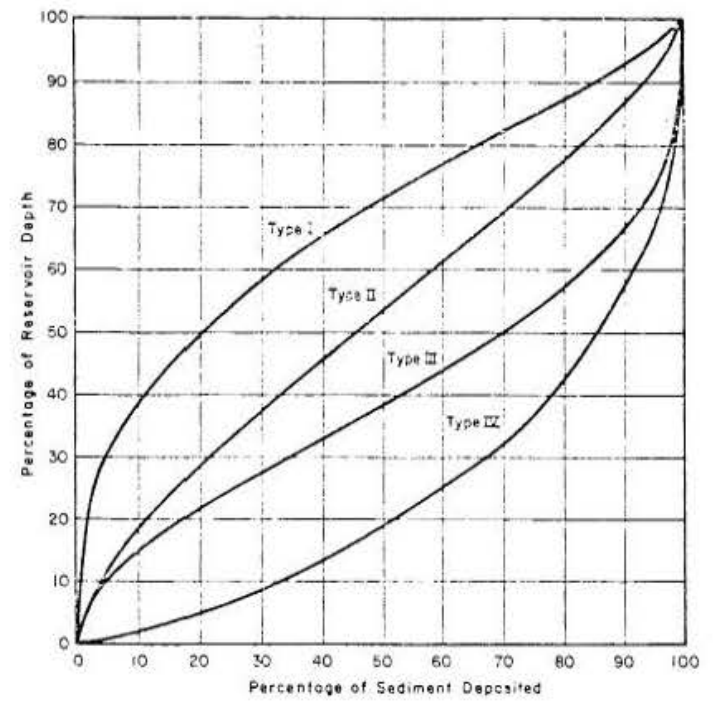

Fig. 2.4 - Reservoir Design Curves (U.S. Bureau of Reclamation, 1973)

\subsubsection{Backwater Deposits}

The backwater deposit is that material deposited in the backwater reach of the stream above the reservoir level. In theory it should grow progressively into the reservoir and upstream, because, as the deposit grows, the backwater effect is extended; however, its growth will be limited as the stream adjusts its channel through the deposit by el iminating meanders, by forming a channel having an optimum width-depth ratio, and by varying the bed form roughness so that these factors in combination, enable the stream to transport its sediment load through the reach (Vanoni, 1975).

The major consequence of these deposits is their effect on raising the backwater profile of the channel upstream of the reservoir which will result possibly in flooding problems.

Borland (1971) reports a situation of the Middle Loup River in Nebraska, above the Milburn Diversion Dam, where the water surface elevation, for a given discharge, rose as much as $5 \mathrm{ft}$ in a $16-\mathrm{yr}$ period.

The aggradation process can also cause undesire able environmental conditions to develop in the backwater zones. Stagnant pools can be formed, adjacent lands may become waterlogged, or the channel waters may deteriorate because of increasing sediment concentrations.

Severe backwater deposition problems have resulted in some areas because of the growth of 
phreatophytes, e.g., salt cedars. These plants grow very thickly and impede the flow of the water and cause the sediment to be deposited. This in turn permits further growth and additional deposition upstream.

\subsubsection{Delta Formation}

Sediment of sand size and larger will normally be deposited soon after the flow enters the reservoir. In a relatively narrow reservoir; i.e., one that is sufficiently narrow for the flow to spread evenly across the pool, the coarse sediments will also be spread evenly across the pool to form a delta in a pattern similar to that shown in Fig. 2.5. The surface of the deposits will be approximately at the average operating level of the pool, sloping downward at a rate of several feet per mile, until the downstream ends drops to the bottom of the reservoir at a slope of perhaps $10-15 \mathrm{ft} / \mathrm{mile}$.

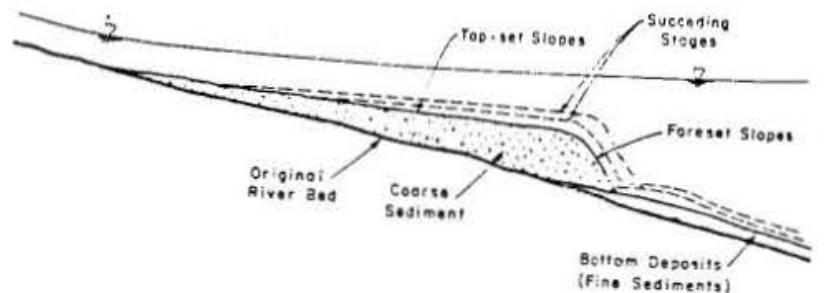

Fig. 2.5 - Typical Reservoir-Delta Profile

Borland (1971) reports that predicting the delta formation is based on an empirical procedure that was developed from a study of the delta depositional patterns of existing reservoirs that were resurveyed. The top set slope can be computed using either the Meyer-Peter, Muller Formula for beginning transport or the Schoklitsch equation for zero bed load transport. These equations compute a slope at which the bed material theoretically will no longer be transported, thus the conditions are established for the delta to begin to form. He further states that, it has been found that for most reservoirs the topset slopes closely approximate one-half the original channel slopes. This value serves as a verification of the slope computed by the two formulas mentioned above.

Locating the pivot point between the topset and foreset slopes depends primarily on the reservoir operation and the existing channel slopes in the delta area, but usually, the normal water surface elevation (conservation pool) is used as the pivot point elevation. The upstream limit of the delta is set at the point where the maximum water surface intercepts the original stream bed. Data of the portion formed by the topset beds which extend from this upstream limit to the pivot point are used to begin the reservoir delta profile computations. Borland also points out that Bureau of Reclamation Surveys indicate that the downstream (forset) slopes average 6.5 times the topset slope.

In the case of a stream entering a wide pool, the flow tends to enter the pool much as a jet and a finite velocity of flow will continue for an appreciable distance. Part of the sand in transport will be carried into the pool to be deposited along this flow line to form an underwater ridge subtending a submerged channel. As this procedure progresses, this channel will be built up to the surface and will extend farther into the reservoir. Vegetative growth encourages additional deposition on the banks during high flows. Such a channel may extend for several miles into the reservoir until a bank is breached at some indeteminate location (avulsion) during a high inflow and a new channel starts to form.

\subsubsection{Bottom Deposits}

The fine grained sediments, silt and clay size, including the wash load material, will be transported into the pool beyond the delta and be deposited on the bottom of the reservoir. These finer fractions, whose settling velocities are low, are composed of cohesive and very small non-cohesive particles and the form of the deposit will depend primarily on the mineral characteristics of the clay material and the chemistry of the water.

The bottom sediments have been observed to deposit most everywhere throughout the reservoir, but preferably in regions of low flow velocities, which exist in the vicinity of the barrage and in slackwater zones. However, before layers of bottom sediments establish themselves, the fine fraction moves frequently in the form of density currents.

Due to the sediment-flocculation effect, the problem becomes difficult to solve and to the present time there does not exist a method to predict successfully the bottom sediment quantitatively.

\subsubsection{Density Currents}

A density current may be defined as the movement of undergravity of a stream of fluid under, through, or over another fluid, the density of which differs by a small amount from that of the primary current. In reservoirs, the underflow density current is caused by the sediment laden river water entering the reservoir with a higher specific weight than the clear water which has been impounded. Considerable sediment is distributed to the deepest parts of a reservoir by the denser silt-laden water flowing beneath the lighter desilted water. Such flows sometime dispense their load by diffusion and mixing or by settlement, thus losing their identity.

Witzig (1943) reports that it has been observed frequently in Lake Mead (above Boulder Dam) and some other reservoirs that muddy underflows often extend to the outlet through a superficially clear lake. Ultimate understanding of the principles of density flows may lead to control of reservoir silting. If the flow is allowed to stagnate, the silt will be deposited in the reservoir; if such flows could be induced and controlled, much of the fine sediment entering a reservoir could be voided before deposition. However, density flows are sometimes of quite low silt content, with the greater part of the difference in density from the reservoir water due to salt content or temperature variations.

\subsection{Control of Reservoir Sedimentation}

Brown (1943) classifies the methods for the control of the reservoir silting into six groups: 1) selection of the reservoir site, 2) design of the reservoir, 3) control of sediment inflow, 4) control of sediment deposition, 5) removal of sediment deposits and 6) watershed erosion control.

These six groups represent three philosophies of approach to the problem of control. Groups 1 and 2 disregard the possibility of changing the rate of 
sediment output from the drainage area, or the control of deposition in the reservoir, but represent an attempt by controlling location and size, to assure the longest possible useful life for the reservoir. The second philosophy which embraces groups 3,4 , and 5 , accepts a fixed rate of sediment production from the drainage area, as well as a fixed size for the reservoir, but attempts by various means, to prevent all or part of the sediment from being permanently deposited in the reservoir. The third philosophy attempts, through control measures in the watershed, to reduce the quantity of sediment that will reach the reservoir.

Whenever a water-storage project permits a choice of sites for the dam and reservoir basin, careful study should be given to the quantity and type of sediment load that will be produced by the respective drainage basins above the alternate sites. Both the total quantity and average size distribution of the load are governed by such characteristics of the drainage basin as soil types, slopes, stream gradients, types of land use, and the extent of erosion of land slopes and stream channels. Thus, the selection of the reservoir site should avoid areas of excessive sediment production wherever possible. The design of the reservoir must include provision of outlets for sediment release.

The inflow of sediment to reservoirs can be decreased by erosion control using reforestation and soil conservation techniques, river training and the construction of additional dams upstream. The feasibility of erosion control methods depends on whether the watershed is the source of sediment or the river channel. If the watershed produces the sediment then obviousiy reforestation, improving farming methods, small dams, etc., will decrease the sediment load. If the river channel and in particular the banks are the principal source of material the river training can decrease the sediment inflow into the reservoir.

A major decrease in sediment inflow into a reservoir can be obtained by the construction of major dams upstream of the reservoir in question. These dams not only trap the sediment which would have entered the downstream reservoir but they change the flow regime of the river which can decrease the sediment load of the stream. This latter factor is particularly true for a gravel bed stream and may not be true for a sand bed stream. Clear water releases from the upstream reservoir may increase the erosion of a sand bed stream, the product of this erosion being deposited in the downstream reservoir.

River training structures may be roughly divided into two groups: those designed primarily to prevent erosion of an existing bank, and those designed primarily to guide the flow or promote deposition of sediment in designated areas, or both. Revetments are structures utilized commonly for bank protection. Blanket revetment is constructed of rock, concrete, asphalt or other materials placed to form a protective cover with or without an accessory mattress extending to the thalweg of the stream. Previous revetment consists of open fence, pile structures, cable connected jacks or baskets, and similar materials placed along the desired alignment both to prevent erosion of an existing bank and to build up the bank by deposition. Training structures to guide the flow along a desired alighment may be timber pile dikes, jacks, single or double row fence, dumped rock, old auto bodies or frames cabled together, broken concrete or other available materials, depending largely upon the magnitude and economics of the project.
Additional methods for decreasing the sediment inflow into the reservoir are: 1) the propagation of vegetative screens, 2) the location of the reservoir off the main channel and 3) the construction of bypassing channels or conduits. Off channel reservoirs are useful for silting control only where the entire flow of the main stream cannot, or does not need to be stored. In this case, the reservoir is developed in any location other than on the stream that is the principal source of water supply for that reservoir and it is filled with water through canals or conduits leading from a diversion dam on a main stream. Bypass canals and conduits involve the diversion of sedimentladen flows through canals leading around, or through pipes laid under, a reservoir located on a main stream channel. This requires the construction of some type of diversion dam or weir at the head of the reservoir basin, and a channel or conduit leading around or under the reservoir to a point below the dam where the flow may re-enter the main channel.

The deposition of sediment in a reservoir can be controlled to a certain extent by designing and operating gates or other outlets in the dam in such a manner as to permit selective withdrawal of water having a higher than average sediment content. The suspended sediment content of part or all of the water in reservoirs is higher during and just after flood flows. Thus, the more water wasted at such times the smaller will be the percentage of the total sediment load to settle into pemanent deposits.

The removal of sediment deposits from a reservoir may be accomplished by a variety of mechanical and hydraulic methods which have been described by Brown (1943) as excavation, dredging, siphoning, draining, flushing, flood sluicing and sluicing aided by such measures as hydraulic or mechanical agitation or blasting of the sediment. The removal of sediment. deposits implies, in general, that the deposits are sufficiently compacted or consolidated to act as a solfd, and therefore are unable to flow or move under their own weight. Excavation is the removal of the sedinent from a reservoir basin by hand or power operated shovel or other mechanical means. This method requires draining most, or all of the water from the basin. Dredging involves the removal of deposits from the bottom of a reservoir and their conveyance to some other point by mechanical or hydraulic means while water storage is being maintained.

Draining and flushing involve the relatively slow release of all stored water in a reservoir through gates or valves located near the bottom of the dam, and the maintenance thereafter of open outlets for a shorter or longer period during which normal stream flow cuts into or is directed against the sediment deposits. Flood sluicing is the practice of removing sediment deposits from a reservoir through large sluice gates near the base of the dam by utilizing the scouring action resulting from the sudden release of the water impounded in the reservoir or of flood flows entering the reservoir.

In general, removal of sediment by dredging or mechanical excavation involves high maintenance costs. A related problem affecting costs is the disposal of the excavated material, which sometimes must be hauled several miles from the basin. For this reason, mechanical removal of silt does not appear to have widespread practicability.

Watershed erosion embraces all of those measures that are effective in preventing or delaying the movement of soil and rock particles from their points of 
origin in the drainage area to the reservoir. Fundamentally, watershed erosion control differs from all other methods of reservoir silting control in that it aims at eliminating the problem at its source by preventing the formation of sediment. The scope of watershed erosion control is as broad as the fields of soil conservation, forestry and land utilization. For a comprehensive treatment of watershed erosion control methods the reader is referred to Brown (1943) and Vanoni (1975).

\subsection{Mathematical Models in Reservoir Sedimentation}

Mathematical models for prediction of sediment distribution in reservoirs may be grouped into two main categories: (1) empirical models developed by analyzing data from reservoir surveys; and (2) analytical mathematical models based on the use of adequate equations of water and sediment movement. In the first category field data is analyzed in order to get potential relations between parameters of influence in reservoir sedimentation. Then empirical relationships for the amount of deposits in the reservoir can be obtained. The most accepted of these methods seems to be the Empirical Area-Reduction Method developed by Borland and Miller and already discussed in section 2.5 of this chapter.

The second group of investigators have the common feature that they seek complete or simplified solutions to the governing differential equations of continuity and motion for both water and sediments throughout the reservoir. Such solutions are to yield the spatial and temporal distributions of sediments in the reservoir. The most common approach, among these analytical models, uses a simple technique based on a simplified form of the basic differential equations. The method consists of simply the application of some selected sediment transport equations to successive short reaches along the reservoir along with the backwater profile calculations. The amount of deposition in each of these reaches is calculated from the difference of the sediments transported at the beginning and at the end of each reach under the given flow and sediment transport conditions. Repetition of this procedure for several time intervals then yields the growth and the advancement of typical delta formations. The results obtained so far with this technique appear to be in at least qualitative agreement with deposition patterns of non-cohesive sediments in some existing reservoirs.

Yucel and Graft (1973) employed the same procedure as outlined above to predict the pattern of bed load deposition in reservoirs. The model considers an arbitrary river-reservoir system suitable for a onedimensional (unit width) analysis. The analysis is made in two parts: 1) the backwater profile and 2) the sediment transport and deposition. These two parts of the analysis are made independently. The backwater profile calculations follow a standard step by step method and the bed load deposition was calculated with the use of three different bed load equations, namely, the Schoklitsch equation, the MeyerPeter, et al., equation, and the Einstein-1942 bed load equation.

The backwater calculations are started at the dam section where the water depth is maximum and proceeded step by step in the upstream direction until the normal river flow conditions are attained. Subsequently, the bed load deposition was calculated beginning from the river and progressing downstream. The difference in the transport capacities between two successive sections is to be deposited within this reach and the thickness of the deposition per unit width was computed. Deposition is subsequently responsible for a change in the bottom of the watercourse which in turn requires a new backwater profile calculation. This in turn requires a new deposition calculation and so on.

An arbitrary set of input information was chosen for the characteristics of the sediment and the riverreservoir system. The authors pointed out that the input data represent very roughly the characteristics of the Missouri River-Ft. Randall Reservoir system as reported by Livesey (1955). The following conclusions are made in the study: 1) the model gives good similarity with the shapes of the deltas observed in existing reservoirs, such as Lake Mead behind Hoover Dam, although quantitative comparisons were not made, 2) The Meyer-Peter et al., and the Einstein-1942 bed load equations predict bed load depositions at rates that are twenty (20) times faster than the modified Schoklitsch equation.

Thomas (1970) employs a similar method for simulating sediment movement in a shallow reservoir. Again, the order of computations is backwater, sediment transport capacities, volume of sediment and resulting bed elevations. Sediment transport capacities are calculated by using a modification of Laursen's relationship to fit Arkansas River data. To account for a mixture of grain sizes, the sediment transport capacity for each grain size class is computed assuming only one size is present in the bed. The total bed material load is calculated by summing the weighted transport capacities for each grain size class.

The model is in essence one-dimensional and can be used to predict the location of the sediment deposits in the longitudinal direction of flow. By using a digital computer, the model was used to simulate 50 years of sediment routing in the 0zark Reservoir on the Arkansas River near 0zark, Arkansas. The results for the total volume of sediment show reasonable agreement with two other empirical methods used in the same study. Thomas pointed out that the problems involved with digital models are similar to those involving movable-bed physical models. The model geometry and roughness coefficients have to be determined, the water discharge hydrograph translated into a suitable histogram and the model verified to experienced conditions.

Asada (1973) made use of a similar method to the one developed by Yecel and Graft but also took into account the effect of variation of the river flow rate as given in the form of a flood hydrograph. The results obtained were applied to several Japanese river-reservoir systems in mountainous regions with good agreement.

Hurst and Chao (1975) developed a model to determine the probable location, extent and gradation of sediment deposition at Tarbela Reservoir for the initial filling year of 1974 . Even though the method is not completely explained in the paper, it appears to follow the same approach as indicated above.

Another group of investigators makes use of mathematical models developed from the one-dimensional equations of continuity for water and sediment, and the momentum equation for sediment-laden water, in addition to a selected sediment transport equation and a bed friction equation. Coupled or uncoupled solutions to the system of equations are then sought by 
making use of numerical techniques, such as the finite difference method and the method of characteristics.

Chang and Richards (1971) developed two characteristics equations derived from the equation of motion of sediment-laden water and two equations of continuity for sediment and water. The only assumption inserted was that the change in bed slope due to deposition of sediment in a short period is insignificant compared to the original bed slope. The computation procedures are divided into two parts: 1) computation of the average velocity and depth of the sedimentladen flow by solving two characteristics equations, and 2) estimation of the deposition of sediment by using the sediment continuity equation, and adding the thickness of the deposited sediment to the previous bed elevation to obtain a new bed elevation for each following step. The authors applied the method to a hypothetical case and obtained reasonable patterns of deposition.

Garde and Swamee (1972) employed five equations: 1) an empirical equation describing the bed load transport per unit river width; 2) a bed friction equation similar to the Manning's equation; 3) the sediment continuity equation; 4) the flow continuity equation; and 5) the classical backwater equation. The authors then combined these equations into one expression and employed an iterative technique by the use of an explicit finite-difference scheme. This iterative procedure was reported to be rapidly converging. However, the resulting bed profiles consisted of undulations due to the general nature of the finite difference computational technique. Thus, a smoothening procedure was applied to these results obtained for a hypothetical set of reservoir characteristics by the use of a Fourier sine series. The authors express that their method permits the use of larger time and space intervals as compared to those used in the method of characteristics, and that the solution is stable over a large number of cycles.
Bonham-Carter and Sutherland (1968) developed a mathematical model for simulating deltaic sedimentation at a single river channel mouth. Even though the purpose of the paper was to describe a mathenatical model of a simple fluvio-marine delta and to explore the interrelationships between the variables important in the constructive phase of delta building, the model considers the hydraulic aspects of sediment deposition at river mouths, and thus is approaching the delta problem from the pracess point of view. A sedimentladen river flowing into a tideless, currentless marine basin is modeled as a plane jet discharging horizontally at the ocean surface. A velocity field is calculated using equations for open-channel and plane jet flow. Sediment behavior is treated statistically; nominal sediment particles are traced along trajectories from the mouth as they spread laterally and settle vertically. The rate of sediment accumulation is calculated for each cell of a horizontal accounting grid. Input parameters include channel dimensions, water and sediment discharges, grain size distribution and bottom topography.

Experiments with a static simulation model illustrate the depositional variation produced by changes in the grain size, river depth, and slope. The depositional area is narrow in plan view; in elevation, foreset slopes are a function of grain size and hydraulic parameters, and are normally less than one degree. A dynamic model permits a delta platform to build forward during several time increments, nominal particle trajectories adjusting automatically to the position of the delta lip. Experiments illustrate the formation of bars building transversely across the river mouth and the development of submerged levees close to the mouth at the margins of the main flow. The study is an excellent example of examining a real process in detail, simulating its action and experimenting with it to learn of its different ramifications. 


\section{Chapter 3 \\ THE MATHEMATICAL MODEL}

\subsection{Introductory Remarks}

When a stream enters a reservoir, its velocity is gradually reduced and then the sediment carried by the stream, either as bed load or suspended load, is deposited largely near the channel mouth. These deposits accumulate to form deltas. To simulate the deposition of sediment in this environment deterministically, it is necessary to develop a mathematical model for both the velocity field and the sediment patterns.

Most of the existent mathematical models for prediction of the sedimentation in reservoirs are onedimensional models (see section 2.7) and consequently they can be used only to predict the sediment deposition in the longitudinal direction of the flow. Since flow in the transition region of the river-reservoir system is highly non uniform it is reasonable to expect that the depositional pattern is not uniform across a section. Thus, a mathematical model able to consider the nonuniform conditions in the transversal direction of the flow must be formulated in order to obtain a more realistic assessment.

Chen (1973) derived the one-dimensional governing differential equations for simulating unsteady flow in natural channels and showed their applicability to study different types of practical problems. Dass (1975) proposed a compound stream model approach for water and sediment routing in nonuniform channels. Bates (1953) defines a delta as a sedimentary deposit built by jet flow into or within a permanent body of water. He further suggested that the position of submerged levees and distributary mouth bars are governed by the structure of the jet velocity field and gave numerous examples of rivers discharging into lakes and oceanic basins to corroborate this hypothesis.
In this chapter, a mathematical model is developed for the prediction of the rate and pattern of the sediment deposition in a river-reservoir system. The model considers the reservoir as a set of multiple channels and uses a compound stream model approach together with a two-dimensional jet theory to route the flow of water and sediment through the system.

\subsection{Modeling of the River-Reservoir System}

As shown in Fig. 3.1, the model considers a reservoir formed by a dam constructed on a course of a river. The river is modeled by a single channel assuming one-dimensional flow phenomena are predominant whereas a set of multiple channels is used to simulate the river and the flood plains in the reservoir. The physical boundaries for the model are an upstream section in the river where the flow of water and sediment is specified and a downstream section in the reservoir limited by the dam, in which the water elevations are known. The upstream water and sediment inflows can be obtained from field data whereas the reservoir operating rules are usually determined by economical considerations (power production, navigation, irrigation, water supply for industry and other considerations).

As a result of the retardation of the flow as it enters the reservoir, the sediment transported by the river is forced to deposit. Such a deposition is usually considered to take place in three different ways: 1) The relatively larger sized sediments are first deposited to develop a delta formation, which builds up at the upstream end (the mouth) of the reservoir and progresses downstream, 2) the backwater from the delta formation causes some deposition in the upstream reaches of the reservoir, and 3) the smaller sized sediments are carried further downstream to be deposited in relatively flat layers often
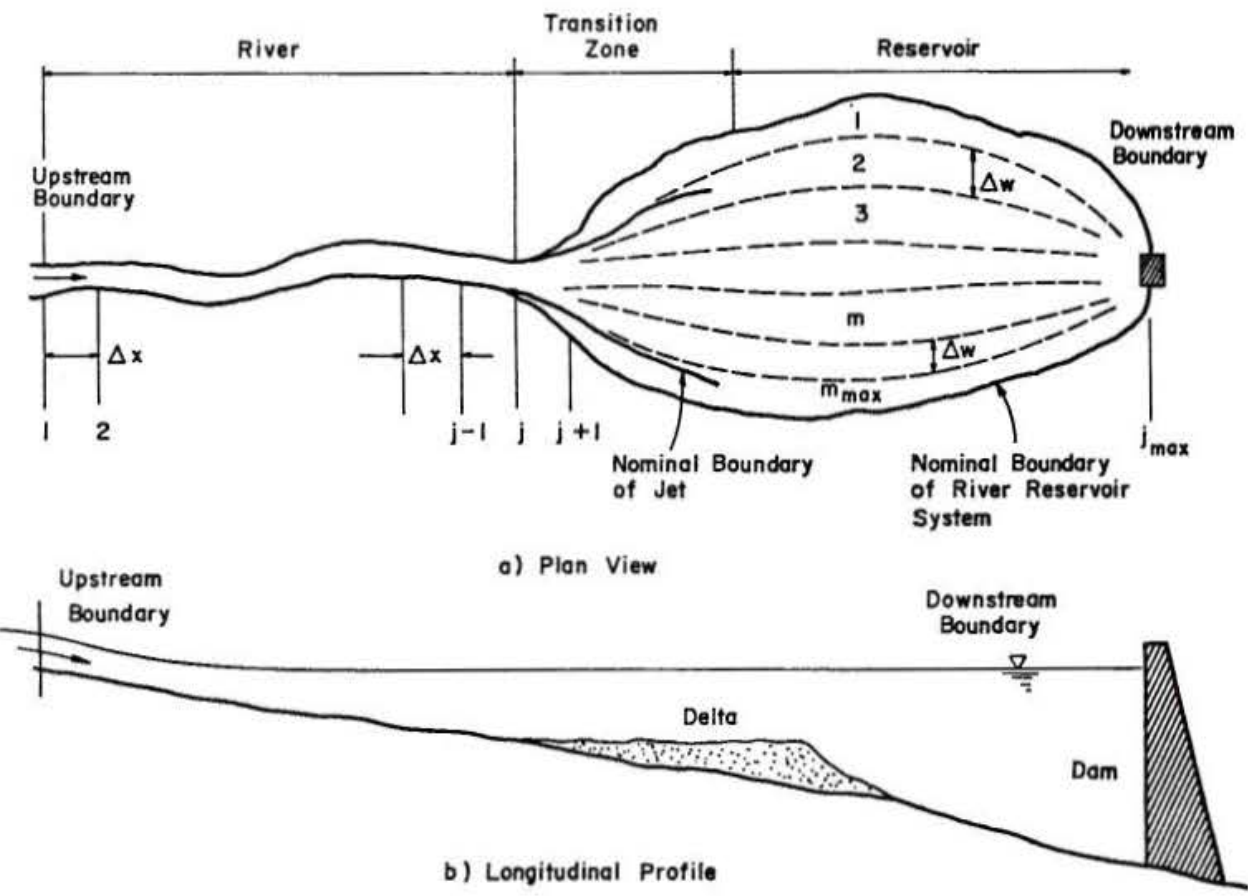

Fig. 3.1 - Schematic of the River-Reservoir System 
referred to as the bottom sediments. Thus, the deposit in general will consist of a backwater deposit, a sand and gravel delta and a bottom deposit of silt and clay materials.

The foregoing paragraph describes the simplest manner in which sediment is deposited in reservoirs. Actually, the manner in which sediment deposits in a reservoir depends on a large number of interrelated factors which tend to affect the process and modify the magnitude and location of the deposits.

Among the most important of these is the fluctuating elevation of the water surface, which occurs in many reservoirs. Usually, the deltas tend to form at the level of the water surface in the lake. When this is at a low elevation they form far down in the reservoir, and when it is at a high level they form near the upper end. After a delta has formed at a high level and the water level in the reservoir is lowered, most of the material in the delta will be washed away and carried down to be deposited downstream at a lower elevation in the reservoir.

In the same way, the temporal variations in flow and sediment discharges will affect the process of del ta formation. At the peak of a flow hydrograph, the velocity of the stream may increase causing a corresponding increase in the stream sediment transport capacity. If this increase in transport capability is greater than the increase in the corresponding inflowing sediment load, degradation of the bed will occur and the delta will be obliged to move downstream. This degradation process usually occurs at the upstream reaches of the reservoir. For lower values of the incoming flow, the process is reversed and the delta will develop again at higher elevations. Then alternate phases of aggradation and degradation may occur in the reservoir as a consequence of variations in flow and sediment hydrographs.

Another factor influencing the deposition of sediment in a reservoir is the shape of the basin. If the reservoir is regular in shape, deposits will normally spread quite uniformly along its axis. If the reservoir is irregular there might be marked irregularities in the depositional pattern. In narrow reservoirs, the flow and the incoming sediment are expected to spread evenly across the pool. If, on the other hand, the stream enters a wide pool, the flow tends to act like a jet and the depositional pattern will be different. Then in order to simulate the deposition of sediment in this environment, the entire river-reservior system is divided into three parts:

1) The River, extending upstream from the mouth of the reservoir

2) The Transition Zone, connecting the riverreservoir system

3) The Reservoir, extending downstream from the Transition Zone down to the dam.

The reservoir and transition zone comprise the major part, in volume, of the system. The slope here is so small that it is difficult to account for it by the usual methods of measurement and for computations of unsteady flow, the water level can be considered as practically horizontal. The velocity of flow is very small and the average water stage in the reservoir changes very slowly. The upper part of the system is formed by the river in which two zones may be distinguished: 1) The upper zone of backwater influence comprising that part of the river in which the water stages are affected by the water level in the reservoir, and 2) the upper zone not affected by the reservoir in which natural river conditions predominate. Actually the boundary between the river and reservoir is not permanent; it can move up and down with changes in river discharge and water level in the reservoir.

In the river, if the flow characteristics are considered to be one-dimensional, the variations in bed elevations with time can be obtained by the usual procedures for flow and sediment routing in onedimensional alluvial channels. On the other hand, the flow may become markedly two-dimensional at the inlet section of a wide reservoir. If the external boundary of the reservoir diverges too rapidly, the major part of the flow will fail to follow the boundaries and flow separation will take place like that shown in Figure 3.1. At this region, the flow phenomena is simulated by comparing the river to a two-dimensional plane jet discharging into a fluid of the same density. The jet effect will extend up to some section downstream in which the flow conditions will be governed by other forces rather than the dynamics of the jet itself.

Downstream in the reservoir, the hydraulic and sediment characteristics across a river section may vary to such an extent that treating the river as a single channel by using average parameters for the cross section may give erroneous results. Furthermore, the depositional pattern of sediment in the reservoir is likely to vary in a transversal flow direction. Thus, the flow characteristics are evaluated in this region by using a conveyance or compound section approach. If the reservoir is divided into a set of subchannels, this approach, as will be explained later in this chapter, permits the determination of the volume of deposition at each subsection in the reservoir.

The breakdown of the river-reservoir system into a certain number of subchannels is not arbitrary but is based as far as possible on the topographic and hydraulic characteristics of the system. If discretization interval $\Delta x$ is selected along the longitudinal flow direction, the entire system has been divided into a certain number of cells, each of these representing an elementary reach corresponding to the space step $\Delta x$ and width $\Delta w$. In the figure, sections and subchannels are denoted by the letters $j$ and $m$ respectively. The maximum number of sections and subchanneis are $j_{\max }$ and $m_{\max }$. The intersection of a section $j$ and a subchannel $m$ defines the subsection $m, j$.

\subsubsection{Basic Unsteady Flow Equations}

The mathematical analyses of riverbed deformation are generally based upon the equations of motion and continuity. These equations describing the motion of water and bed waves in alluvial channels are derived from the principles of conservation of mass and Newton's second law of motion. In the process of riverbed deformation, the hydraulic conditions vary with time and space, and hence the deformation is an unsteady motion. In the analysis at present the variation of velocity in the vertical direction is neglected and the equation of one-dimensional motion is used. The problem then reduces to solving the flow discharge or average velocity, the water depth and the thickness of the riverbed deformation for any point (along the longitudinal axis) and for any 
The basic governing equations used in this study are the differential equations for simulating gradually varied unsteady flow in natural alluvial channels (Chen, 1973). These equations are the flow continuity and momentum equations and the sediment continuity equation. is:

The continuity equation for sediment-laden water

$$
\frac{\partial Q}{\partial x}+\frac{\partial A}{\partial t}+\frac{\partial A d}{\partial t}-q_{l}=0
$$

in which $Q$ is the discharge of sediment-laden water; $A$ is the cross-sectional area of the channel; Ad is the volume of deposition or erosion of sediment on unit length of channel bed; $q_{e}$ is the lateral inflow of sediment laden water into the stream; $x$ is the distance along the channel bed measured in the downstream direction; and $t$ is the time. A definition sketch for one-dimensional flow movement in natural channels is qiven in Fig. 3.2.

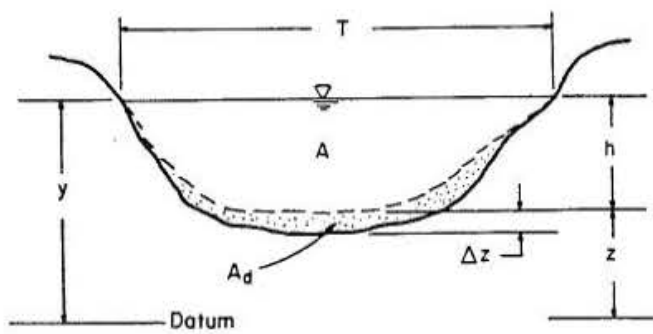

a) Sectional View

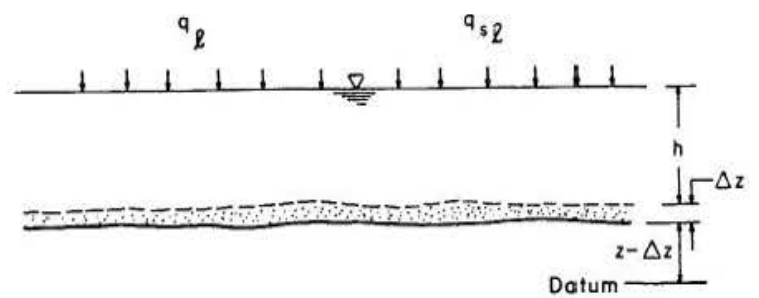

b) Longitudinal Profile

Fig. 3.2 - Definition Sketch for One-Dimensional Flow Movement in Natural Channels

In a fixed bed channel $A d=0$, and equation $(3-2-1-1)$ reduces to the wel1-known equation of continuity for unsteady flow. However, in the case of sediment-laden water the term $Q$ represents a total volume of water and sediment passing through a cross section in unit time.

The momentum equation for sediment-laden water is given by:

$$
\frac{\partial(\rho B Q V)}{\partial x}+\frac{\partial(\rho Q)}{\partial t}+g A \frac{\partial(\rho h)}{\partial x}=\rho g A\left(S_{0}-S_{f}\right)+\rho q_{l} V_{l}
$$

in which $V$ is the mean flow velocity; $g$ is the gravitational acceleration; $\rho$ is the density of the sediment-laden water; $\beta$ is the momentum correction factor for velocity distribution; $h$ is the flow depth; $S_{0}$ is the bed slope; $S_{f}$ is the friction slope; $q_{\ell}$ is the lateral inflow of sedimentladen water into the stream; and $V_{\ell}$ is the velocity component of the lateral flow in the $x$-direction.

The sediment continuity equation is given as:

$$
\frac{\partial Q_{S}}{\partial x}+\frac{P A d}{\partial t}+\frac{\partial\left({ }^{A C} s\right)}{\partial t}-q_{S_{\ell}}=0
$$

in which $Q_{S}$ is the total sediment load in units of volume per unit time; $p$ is the volume of sediment in a unit volume of bed layer; $C_{s}$ is the average sediment concentration in the cross section on a volume basis; and $q_{s_{\ell}}$ is the lateral sediment inflow into the stream.

The following assumptions are made in deriving these equations:

1. The channel is sufficiently straight and uniform in the river reach so that the flow characteristics may be physically represented by a onedimensional model.

2. The flow velocity is uniformly distributed over the cross section.

3. Hydrostatic pressure prevails at every point in the channel flow.

4. The water surface slope is small.

5. The density of the sediment-laden water is constant over the cross section.

6. The unsteady flow resistance coefficient is assumed to be the same as for steady flow in alluvial channels.

The basic equations, equations $(3-2-1-1)$, (3-2-12) and $(3-2-1-3)$, form a set of nonl inear first order partial differential equations of the hyperbolic type. They contain two independent variables, $x$ and $t$, and three dependent variables, $Q, h$ and Ad. Thus, the remaining terms must be expressed as function of the three basic unknowns in order to obtain a solution.

The geometric properties of the cross sections can be expressed as a function of the water depth from the known channel geometry. If the cross-section is regular in shape, a rectangular or trapezoidal approximation can be used for computing the area of the flow. If the cross: section is irregular in shape, a tabulated function of area and top width against flow depth can be established and their values fitted by a polynomial equation.

The mean bed slope can be related to the change in bed elevation by writing:

$$
S_{0}=\frac{\partial z}{\partial x}=\frac{1}{T} \frac{\partial A d}{\partial x}
$$

in which $T$ is the section top width and $z$ is the mean bed elevation.

The friction slope $S_{f}$ is a function of flow and channel characteristics. The resistance functions such as Manning's or Chezy's equations can be employed 
to relate $S_{f}$ to the basic unknowns. If Manning's equation is used, $S_{f}$ is given by:

$$
S_{f}=\left(\frac{\operatorname{lin}}{1.486 \mathrm{AR}^{2 / 3}}\right)^{2}
$$

If Chezy's equation is used, $S_{f}$ is given by:

$$
S_{f}=\frac{1}{R}\left(\frac{V}{C}\right)^{2}
$$

in which $R$ is the hydraulic radius and $n$ and $C$ are the Manning's and Chezy's coefficients, respectively.

Although these equations were first derived for uniform steady flow, their use has become common in nonuniform and unsteady flow. Both Chezy and Manning equations require estimation of a resistance coefficient. The primary difficulty in predicting the frictional resistance still lies in estimating the resistance coefficient for a natural situation. The interaction between the flow of the water-sediment mixture and the sediment-bed creates different bed configurations which change the bed resistance to flow and the flow conditions in the river reach. Observations on natural sandbed streams indicate that Manning's $n$ changes from values as large as 0.050 at low flow to as small as 0.012 at high flow. The amount of variation in Manning's coefficient with the changing flow conditions in the reach may signify the importance of calibrating a resistance function to be used in the mathematical model.

In natural streams the sediment discharge $Q_{S}$ is a function of many variables like: kinematic viscosity $\nu$ and water density $\rho_{\omega}$; density of sediment particles $D_{S}$; fall velocity $V_{f}$; acceleration of gravity $g$; geometric mean size $d_{g}$ and geometric standard deviation of sizes $\sigma_{g}$; flow discharge $Q$ and flow depth $h$.

In a functional relationship $Q_{S}$ can be expressed as:

$$
Q_{s}=f_{f}\left(Q, i, v, \rho_{w}, p_{s}, v_{f}, g, d_{g}, \sigma_{g}\right)
$$

Many theoretical attempts have been made to find a unique relationshop for this function. Because of the complexity of sediment transport phenomena, many of the theoretical relations do not completely describe the processes and their agreement with observations is often less than satisfactory. Empirical relationships based on field observations are then often developed by fitting mathematical equations to measurements of the sediment load. The bed shear stress or the mean velocity is usualiy used as the dependent variable. These equations can be easily incorporated to the mathematical model for sediment routing purposes but have the disadvantage that they can be applied only to the particular river system from which they were obtained.

If the fluid and sediment properties are assumed to be constant in the river system, this relation reduces to:

$$
\begin{aligned}
& Q_{S}=f_{2}(Q, h) \\
& Q_{S}=f_{3}(V)
\end{aligned}
$$

Experience has indicated that sediment discharge is strongly correlated with mean velocity. These relations are seen to be continuous and singlevalued functions of the velocity (Vanoni, 1975). Thus, in the mathematical model a functional relationship like equation $(3-2-1-8)$ can be obtained from field surveys or by using one of the many methods that have been developed for computing the sediment load.

The density of the sediment-laden water can be expressed in terms of the density of water $\rho_{\omega}$ and density of sediment particles $\rho_{S}$ as:

$$
\rho=\rho_{\omega}+C_{S}\left(\rho_{S}-\rho_{\omega}\right)
$$

in which $C_{S}$ is the mean sediment concentration given by $C_{S}=Q_{S} / Q$, where $Q_{S}$ is taken on a volume basis.

If the lateral inflow of water and sediment into the stream, $q_{\ell}$ and $q_{s_{\ell}}$, is specified in advance, the differential equations together with the supplementary relationships contain only three unknowns and can be solved in conformance with prescribed initial and boundary conditions for the flow discharge $Q$, the flow depth $h$ and the volume of sediment deposition Ad.

\subsubsection{Jet Flow Theory}

By a jet is meant a stream of material which travels for many diameters in a nearly constant direction. To produce such a jet, it is sufficient to make a hole or insert a tube into a reservoir whose local pressure is higher than the surrounding pressure. Flow jets refer to liquid (or solid) jets in air, gas jets in air and water jets in water. A submerged jet differs from a free jet, on the one hand in the lack of gravitational influence, and on the other hand in the interaction between the jet and the surrounding fluid. Because a stream of turbulent fluid discharging into a large basin through a well defined and stable orifice may be considered a free or submerged jet, jet flow exists whenever a major river discharges directly into a lake, gulf or ocean. Bates (1953) defines a delta as a sedimentary deposit built by jet flow into or within a permanent body of water. He further suggested that the position of submerged levees and distributary mouth bars are governed by the structure of the jet velocity field and gave numerous examples of rivers discharging into lakes and oceanic basins to corroborate this hypothesis.

Jet flows have been studied by many investigators since 1926 when Tollmien first developed a comprehensive theory for the behavior of an axially symmetrical jet issuing from a point source. This theory has been further developed and tested in many laboratories by such varied types of scientists as aerodynamicists, chemical engineers, heating engineers and hydraulic engineers. Albertson et al., (1950) demonstrated a satisfactory agreement between theory and observations with models in the case of plane and axial jets discharging from slots and orifices into a fluid of the same density. The characteristics of the mean flow were derived analytically, with the exception of a single experimental constant, through assumptions that: 1) The pressure is hydrostatically distrib. uted throughout the flow; 2) the diffusion process is dynamically similar under all conditions; and 3) the longitudinal component of velocity within the diffusion regions varies according to the normal probability function at each cross section. 
All of the above workers assumed that the jet will spread at a linear rate and that the crosssectional area of the flow must continue to increase continually downstream. River flow entering a lake, ocean or reservoir seems to produce a curvilinear type of boundary instead of a linear one. Such kinds of parabolic tongues are readily visible on aerial photographs of the outflow patterns of the Mississippi River and off tidal inlets of the Louisiana coast as reported by Bates (1953). Laboratory observations made by Chang (1967), on a study of delta formation, suggest also that the boundary of this two-dimensional jet is curvilinear.

In this section, a simplified model for the velocity distribution of a two-dimensional submerged jet is proposed. The boundary of this jet spreads parabolically and the velocity distribution in the zone of diffusion is assumed for simplicity to be triangular. A submerged plane jet discharging from a slot of width $B_{0}$ into a large body of water in the rectangular coordinates system $\mathrm{x}-\mathrm{w}$ is shown in Fig. 3.3.

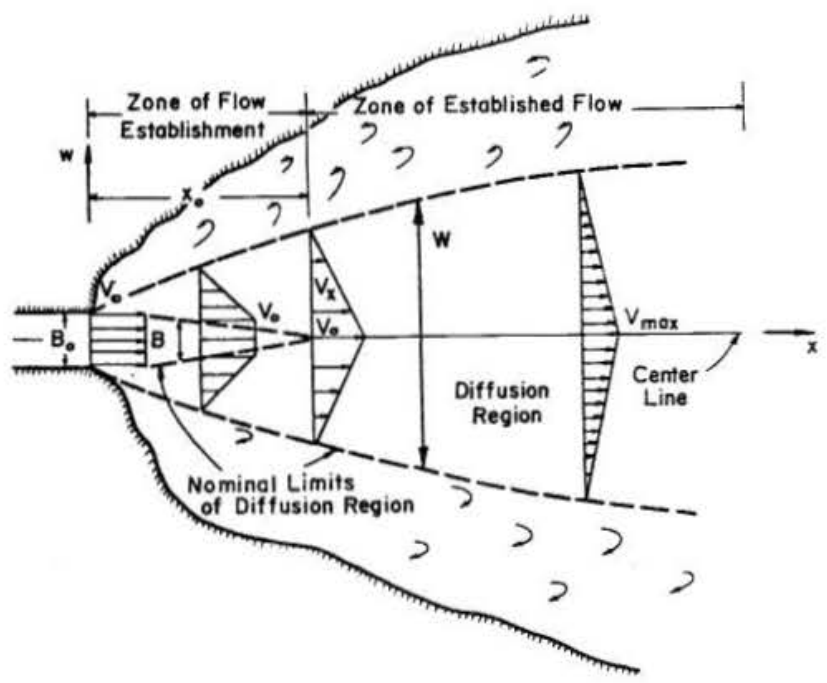

Fig. 3.3 - Schematic Representation of Jet Diffusion

It is seen that an initial zone of flow establishment must exist beyond the mouth of the opening of either a two-dimensional or a three-dimensional jet. That part of the discharged fluid which has not yet become part of the ever-growing zone of diffusion is termed the irrotational core. This core ends where the zone of diffusion reaches the centerline of the jet. Downstream from this section the maximum velocity of the jet must decrease as the diffusion zone further expands. The process of diffusion continues, theoretically at least, until there is at infinity a jet of zero velocity, or until the velocity of the flow becomes so low that extraneous effects rather than the dynamics of the jet itself will begin to govern the flow pattern.

In contrast to the plane jet of Albertson et al. as a direct result of limiting the lateral extent of the three basic changes occur in the phenomenon:

a) A return flow is originated in the separation zone between the boundary of the reservoir and the boundary of the jet.

b) Fluid undergoing the induced motion because of the accelerative action of the jet is counter balanced by the return flow and then the flow discharge past successive sections perpendicular to the jet, instead of increasing continually, is constant and equal to the discharge at the mouth of the reservoir.

c) The lateral expansion of the jet does not continue indefinitely but is limited by the intersection of the boundary of the reservoir with the jet boundary.

An additional difference between the two types of jets is the existence of a free surface and the effect of the bottom resistance. Albertson's theory assumes a submerged jet of infinite extent (no boundary effect) with no external forces acting in the system. Actually, the sole force producing the deceleration of this jet is the internal shear within the mixing region. For the type of jet considered in this study, the bottom friction plays an important role as the main force opposing the movement and changing the diffusion pattern.

Consequently, by continuity principles the rate of flow or volume flux $Q$ past successive normal sections may be written as:

$$
\frac{Q}{Q_{0}}=\frac{\int_{0}^{W / 2} v_{x} d w}{0.5 V_{0} B_{0}}=1
$$

in which $V_{0}, Q_{0}$, and $B_{0}$ are the uniform flow velocity, flow discharge and slot width, respectively at the inlet section; $V_{x}$ is the longitudinal component of the velocity and, $W$ is the jet width.

In the zone of flow establishment of the plane jet this equation can be written as:

$$
\int_{0}^{0.5 B} v_{0} d w+\int_{0.5 B}^{W 2} v_{x} d w=0.5 v_{0} B_{0}
$$

The velocity distribution in the diffusion region of this zone is given by:

$$
v_{x}=v_{0}\left(\frac{W-2 W}{W-B}\right)
$$

Evaluation of the integral for the assumed velocity distribution shows directly that:

$$
B=2 B_{0}-W
$$

which gives the equation for the inner boundary of the diffusion region.

If the boundary of the jet spreads at a linear rate, i.e., $W=C_{1} x$ the equation for the inner boundary would be evidently a plane. As in this case the boundary of the jet is assumed to be parabolic, the equation for $B$ will describe a curvilinear surface.

The boundary of the jet is assumed to be parabolic: thus the jet width is given by

$$
W=a \sqrt{x}+B_{0}
$$

Equation (3-2-2-5) introduces into the analys is an additional information regarding the dynamics of the flow that allows for the simplification of the problem. 
It is clear that the linear jet boundary of Albertson et al., is valid only for a theoretical jet of infinite extent and consequently it does not apply in this case where the effect of external forces acting in the system like the bottom shear stress and the bank resistance change the basic assumptions introduced in Albertson's paper. Thus, the boundary of the jet spreads curvilinearly and in this study is assumed to follow equation $(3-2-2-5)$.

The value of the constant a depends on the specific characteristics of the river-reservoir system in consideration. It can be input as an unknown to the mathematical model and its value obtained by calibration procedures.

By using equation (3-2-2-5) the equation describing the inner boundary of the diffusion region transforms to:

$$
B=B_{0}-a \sqrt{x}
$$

The limit of the zone of flow establishment can be obtained by evaluating the last equation at the point where $B=0$. Then,

$$
x_{0}=\left(\frac{B_{0}}{a}\right)^{2}
$$

in which $x_{0}$ represents the distance from the inlet section to the end of the zone of flow establishment.

The velocity distribution in the diffusion region of the zone of flow establishment then takes the explicit form:

$$
\frac{V_{x}}{V_{0}}=\frac{3 \sqrt{x}+B_{0}-2 w}{2 a \sqrt{x}}
$$

In the zone of established flow the function for $V$ is given by:

$$
v_{x}=v_{\max }\left(\frac{W-2 W}{W}\right)
$$

Evaluation of the integral equation $(3-2-2-1)$ at this zone leads to:

$$
\frac{V_{\max }}{V_{0}}=\frac{2 B_{0}}{a \sqrt{x}+B_{0}}
$$

which shows directly that the maximum velocity varies inversely as the square root of the distance from the mouth in the zone of established flow.

Introduction of the last equation into equation (3-2-2-9) leads to the velocity distribution for the zone of established flow:

$$
\frac{V_{x}}{V_{0}}=\frac{2 B_{0}}{\left(a \sqrt{x}+B_{0}\right)^{2}}\left(a \sqrt{x}+B_{0}-2 w\right)
$$

\subsubsection{Compound Flow Equations}

In the reservoir the flow conditions are complicated by the existence of large differences in hydraulic resistance and cross-sectional geometry between the river channel and the flood plains. Thus, the depositional pattern of sediment will not be uniform across a section and this is the reason for attempting to model the reservoir as a set of multiple channels.
A compound model approach (Dass, 1975) for routing the flow of water and sediment through nonuniform channels is applied to the reservoir with some modifications to account for nonuniform grain size distribution and variation of specific weight of sediment deposits with time. This compound model approach is based on a modified form of the basic one-dimensional differential equations $(3-2-1-1),(3-2-1-2)$ and $(3-2-1-3)$, and thus avoids the use of the more complex two-dimensional unsteady flow equations.

The flow discharge in a channel may be expressed as the product of

$$
Q=K \sqrt{S_{f}}
$$

where $S_{f}$ is the friction slope and $K$, the conveyance, is a measure of the carrying capacity of the channel section given by

$$
K=\frac{1.49}{n} \quad A^{2 / 3}
$$

Denoting the total conveyance of a cross section $j_{a}$ as $K_{j}$ and the conveyance for any subsection $m, j$ as $k_{m, j}$ (see Fig. 3.1 ), the discharge in this subsection can be given by:

$$
Q_{m, j}=\frac{Q_{j} K_{m, j}}{K_{j}}
$$

in which $K_{j}$ is given by the sum of the individual conveyances:

$$
K_{j}=\sum_{m=1}^{m_{\text {max }}} K_{m, j}
$$

The assumptions involved in deriving equation (3-2-3-3) are: 1) the water surface is horizontal across the section and 2) the friction slope for flow at a subsection is equal to the friction slope available for the whole section.

Equation (3-2-3-3) allows for the determination of the flow discharge at each subsection in the discretized river-reservoir system of Figure 3-1, provided that the total discharge and conveyance for the section and the individual conveyance for the particular subsection are known.

\subsection{Method of Solution}

The method of solution for the mathematical model described in the last section consists of two steps: a) the Flow Routing in which the flow field is determined in the entire river-reservoir system and b) the Sediment Routing in which the magnitude of the sediment deposition is obtained. These two parts of the analysis are made independently. Thus, a constant geometry of the river-reservoir system with no sediment transport is assumed in calculating the flow discharges and water elevations and, similarly, the water profile is assumed to remain unchanged during each series of calculation made for the sediment deposition. This method of solution is usually called the uncoupled method of solution for the governing equations.

\subsubsection{Flow Routing}

The process of tracing by calculation the course of a flood wave is usually known as flood or flow 
routing. For the river-reservoir system depicted in Fig. 3.1, flow routing is recognized as a procedure required in order to determine the flow discharges and water elevations, as a function of time, at each section or subsection in the discretized system.

The flow routing procedure described herein follows, with some modifications, the approach of Dass (1975) to route the flow of water and sediment in nonuniform channels. First, it is assumed that $\partial A d / \partial t \ll \partial A / \partial t$ and the equation of continuity and the equation of motion for the sediment-1aden water (Equations $3-2-1-1$ and $3-2-1-2$ ) can be rewritten as:

$$
\frac{\partial Q}{\partial x}+\frac{\partial A}{\partial t}-q_{\ell}=0 \text {, and }
$$

$\frac{\partial(\beta Q V)}{\partial x}+\frac{\partial Q}{\partial t}+g A \frac{\partial h}{\partial x}=g A\left(S_{0}-S_{f}\right)+q_{l} V_{l}$

in which for simplicity the term of $\partial \rho / \partial x=\partial \rho / \partial t=0$

These two equations contain two basic unknowns, the flow discharge $Q$ and the flow depth $h$, being the remaining terms constants or functions of the two dependent variables. The solution of the above two equations can be accomplished by treating the entire river-reservoir system as a single channel, to yield values for the unknowns $Q$ and $h$ at all sections, $j-1, \ldots j_{\max }$, along the reach in consideration.

After solving for $Q_{j}$ and $h_{j}$, for $j=1, \ldots$ $j_{\text {max }}$, as explained above, the next step in the flow routing calculations is to determine the value of these variables at each individual subsection i.e., $Q_{m, j}$ and $h_{m, j}$, in the discretized system of Figure 2.3. By assuming that the water surface elevation remains the same (horizontal) across a section, the water discharge in the $m t h$, $j$ th subsection of the reservoir can be computed by using equation $(3-2-3-3)$ :

$$
Q_{m, j}=\frac{Q_{j} K_{m, j}}{K_{j}}
$$

where $K_{m, j}$ and $K_{j}$ are given by equations (3-2-3-2) and $(3-2-3-4)$ respectively.

In the transition zone, integration of the veloity distribution equations $(3-2-2-8)$ and $(3-2-2-11)$ leads directly to the determination of the discharge at each individual subsection. In the zone of flow establishment $Q_{m, j}$ is given by:

$$
Q_{m, j}=\int_{0}^{w_{1}} v_{0} d A+\int_{w_{1}}^{w_{2}} v_{x} d A
$$

in which $w_{1}$ and $w_{2}$ are the boundary limits defining the individual stream $m$ and $V_{x}$ is given by equation (3-2-2-8).

In the zone of established flow the flow discharge at the (mth, $j$ th) subsection is computed from:

$$
Q_{m, j}=\int_{w_{3}}^{w_{4}} v_{x} d A
$$

where $V_{x}$ is defined by equation $(3-2-2-11)$ and $w_{3}$ and $w_{4}$ are again the corresponding boundary limits for the mth subchannel at this zone.

\subsubsection{Sediment Routing}

Sediment routing is understood herein as the process of determining the variations in bed elevations with time for all sections and subsections in the river-reservoir system. It is usually accomplished by solving the sediment continuity equation, equation $(3-2-1-3)$, for the unknown Ad. Since the value of this variable must be determined for all the subchannels in the system, a modified form of the sediment continuity equation, applicable to each individual stream, is given by Dass (1975) as:

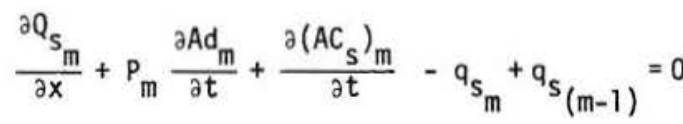

for $m=1,2 \ldots m_{\max }$

where a river reach between two consecutive sections $j$ and $j+1$ is considered divided into $m_{\max }$ streams, as indicated in Fig. 3.4. The water and sediment transfer terms between any two adjoining streams, say streams $m$ and $(m+1)$, are denoted by $q_{m}$ and $q_{s_{m}}$, respectively, and are assumed to be positive in the directions marked by the arrows in the figure. The terms $a_{b}$ and $a_{b}$ represent the inflow per unit length to the stream through the left and right bank respectively.

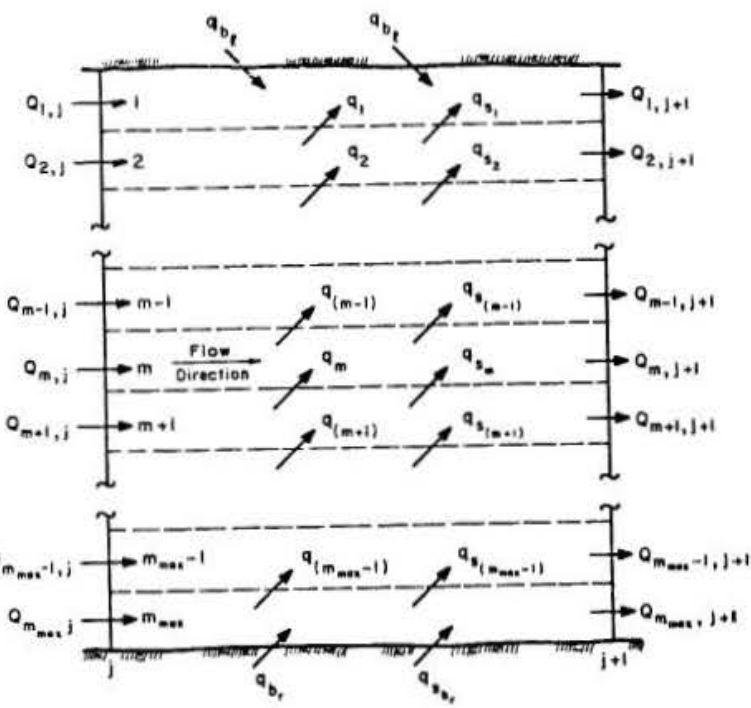

Fig. 3.4 - Flow Interaction Terms for Water and Sediment Movement in a Multiple Stream Approach (after Dass, 1975)

To evaluate the lateral transfer of sediment, terms ${ }^{q_{s}}$ and ${ }^{q} s_{(m-1)}$ in the above equation, the corresponding flow transfer terms need to be known. A recursive procedure is to be followed to obtain those terms.

The equation of continuity of the sediment-laden water can be written for the mth streams as: 


$$
\begin{aligned}
& \frac{\partial Q_{m}}{\partial x}+\frac{\partial A_{m}}{\partial t}-q_{m}+q_{m-1}=0 \\
& \text { for } m=1,2, \ldots m_{\max }
\end{aligned}
$$

Noting that $Q_{m}$ and $A_{m}$ are known from the flow routing calculations and that ${ }^{q}(m-1)$ for $m=1$ is the lateral inflow or boundary condition which must be specified in advance, the equation (3-3-2-2) can therefore be solved recursively for $q_{m}$, $m=1,2, \ldots\left(m_{\max }-1\right)$.

Evaluation of the lateral transfer of sediment between adjoining stream, $\mathrm{q}_{\mathrm{s}_{\mathrm{m}}}$ and ${ }^{\mathrm{q}_{\mathrm{s}}}(\mathrm{m}-1)$ in equation (3-3-2-1), is complicated due to the twodimensional nature of the flow. Since the velocity of flow in the lateral direction is very low in comparison to the velocity of flow in the longitudinal direction, it can be assumed that the flow conditions in the longitudinal direction will mainly control the transference of sediment between streams. If the flow is taking place across a section aa' as shown in Fig. 3.5, the lateral discharge of sediment can be written as:

$$
\left.q_{s_{m}}=C^{\prime}{ }_{s}\right)_{a a^{\prime}} q_{m}+\varepsilon_{s} d \frac{\partial C^{\prime} s}{\partial n}
$$

in which $C_{s}^{\prime}$ is the suspended sediment concentration in the longitudinal direction at section aa'; $\varepsilon_{S}$ is a diffusion coefficient for the sediment particles; d represents an average flow depth and $\partial C_{s}^{\prime} / \partial n$ is

the suspended sediment concentration gradient in the lateral direction.

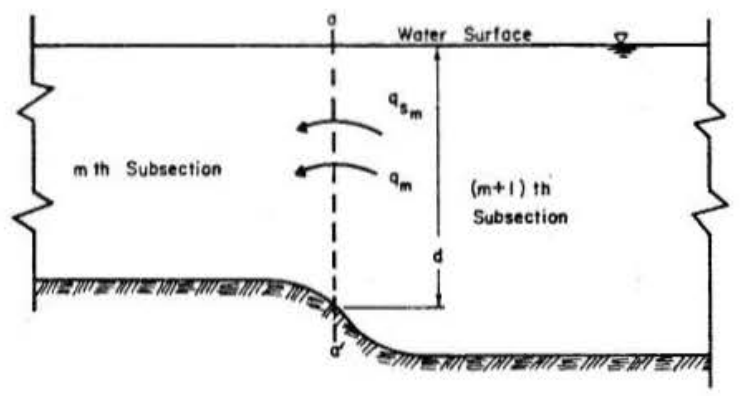

Fig. 3.5 - Flow Elements to Evaluate the Lateral Transfer of Sediment

The inclusion of the diffusion term in equation (3-3-2-3) was not considered in Dass' formulation of the sediment transfer problem. This term attempts to account for the lateral diffusion of the sediment particles as they enter the reservoir. Usually it is much smaller than the convective term in the same equation. For a river entering a large basin, this may not be true due to the flow separation which could create larger concentration gradients in the lateral direction making the inclusion of this term justifiable.

A typical assumption involved in river mechanics is the principle that with a stream flowing in equilibrium through an alluvial channel, the amount and type of sediment transported by the stream per unit mass of water are functions of the velocity of the stream flow. If there is a change in this velocity, then there must be either deposition or erosion in the channel until a new equilibrium is reached. Then, here in the mathematical model it is assumed that the sediment transport is only varying with the velocity in a functional relationship such as:

$$
Q_{S}=m v^{n}
$$

in which $m$ and $n$ are two parameters which can be obtained by calibration from field surveys or from the available equilibrium data.

Nonuniform grain size distribution is treated by considering the different size fracions separately and by calculating the transport capacities for each grain size. The total bed material load is calculated by summing the weighted transport capacities for each qrain size class. Then the total variation in bed elevations can be obtained by superimposing the results obtained from the sediment routing for each sediment fraction. In this way the larger sediment sizes are allowed to deposit before the smaller ones and the sorting process and its effect in the delta formation can be investigated.

To estimate the sediment accumulation in a resêrvoir, the sediment discharge data, usually reported on the basis of sediment concentration by weight, must be converted into volume units by means of an estimated specific or unit weight. If this value is not correctly estimated, the estimated volume of deposited sediment will be in error by the same percentage as the error in the estimated specific weight. The specific weight of deposited sediments in reservoirs has been observed to vary from 18 to 125 lbs per cubic foot. Therefore the proper determination of this value becomes quite important.

The specific weight of the sediment deposits depends on many interrelated factors as size of material, degree of sorting and gradation, and consolidation of the bed material. The rate of consolidation in itself varies with a number of factors such as time and reservoir operating rules. Thus, the specific weight cannot be considered as a constant in any hydraulics calculations trying to estimate the storage loss in reservoir with time.

For sediment routing purposes in reservoirs the specific weight of the sediment deposits may be incorporated as a variable in the mathematical model by rewriting the sediment continuity equation (3-3-2-1) as:

$$
\frac{\partial Q_{s_{m}}}{\partial x}+\gamma_{d_{m}} \frac{\partial A d_{m}}{\partial t}+\gamma_{s_{m}} \frac{\partial\left(A C_{s}\right)_{m}}{\partial t}-q_{s_{m}}+q_{s_{(m-1)}}=0
$$

in which $\gamma_{d_{m}}$ is the specific weight of the sediment deposits at the mth stream; $\gamma_{s_{m}}$ is the specific weight of the sediment particles and $Q_{s_{m}}$ is the total sediment load at the mth stream expressed in units of weight per unit time.

Since quartz is by far the most common mineral found in sediments moved by water, it can be assumed, with reasonable accuracy, that all sediment particles have the same specific gravity, about 2.65 , i.e., $\gamma_{s}=165.36 \mathrm{lb} / \mathrm{ft}^{3}$. 
The specific weight of the sediment deposits $\gamma_{d}$ is computed by using the method developed by Lara and Pemberton (1963)

$$
\gamma_{d_{i}}=W_{c} P_{c}+W_{m} P_{m}+W_{s} P_{s}
$$

in which $\gamma_{d_{i}}$ refers to the initial specific weight of the sediment deposits in pounds per cubic foot; $\mathrm{P}_{\mathrm{c}}, \mathrm{P}_{\mathrm{m}}$ and $\mathrm{P}_{\mathrm{s}}$ are percentages of clay, silt and sand, respectively of the incoming sediment, and $W_{c}$ $W_{m}$ and $W_{s}$ are coefficients which can be obtained from Table 1.1.

Equation (3-3-2-6) gives the specific weight of the sediments deposited in the reservoir at the beginning of the hydraulic calculations, i.e., time $=0$ Since the grain size distribution in the bed material changes as sediment is being deposited, the specific weight of the sediment deposits will also change as time passes in the sedimentation process. This is taken into account in the model by carrying out the sediment routing for different fractions of the bed material which permits for the correction at each time step of the specific weight due to the change in the grain size distribution of the bed material.

The volume of sediment per unit volume of bed layer, $p$, can be related to the specific weight by the relation:

$$
p=\frac{\gamma_{d}}{\gamma_{s}}
$$

After computing the sediment transfer terms and the specific weight and porosity of the sediment deposits, the sediment continuity equation (3-3-2-5) can be applied to each individual stream to solve for the volume of deposition at all sections in the entire river-reservoir system.

\subsubsection{Sediment Sorting}

Studies of river bed material have shown that the size of particles forming the bed of rivers gradually decrease in size in the downstream direction. The principal causes of particle size reduction are abrasion of the particles, hydraulic sorting, and chemical weathering. A size reduction relationship is usually expressed as an exponential function such as:

$$
D=D_{0} e^{-\alpha L}
$$

in which $D$ represents the size of the particles at some distance $L$ downstream of a reference station, $D_{0}$ is the size of bed material at the reference station, and $\alpha$ is the sorting coefficient.

The reduction in size of bed material with distance assumes considerable importance when a riverreservoir system is studied. It has been mentioned before that the fine particles brought in by the stream settle slowly and may be moved a long distance into the reservoir, usually depositing over most of the reservoir bottom in thin layers. On the other hand, coarser sediment carried by the stream is deposited where the current is retarded as it flows into the reservoir. This natural sorting of sediment sizes in reservoirs changes the granulometric composition of the bed material affecting then the sediment transport capability of the stream and the delta formation. The specific weight of the sediment deposits, which depends on the size and gradation of the sediment material, is also affected by the degree of sorting of the bed material.

Sediment sorting is considered in the mathematical model by routing the sediment per individual size fractions. It means that equations describing the sediment transport capacity of the stream must be obtained per each indivicual size. By applying the sediment continuity equation repeatedly to each sediment fraction, the value of sediment deposition is obtained. The total amount of deposition is equal to the sum of values obtained per each fraction.

If the sediment transport equations for the different size fractions are properly calibrated, the sediment continuity equation provides a mean for routing the different fractions separately allowing the coarser material to be deposited before the smaller ones. Since the size distribution of the bed material changes as sediment is being deposited and the transport capacity for a given size depends upon the fraction of bed material composed of that size, it is necessary to recalculate the fractions present as material is being exchanged with the bed at each step in the routing process.

The evaluation of the original composition of bed material presents no difficulties; it can be obtained from the data of direct measurements usually available for the system in consideration. For the subsequent intervals of time, evaluation of the composition of bed material for all the computational sections can be achieved from the sediment deposition values obtained after routing the sediment. This is natural since the sediment being deposited will cover the surface of the bottom and form its active layer.

Designating the fraction of the $i$ th size in the bed material at time $n$ by $F_{b_{j}}$ we can write:

$$
F_{b_{i}}^{n}=\frac{z_{i}^{n-1}+D z_{i}^{n}}{d_{s}^{n-1}+\sum_{i=1}^{N} D z_{i}^{n}} \quad \text { for } i=1, \ldots \text { NGS }
$$

in which $D z_{i}^{n}$ is the bed elevation change of size fraction $i$ at time step $n$; NGS is the number of grain sizes; NMAX is the number of time steps and $d_{s}^{n-1}$ and $z_{i}^{n-1}$ are given by:

$d_{s}^{n-1}=d_{s}^{n-2}+\sum_{i=1}^{N} D z_{i}^{n-1}$ for $n=2, \ldots$ NMAX

$z_{i}^{n-1}=F_{b_{i}}^{n-1} \cdot d_{s}^{n-1} \quad$ for $n=2, \ldots$ NMAX

with the initial condition:

$$
z_{i}^{0}=F_{b_{i}}^{0} \cdot d_{s}^{0}
$$

In nature the delta formation in a reservoir is a very unsteady process. At different times the stream may be either depositing or eroding material. Thus, the terms $z_{i}$ and $d_{s}$ in the above formulation attempt to account for the erosion of the bed material in the reservoir. The term $z_{i}$ represents the available sediment depth of the ith fraction of the bed material and $d_{s}$ is the total sediment depth available for transport that exists in the bed at anv 
time period $n$. Estimation of the initial value $d_{s}^{0}$ of sediment depth requires information about the specific river system in consideration, such as the depth to bedrock or some other material that might arrest degradation, etc.

Equation(3-3-3-3) allows for the determination of the gradation of sediment particles on the stream bed at any time period in the sediment routing.

\subsubsection{Model Flow Chart and Data Requirements}

The set of governing equations described in the last section and their method of solution constitutes a mathematical model for the simulation of the sediment deposition in reservoirs. A mathematical model may be defined as a conceptualization of a real system, by a complete set of equations, containing the essence of the real system, with respect to some specific purpose or use. The purpose herein is to imitate, understand and predict the behavior of the physical system being studied; the river-reservoir system in this case.

Such general definition implies the development of mathematical algorithms to solve the governing equations and perform the calculations and the selection of the data required for the model. It is clear that the interaction between these equations is so complex that it is necessary to resort to approximations or to some sort of numerical analysis whereby the object is broken into small pieces and each piece is treated separately. A finite difference approach with discretization intervals in space and time is used in the next chapter to develop the numerical solution to the governing equations.

The basic data required for the solution of the governing equations may be grouped into three main categories: Geometric, Hydraulic and Sediment data.

Geometric data implies the definition of the geometric characteristics for the river-reservoir system. It includes the selection of the upstream, downstream and lateral boundary limits for the system; the selection of the discretization intervals $\Delta x$ and $\Delta t$; the number and location of cross sections and the number and location of subchannels necessary to divide the study area. Top widths and crosssectional areas must also be defined as a function of stage from the known channel geometry.

Hydraulic data includes: 1) the definition of the initial flow conditions, bed elevations, water elevations and resistance coefficients, at each cell in the discretized river-reservoir system, and 2) the definition of the boundary conditions. Two conditions, one for the flow and one for the sediment, must be specified at the upstream section whereas one flow condition is required downstream. The upstream boundary condition can be a stage or aischarge hydrograph and a sediment hydrograph. The downstream condition is the reservoir operating rule which controls the water surface elevation with time.

The sediment data includes: 1) the input to the model of a functional relationship between the total sediment load and the mean flow velocity, and 2) general information about gradation of the bed material and fluid and sediment properties. The functional relationship of $Q_{S}$ and $V$ can be obtained by fitting a power equation to computed or measured values of these variables. The sediment discharge can be derived from field surveys by measuring the suspended sediment portion of the load using samplers and estimating the unmeasured discharge, or by using one of the many methods that have been developed for computing the bed material discharge and estimating the wash load.

With this information the flow of water and sediment can be routed through the river-reservoir system and the magnitude and location of the deposits as a function of time can be determined. A simplified logic scheme of the mathematical model is shown in the flow chart given by Fig. 3.6.

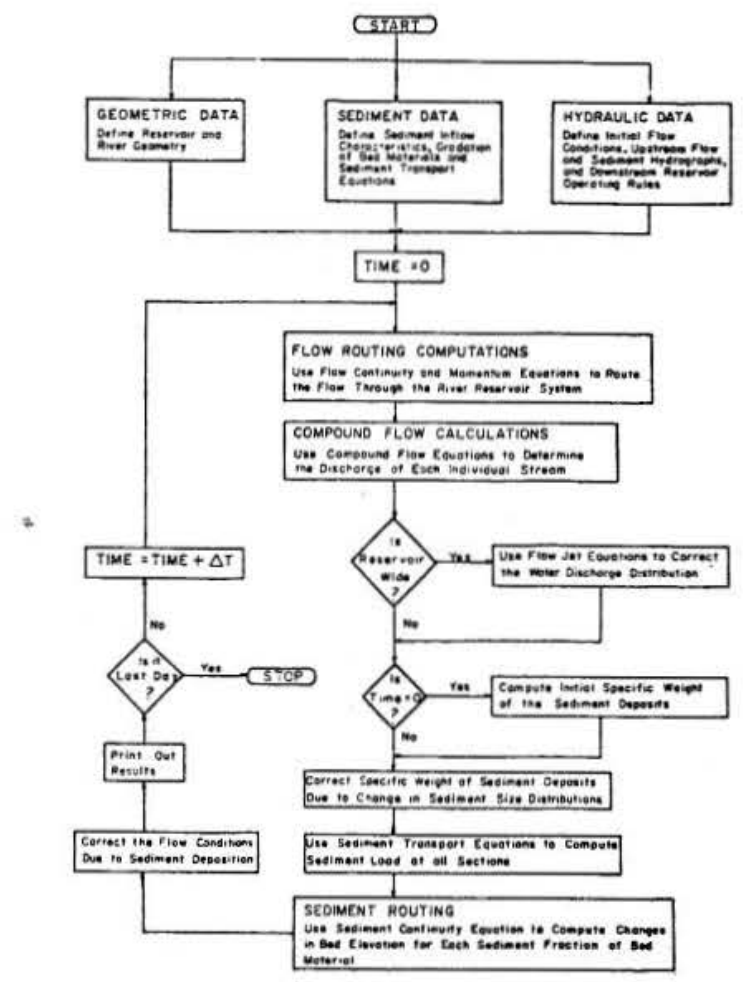

Fig. 3.6. - Flow Chart of the Mathematical Model

\subsection{Limitations of the Model}

Effective use of the mathematical model necessitates a recognition of the limitations of the model. The following limitations are listed in this section:

a) The present model can be applied to predict the distribution of sediments in small reservoirs in which the effect of density currents may be neglected.

b) The bed material is assumed to be formed of noncohesive grains.

c) The model is still in essence one-dimensional even though it considers the nonuniform conditions existent in the cross sections of the flow.

d) The model is uncoupled in the sense that the flow and sediment routing are solved independently. Thus, a constant geometry of the river-reservoir system with no sediment movement is assumed in calculating the flow routing. Similarly, the water profiles are assumed to be unchanged during the calculations made for routing the sediment through the system.

e) The model may not be applicable in cases where the friction slope for a flood plain channel may be significantly different from the friction slope for the main channel.

f) The model can be applied for water and sediment routing in subcritical flows. 


\section{Chapter 4}

\section{NUMERICAL ANALYSIS TECHNIQUE}

The basic equations governing the unsteady flow of water and sediment in alluvial channels constitutes a system of nonlinear hyperbolic partial differential equations. Because of the nonlinear nature of these equations analytical solutions for the complete system of equations are not available and numerical techniques using digital computers are the only methods of obtaining solutions.

The uncoupled method of solution described in the model flow chart of the last chapter requires initially the simultaneous solution of the flow continuity and momentum equations (Equations $3-2-1-1$ and $3-2-1-2$ ) and secondly the solution of the sediment continuity equation (Equation $3-2-1-3$ ). The numerical solution of these equations can proceed in one of two directions. Either an attempt can be made to convert the original system of partial differential equations into an equivalent system of ordinary differential equations using the method of characteristics, or one can replace the partial derivatives in the original system with quotients of finite-differences using explicit or implicit schemes.

Chen (1973) compared five numerical methods for solving these equations and found that the linearimplicit method is the most suitable numerical method when applied to the mathematical modeling of various types of time-dependent transient river problems.

Herein, the partial derivatives of the flow continuity and momentum equations are approximated by a linear-implicit scheme of finite differences whereas an explicit scheme is used for solving the sediment continuity equation. The resultant system of algebriac equations obtained from the implicit scheme is solved by using a double sweep method.

\subsection{Finite Difference Scheme}

The Preissmann implicit scheme of finite differences approximates any function $f(x, t)$ and its derivatives $\partial f / \partial x$ and $\partial f / \partial t$ in the rectangular grid in the $x-t$ plane as follows (Liggett and Cunge, 1974).

$$
\begin{aligned}
& \left.f(x, t)\right|_{M}=\frac{\theta}{2}\left(f_{j+1}^{n+1}+f_{j}^{n+1}\right)+\frac{1-\theta}{2}\left(f_{j+1}^{n}-f_{j}^{n}\right) \\
& \left.\frac{\partial f}{\partial x}\right|_{M}=\theta\left(\frac{f_{j+1}^{n+1}-f_{j}^{n+1}}{\Delta x}\right)+(1-\theta)\left(\frac{f_{j+1}^{n}-f_{j}^{n}}{\Delta x}\right) \\
& \left.\frac{\partial f}{\partial t}\right|_{M}=\frac{1}{2}\left\{\left(\frac{f_{j+1}^{n+1}-f_{j+1}^{n}}{\Delta t}\right)+\left(\frac{f_{j}^{n+1}-f_{j}^{n}}{\Delta t}\right)\right\}
\end{aligned}
$$

where $f_{j}^{n}=f(j \Delta x, n \Delta t) ; \quad f_{j+1}^{n+1}=f((j+1) \Delta x,(n+1) \Delta t)$, etc; $\Delta x$ and $\Delta t$ are the discretization intervals along the $x$ and $t$ axes, and $\theta$ is a weighting coeffictent, $0 \leq \theta \leq 1$, defined by $\theta=\delta t / \Delta t$ (Fig. 4.1). For $\theta=1 / 2$, the scheme is center-implicit and for $c^{4}=1$, the scheme is fully-implicit.

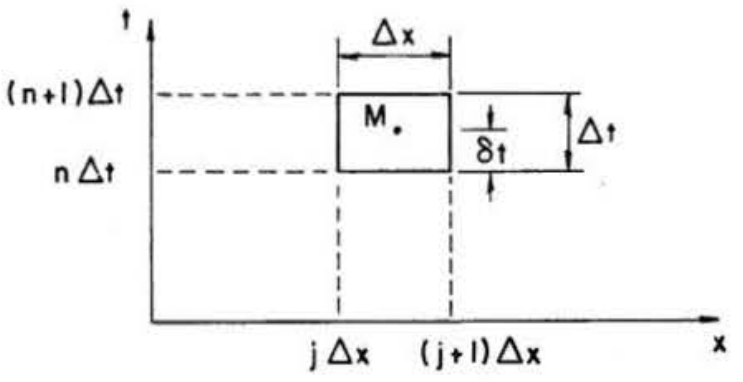

Fig. 4.1 - Network in the $x-t$ Plane for the Implicit Method of Finite Differences

By writing:

$$
\begin{aligned}
& f_{j}^{n+1}=f_{j}^{n}+\Delta f_{j} \\
& f_{j+1}^{n+1}=f_{j+1}^{n}+\Delta f_{j+1}
\end{aligned}
$$

where $\Delta f$ is the unknown increment of the $f$ function in the time increment $\Delta t$, the finite difference approximation is then written as:

$$
\begin{aligned}
& \left.f(x, t)\right|_{M}=\frac{e}{2}\left(\Delta f_{j+1}+\Delta f_{j}\right)+\frac{1}{2}\left(f_{j+1}^{n}+f_{j}^{n}\right) \\
& \left.\frac{\partial f}{\partial x}\right|_{M}=\frac{\theta}{\Delta x}\left(\Delta f_{j+1}-\Delta f_{j}\right)+\frac{1}{\Delta x}\left(f_{j+1}^{n}-f_{j}^{n}\right) \\
& \left.\frac{\partial f}{\partial t}\right|_{M}=\frac{1}{2 \Delta t}\left(\Delta f_{j+1}+\Delta f_{j}\right)
\end{aligned}
$$

For sediment routing purposes, the following explicit scheme of finite differences is used:

$$
\begin{aligned}
& f(x, t)=\frac{1}{4}\left(f_{j-1}^{n+1}+f_{j-1}^{n}+f_{j}^{n+1}+f_{j}^{n}\right) \\
& \frac{\partial f}{\partial x}=\frac{1}{2}\left(\frac{\left.f_{j}^{n+1}-f_{j-1}^{n+1}+f_{j}^{n}-f_{j-1}^{n}\right)}{\Delta x}\right) \\
& \frac{\partial f}{\partial t}=\frac{f_{j}^{n+1}-f_{j}^{n}}{\Delta t}
\end{aligned}
$$

which is a kind of forward difference in time and backward difference in space. This scheme is explicit because the only unknown in the sediment continuity equation (Equation $3-2-1-3$ ), the term $\mathrm{Ad}$, appears explicitly in the above formulation.

Equations $(4-1-3)$ and $(4-1-4)$ are used next to develop the finite difference forms of the governing equations $(3-2-1-1),(3-2-1-2)$ and $(3-2-1-3)$. 


\subsection{Discretization of the Flow Continuity Equation}

The discretization of equation $(3-2-1-1)$ according to equation $(4-1-3)$ results in:

$$
\begin{aligned}
& \frac{\theta}{\Delta x}\left(\Delta Q_{j+1}-\Delta Q_{j}\right)+\frac{1}{\Delta x}\left(Q_{j+1}^{n}-Q_{j}^{n}\right)+\frac{1}{2 \Delta t}\left(\Delta A_{j+1}+\Delta A_{j}\right)- \\
& -\frac{1}{2}\left(q_{l j+1}^{n}+q_{l j}^{n}\right)=0
\end{aligned}
$$

where the term $\Delta q_{\&}$ is supposed to be small enough to be neglected in the equation.

By using a first-order Taylor Series expansion the term $\triangle A$ in the last equation can be approximated as:

$$
\Delta A=\frac{\partial A}{\partial Y} \Delta Y=T \Delta Y
$$

Substitution of $\triangle A$ by the expression $T \Delta Y$, in which $T$ is the top width, gives:

$$
\begin{aligned}
& \frac{\Delta}{\Delta x}\left(\Delta Q_{j+1}-\Delta Q_{j}\right)+\frac{1}{\Delta x}\left(Q_{j+1}^{n}-\partial_{j}^{n}\right)+\frac{T_{j+1}}{2 \Delta t} \Delta Y_{j+1}+\frac{T_{j}}{2 \Delta t} \Delta Y_{j}- \\
& \frac{1}{2}\left(Q_{i j+1}^{n}+Q_{i j}^{n}\right)=0
\end{aligned}
$$

Then, the following linear algebraic equation is obtained:

$$
\text { a } \Delta Q_{j+1}+b \Delta Q_{j}+c \Delta Y_{j+1}+d \Delta Y_{j}+e=0
$$

in which:

$$
\begin{aligned}
& a=\frac{\partial}{\Delta x} \\
& b=-\frac{\theta}{\Delta x} \\
& c=\frac{T+1}{2 \Delta t} \\
& d=\frac{T j}{2 \Delta t} \\
& e=\frac{1}{\Delta x}\left(Q_{j+1}^{n}-Q_{j}^{n}\right)-\frac{1}{2}\left(q_{l j+1}^{n}+q_{l, j}^{n}\right)
\end{aligned}
$$

Equation (4-2-4) contains four unknowns, $\Delta Q_{j+1}$, $\Delta Q_{j}, \Delta Y_{j+1}$, and $\Delta Y_{j}$, since the coefficients are all in terms of known values at the previous time step $t^{n}$.

\subsection{Discretization of the Flow Momentum Equation}

The momentum equation for the sediment-laden water can be written as:

$$
\frac{\partial(B Q V)}{\partial x}+\frac{\partial Q}{\partial t}+g A \frac{\partial A}{\partial x}+g A S_{f}-q_{\ell} v_{\ell}=0
$$

where $y$ corresponds to the water elevation and the density of sediment-laden water is assumed to be constant, so that $20 / 3 x=30 / 3 t=0$. By expanding the first term of equation (4-3-1), we may obtain:

$$
\begin{aligned}
\frac{\partial(\Theta Q V)}{\partial x} & =Q V \frac{\partial \beta}{\partial x}+\beta V \frac{\partial Q}{\partial x}+B Q \frac{\partial V}{\partial x} \\
& =Q V \frac{\partial B}{\partial x}+\beta V \frac{\partial Q}{\partial x}+\beta Q \frac{\partial(Q / A)}{\partial x} \\
& =Q V \frac{\partial B}{\partial x}+2 B V \frac{\partial Q}{\partial x}-\beta V^{2} \frac{\partial A}{\partial x}
\end{aligned}
$$

The term $\frac{\partial A}{\partial x}$ can be further expanded by using:

$$
\frac{\partial A}{\partial x}=\left.\frac{\partial A}{\partial x}\right|_{y=\text { const. }}+\frac{\partial A}{\partial y} \frac{\partial y}{\partial x}=\left.\frac{\partial A}{\partial x}\right|_{y=\text { const. }}+T \frac{3 y}{\partial x}=A_{x}^{y}+T \frac{\partial y}{\partial x}
$$

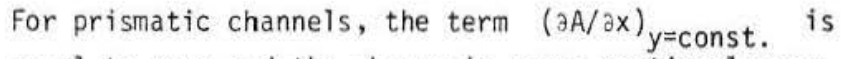
equal to zero and the change in cross-sectional area is only due to the change in water elevation. Then, this term represents the departure from a prismatic channel and equation (4-3-2) takes the form:

$$
\frac{\partial(B V Q)}{\partial x}=Q V \frac{\partial B}{\partial x}+2 B V \frac{\partial Q}{\partial x}-B V^{2} A_{x}^{y}-\beta V^{2} T \frac{\partial y}{\partial x}
$$

Introducing the last expression in equation (4-3-1) and eliminating the velocity by replacing the dependent variable $V$ by the discharge $Q=V A$, we obtain:

$\frac{Q^{2}}{A} \frac{\partial B}{\partial x}+\frac{2 Q Q}{A} \frac{\partial Q}{\partial x}-\frac{B O^{2}}{A^{2}} A_{x}^{y}-\frac{B 0^{2} T}{A^{2}} \frac{\partial y}{\partial x}+\frac{\partial Q}{\partial t}+g A^{\partial y} \partial+g A S_{f}-Q_{2} V_{2}=0 \quad(4-3-5)$

Equation (4-3-5) represents the final form of the momentum equation $(4-3-1)$ after expanding all terms. The discretization of this equation, according to equations $(4-1-3)$ is carried out by considering each individual term separately.

1. Consider the term $\frac{Q^{2}}{A} \frac{\partial B}{\partial x}$;

$\frac{Q^{2}}{A} \frac{\partial B}{\partial X}=\left\{\frac{\theta}{2}\left(\Delta Q_{j+1}+\Delta Q_{j}\right)+\frac{1}{2}\left(Q_{j+1}^{n}+Q_{j}^{n}\right)\right\}^{2}$.

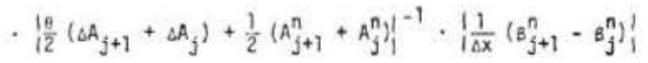

where it is assumed that in a small time increment $\Delta t$ the change in $B$ is comparatively small and can be neglected.

This equation is linearized by developing the denominator in a power series and keeping only the first-order term, so that:

$$
\begin{aligned}
& \frac{1}{\frac{1}{2}\left(A_{j+1}^{n}+A_{j}^{n}\right)+\frac{\theta}{2}\left(\Delta A_{j+1}+\Delta A_{j}\right)}=\frac{2}{A_{j+1}^{n}+A_{j}^{n}}-\frac{2 \theta\left(\Delta A_{j+1}+\Delta A_{j}\right)}{\left(A_{j+1}^{n}+A_{j}^{n}\right)^{2}}= \\
& =\frac{2}{A_{j+1}^{n}+A_{j}^{n}}-\frac{2 \theta \Delta A_{j+1}}{\left(A_{j+1}^{n}+A_{j}^{n}\right)^{2}}-\frac{2 \theta \Delta A_{j}}{\left(A_{j+1}^{n}+A_{j}^{n}\right)^{2}}
\end{aligned}
$$

Then, by using this approximation and by neglecting the second order terms in $\Delta Q$, we have: 
$\frac{Q^{2}}{A} \frac{\partial B}{\partial x}=\left\{\frac{Q}{2}\left(\Delta Q_{j+1}+\Delta Q_{j}\right)\left(Q_{j+1}^{n}+Q_{j}^{n}\right)+\frac{1}{4}\left(Q_{j+1}^{n}+Q_{j}^{n}\right) 2\right\}$.

$$
\cdot\left\{\frac{2}{A_{j+1}^{n}+A_{j}^{n}}-\frac{2 \theta \Delta A_{j+1}}{\left(A_{j+1}^{n}+A_{j}^{n}\right)^{2}}-\frac{2 \theta \Delta A_{j}}{\left(A_{j+1}^{n}+A_{j}^{n}\right)^{2}}\right\}:\left\{\frac{1}{\alpha x}\left(B_{j+1}^{n}-B_{j}^{n}\right)\right\}(4-3-8)
$$

By using $\triangle A Z T \Delta Y$ and by regrouping terms, a final expression for the first term of equation $(4-3-5)$ is obtained:

$$
\begin{aligned}
& \frac{Q^{2}}{A} \frac{\partial B}{\partial x}=\frac{\theta}{\Delta x} \frac{\left(B_{j+1}^{\prime \prime}-B_{j}^{n}\right)\left(Q_{j+1}^{n}+Q_{j}^{n}\right)}{\left(A_{j+1}^{n}+A_{j}^{n}\right)} \Delta Q_{j+1}+ \\
& +\frac{\theta}{\Delta x} \frac{\left(B_{j+1}^{n}-\beta_{j}^{n}\right)\left(Q_{j+1}^{n}+Q_{j}^{n}\right)}{\left(A_{j+1}^{n}+A_{j}^{n}\right)} \Delta Q_{j}- \\
& -\frac{\theta T}{2 \Delta x} \frac{\left(B_{j+1}^{n}-B_{j}^{n}\right)\left(Q_{j+1}^{n}+Q_{j}^{n}\right)^{2}}{\left(A_{j+1}^{n}+A_{j}^{n}\right)^{2}} \Delta y_{j+1}- \\
& -\frac{\theta T_{j}^{n}}{2 \Delta x} \frac{\left(B_{j+1}^{n}-B_{j}^{n}\right)\left(Q_{j+1}^{n}+Q_{j}^{n}\right)^{2}}{\left(A_{j+1}^{n}+A_{j}^{n}\right)^{2}} \Delta Y_{j}+ \\
& +\frac{1}{2 \Delta x} \frac{\left(B_{j+1}^{n}-B_{j}^{n}\right)\left(Q_{j+1}^{n}+Q_{j}^{n}\right)}{\left(A_{j+1}^{n}+A_{j}^{n}\right)}
\end{aligned}
$$

in which the second order terms have been neglected, e.g., $\Delta Q \cdot \Delta Q=\Delta Q \Delta Y=0$.

2. Consider the term $2 B \frac{Q}{A} \frac{\partial Q}{\partial x}$;

$2 B \frac{Q}{A} \frac{\partial Q}{\partial x}=2 \mid \frac{1}{2}\left(\left(\beta_{j+1}^{n}+B_{j}^{n}\right)|\cdot| \frac{\theta}{2}\left(\Delta Q_{j+1}+\Delta Q_{j}\right)+\frac{1}{2}\left(Q_{j+1}^{n}+Q_{j}^{n}\right) \mid\right.$

$$
\cdot\left\{\frac{2}{A_{j+1}^{n}+A_{j}^{n}}-\frac{2 \theta T_{j+1}^{n}}{\left(A_{j+1}^{n}+A_{j}^{n}\right)^{2}} \Delta r_{j+1}-\frac{2 \theta T_{j}^{n}}{\left(A_{j+1}^{n}+A_{j}^{n}\right)^{2}} \Delta r_{j}\right\}
$$

Where once again the term $1 / A$ has been linearized by using a first-order power series expansion to approxmate the denominator. By expanding the last equation and by further linearization according to the principle that $(\Delta f)^{2} \approx \Delta f \Delta g=0$ we obtain:

$$
\begin{aligned}
& 2 \beta \frac{Q}{A} \frac{\partial Q}{\partial x}=\frac{2 \theta}{\Delta x} \frac{\left(B_{j+1}^{n}+\beta_{j}^{n}\right) Q_{j+1}^{n}}{\left(A_{j+1}^{n}+A_{j}^{n}\right)} \Delta Q_{j+1}- \\
& -\frac{2 \theta}{\Delta x} \frac{\left(B_{j+1}^{n}+\beta_{j}^{n}\right) Q_{j}^{n}}{\left(A_{j+1}^{n}+A_{j}^{n}\right)} \Delta Q_{j}- \\
& -\frac{\theta T_{j+1}^{n}}{\Delta x} \frac{\left(B_{j+1}^{n}+B_{j}^{n}\right)\left(Q_{j+1}^{n}+Q_{j}^{n}\right)\left(Q_{j+1}^{n}-Q_{j}^{n}\right)}{\left(A_{j+1}^{n}+A_{j}^{n}\right)^{2}} \cdot \Delta Y_{j+1}- \\
& -\frac{\theta T_{j}^{n}}{\Delta x} \frac{\left(B_{j+1}^{n}+\beta_{j}^{n}\right)\left(Q_{j+1}^{n}+Q_{j}^{n}\right)\left(Q_{j+1}^{n}-Q_{j}^{n}\right)}{\left(A_{j+1}^{n}+A_{j}^{n}\right)^{2}} \Delta Y_{j}+ \\
& +\frac{1}{\Delta x} \frac{\left(B_{j+1}^{n}+\beta_{j}^{n}\right)\left(Q_{j+1}^{n}+Q_{j}^{n}\right)\left(Q_{j+1}^{n}-Q_{j}^{n}\right)}{\left(A_{j+1}^{n}+A_{j}^{n}\right)}
\end{aligned}
$$

3. Consider the term $\frac{B Q^{2} T}{A^{2}} \frac{\partial y}{\partial x}$

$$
\begin{aligned}
& \frac{Q^{2} T}{A^{2}} \frac{\partial y}{\partial x}=\left(\frac{1}{2}\left(\theta_{j+1}^{n}+B_{j}^{n}\right)\right\} . \\
& \cdot\left(\frac{\theta}{2}\left(Q_{j+1}^{n}+Q_{j}^{n}\right) \Delta Q_{j+1}+\frac{\theta}{2}\left(Q_{j+1}^{n}+Q_{j}^{n}\right) \Delta Q_{j}+\frac{1}{4}\left(Q_{j+1}^{n}+Q_{j}^{n}\right)^{2}\right\} . \\
& \cdot\left(\frac{1}{2}\left(T_{j+1}^{n}+T_{j}^{n}\right)\right) \cdot\left(\frac{\theta}{\Delta x}\left(\Delta Y_{j+1}-\Delta Y_{j}\right)+\frac{1}{\Delta x}\left(Y_{j+1}^{n}-Y_{j}^{n}\right)\right\} . \\
& \cdot\left(\frac{4}{\left(A_{j+1}^{n}+A_{j}^{n}\right)^{2}} \cdot \frac{8 \theta T_{j+1}^{n}}{\left(A_{j+1}^{n}+A_{j}^{n}\right)^{3}} \Delta Y_{j+1}-\frac{8 \theta T_{j}^{n}}{\left(A_{j+1}^{n}+A_{j}^{n}\right)^{3}} \Delta Y_{j}\right\}
\end{aligned}
$$

in which $\Delta B=\Delta T \approx 0$.

After expanding this expression, the following equation is obtained:

$$
\begin{aligned}
& \frac{B Q Q T}{A^{2}} \frac{\partial y}{\partial x}=\frac{\theta}{2 \Delta x} \frac{\left(B_{j+1}^{n}+B_{j}^{n}\right)\left(T_{j+1}^{n}+T_{j}^{n}\right)\left(Q_{j+1}^{n}+Q_{j}^{n}\right)\left(Y_{j+1}^{n}-r_{j}^{n}\right)}{\left(A_{j+1}^{n}+A_{j}^{n}\right)^{2}} \Delta Q_{j+1} \\
& +\frac{\theta}{2 \Delta x} \frac{\left(B_{j+1}^{n}+B_{j}^{n}\right)\left(T_{j+1}^{n}+T_{j}^{n}\right)\left(Q_{j+1}^{n}+Q_{j}^{n}\right)\left(Y_{j+1}^{n}-Y_{j}^{n}\right)}{\left(A_{j+1}^{n}+A_{j}^{n}\right)^{2}} \Delta Q_{j} \\
& +\frac{\theta}{4 \Delta x} \frac{\left(B_{j+1}^{n}+B_{j}^{n}\right)\left(T_{j+1}^{n}+T_{j}^{n}\right)\left(Q_{j+1}^{n}+n_{j}^{n}\right)^{n}}{\left(A_{j+1}^{n}+A_{j}^{n}\right)^{2}} \mid 1-2 T_{j+1}^{n} \frac{\left(Y_{j+1}^{n}-Y_{j}^{n}\right)}{\left(A_{j+1}^{n}+A_{j}^{n}\right)} \Delta Y_{j+1} \\
& +\frac{\theta}{4 \Delta x} \frac{\left(B_{j+1}^{n}+B_{j}^{n}\right)\left(T_{j+1}^{n}+T_{j}^{n}\right)\left(Q_{j+1}^{n}+Q_{j}^{n}\right)^{2}}{\left(A_{j+1}^{n}+A_{j}^{n}\right)^{2}} \mid 1+2 T_{j}^{n} \frac{\left(Y_{j+1}^{n}-Y_{j}^{n}\right)}{\left(A_{j+1}^{n}+A_{j}^{n}\right)} \Delta Y_{j} \\
& +\frac{1}{4 \Delta x} \frac{\left(B_{j}^{n}+B_{j}^{n}\right)\left(T_{j+1}^{n}+T_{j}^{n}\right)\left(Q_{j+1}^{n}+Q_{j}^{n}\right)^{2}\left(Y_{j+1}^{n}-Y_{j}^{n}\right)}{\left(A_{j+1}^{n}+A_{j}^{n}\right)^{2}} \quad(4-3-13)
\end{aligned}
$$

4. Consider the term $\frac{B Q^{2}}{A^{2}} A_{x}^{y}$ Similarly to equation (4-3-13):

$$
\begin{aligned}
& \frac{\theta Q^{2}}{A^{2}} A_{x}^{y}=\frac{\theta}{2} \frac{\left(\theta_{j+1}^{n}+B_{j}^{n}\right)\left(Q_{j+1}^{n}+Q_{j}^{n}\right)\left(A_{x_{j+1}}^{y^{n}}+A_{x_{j}}^{y^{n}}\right)}{\left(A_{j+1}^{n}+A_{j}^{n}\right)^{2}} \Delta Q_{j+1} \\
& +\frac{\theta}{2} \frac{\left(e_{j+1}^{n}+a_{j}^{n}\right)\left(Q_{j+1}^{n}+Q_{j}^{n}\right)\left(A_{x_{j+1}}^{y^{n}}+A_{x_{j}}^{y^{n}}\right)}{\left(A_{j+1}^{n}+A_{j}^{n}\right)^{2}} \Delta Q_{j} \\
& -\frac{\theta T_{j+1}^{n}}{2} \frac{\left(2_{j+1}^{n}+a_{j}^{n}\right)\left(Q_{j+1}^{n}+Q_{j}^{n}\right)^{2}\left(A_{x_{j+1}}^{y^{n}}+A_{x_{j}}^{y^{n}}\right)}{\left(A_{j+1}^{n}+A_{j}^{n}\right)^{3}} \Delta Y_{j+1} \\
& -\frac{\theta T_{j}^{n}}{2} \frac{\left(B_{j+1}^{n}+B_{j}^{n}\right)\left(Q_{j+1}^{n}+Q_{j}^{n}\right)\left(A_{x_{j+1}}^{y^{n}}+A_{x_{j}}^{y^{n}}\right)}{\left(A_{j+1}^{n}+A_{j}^{n}\right)^{3}} \Delta Y_{j} \\
& +\frac{1}{4} \frac{\left(B_{j+1}^{n}+B_{j}^{n}\right)\left(Q_{j+1}^{n}+Q_{j}^{n}\right)^{2}\left(A_{x_{j+1}}^{y^{n}}+A_{x_{j}}^{y^{n}}\right)}{\left(A_{j+1}^{n}+A_{j}^{n}\right)^{2}}
\end{aligned}
$$

5. Consider the term $\frac{\partial Q}{\partial t}$

$$
\frac{\partial Q}{\partial t}=\frac{1}{2 \Delta t} \Delta Q_{j+1}+\frac{1}{2 \Delta t} \Delta Q_{j}
$$

6. Consider the term $g A \frac{\partial y}{\partial x}$

By using again $\Delta A=T \Delta Y$ and retaining only first order terms, this term becomes:

24 


$$
\begin{aligned}
& g A \frac{\partial y}{\partial x} \cdot \frac{g \theta}{2 \Delta x}\left(\left(A_{j+1}^{n}+A_{j}^{n}\right)+\left(Y_{j+1}^{n}-Y_{j}^{n}\right) T_{j+1}^{n}\right) \Delta Y_{j+1} \\
& +\frac{g \theta}{2 \Delta x}\left[\left(Y_{j+1}^{n}-Y_{j}^{n}\right) T_{j}^{n}-\left(A_{j+1}^{n}+A_{j}^{n}\right)\right] \Delta Y_{j} \\
& +\frac{g}{2 \Delta x}\left(A_{j+1}^{n}+A_{j}^{n}\right)\left(Y_{j+1}^{n}-Y_{j}^{n}\right)
\end{aligned}
$$

7. Consider the term $g \mathrm{AS}_{\mathrm{f}}$

$$
\begin{aligned}
& g A S_{f}=g\left\{\frac{\theta}{2}\left(\Delta A_{j+1}+\Delta A_{j}\right)+\frac{1}{2}\left(A_{j+1}^{n}+A_{j}^{n}\right)\right\} . \\
& \cdot \frac{\theta}{2}\left(\Delta S_{f_{j+1}}+\Delta S_{f_{j}}\right)+\frac{1}{2}\left(S_{f_{j+1}}^{n}+S_{f_{j}}^{n}\right) \quad(4-3-17)
\end{aligned}
$$

To evaluate the friction slope the Manning's equation is used as:

$$
S_{f}=\frac{Q^{2}}{K^{2}}
$$

in which $K$ is the conveyance of the cross section given by

$$
K=\frac{1.486 A R^{2 / 3}}{n}
$$

and $n$ is the Manning's roughness coefficient as a function of $Q$ and $Y$.

The energy slope, which is a quadratic function of $Q$ and $K$, can be linearized by using a Taylor Series expansion:

$$
\Delta S_{f}=\frac{\partial S_{f}}{\partial Q} \Delta Q+\frac{\partial S}{\partial Y} \Delta Y
$$

Hence, by using equations (4-3-18) and (4-3-19);

$$
\begin{gathered}
\frac{\partial S_{f}}{\partial Q}=2 S_{f}\left(\frac{1}{Q}-\frac{1}{n} \cdot \frac{\partial n^{\prime}}{\partial G}\right) \\
\frac{\partial S_{f}}{\partial Y}=-2 S_{f}\left[\frac{1}{A}\left(\frac{5}{3} T-\frac{2}{3} R \frac{d P}{d Y}\right)+\frac{1}{n} \frac{\partial n^{\prime}}{\partial Y !}\right.
\end{gathered}
$$

where $R$ is the hydraulic radius; $P$ is the whetted perimeter and $n^{\prime}$ is the coefficient $1.486 / n$.

Substitution of equation (4-3-20) and (4-3-17) gives:

$$
\begin{aligned}
& +\frac{g \theta}{4}\left[\left(S_{f_{j+1}}^{n}+S_{f_{j}}^{n}\right) T_{j}^{n}+\left(A_{j+1}^{n}+A_{j}^{n}\right)\left(\frac{\partial S_{f}}{\partial Y}\right)_{j}^{n}\right] \Delta Y_{j} \\
& +\frac{g \theta}{4}\left(A_{j+1}^{n}+A_{j}^{n}\right)\left(\frac{\partial S_{f}}{\partial Q}\right)_{j+1}^{n} \Delta Q_{j+1} \\
& +\frac{g \theta}{4}\left(A_{j+1}^{n}+A_{j}^{n}\right)\left(\frac{\partial S_{f}}{\partial Q}\right)_{j}^{n} \Delta Q_{j} \\
& +\frac{g}{4}\left(A_{j+1}^{n}+A_{j}^{n}\right)\left(S_{f_{j+1}}^{n}+S_{f_{j}}^{n}\right)
\end{aligned}
$$

8. Consider the term $q_{\ell} V_{\ell}$

$$
q_{\ell} v_{\ell}=\frac{1}{4}\left(q_{l_{j+1}}^{n}+q_{l_{j}}^{n}\right)\left(v_{l_{j+1}}^{n}+v_{l_{j}}^{n}\right)
$$

By adding equations $(4-3-9),(4-3-11),(4-3-13)$, $(4-3-14),(4-3-15),(4-3-16),(4-3-23)$, and $(4-3-24)$, the momentum equation $(4-3-5)$ can be written symbol i: coly in finite difference form as:

$$
a^{\prime} \Delta Q_{j+1}+b^{\prime} \Delta Q_{j}+c^{\prime} \Delta Y_{j+1}+d^{\prime} \Delta Y_{j}+e^{\prime}=0
$$

where

$$
\begin{aligned}
a^{\prime} & =\frac{\theta}{\Delta x} \frac{\left(Q_{j+1}^{n}+Q_{j}^{n}\right)\left(B_{j+1}^{n}+B_{j}^{n}\right)}{\left(A_{j+1}^{n}+A_{j}^{n}\right)}+ \\
& +\frac{2\left(B_{j+1}^{n}+B_{j}^{n}\right) Q_{j+1}^{n}}{\left(A_{j+1}^{n}+A_{j}^{n}\right)} \\
& -\frac{1}{2} \frac{\left(B_{j+1}^{n}+B_{j}^{n}\right)\left(T_{j+1}^{n}+T_{j}^{n}\right)\left(Q_{j+1}^{n}+Q_{j}^{n}\right)\left(Y_{j+1}^{n}-Y_{j}^{n}\right)}{\left(A_{j+1}^{n}+A_{j}^{n}\right)^{2}}
\end{aligned}
$$$$
-\frac{\Delta x}{2} \frac{\left(B_{j+1}^{n}+B_{j}^{n}\right)\left(Q_{j+1}^{n}+Q_{j}^{n}\right)\left(A_{x_{j+1}}^{y^{n}}+A_{x_{j}}^{y^{n}}\right)}{\left(A_{j+1}^{n}+A_{j}^{n}\right)^{2}}
$$$$
\left.+\frac{g \Delta x}{4}\left(A_{j+1}^{n}+A_{j}^{n}\right)\left(\frac{\partial S_{f}}{\partial Q}\right)_{j+1}^{n}\right\}+\frac{1}{2 \Delta t}
$$

$$
\begin{aligned}
b^{\prime} & =\frac{\theta}{\Delta x} \frac{\left(Q_{j+1}^{n}+Q_{j}^{n}\right)\left(B_{j+1}^{n}-B_{j}^{n}\right)}{\left(A_{j+1}^{n}+A_{n}^{n}\right)}-\frac{2\left(B_{j+1}^{n}+B_{j}^{n}\right) Q_{j}^{n}}{\left(A_{j+1}^{n}+A_{j}^{n}\right)} \\
& -\frac{1}{2} \frac{\left(B_{j+1}^{n}+B_{j}^{n}\right)\left(T_{j+1}^{n}+T_{j}^{n}\right)\left(Q_{j+1}^{n}+Q_{j}^{n}\right)\left(Y_{j+1}^{n}-Y_{j}^{n}\right)}{\left(A_{j+1}^{n}+A_{j}^{n}\right)^{2}} \\
& -\frac{\Delta x}{2} \frac{\left(B_{j+1}^{n}+B_{j}^{n}\right)\left(Q_{j+1}^{n}+Q_{j}^{n}\right)\left(A_{x_{j+1}}^{n}+A_{x_{j}}^{n}\right)}{\left(A_{j+1}^{n}+A_{j}^{n}\right)^{2}} \\
& \left.+\frac{g \Delta x}{4}\left(A_{j+1}^{n}+A_{j}^{n}\right)\left(\frac{\partial S_{f}}{\partial Q}\right)_{j}^{n}\right\}+\frac{1}{2 \Delta t}
\end{aligned}
$$

25 


$$
\begin{aligned}
c^{\prime} & =\frac{\theta}{2 \Delta x}\left\{-\frac{T_{j+1}^{n}\left(Q_{j+1}^{n}+Q_{j}^{n}\right)^{2}\left(B_{j+1}^{n}+B_{j}^{n}\right)}{\left(A_{j+1}^{n}+A_{j}^{n}\right)^{2}}\right. \\
& -2 T_{j+1}^{n} \frac{\left(B_{j+1}^{n}+B_{j}^{n}\right)\left(Q_{j+1}^{n}+Q_{j}^{n}\right)\left(Q_{j+1}^{n}-Q_{j}^{n}\right)}{\left(A_{j+1}^{n}+A_{j}^{n}\right)^{2}} \\
& -\frac{1}{2} \frac{\left(B_{j+1}^{n}+B_{j}^{n}\right)\left(T_{j+1}^{n}+T_{j}^{n}\right)\left(Q_{j+1}^{n}+Q_{j}^{n}\right)^{2}}{\left(A_{j+1}^{n}+A_{j}^{n}\right)^{2}} \\
& {\left[1-2 T_{j+1}^{n} \frac{\left(Y_{j+1}^{n}-Y_{j}^{n}\right)}{\left(A_{j+1}^{n}+A_{j}^{n}\right)}\right] } \\
& +\Delta x T_{j+1}^{n} \frac{\left(B_{j+1}^{n}+\beta_{j}^{n}\right)\left(Q_{j+1}^{n}+Q_{j}^{n}\right)^{2}\left(A_{x_{j+1} y^{n}}+A_{x_{j}}^{y^{n}}\right)}{\left(A_{j+1}^{n}+A_{j}^{n}\right)^{3}} \\
& +g\left[\left(A_{j+1}^{n}+A_{j}^{n}\right)+\left(Y_{j+1}^{n}-Y_{j}^{n}\right) T_{j+1}^{n}\right] \\
& \left.+\frac{g \Delta x}{2}\left[\left(S_{f}^{n}+S_{j+1}^{n}\right) T_{j+1}^{n}+\left(A_{j+1}^{n}+A_{j}^{n}\right)\left(\frac{\partial S_{f}}{\partial Y}\right)_{j+1}^{n}\right]\right\} \\
d^{\prime} & =\frac{\theta}{2 \Delta x}\left\{-T_{j}^{n} \frac{\left(Q_{j+1}^{n}+Q_{j}^{n}\right)^{2}\left(B_{j+1}^{n}-B_{j}^{n}\right)}{\left(A_{j+1}^{n}+A_{j}^{n}\right)^{2}}\right.
\end{aligned}
$$

$$
\begin{aligned}
& -2 T_{j}^{n} \frac{\left(B_{j+1}^{n}+B_{j}^{n}\right)\left(Q_{j+1}^{n}+Q_{j}^{n}\right)\left(Q_{j+1}^{n}-Q_{j}^{n}\right)}{\left(A_{j+1}^{n}+A_{j}^{n}\right)^{2}} \\
& +\frac{1}{2} \frac{\left(B_{j+1}^{n}+B_{j}^{n}\right)\left(T_{j+1}^{n}+T_{j}^{n}\right)\left(Q_{j+1}^{n}+Q_{j}^{n}\right)^{2}}{\left(A_{j+1}^{n}+A_{j}^{n}\right)^{2}}\left[1+\frac{2 T_{j}^{n}\left(y_{j+1}^{n}-y_{j}^{n}\right)}{\left(A_{j+1}^{n}+A_{j}^{n}\right)}\right] \\
& +\Delta x T_{j}^{n} \frac{\left(B_{j+1}^{n}+A_{j}^{n}\right)\left(Q_{j+1}^{n}+Q_{j}^{n}\right)^{2}\left(A_{x_{j+1}}^{y^{n}}+A_{x_{j}}^{y^{n}}\right)}{\left(A_{j+1}^{n}+A_{j}^{n}\right)^{3}} \\
& \left.+g I\left(Y_{j+1}^{n}-Y_{j}^{n}\right) T_{j}^{n}-\left(A_{j+1}^{n}+A_{j}^{n}\right)\right] \\
& \left.+\frac{g \Delta x}{2}\left[\left(S_{f_{j+1}}^{n}+S_{f_{j}}^{n}\right) T_{j}^{n}+\left(A_{j+1}^{n}+A_{j}^{n}\right)\left(\frac{\partial S_{f}}{\partial y}\right)_{j}^{n}\right]\right\}
\end{aligned}
$$

$$
\begin{aligned}
e^{\prime} & =\frac{1}{2 \Delta x} \frac{\left(Q_{j+1}^{n}+Q_{j}^{n}\right)^{2}\left(B_{j+1}^{n}-B_{j}^{n}\right)}{\left(A_{j+1}^{n}+A_{j}^{n}\right)} \\
& +2 \frac{\left(B_{j+1}^{n}+B_{j}^{n}\right)\left(Q_{j+1}^{n}+Q_{j}^{n}\right)\left(Q_{j+1}^{n}-Q_{j}^{n}\right)}{\left(A_{j+1}^{n}+A_{j}^{n}\right)} \\
& -\frac{1}{2} \frac{\left(B_{j+1}^{n}+B_{j}^{n}\right)\left(T_{j+1}^{n}+T_{j}^{n}\right)\left(Q_{j+1}^{n}+Q_{j}^{n}\right)^{2}\left(Y_{j+1}^{n}-Y_{j}^{n}\right)}{\left(A_{j+1}^{n}+A_{j}^{n}\right)^{2}} \\
& -\frac{\Delta x}{2} \frac{\left(B_{j+1}^{n}+B_{j}^{n}\right)\left(Q_{j+1}^{n}+Q_{j}^{n}\right)^{2}\left(Q_{x_{j+1}}^{y^{n}}+A_{x_{j}}^{y^{n}}\right)}{\left(A_{j+1}^{n}+A_{j}^{n}\right)^{2}}
\end{aligned}
$$

$$
\begin{aligned}
& +g\left(A_{j+1}^{n}+A_{j}^{n}\right)\left(Y_{j+1}^{n}-Y_{j}^{n}\right) \\
& +\frac{a \Delta x}{2}\left(A_{j+1}^{n}+A_{j}^{n}\right)\left(S_{f_{j+1}}^{n}+S_{f_{j}}^{n}\right) \\
& \left.+\frac{\Delta x}{2}\left(Q_{l_{j+1}^{n}}^{n}+q_{\ell_{j}}^{n}\right)\left(V_{\ell_{j+1}}^{n}+V_{\ell_{j}}^{n}\right)\right\}
\end{aligned}
$$

The coefficients $a^{\prime}, b^{\prime}, c^{\prime}, d^{\prime}$ and $e^{\prime}$ may be computed at any time $t^{n}$ because all the variables, $A, Y, \beta, Q, T$, etc., are known at time $t^{n}$. Then equation $(4-3-25)$ contains also four unknowns, $\Delta Q_{j+1}, \Delta Q_{j}, \Delta Y_{j+1}$ and $\Delta Y_{j}$.

4.4 Discretization of the Sediment Continuity Equation

The discretization of equation (3.3.2.5) according to equation $(4-1-4)$ results in

$$
\begin{aligned}
& \frac{1}{2 \Delta x}\left(Q_{s_{m_{j}}^{n+1}}^{n+1}-Q_{s_{m_{j-1}}^{n+1}}+Q_{s_{m_{j}}}^{n}-Q_{s_{m_{j-1}}}^{n}\right) \\
& +\frac{1}{4}\left(\gamma_{d_{m_{j-1}}^{n+1}}^{n+1}+\gamma_{d_{m_{j-1}}^{n}}^{n}+\gamma_{d_{m_{j}}^{n+1}}^{n+}+\gamma_{d_{m_{j}}^{n}}^{n}\right) \cdot \\
& \frac{1}{\Delta t}\left(A_{d_{m_{j}}}^{n+1}-A_{d_{m_{j}}^{n}}^{n}\right)+\frac{1}{2 \Delta t}\left[\left(A_{m} c_{s_{m}}\right)_{j}^{n+1}-\left(A_{m} c_{s_{m}}\right)_{j}^{n}\right] \\
& +\frac{1}{4}\left(q_{s}^{n+1}(m-1)_{j-1}+q_{s}^{n}(m-1)_{j-1}+q_{s}^{n+1}(m-1)_{j}+q_{s}^{n}(m-1)_{j}\right) \\
& -\frac{1}{4}\left(q_{s_{m_{j-1}}}^{n+1}+q_{s_{m_{j-1}}}^{n}+q_{s_{m_{j}}}^{n+1}+q_{s_{m_{j}}}^{n}\right)=0 \quad(4-4-1)
\end{aligned}
$$

in which the sediment concentration $C_{s}$ is given in units of weight per unit of volume.

The sediment routing procedure described in the last chapter requires the solution of this equation for the changes in bed elevation. Then, by making:

$$
\Delta A_{d_{m_{j}}}=A_{d_{m_{j}}^{n+1}}^{n+1}-A_{d_{m_{j}}}^{n}
$$
and solving for $\Delta A_{d_{m_{j}}}$, the following expression is
obtained:

$$
\begin{aligned}
& \Delta A_{d_{m_{j}}}=\frac{4 \Delta t}{\left(\gamma_{d_{m_{j-1}}^{n+1}}+\gamma_{d_{m_{j-1}}}^{n}+\gamma_{d_{m_{j}}^{n+1}}+\gamma_{d_{m_{j}}}^{n}\right)} \\
& \cdot\left(-\frac{1}{2 \Delta x}-\left(Q_{s_{m_{j}}}^{n+1}-Q_{s_{m_{j-1}}}^{n+1}+Q_{s_{m_{j}}}^{n}-Q_{s_{m_{j-1}}}^{n}\right)\right. \\
& -\frac{1}{2 \Delta t}\left(\left(A_{m} c_{s_{m}}\right)_{j}^{n+1}-\left(A_{m} c_{s_{m}}\right)_{j}^{n}\right) \\
& \left.-\frac{1}{4}\left(q_{s(m-1)}^{n+1}\right)_{j-1}+q_{s(m-1)}^{n}+q_{s-1}^{n+1}+q_{(m-1))_{j}}^{n}+q_{s(m-1)}^{n}\right)_{j}^{\prime} \\
& \left.+\frac{1}{4}\left(q_{s_{m_{j-1}}}^{n+1}+q_{s_{m_{j-1}}}^{n}+q_{s_{m_{j}}}^{n+1}+q_{s_{m_{j}}}^{n}\right)\right\}
\end{aligned}
$$

26 
Equation (4-4-3) gives an explicit solution for the sediment deposition at any section $j$ for any subchannel $m$ in the river reach. The change in the bed elevation at any cross-section of the mth. Stream can be approximated by:

$$
\Delta z_{n_{j}}=\Delta A_{d_{m_{j}}} / T_{m_{j}}
$$

where $T_{m_{j}}$ is the top width of the section $j$ for the stream $\mathrm{m}$.

\subsection{Solution Algorithm}

The method of solution consists in solving initially the flow continuity and momentum equations simultaneously for the unknowns $\Delta Q$ and $\Delta y$, and secondly the sediment continuity equation for the change in bed elevations $\Delta \mathrm{A}_{d}$.

Equations $(4-2-4)$ and $(4-3-25)$ form a set of two simultaneous linear equations in four unknowns $\Delta Q_{j+1}, \Delta Q_{j}, \Delta y_{j+1}$ and $\Delta y_{j}$ written for any pair of spatial points $j$ and $j+1$. All the coefficients in these equations are functions of quantities known for spatial points $j$ and $j+1$ at time step $n$. However, they are not sufficient to find the values of the four unknowns because only two equations are available. But if the channel being modeled is divided into $(\mathrm{N}-1)$ segments, there are a total of $2 \mathrm{~N}$ unknowns and $2(\mathrm{~N}-1)$ equations. Then, two additional equations are needed to evaluate the values of $\Delta Q_{j}$ and $\Delta y_{j}$ for $j=1, \ldots N$. These two equations are provided by the boundary conditions and thus the system may be solved for any time step $\Delta t$.

The double-sweep method of solution as applied by Liggett and Cunge (1974) is used here to soive the system of linear algebraic equations.

Consider the system of equations $(4-2-4)$ and $(4-3-25)$ :

$$
\begin{aligned}
& a \Delta Q_{j+1}+b \Delta Q_{j}+c \Delta y_{j+1}+d \Delta y_{j}+e=0 \\
& a^{\prime} \Delta Q_{j+1}+b^{\prime} \Delta Q_{j}+c^{\prime} \Delta y_{j+1}+d^{\prime} \Delta y_{j}+e^{\prime}=0
\end{aligned}
$$

If a linear relationship can be established at any section $j+1$ in the form:

$$
\Delta Q_{j+1}=P_{j+1} \Delta y_{j+1}+R_{j+1}
$$

We can substitute equation (4-5-3) into (4-5-1) and $(4-5-2)$ and eliminate $\Delta y_{j+1}$ to obtain

$$
\Delta Q_{j}=P_{j} \Delta y_{j}+R_{j}
$$

in which

$$
p_{j}=\frac{\left(a P_{j+1}+c\right) d^{\prime}-\left(a^{\prime} P_{j+1}+c^{\prime}\right) d}{b\left(a^{\prime} P_{j+1}+c^{\prime}\right)-\left(a P_{j+1}+c\right) b^{\prime}}
$$

$$
R_{j}=\frac{\left(a P_{j+1}+c\right)\left(a^{\prime} R_{j+1}+e^{\prime}\right)-\left(a R_{j+1}+e\right)\left(a^{\prime} P_{j+1}+c^{\prime}\right)}{b\left(a^{\prime} P_{j+1}+c^{\prime}\right)-\left(a P_{j+i}+c\right) b^{\prime}}
$$

Then if $P_{j+1}$ and $R_{j+1}$ are known from the downstream boundary condition, the coefficients $P_{j}$ and $R_{j}$ for all sections can be calculated by recurrence by using equations $(4-5-5)$ and $(4-5-6)$, Eliminating $\Delta y_{j+1}$ between equations $(4-5-1)$ and (4-5-2) and substituting for $\Delta y_{j}$ as given by (4-5-4) a relation between $\Delta Q_{j}$ and $\Delta Q_{j+1}$ can be obtained

$$
\Delta Q_{j+1}=L_{j} \Delta Q_{j}+M_{j}
$$

in which

$$
\begin{aligned}
L_{j} & =\frac{\left(c d^{\prime}-c^{\prime} d\right)+P_{j}\left(b^{\prime} c-b c^{\prime}\right)}{P_{j}\left(a c^{\prime}-c a^{\prime}\right)} \\
M_{j} & =\frac{R_{j}\left(d c^{\prime}-d^{\prime} c\right)+P_{j}\left(c e^{\prime}-c^{\prime} e\right)}{P_{j}\left(a c^{\prime}-a^{\prime} c\right)}
\end{aligned}
$$

Equations (4-5-4) and (4-5-7), with the coefficient expressed by equations $(4-5-5),(4-5-6)$, $(4-5-3)$ and $(4-5-9)$, define the method of solving the $2(\mathrm{~N}-1)$ algebraic equations of the form of $(4-5-1)$ and $(4-5-2)$ coupled with the two boundary conditions. The method is explained in the flow chart of Fig. 4.2 .

The equations (4-5-1), (4-5-2), when written for all the $\mathrm{N}$ space points in the river reach, constitute a very special system of linear equations because ail the elements in the corresponding matrix vanish except those in the five diagonals. For this system, the double sweep method of solution is very efficient and suitable for automatic computation. The computer programs for the standard numerical technique for solving a system of $2 \mathrm{~N}$ equations such as Gauss elimination technique require a storage of a $2 \mathrm{~N} \times 2 \mathrm{~N}$ matrix and the number of operations in the solution are proportional to $\mathrm{N}^{3}$ whereas in the double-sweep method, both the storage and the number of operations in the solution are proportional to N (Strelkoff, 1970).

For sediment routing purposes, the sediment continuity equation in finite difference form, equation (4-4-3), must be solved for the sediment deposition $\Delta A_{d}$. Since all the variables in the right term of this equation are either known or function of the computed values $\Delta Q$ and $\Delta y$, it can be solved directly for the change in bed elevations $\Delta A_{d}$, for $j=1, \ldots N$, provided that the required boundary condition is specified at the most upstream section $j=1$.

\subsection{Boundary Conditions}

The analysis of the basic governing equations by the method of characteristics has been presented by DeVries (1965). From his results it is noted that the set of equations (3.2.1.1), (3.2.1.2) and (3.2.1.3), has three characteristcs in the plane $(x, t)$ (Fig. 4.3). In subcritical flow two characteristics have 
a positive slope and one has a negative slope whereas in supercritical flow the three characteristics have a positive slope. These characteristic directions indicate that: 1) in subcritical flow the water disturbances propagate in both directions up and downstream whereas the bed disturbances travel downstream. 2) for supercritical flow the three positive slopes indicate that no perturbation can be propagated upstream in this regime.

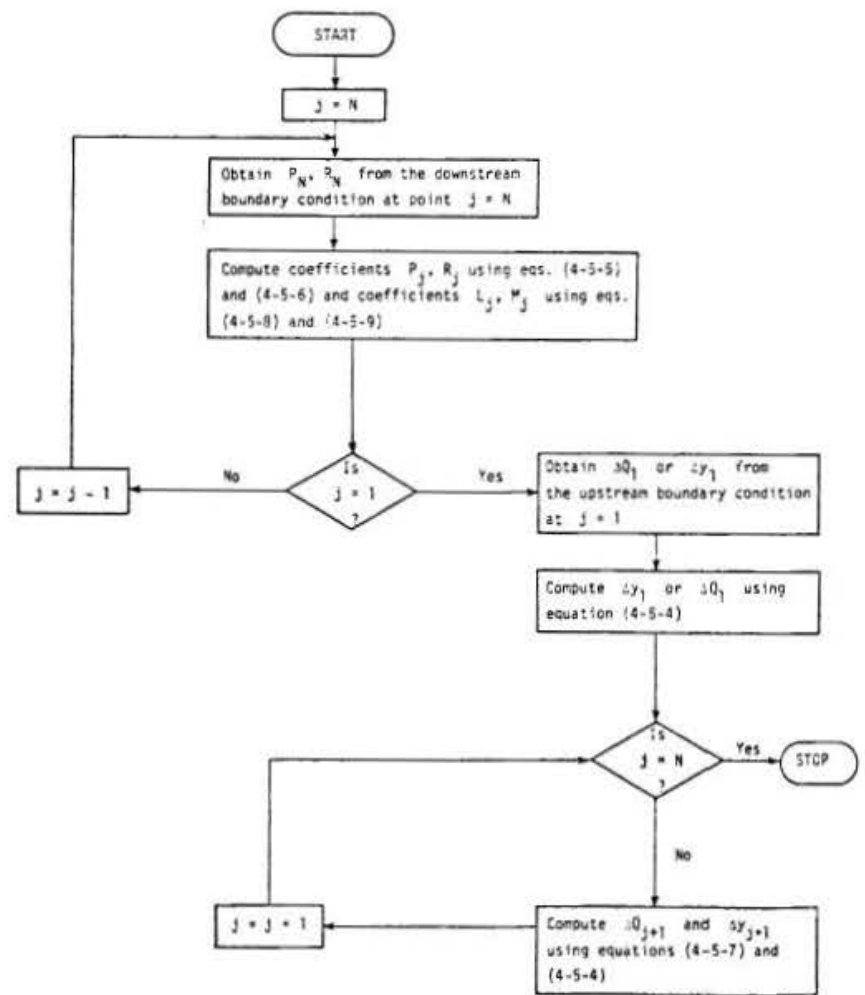

Fig. 4.2 - Flow Chart for the Double-Sweep Method of Solution

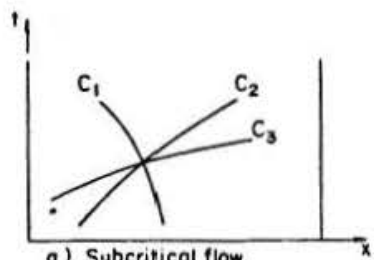

a) Subcritical flow

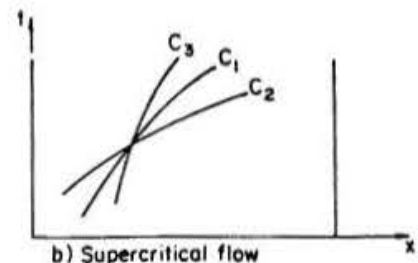

b) Supercritical flow
Fig. 4.3 - Characteristic Directions in the $x-t$ Plane

Consequently, if the complete mixed problem of subcritical flow is to be well posed from the mathematical standpoint it is necessary to specify the following initial and boundary conditions:

1) Three functions $Q(x, t), y(x, t)$ and $A_{d}(x, t)$ over the interval $0 \leq x \leq L$ at the initial time $\mathrm{t}=0$.

2) Two conditions, function of time, at the upstream boundary $x=0$ of the model.

3) A time function condition at the downstream boundary $\mathrm{x}=\mathrm{L}$ of the model. $c_{1} c_{2}=$ characteristic line indicating the direction of propagation of water disturbances.

$c_{3}=$ characteristic line indicating the direction of propagation of bed disturbances.

To be able to use the solution algorithm explained in the flow chart of the last section, the boundary conditions must be lacally linearized. This means that one has to express them under the following form:

1. On the downstream boundary, $j=N$, one needs to know the relationship:

$$
\Delta Q_{N}=P_{N} \Delta y_{N}+R_{N}
$$

2. On the upstream boundary, $j=1$, one needs to know either the value of $\Delta Q_{1}$ or $\Delta y_{1}$.

According to the proposed method of solution, the flow routing procedure requires the specification of one condition at each boundary in the model. Any of the following can be used as the upstream boundary condition:

1. Discharge Hydrograph $Q_{1}(t)$ is given in which $\Delta Q_{1}$ is specified at each time step.

2. Flow Hydrograph $y_{1}(t)$ is given in which $\Delta y_{1}$ is specified at each time step.

Similarly, any of the following conditions can be used for the downstream boundary:

1. Rating Curve, $Q_{N}-f\left(y_{N}\right)$ is given where $f\left(y_{N}\right)$ could either be a polynomial or a tabulated function. Then the coefficients $P_{N}$ and $R_{N}$ are needed for the linear relationship equation (4-6-1). To determine $P_{N}$ and $R_{N}$ let's expand $Q$ in a Taylor series considering only the first order terms:

$$
Q_{N}^{n+1}=Q_{N}^{n}+\frac{\partial Q_{N}^{n}}{\partial y_{N}}\left(y_{N}^{n+1}-y_{N}^{n}\right)
$$

Since $Q_{N}^{n}$ is computed from the function $Q_{N}=f\left(y_{N}\right)$ we can write:

$$
Q_{N}^{n+1}=f\left(y_{N}^{n}\right)+\frac{\partial f}{\partial y_{N}} \Delta y_{N}
$$

Substitution of $Q_{N}^{n+1}=Q_{N}^{n}+\Delta Q_{N}$ in equation (4-6-3) gives:

$$
\Delta Q_{N}=\frac{\partial f}{\partial y_{N}} \Delta y_{N}+f\left(y_{N}^{n}\right)-Q_{N}^{n}
$$

By comparing equations (4-6-1) and (4-6-4) the coefficients $P_{N}$ and $R_{N}$ are identified as:

$$
\begin{aligned}
& P_{N}=\frac{\partial f}{\partial y_{N}} \\
& R_{N}=f\left(y_{N}^{n}\right)-Q_{N}^{n}
\end{aligned}
$$


in which $R_{N}$ represents a kind of correction factor in.order to avoid accumulation of the error due to the linearization of the equation.

2. Reservoir Operating Rules $y_{N}(t)$ are given. For this case $P_{N}$ and $R_{N}$ are defined as:

$$
\begin{aligned}
& P_{N}=\alpha \\
& R_{N}=-\alpha \Delta y_{N}
\end{aligned}
$$

in which $\alpha$ is a very large number, say of the order of $10^{6}$. Then, when the computations are made $\Delta y_{N}$ is computed from equation $(4-6-1)$ :

$$
\Delta y_{N}=\frac{\Delta Q_{N}}{P_{N}}-\frac{R_{N}}{P_{N}}
$$

or

$$
\Delta y_{N}=\frac{\Delta Q_{N}}{\alpha}-\frac{\alpha y_{N}}{\alpha} z \Delta y_{N}
$$

For the sediment routing, one of the following conditions must be specified at the upstream boundary:

1. Sediment discharge hydrograph where $Q_{S}$, a function of time, is given.

2. The variations in bed elevations with time $z(t)$ can be given in the model.

\subsection{Stability and Accuracy}

A finite difference procedure for calculating timedependent phenomena is considered stable when small numerical errors of truncation and round-off inevitably introduced at stage $t_{0}$, are not amplified during successive applications of the procedure, and at subsequent time $t$ have not grown so large as to obscure the valid part of the solution. In practical computational experience, instability of a process for calculating unsteady open-channel flows shows up as wildly oscillating values of the dependent variables with respect to $t$ and $x$. In practice, this means that limitations in the maximum size of the space and time intervals must be imposed to the numerical scheme in order to avoid stability problems.

Implicit methods of finite differences are generally regarded as unconditionally stable, the maximum size of the time step being limited only by accuracy requirements. On the other hand, explicit methods are limited in the maximum size of the time step by a strict stability criterion called the Courant condition,

$$
\Delta \mathrm{t} \leq \frac{\Delta \mathrm{x}}{\mathrm{c}}
$$

where $c$ is the celerity of the small gravity wave given by $c=\sqrt{g h}+V ; \quad V$ is the mean flow velocity; and $\Delta \mathrm{x}$ and $\Delta \mathrm{t}$ are the space and time increments.
Accuracy is understood as the degree of difference between observed real-life data (such as measured hydrographs) and computed results. Unfortunately, however, true values are not available since the equations in consideration are analytically unsolvable and the field or laboratory measurements may be subject to uncertainties just as great as those in the mathematical model solutions. Liggett and Cunge (1974) point out that there might be several reasons for discrepancy between a mathematical model and the prototype such as:

1) Inaccurate simplifications and approximations in the basic equations fail to simulate the complexity of the prototype.

2) Insufficiently accurate measuring techniques, e.g., surveying errors, badly located gages, etc.

3) Insufficient data, e.g., unknown tributary discharges, exchange of discharge with underground water, etc.

4) Phenomena which are not taken into account, e.g., infiltration into the dried-up soil at the bieginning of a flood, variation of roughness coefficients with vegetation, etc.

5) Poor schematization of topographic features.

An additional estimate of accuracy, often used in numerical schemes, is introduced by the concept of convergence. Convergence refers to the ability of a numerical scheme to reproduce the terms of the differential equation without introducing extraneous terms that impair the accuracy of the solution. In theory, the numerical solution converges to the analytical solution as $\Delta t$ and $\Delta x$ tend to zero. In practice, however, $\Delta x$ and $\Delta t$ equal to zero is an impossibility. Therefore, when using mathematical models it is necessary to introduce the concept of degree of convergence. This concept refers to the approximation of the numerical solution to the analytical solution. The problem arises because there is no analytical solution to the set of governing partial differential equations used in the study.

The best "standard" against which the results from any particular scheme can be measured is the solution to a simplified problem which has been determined by other than the numerical methods. Price (1974) used this approach to compare results from four of the more important numerical methods for flood routing with exact analytical solutions for the monoclinal wave. He found that the Preissmann implicit scheme is the most efficient method for flood routing problems, and the optimum accuracy is obtained when the finite difference time step is chosen approximately equal to the space step divided by the kinematic wave speed

$$
\Delta t=\frac{\Delta x}{c_{k}}
$$

in which the kinematic wave speed is given by $c_{k}=1.5 \mathrm{~V}$.

The importance of the Courant criterion in numerical modeling is apparent when the similarity of equations $(4-7-1)$ and $(4-7-2)$ is recognized. In explicit schemes, the Courant number cannot exceed one for stability reasons, i.e., $c=c \Delta t / \Delta x \leq 1$. In implicit schemes, no limitations of stability are imposed and the Courant number can take values greater than one depending on the spatial resolution 
and the accuracy requirements. In addition, there is a definite computational advantage of the implicit over the explicit scheme because the explicit Courant condition is based on the celerity of small disturbances while the implicit Courant "condition" (equation $4-7-2$ ) is based on the flood wave celerity (Ponce et al., 1978). This means that for a comparable degree of accuracy, the implicit time step can be many times larger than the explicit time step.

Another estimate of convergence consists in considering linearized equations and comparing their known analytical solution with the numerical solution found when a given finite difference method is used. Usually the solutions are assumed to be a Fourier series and then the components of the two solutions are compared. Liggett and Cunge (1974) performed such an analysis by applying the Preissmann implicit scheme of finite differences to a highly simplified set of linear differential equations. It was shown that each component of the series obtained by the numerical method is characterized by its damping factor and its celerity, and that the convergence criterion is a function of the Fourier series component wavelengths and also of the ratio $\Delta t / \Delta x$. They reported better accuracy for the implicit scheme than for other well-known explicit schemes of finite differences.

The stability of the Preissmann scheme was also studied by the same authors, Liggett and Cunge (1974). As explained by them, there is no general theory giving an estimate of the numerical stability for a nonlinear system. Linear analysis, however, gives results which are usually transposable to the full equations. Their conclusions concerning stability and accuracy of the linear system are as follows: 1) the system of difference equations is an approximation of the differential equations. This approximation is of the first-order with regard to $\Delta x$ for an arbitrary value of the coefficient $\theta$, and is of the second-order when $\theta=1 / 2 ; 2$ ) the difference scheme is numerically stable when $1 / 2<\theta \leq 1$; it is always unstable for $\theta \leq 1 / 2$. Liggett and Cunge also state that numerical experiments showed that these conclusions are also valid for the full nonlinear equations.

Fread (1974) analyzed the Saint Venant equations by using the Von Neumann technique to investigate the stability and convergence properties of the fourpoint implicit schemes, i.e., the Preissmann scheme. Since this method is only applicable to linear differential equations, the governing equations were simplified by neglecting the convective-inertia and bed slope terms in the equation of motion, and the wedge storage term in the equation of continuity.

The complete linear analysis has been made possible by the recent studies of Ponce et al., (1978) who performed a comprehensive theoretical treatment of the convergence of the four-point implicit scheme.

Based on the above considerations, the Preissmann implicit scheme of finite differences, as far as stability is concerned, allows for the use of any time step in the solution domain. In such a case, however, the time step will be governed by the other requirements, as accuracy and convenience in use, for instance. However, since in this study the proposed uncoupled method of solution to the three basic differential equations uses an implicit scheme for the flow routing and an explicit scheme for the sediment routing, the selection of the time step will be governed by the stability of the latter one, rather than the former one.
In order to obtain a stability criterion for the adopted explicit scheme of finite differences, equations $4-1-4$, the following procedure is carried out. First, an expression for the celerity of the sand wave is developed and further adjusted by numerical experiments. Second, the migration of a bed wave specified as initial condition on the channel bed is studied and a critical value of $\Delta x / \Delta t$ for which the scheme becomes unstable is obtained.

Consider a simplified form of the sediment continuity equation:

$$
\frac{\partial Q_{s}}{\partial x}+\frac{\partial A_{d}}{\partial t}=0
$$

in which the lateral flow and the variation of suspended sediment concentration with time have been neglected, and $Q_{S}$ is written on a volume basis.

Assuming that $A_{d}$ is a unique function of $Q_{S}$ we can write:

$$
\frac{\partial A_{d}}{\partial t}=\frac{d A_{d}}{d Q_{s}} \frac{\partial Q_{s}}{\partial t}
$$

Introducing $(4-7-4)$ into $(4-7-3)$ :

$$
\frac{\mathrm{dQ}_{s}}{\mathrm{dA}} \frac{\partial \mathrm{Q}_{\mathrm{d}}}{\partial \mathrm{x}}+\frac{\partial \mathrm{Q}_{\mathrm{S}}}{\partial t}=0
$$

which is a nonlinear equation since $d_{s} / d A_{d}$ is itself function of $Q_{S}$.

For any given reach of the river, the solid discharge $Q_{S}$ depends solely upon two independent variables $x$ and $t$. Hence, by writing the basic equation of partial differentiation:

$$
d Q_{s}=\frac{\partial Q_{s}}{\partial x} d x+\frac{\partial Q_{s}}{\partial t} d t
$$

Equations (4-7-5) and (4-7-6) can be written in matrix form as:

$\left[\frac{d Q}{d A}\right.$
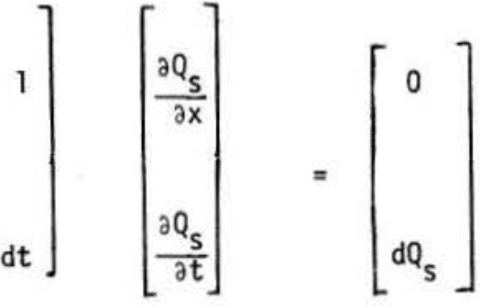

$(4-7-7)$

Since equations (4-7-6) and (4-7-5) are not independent, the determinant of the coefficient matrix must vanish. Hence,

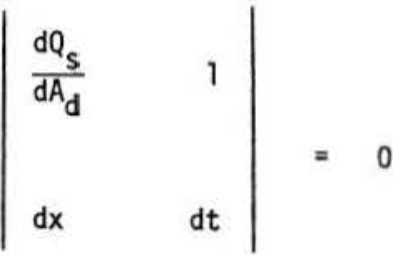


or

$$
\frac{d x}{d t}=\frac{d Q_{s}}{d A_{d}}
$$

Equation (4-7-9) represents the celerity or velocity of propagation of the bed waves. It describes a positive characteristic direction in the $\mathrm{x}-\mathrm{t}$ plane indicating that any perturbation on the bed can only be propagated downstream.

An expression for the celerity can be obtained by assuming that the sediment discharge is a power function of the velocity;

$$
Q_{S}=m V^{n} T
$$

in which $T$ is the cross-section top width and $m$ and $n$ are constants which can be obtained by calibration or from the available equilibrium data. as:

With reference to Fig. $3.2, Q_{s}$ can be written

$$
\begin{aligned}
& Q_{S}=m\left(\frac{Q}{A}\right)^{n} T=m \frac{Q^{n}}{(h-z)^{n}} T^{l-n} \\
& \frac{\partial Q_{S}}{\partial z}=m Q^{n} T^{1-n} n(h-z)^{-n-1}
\end{aligned}
$$

where $i t$ was assumed that $\partial Q / \partial z=\partial h / \partial z=\partial T / \partial z=0$. Then,

$$
\begin{gathered}
\frac{\partial Q_{S}}{\partial z}=m \frac{Q^{n}}{T^{n} y^{n}} \quad T \frac{n}{y}=m V^{n} T \frac{n}{y} \\
\frac{\partial Q_{S}}{\partial z}=\frac{n Q_{S}}{y}
\end{gathered}
$$

since

$$
\frac{\partial Q_{s}}{\partial A_{d}}=\frac{1}{T} \frac{\partial Q_{s}}{\partial z}
$$

we have

$$
\frac{\partial Q_{s}}{\partial A_{d}}=\frac{n Q_{s}}{T y}
$$

For the case that $Q_{S}$ is expressed on a weight basis, equation (4-7-16) takes the form:

$$
\frac{\partial Q_{S}}{\partial A_{d}}=\frac{n Q_{S}}{r_{s} T y}
$$

Equation (4-7-17) gives the celerity of the small bed waves indicating that it is proportional to the sediment discharge $Q_{s}$ and inversely proportional to the flow depth $y$.

Equation (4-7-17) is adjusted by carrying out some test runs with the numerical model. A bed wave of trapezoidal shape was imposed as initial condition on the channel bed and its velocity of propagation was measured for different initial flow conditions. Figure 4-4 shows the measured celerity $C_{m}$ against the theoretical celerity computed by using equation
(4-7-17). A straight line fits the data in a $10 \mathrm{~g}-\log$ paper. A coefficient and an exponent are obtained such that: $C_{m}=2.33 C_{c}^{0.96}$. Equation (4-7-17) then takes the form:

$$
C=2.33\left(\frac{n Q_{s}}{s^{T y}}\right) 0.96
$$

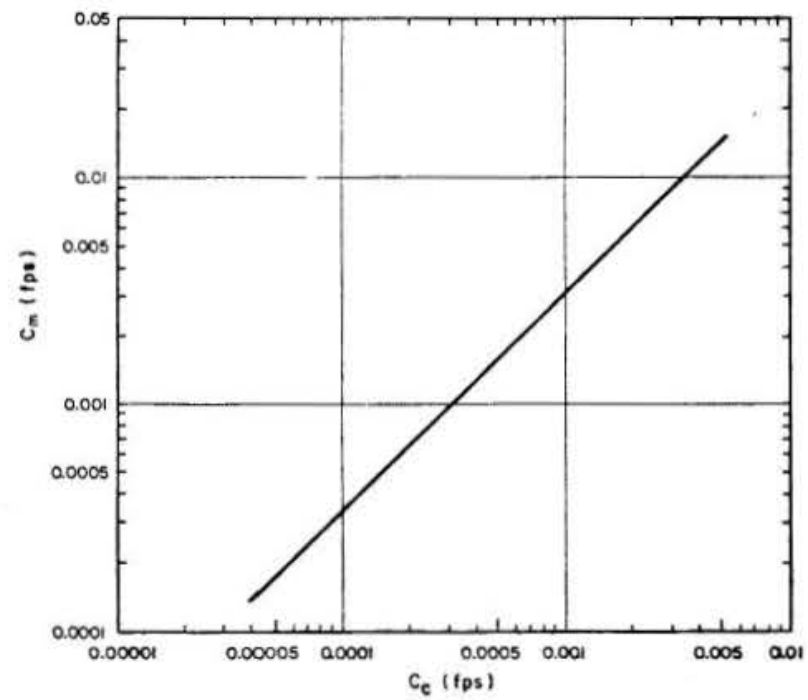

Figure 4.4 - Measured Bed Celerity versus Computed Bed Celerity.

At the same time, the dissipation and migration of the bed wave was studied in order to establish a stability criterion for the numerical scheme. Figure 4.5 shows the bed wave celerity computed by equation $(4-7-18)$ against the critical value of $\Delta x / \Delta t$ at which instabilities started developing in the numerical experiments. Consequently, this figure in addition to equation $(4-7-18)$ can be used to select the proper values of $\Delta x$ and $\Delta t$ to insure the stability of the scheme. For practical purposes, the following procedure is recommended:

1) Compute the bed wave celerity by using equation $(4-7-18)$.

2) Use Figure 4.5 to obtain the critical value of $\Delta x / \Delta t$.

3) Select a value of $\Delta x / \Delta t$ smaller than the critical value to insure stability of the scheme.

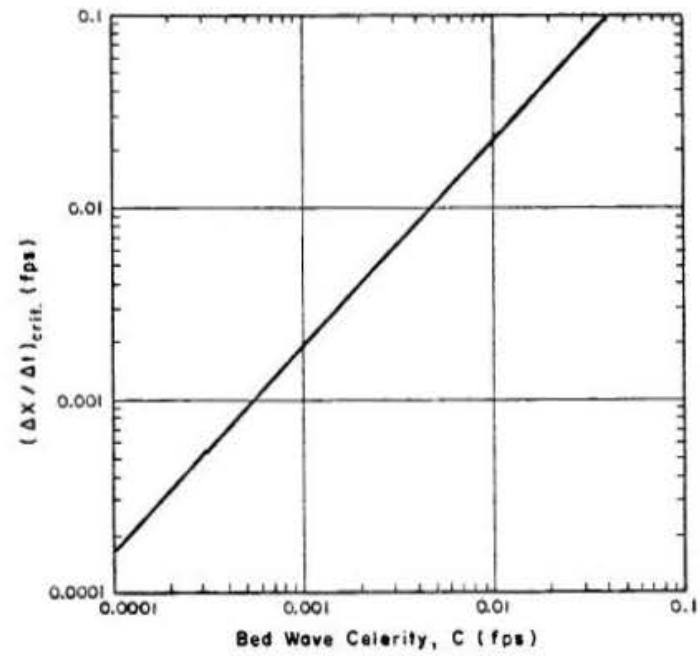

Figure 4.5 - Critical Value of $\Delta x / \Delta t$. 


\section{Chapter 5 \\ VERIFICATION OF THE MATHEMATICAL MODEL}

\subsection{Introductory Remarks}

Regardless of the theory on which a model is based, the real test of its utility lies in its capability to adequately reproduce prototype behavior. The difficulties associated with simulating the hydraulic characteristics of a river system are many and complex. A large amount of assumptions and simplifications are made when attempting to formulate the movement of sediment-laden water in natural channels. Discretizing the system and numerical solution of the equations involves additional simplifications which can affect the predicted response of the system. Thus, calibration and verification of the mathematical model must precede any problem analysis or any attempt to use the model for prediction purposes.

Model calibration is understood here as the process of adjusting the resistance functions and sediment transport parameters along the river channel until the model demonstrates the ability to reproduce, with reasonable accuracy, the historical water surface elevations, the changes in bed profile and the accompanying sediment deposition characteristics. Once calibrated, a reconstitution of the behavior of the prototype can be attempted. Model verification is understood as the process of reconstituting an experienced event or period of record. Thus, reasonable agreement between the computed results from the calibrated model and the available historical observations must form as essential criterion in ascertaining the reliability and range of applicability of the simulation technique.

In this study verification of the mathematical model is carried out in two steps. First, the sediment deposition pattern in a sudden expansion is studied by means of a physical model built in a laboratory flume, and secondly, available data from the lower Colorado River above Imperial Dam is used to compare with generated bed profiles from the mathematical model.

\subsection{Flume Study}

To test the feasibility of the mathematical model, a physical model was built in a laboratory flume to collect the required data. A recirculating flume having a rectangular cross section $60 \mathrm{ft}(18.3 \mathrm{~m})$ long and $2 \mathrm{ft}(0.61 \mathrm{~m})$ wide was used. A small channel of $8 \mathrm{in} .(20.3 \mathrm{~cm})$ wide and $35 \mathrm{ft}(10.7 \mathrm{~m})$ long was built in the sand bed flume to create a sudden expansion in the channel. Variations in water surface elevations were produced by using a sluice gate downstream to control the flow conditions in the channel. Figure 5.1 shows a schematic diagram of the flume and Figure 5.2 indicates the geometric characteristics of the channel expansion.

\subsubsection{Experimental Equipment and Procedure}

The water discharge was measured by a calibrated orifice meter placed on the return flow pipe and water-air manometer. The flume slope was obatined by an ordinary surveyor's level. Bed elevation variations were obtained by tracing the bed profiles on transparency paper placed on the side walls of the flume.

The experimental procedure consisted of: 1) The discharge was kept constant throughout the run and water and sand were allowed to recirculate through the system, 2) after recording initial conditions, the gate was partially closed and the corresponding time was noted as the starting time of the experiment, 3) at time equal to $t=1 \mathrm{hr} 15 \mathrm{~min}$ the discharge was increased and at $t=2 \mathrm{hrs} 15 \mathrm{~min}$ the gate was completely opened, 4) during the whole experiment at certain intervals of time, bed elevation measurements were taken at selected sections along the channel bed. Sediment discharge data were also collected by using a total load sampler at the downstream end of the flume. A power relationship between the sediment discharge and the flow velocity was found by fitting the experimental data.
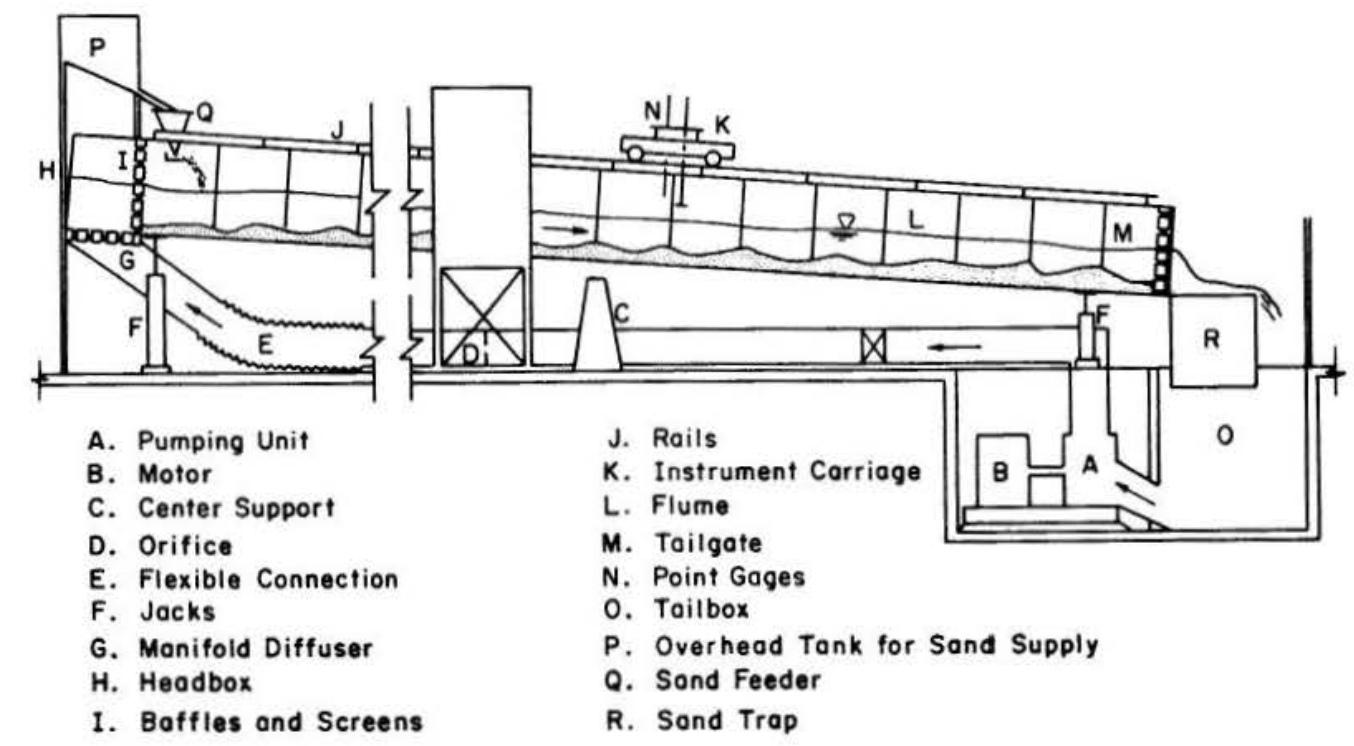

Fig. 5.1 - Schematic Diagram of the Flume 


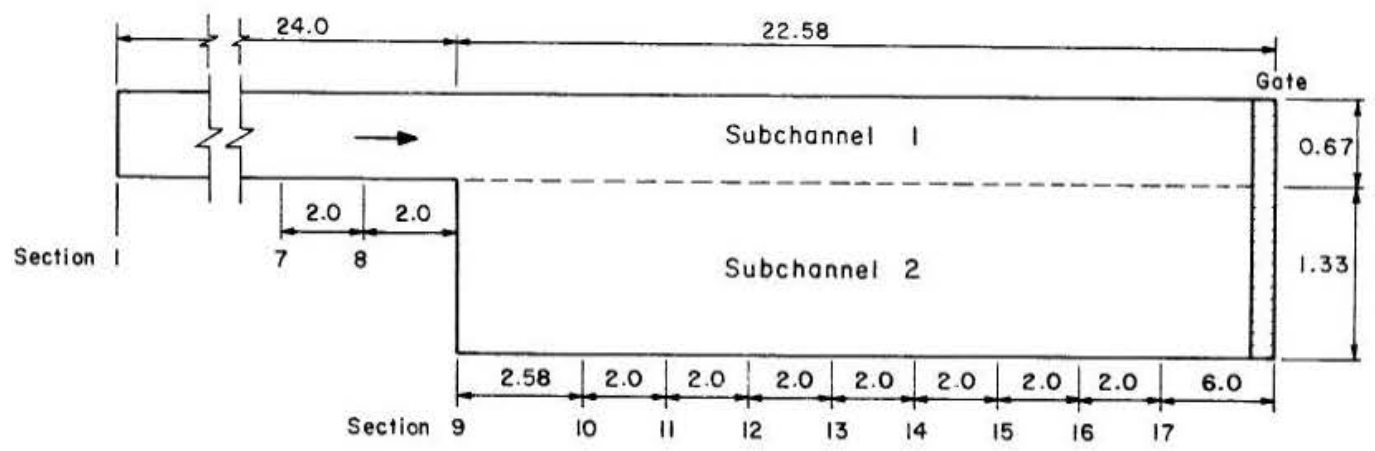

Note: Dimensions are in feet

Fig. 5.2 - Sudden Expansion in a Laboratory Flume

$$
Q_{s}=0.000035 T v^{4.0}
$$

in which $T$ is the top width and $Q_{S}$ is given in a
volume basis.

The upstream boundary condition for the mathematical model is a discharge hydrograph whereas a stage hydrograph was used as the downstream boundary condition. Figure 5.3 indicates the variations in discharge and water elevations at both ends of the model.

Additional input data for the mathematical model must include an estimation of the resistance coefficients and the jet constant "a". The values of Mannings's coefficient and jet coefficient used in the simulation run are as follows:

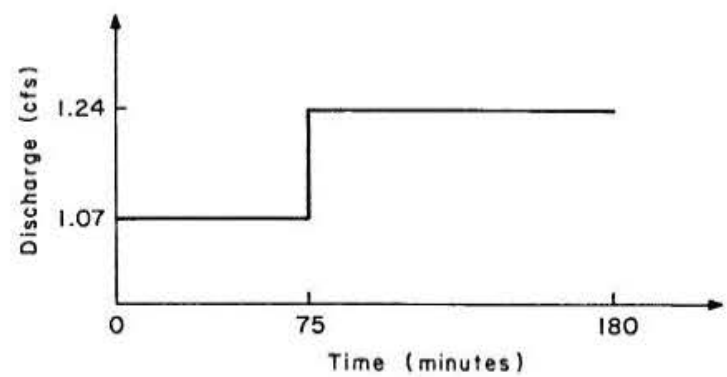

a) Upstream Boundary Condition

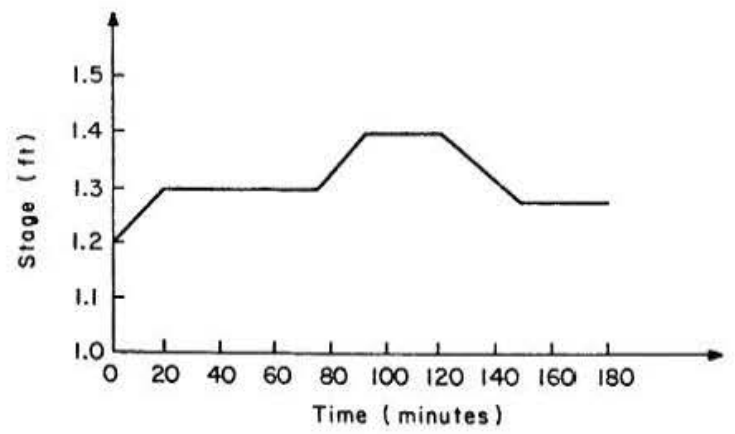

b) Downstream Boundory Condition

Fig. 5.3 - Boundary Conditions for the Flume Study

$$
\begin{aligned}
& n=0.040 \\
& a=0.30
\end{aligned}
$$

\subsubsection{Model Evaluation}

The feasibility of the developed mathematical model was evaluated using the experimental results to see if the model was able to simulate with reasonable accuracy the depositional pattern in a sudden expansion. As shown in Fig. 5.2, the channel in the expansion was divided into two subchannels. Eight sections were taken along the channel bed in the expansion reach. The initial flow conditions prevailing in the flume at the beginning of the study are indicated in Table 5.1. The space increment was selected to be $2 \mathrm{ft}(0.61 \mathrm{~m})$ and a time increment of $1 \mathrm{~min}$

Table 5.1 Initial Flow Conditions for the Flume Study

\begin{tabular}{ccccc}
\hline $\begin{array}{c}\text { Computer } \\
\text { Section }\end{array}$ & $\begin{array}{c}\Delta x \\
(\mathrm{ft})\end{array}$ & $\begin{array}{c}\text { Bed Elevation in feet } \\
\text { Channel }\end{array}$ & $\begin{array}{c}\text { Water Elevation } \\
(\mathrm{ft})\end{array}$ \\
\hline 1 & 4.0 & - & 0.72 & 1.30 \\
2 & 4.0 & - & 0.64 & 1.24 \\
3 & 4.0 & - & 0.65 & 1.22 \\
4 & 4.0 & - & 0.57 & 1.20 \\
5 & 2.0 & - & 0.51 & 1.20 \\
6 & 2.0 & - & 0.50 & 1.20 \\
7 & 2.0 & - & 0.50 & 1.20 \\
8 & 2.0 & - & 0.46 & 1.19 \\
9 & 2.58 & - & 0.46 & 1.17 \\
10 & 2.0 & 0.56 & 0.56 & 1.18 \\
11 & 2.0 & 0.62 & 0.58 & 1.17 \\
12 & 2.0 & 0.63 & 0.63 & 1.18 \\
13 & 2.0 & 0.71 & 0.69 & 1.18 \\
14 & 2.0 & 0.64 & 0.74 & 1.18 \\
15 & 2.0 & 0.73 & 0.73 & 1.18 \\
16 & 2.0 & 0.78 & 0.73 & 1.18 \\
17 & 6.0 & 0.76 & 0.71 & 1.19 \\
18 & - & 0.73 & 0.68 & 1.20 \\
\hline
\end{tabular}


was selected to insure the stability of the numerical scheme. The mathematical model was established for this flume system by assuming uniform grain size distribution with no correction for the specific weight of the sediment deposits. The variations in bed elevations at all sections were measured for each subchannel. The computed bed profiles at different time intervals together with the observed bed elevations are indicated in Figs. 5.4 and 5.5.

At 20 minutes after implementation of the experiment aggradation was taking place along channel 1. The computed results show more aggradation at the first sections than the measured ones. Less deposition occurred on channel 2 at the same period of time, and the computed and measured results are in better agreement. When the discharge increased, the water flow started eroding the bed material at the mouth of the expansion and the delta appeared to be moving downstream. The measured bed profile at time $t=100$ min shows that the peak of this delta is located approximately at section 5 whereas the computer model predicts a delta moving slower with its peak between sections 3 and 4 . A flatter delta that progressed downstream was also observed on channel 2. By completely opening the control gate at the downstream end of the flume, the velocity of the flow increased and the delta was forced to move farther downstream, as shown in Figs. 5.4 and 5.5 .

The depositional patterns on both channels suggest that submerged levees formed along channel 2. After examining the computed bed profiles in Fig. 5.6 , it was found that levees were formed by the buildup of sediment along channel 2 . These levees

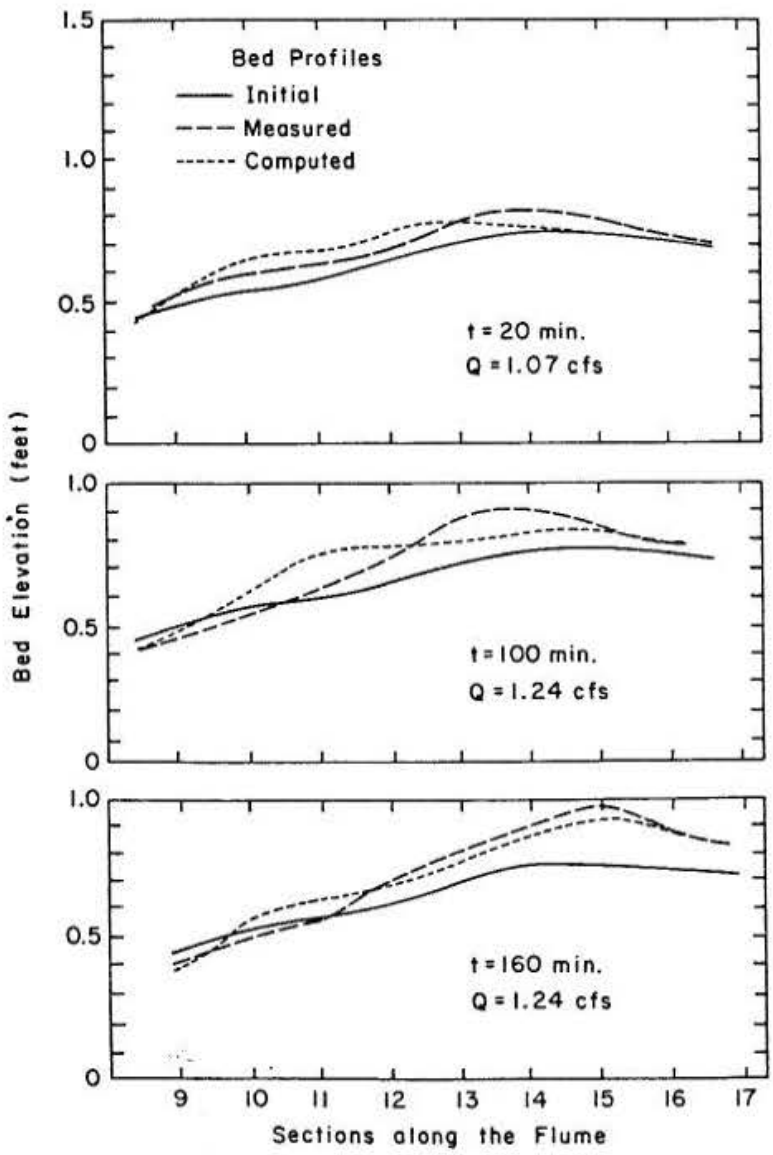

Fig. 5.4 - Bed Elevation Changes in Subchannel 1 become less prominent away from the mouth and finally disappeared into the peak of the delta. This high peak indicated that a transverse bar may eventually be formed at that section obstructing the flow and causing it to divide.
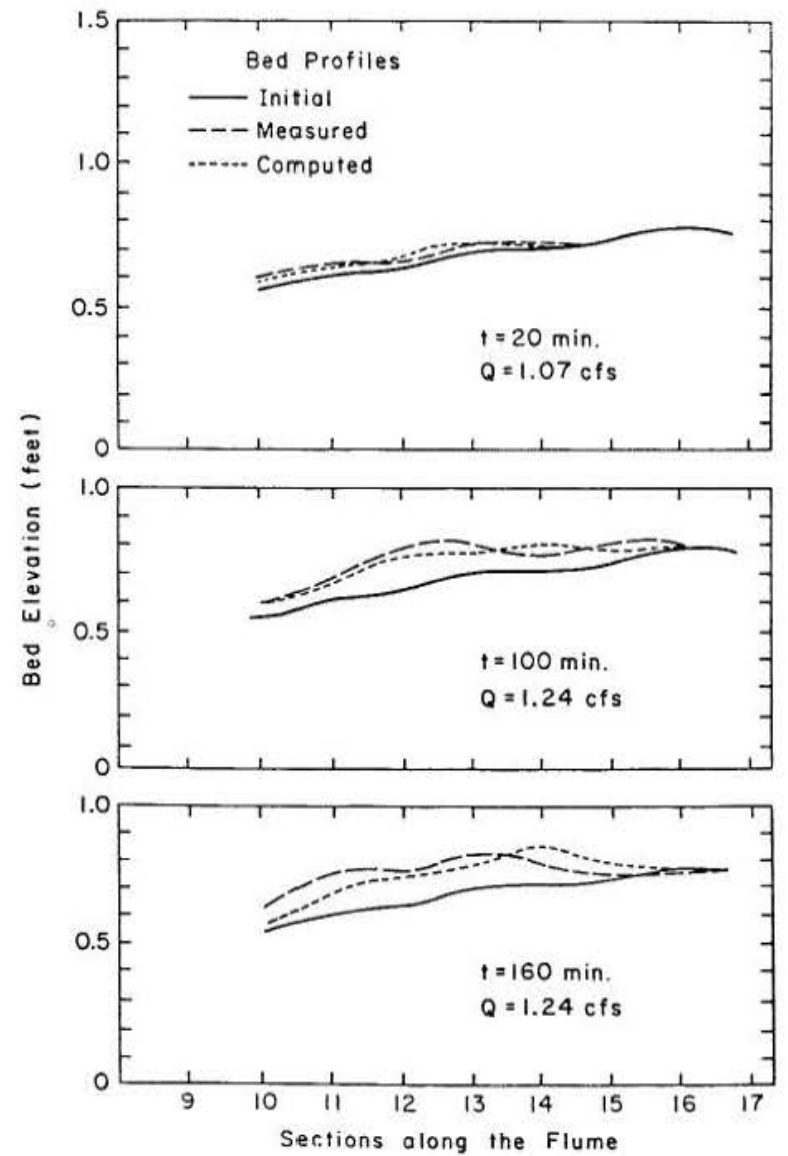

Fig. 5.5 - Bed Elevation Changes in Subchannel 2

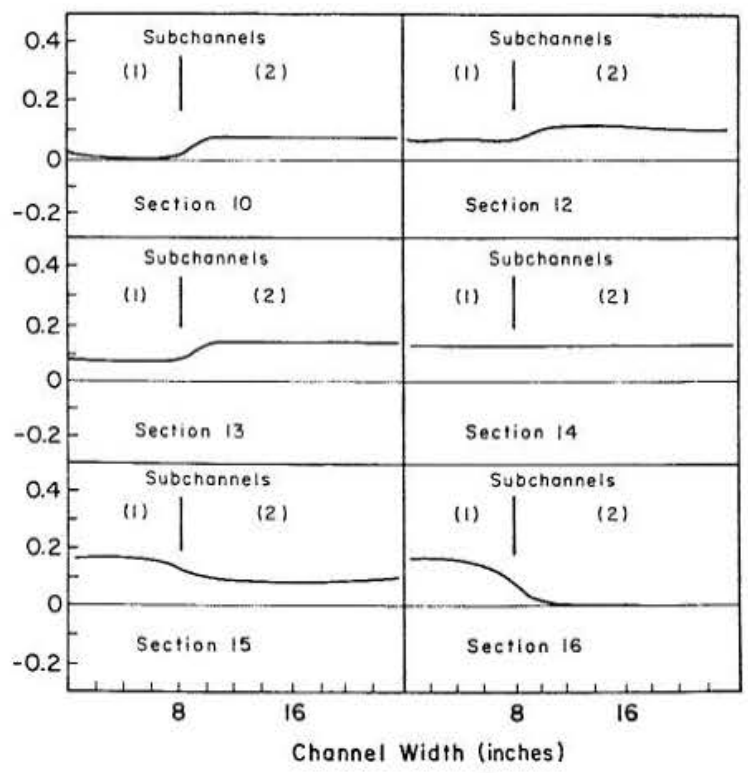

Fig. 5.6 - Vertical Cross-Sectional Geometries Showing the Computed Bed Elevation Changes at Time 160 Minutes for Different Sections along the Channel 
In nature, formation of submerged levees and transverse bars determine the shape and development of the delta. Furthermore, it is characteristic for delta-building rivers to bifurcate repeatedly in the downstream direction to form an irregular pattern of distributary channels. This bifurcation is commonly associated with the formation of a transverse bar across the channel mouth as reported by many observers for rivers discharging into oceanic basins. Similar phenomena were produced by the mathematical model developed herein.

\subsubsection{Discussion of Results}

The jet theory incorporated into the flow and sediment routing model attempts to account for the momentum effect of the incoming stream flow from the river mouth into the reservoir. For rivers entering a wide basin, flow separation may take place and the concentration of the flow in the main channel will govern the sediment deposition process in the reservoir and will affect the development and movement of the delta.

The mathematical model formulated in this study assumes that the jet will spread downstream from the inlet section with a parabolic boundary. The coefficient of this parabola is an unknown value which must be obtained by calibration procedures. In the case of the flume study, the jet constant "a" was obtained to be equal to 0.30 and the comparison of results between observed and computed bed profiles showed a reasonable agreement. The effect of the jet constant in the deposition pattern of the sudden expansion is shown in Fig. 5.7. The highest peak of the delta corresponds to the condition of a compound model with no corrections for jet effect. As much as the value of the jet constant is decreased, the delta will progress downstream lowering its peak. For the case $a=0.70$, the concentration of flow in the main channel is not large enough to move the delta downstream. When $a=0.30$ the flow velocity has been sufficiently increased in the main channel to produce a flatter delta and sediment deposits can be seen at the most downstream sections.

The last paragraph stresses the importance of properly considering the jet effect in the sediment deposition characteristics of wide basins. A simple compound model is not applicable to simulate flow in reservoirs because the flow inertia is not accurately accounted for in the formulation. The basic assumption of this model, that the friction slope for each individual stream is equal to the average friction slope for the whole channel, is no longer true in the transition zone connecting the river and reservoir where flow separation may take place and the momentum effect of the incoming flow becomes important.

\subsection{Colorado River Study}

\subsubsection{General}

The mainstream of the Colorado River rises in northern Colorado, in the high peaks of the Rocky Mountains. From its source at Grand Lake, the river flows southwest about 1400 miles to the Gulf of California, traversing the mountain valleys of Colorado, the spectacular canyons of southeastern Utah and northern Arizona, including the Grand Canyon, and finally, below Lake Mead, desert alluvial valleys interspersed with barren mountain chains.

In its virgin condition, the Colorado River is estimated to have had an average flow of about 17 million acre-feet of water annually at the site of

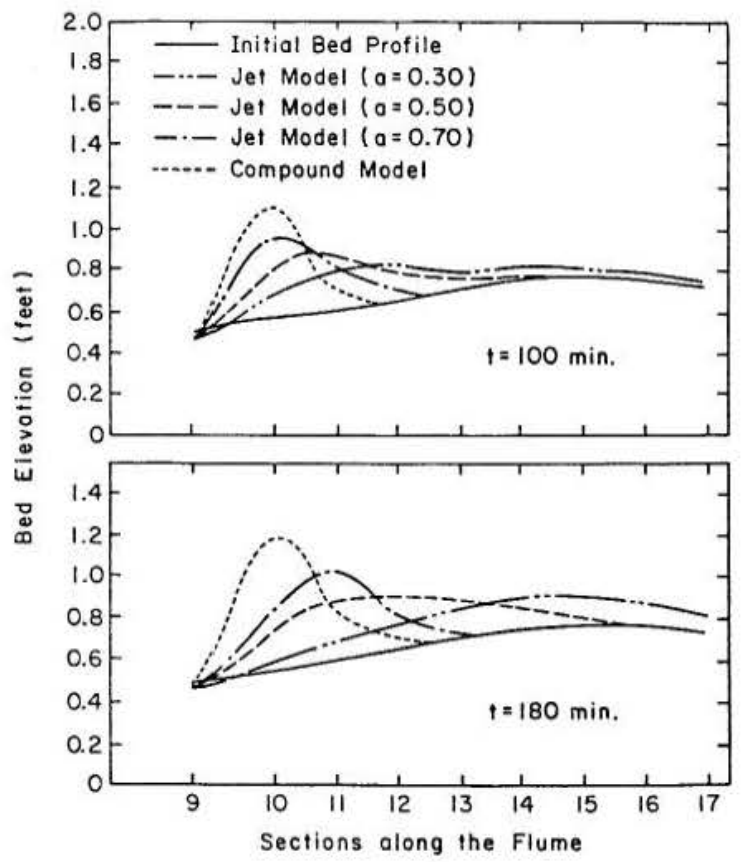

Fig. 5.7 - Effect of Jet Constant in Delta Formation

Hoover Dam. The annual flow varied from about 5 million acre-feet to 27 million acre-feet. The river also carried a tremendous volume of sediment and ranked as one of the largest sediment-carrying rivers in the world. Figure 5.8 shows the course of the river and the structural control between Glen Canyon Dam and the Gulf of California.

From Parker Dam to Imperial Dam, in the Lower Colorado River, the river flows about 100 miles through a series of three rich agricultural valleys, Parker, Palo Verde and Cibola, and finally enters a more confined and relatively inaccessible reach, 40 miles long, ending at Imperial Dam (Fig. 5.9).

The study area extends between Imperial Dam and Taylors Ferry located about 60 miles upstream. Imperial Dam, completed in 1938, was designed and built as a diversion dam to raise the water surface so that irrigation diversions could be made. The drainage area which contributes sediment to the reservoir formed by Imperial Dam is limited to the $5800 \mathrm{sq}$. miles downstream from Parker Dam.

The clear water released from Parker Dam, completed also in 1938, has resulted in scour of the riverbed and bank materials in the reach below the dam, with resultant aggradation in the backwater reaches of Imperial Dam downstream. Then, the pattern of scour and deposition in the reach between Parker and Imperial Dams was caused primarily by three factors: the clear water issuing from Parker Dam, the backwater effects of Imperial Dam, and a concave river profile with steeper slopes in the upstream reaches than the downstream reaches. A balance point, or rather a balance reach about 10 miles long, developed near River Section 22, and within 2 years after closure of the dams consistent scour was occurring above that reach and consistent deposition was occurring below it. The reach of the river between Adobe Ruins and Imperial Dam constitutes the diversion pool and associated backwater areas of Imperial Dam. Most of the incoming sediment is deposited within the reach, largely in areas outside the main channel. 


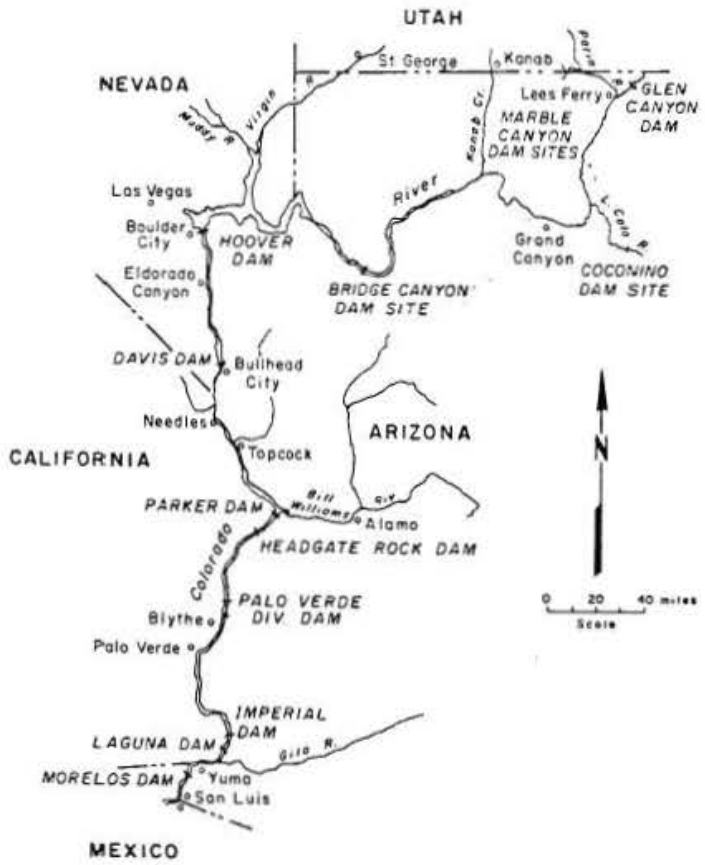

Fig. 5.8 - Lower Colorado River, Lees Ferry to Gulf of California

Palo Verde Diversion Dam, located between Parker and Imperial Dams, was built in 1952 affecting consequently the regime of the river above Imperial Dam. Thus, this study is only concerned with the sedimentation above Imperial Dam between the years 1938 and 1943 , prior to the construction of Palo Verde Dam.

\subsubsection{Available Data}

Data available in the Lower Colorado River, above Imperial Dam, that can be utilized in the verification of the mathematical model includes: a) Topographic maps - Topographic maps at a scale of $1: 24,000$ showing contour lines obtained from the Jepartment of the Interior, USGS.

b) River cross sections - Twenty three (23) cross sections, extending from Imperial Dam to Taylors Ferry, have been resurveyed at regular intervals since Imperial Dam closure and the average bed elevations and the amounts of bed material deposited have been computed. These sections spaced approximately 2 or 3 miles apart, and shown in Fig. 5.9, give information on general river aggradation and degradation. The numbering of the sections in this figure corresponds to the numbering used in the computer model. Original river cross sectioning starts at section 1 above Imperial and ends at section 23 at Taylors Ferry.

c) Suspended sediment sampling - Suspended sediment samples have been taken at Taylors Ferry Station on the Colorado River since 1939 to determine both the suspended sediment discharge and the size analysis of the materials in suspension. Size analysis of the suspended bed material is shown in Fig. 5.10 .

d) Bed material samples - These samples have been collected in conjunction with the river cross sectioning. The sizes are analyzed and grain size gradation curves are plotted. Figure 5.11 shows an average bed material size distribution curve near Taylors Ferry.

e) River discharge records - These records are available from the suspended load measurements at Taylor's Ferry and Red Cloud Cable Station. Measurements of the discharge for the period 1938-1943 are indicated in Table 5.2 together with measurements of the sediment load.

For details on the sediment sampling, bed material sampling, river cross sectioning, and river and sediment discharge, reference is made to publications such as the U.S. Geological Survey Water Supply Papers, and Reports on River Control Work and Investigations (U.S. Bureau of Reclamation, 1966 and 1969).

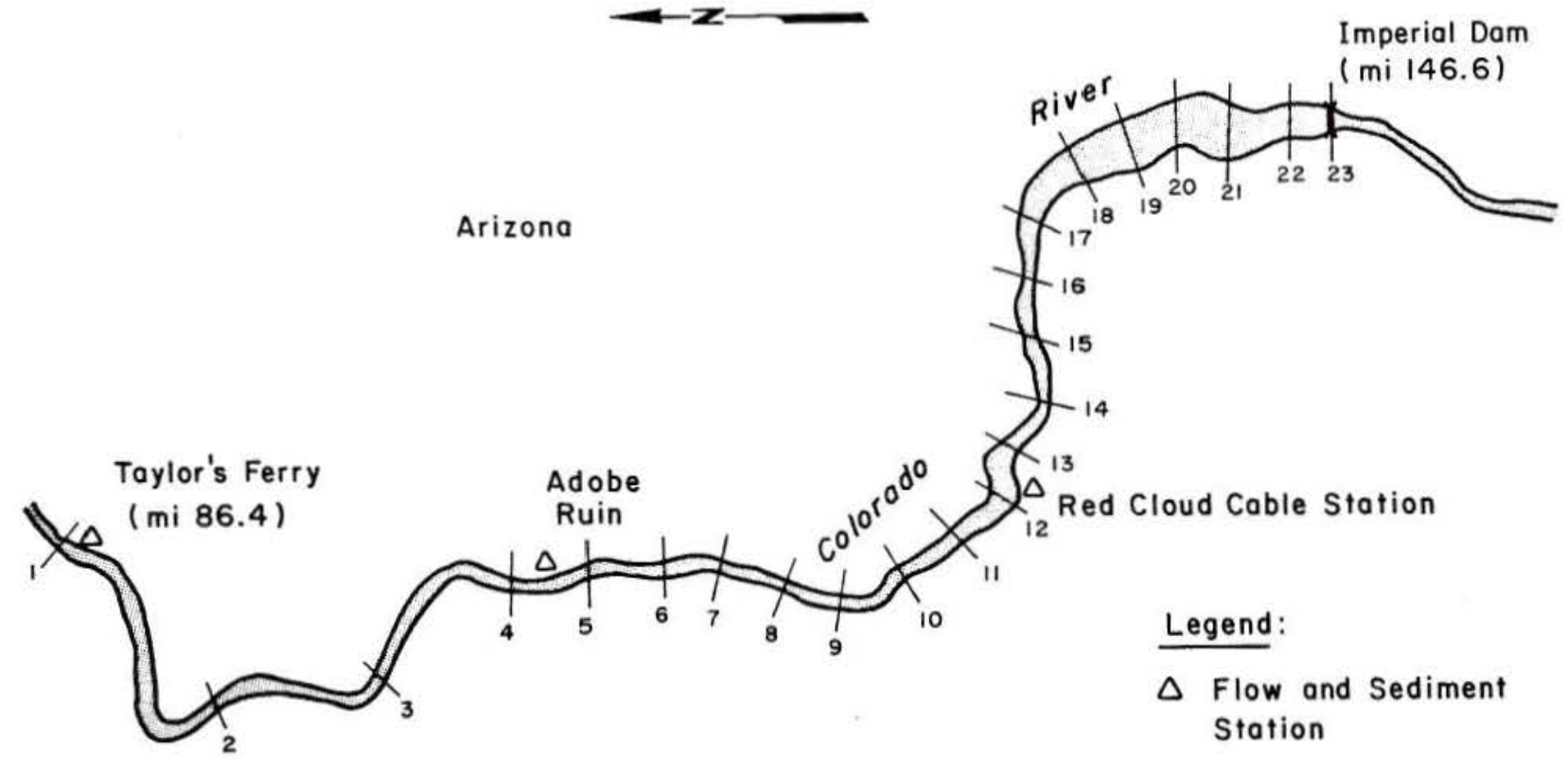

Colifornia

Fig. 5.9 - Sketch of the Study Area Showing the River Cross Sections 


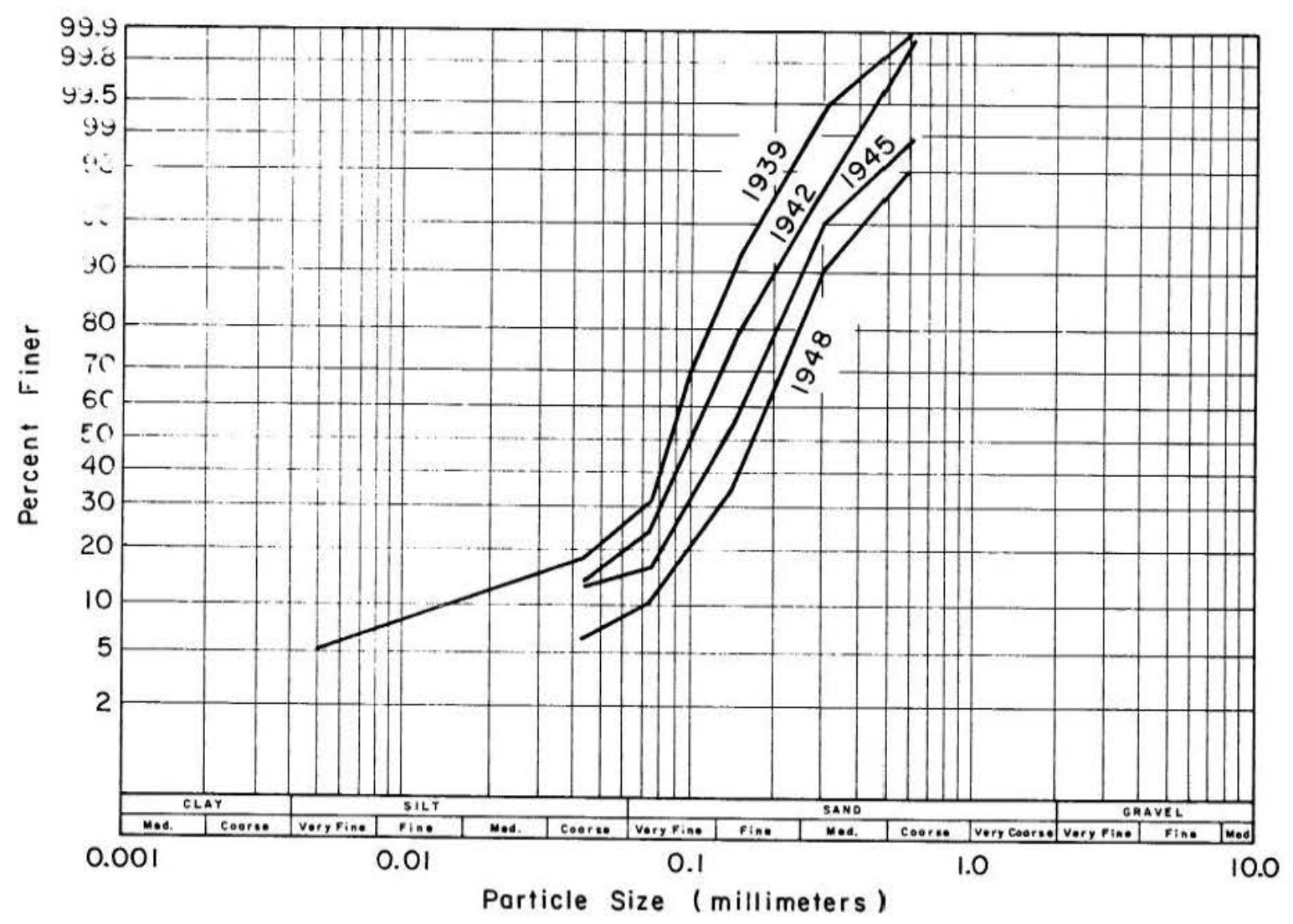

Fig. 5.10 - Suspended Load Size Analysis at Taylors Ferry

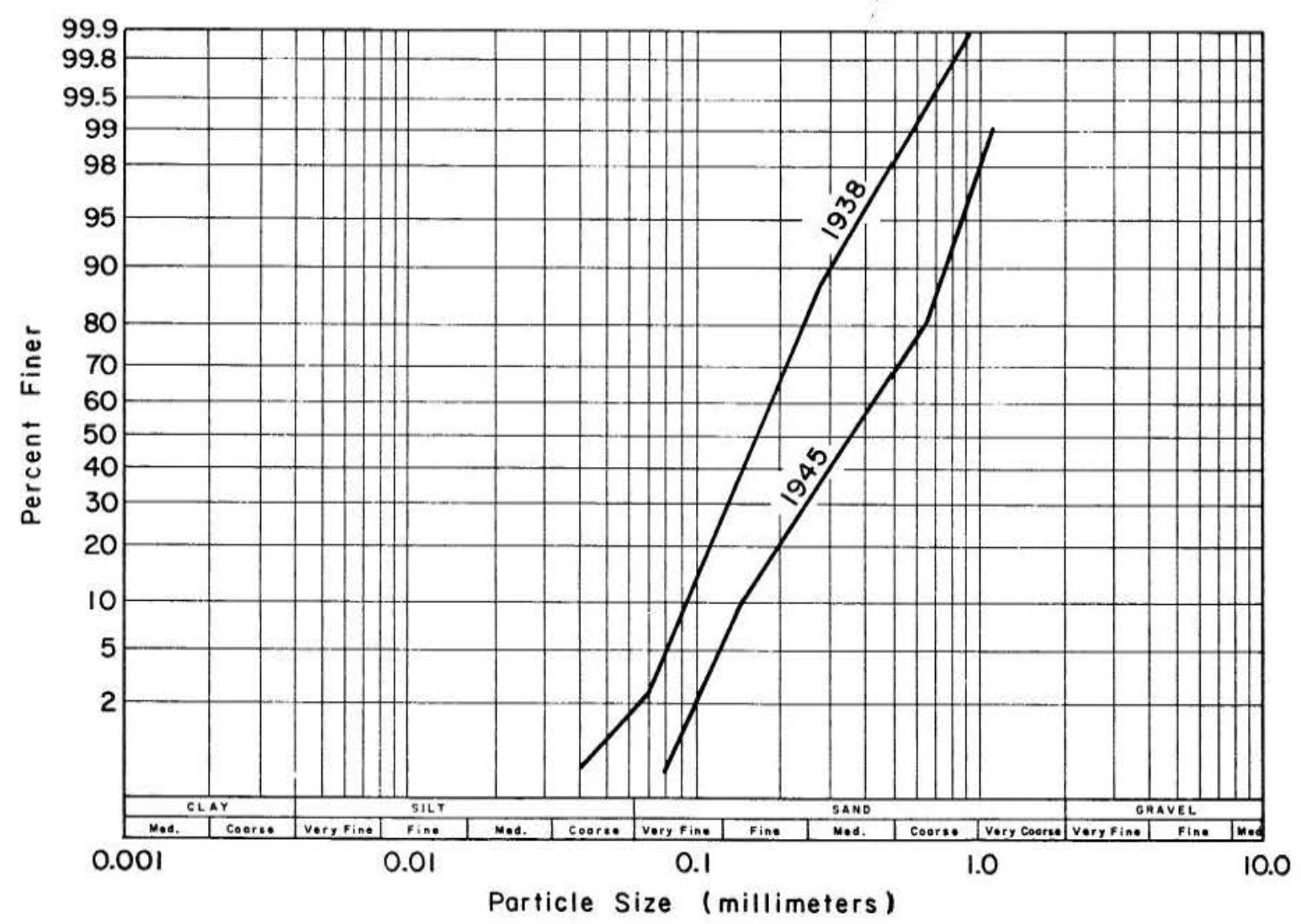

Fig. 5.11 - Size Analysis of Bed Material near Taylors Ferry 
Table 5.2. River Discharge Records at Red Cloud Cable Station (from 5-14-38 to 4-24-39) and at Taylors Ferry (from 4-24-39 to 1943)

\begin{tabular}{|c|c|c|c|}
\hline DATE & $\begin{array}{l}\text { DISCHARGE } \\
(\mathrm{cfs})\end{array}$ & $\begin{array}{c}\text { SUSPENDED } \\
\text { CONCENTRATION } \\
\text { (\% by weight) }\end{array}$ & $\begin{array}{c}\text { MEASURED } \\
\text { LOAD } \\
\text { (Tons/Day) }\end{array}$ \\
\hline $5-14-38$ & 7,670 & 0.19 & 39270 \\
\hline $5-28-38$ & 7,270 & 0.18 & 35270 \\
\hline $6-13-38$ & 8,150 & 0.19 & 41730 \\
\hline $6-2,8-38$ & 11,800 & 0.34 & 108320 \\
\hline $7-11-38$ & 8,600 & 0.19 & 44040 \\
\hline $7-25-38$ & 9,440 & 0.16 & 40700 \\
\hline $8-08-38$ & 9,400 & 0.19 & 48130 \\
\hline $8-22-38$ & 8,360 & 0.16 & 35050 \\
\hline $9-06-38$ & 7,990 & 0.14 & 30150 \\
\hline $9-22-38$ & 8,150 & 0.21 & 46120 \\
\hline $10-03-38$ & 7,390 & 0.14 & 27880 \\
\hline $10-17-38$ & 12,070 & 0.22 & 71560 \\
\hline $11-01-38$ & 7,630 & 0.14 & 28790 \\
\hline $11-14-38$ & 5,680 & 0.18 & 32400 \\
\hline $11-28-38$ & 6,410 & 0.15 & 25910 \\
\hline $12-12-38$ & 6.600 & 0.13 & 23120 \\
\hline $12-27-38$ & 5,840 & 0.16 & 25180 \\
\hline $1-10-39$ & 6,000 & 0.14 & 22680 \\
\hline $1-17-39$ & 8,370 & 0.26 & 58760 \\
\hline $1-23-39$ & 12.500 & 0.33 & 111380 \\
\hline $1-26-39$ & 15,900 & 0.38 & 163130 \\
\hline $1-28-39$ & 19,400 & 0.44 & 230470 \\
\hline $2-02-39$ & 23,700 & 0.48 & 307150 \\
\hline $2-15-39$ & 23,100 & 0.45 & 280670 \\
\hline $2-28-39$ & 21,800 & 0.36 & 211900 \\
\hline $3-13-39$ & 8,710 & 0.13 & 30610 \\
\hline $3-27-39$ & 9.550 & 0.175 & 45120 \\
\hline $4-10-39$ & 8.950 & 0.16 & 38660 \\
\hline $4-24-39$ & 8,980 & 0.15 & 36370 \\
\hline $5-09-39$ & 7,870 & 0.12 & 25500 \\
\hline $5-22-39$ & 7,950 & 0.17 & 36490 \\
\hline $6-05-39$ & 7,670 & 0.14 & 28990 \\
\hline $6-19-39$ & 8,730 & 0.14 & 33000 \\
\hline $7-05-39$ & 8,600 & 0.15 & 34830 \\
\hline $7-17-39$ & 8,940 & 0.12 & 28970 \\
\hline $7-31-39$ & 9,190 & 0.13 & 32260 \\
\hline $8-14-39$ & 10,100 & 0.19 & 51830 \\
\hline $8-28-39$ & 8,390 & 0.11 & 24920 \\
\hline $9-13-39$ & 19,000 & 0.25 & 128250 \\
\hline $9-26-39$ & 12,200 & 0.31 & 102110 \\
\hline $10-09-39$ & 10,400 & 0.17 & 47740 \\
\hline $10-23-39$ & 9.620 & 0.12 & 31170 \\
\hline $11-06-39$ & 9,800 & 0.18 & 47630 \\
\hline $11-20-39$ & 10,900 & 0.27 & 79.450 \\
\hline $12-04-39$ & 10.700 & 0.21 & 60,670 \\
\hline $12-18-39$ & 10,900 & 0.24 & 70,630 \\
\hline $1-02-40$ & 9.240 & 0.21 & 52,400 \\
\hline $1-15-40$ & 11.300 & 0.255 & 79,300 \\
\hline $1-29-40$ & 10.600 & 0.21 & 60,100 \\
\hline $2-12-40$ & 7,300 & 0.17 & 33,500 \\
\hline $2-26-40$ & 7,310 & 0.12 & 23,700 \\
\hline $3-11-40$ & 7,420 & 0.14 & 28,100 \\
\hline $3-25-40$ & 9,500 & 0.14 & 35,900 \\
\hline $4-02-40$ & 10,300 & 0.18 & 50,100 \\
\hline $4-08-40$ & 10,900 & 0.17 & 50,000 \\
\hline $4-22-40$ & 8,980 & 0.14 & 33,900 \\
\hline $5-06-40$ & 8,910 & 0.13 & 31,300 \\
\hline $5-20-40$ & 7,090 & 0.11 & 21,100 \\
\hline $6-03-40$ & 7,000 & 0.092 & 19,800 \\
\hline $6-18-40$ & 8.200 & 0.096 & 21,300 \\
\hline $7-01-40$ & 8,600 & 0.11 & 25,500 \\
\hline $7-15-40$ & 8,900 & 0.067 & 16,100 \\
\hline
\end{tabular}

\begin{tabular}{|c|c|c|c|}
\hline DATE & $\begin{array}{l}\text { DISCFARGE } \\
\text { (cfs) }\end{array}$ & 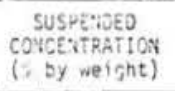 & $\begin{array}{l}\text { MEASURED } \\
\text { LOAD } \\
\text { (TONS/Day) }\end{array}$ \\
\hline $7-29-40$ & 8,550 & 0.10 & 23,100 \\
\hline $8-12-40$ & 8.190 & 0.03 & 17,700 \\
\hline $8-26-40$ & 9.200 & 0.128 & 31,300 \\
\hline $9-09-40$ & 9,200 & 0.113 & 28,100 \\
\hline $9-23-40$ & 11,300 & 0,193 & 58,900 \\
\hline $10-08-40$ & 12.650 & 0.164 & 56,000 \\
\hline $10-27-40$ & 12,650 & 0.16 & 54,700 \\
\hline $11-04-40$ & 11.200 & 0.21 & 63,500 \\
\hline $11-18-40$ & 12,000 & 0.22 & 71,300 \\
\hline $12-02-40$ & 13,200 & 0.245 & 93,000 \\
\hline $12-16-40$ & 11.200 & 0.225 & 68,000 \\
\hline $1-02-41$ & 13,580 & 0.21 & 77.566 \\
\hline $1-13-41$ & 10,500 & 0.138 & 39.123 \\
\hline$|-27-4|$ & 11,000 & 0.23 & 68,310 \\
\hline $2-10-41$ & 9.000 & 0.0985 & 23,936 \\
\hline $2-24-41$ & 13,300 & 0.156 & 58,125 \\
\hline $3-07-41$ & 11.600 & 0.24 & 75,168 \\
\hline $3-19-41$ & 18,800 & 0.25 & 126.900 \\
\hline $3-31-41$ & 8.460 & 0.092 & 21,014 \\
\hline $4-15-41$ & 21,000 & 0.247 & 140,049 \\
\hline $4-28-41$ & 5,590 & 0.054 & 8.150 \\
\hline $5-07-41$ & 8.290 & 0.086 & 19,249 \\
\hline $5-14-41$ & 23,300 & 0.30 & 188,730 \\
\hline $5-19-41$ & 23,700 & 0.263 & 168,294 \\
\hline $5-27-41$ & 30,250 & 0.21 & 171.517 \\
\hline $6-03-41$ & 34,300 & 0.20 & 187,920 \\
\hline $6-16-41$ & 25,800 & 0.21 & 146,286 \\
\hline $6-30-41$ & 23,900 & 0.185 & 119,380 \\
\hline $7-14-41$ & 15,000 & 0.145 & 58.725 \\
\hline $7-28-41$ & 14,100 & 0.095 & 36,166 \\
\hline $8-11-41$ & 19,300 & 0.19 & 99,009 \\
\hline $8-25-41$ & 24,700 & 0.16 & 106.704 \\
\hline $9-08-41$ & 26,300 & 0.24 & 170,424 \\
\hline $9-22-41$ & 25,800 & 0.21 & 146,286 \\
\hline $10-06-41$ & 24,600 & 0.21 & 136,482 \\
\hline $10-20-41$ & 24,500 & 0.17 & 112,455 \\
\hline $11-03-41$ & 27,300 & 0.18 & 132.678 \\
\hline $11-17-41$ & 28,400 & 0.20 & 153,360 \\
\hline $12-03-41$ & 31,700 & 0.225 & 192,578 \\
\hline $12-15-41$ & 34,800 & 0.21 & 197,316 \\
\hline $1-12-42$ & 30,000 & 0.21 & 170,100 \\
\hline $1-26-42$ & 34,000 & 0.255 & 234,100 \\
\hline $2-09-42$ & 33,500 & 0.22 & 199,000 \\
\hline $2-23-42$ & 24,500 & 0.32 & 211,700 \\
\hline $3-09-42$ & 25,400 & 0.21 & 144,000 \\
\hline $3-23-42$ & 25,300 & 0.142 & 98,900 \\
\hline $4-03-42$ & 11,600 & 0.079 & 24,700 \\
\hline $4-20-42$ & 24,500 & 0.19 & 125,700 \\
\hline $5-04-42$ & 24,200 & 0.12 & 78,400 \\
\hline $5-26-42$ & 27,600 & 0.105 & 78,300 \\
\hline $6-15-42$ & 25,000 & 0.11 & 74,300 \\
\hline $7-06-42$ & 26,100 & 0.119 & 83,900 \\
\hline $7-28-42$ & 11,500 & 0.081 & 25,200 \\
\hline $8-18-42$ & 13,400 & 0.082 & 29,700 \\
\hline $9-03-42$ & 13.300 & 0.07 & 25,100 \\
\hline $9-29-42$ & 12,900 & 0.068 & 23.700 \\
\hline $10-21-42$ & 12,900 & 0.077 & 26,000 \\
\hline $11-17-42$ & 19,600 & 0.126 & 66,700 \\
\hline $12-07-42$ & 19,000 & 0.131 & 67,200 \\
\hline $1-04-43$ & 16,000 & 0.131 & 56,502 \\
\hline $2-01-43$ & 13,400 & 0.113 & 40,883 \\
\hline $3-01-43$ & 14,800 & 0.104 & 41,558 \\
\hline $4-06-43$ & 13,500 & 0.094 & 34,263 \\
\hline $5-05-43$ & 14,300 & 0.066 & 25,483 \\
\hline $6-01-43$ & 17,800 & 0.052 & 24,991 \\
\hline $7-26-43$ & 17,000 & 0.055 & 25,245 \\
\hline
\end{tabular}




\subsubsection{Computer Model}

The geometry of the system is represented by 23 cross sections as shown in Fig. 5.9. Each cross section is divided into a certain number of parts called subsections. The maximum number of subsections selected for this study is three. Figure 5.12 shows the cross sections and subsections for the geometric model, and Table 5.3 indicates the space interval $\Delta x$ between sections. The encircled numbers in this figure indicate the subsection numbers; the distance in the $x$-axis is measured from the California Anchor. The total length of the study reach between Taylor's Ferry and Imperial Dam is 60.2 miles.

The mean cross-sectional areas and the top widths at each subsection were determined as a function of
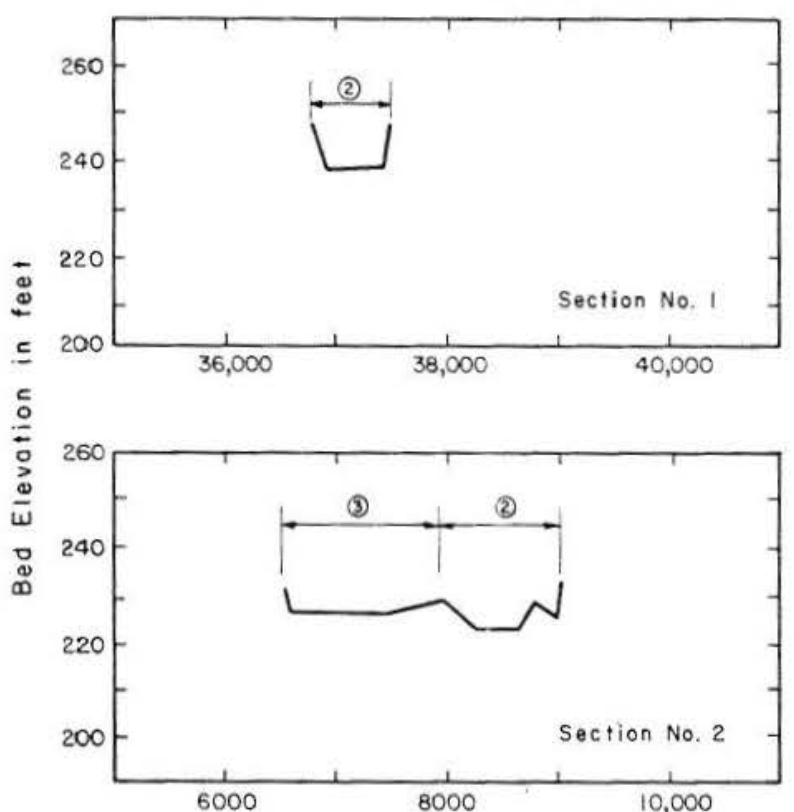

Distance
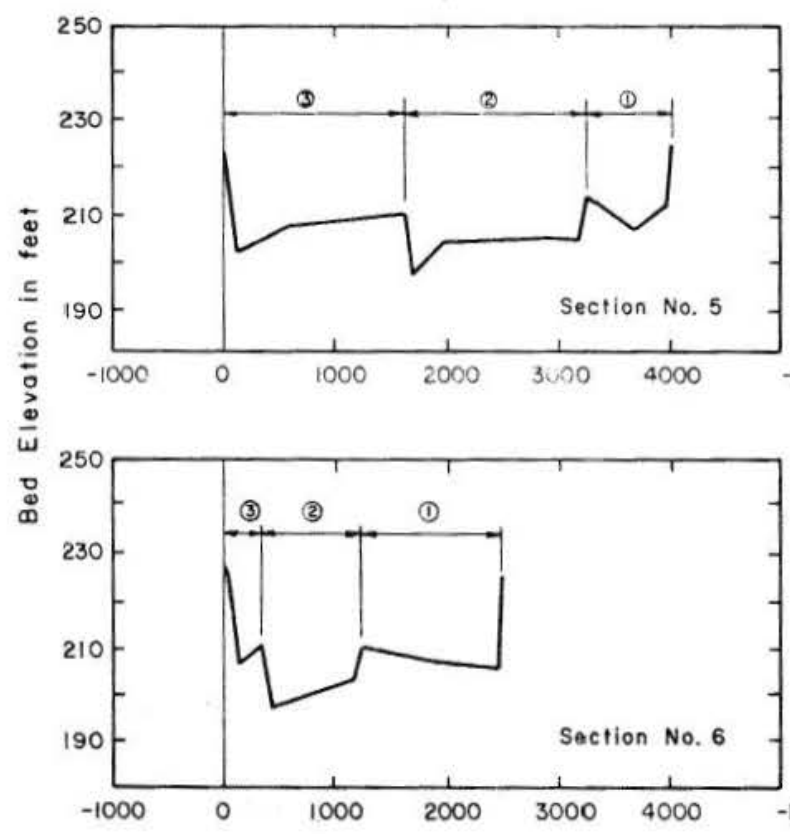

Distance

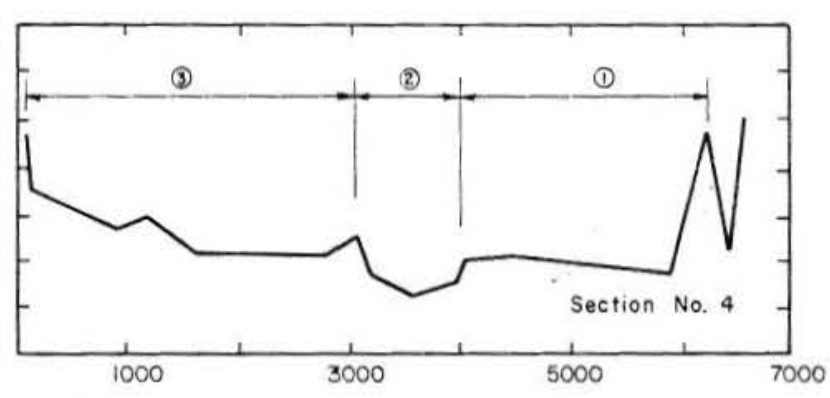

in feet

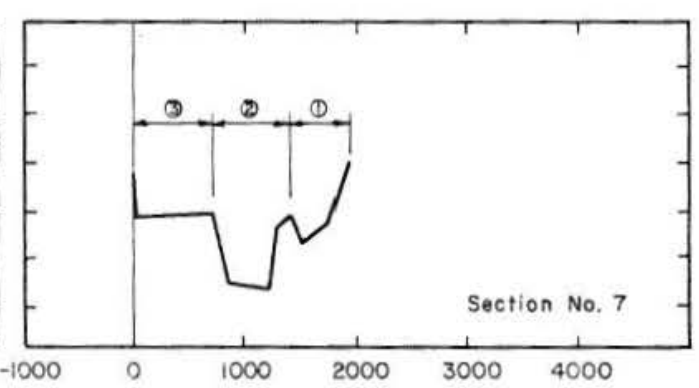

flow depths from the river cross sectioning available data by using the computer program AREA given in Appendix B. These are tabulated in Table 5.4. A table of $T$ vs. $h$ and $A$ vs. $n$ is input into the computer model and thus the actual values of the channel geometry are used in the computations. In this case is represents the initial value of the flow deptir measured from the lowest point of the cross section. Then in order to preserve the geometry of the sections, the flow area at any time in the simulation process is computed by the equation

$$
A=A_{T}-\quad \therefore A d
$$

in which $A_{T}$ is the value of the area given by the table and $\sum \mathrm{Ad}$ is the accumulated area of sediment deposition.
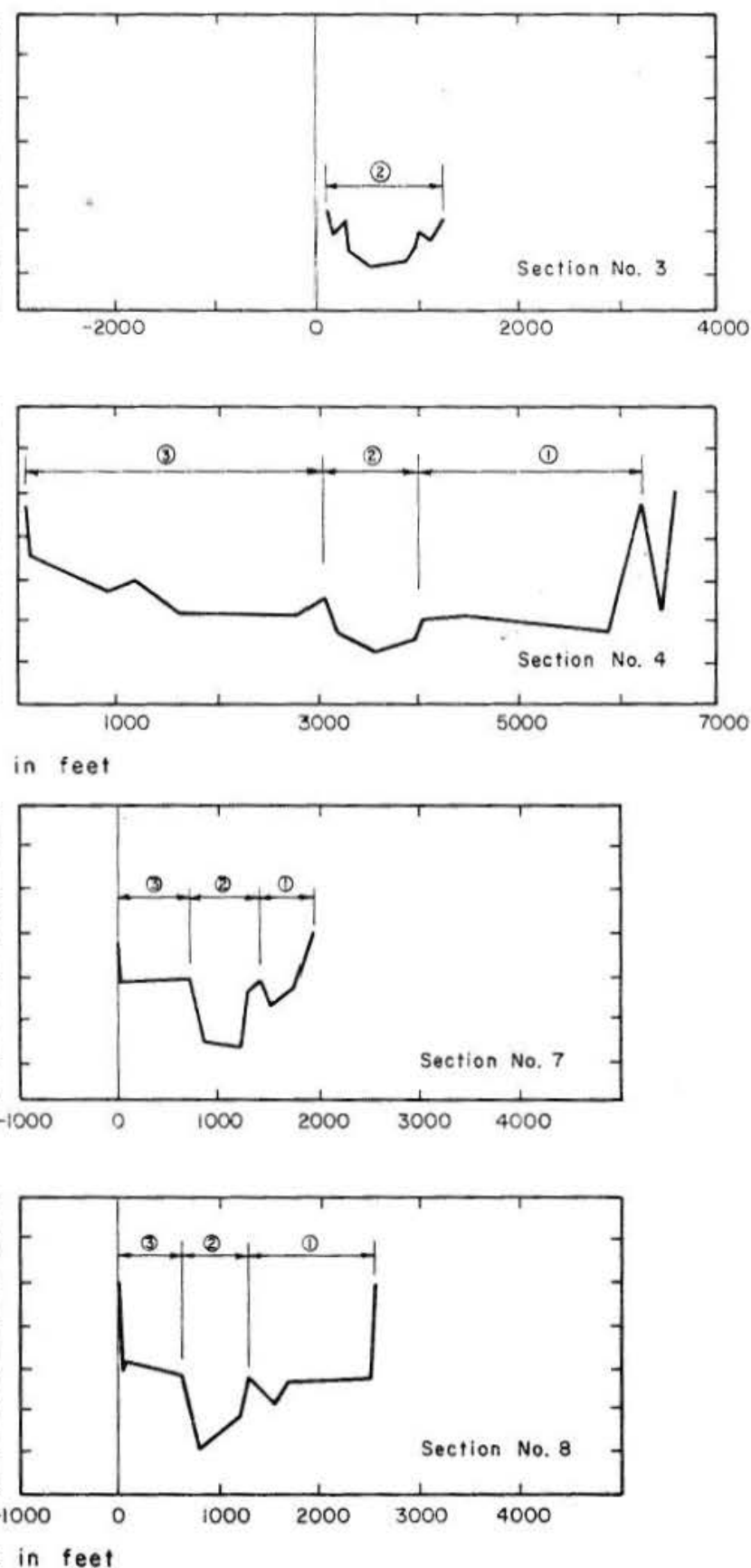

Fig. 5.12 - Cross Sections and Subsections for the Geometric Model 

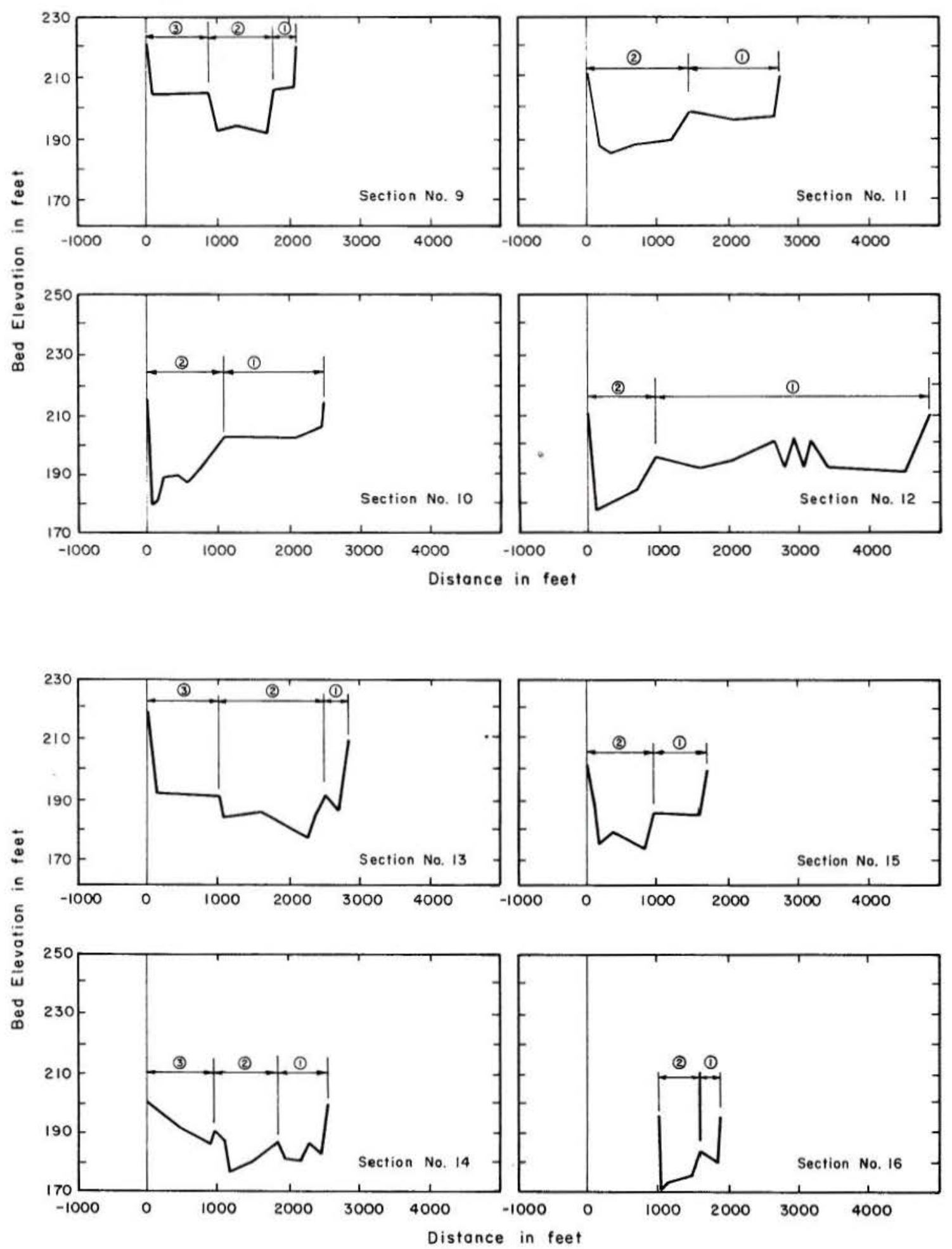

Fig. 5.12 (continued) 

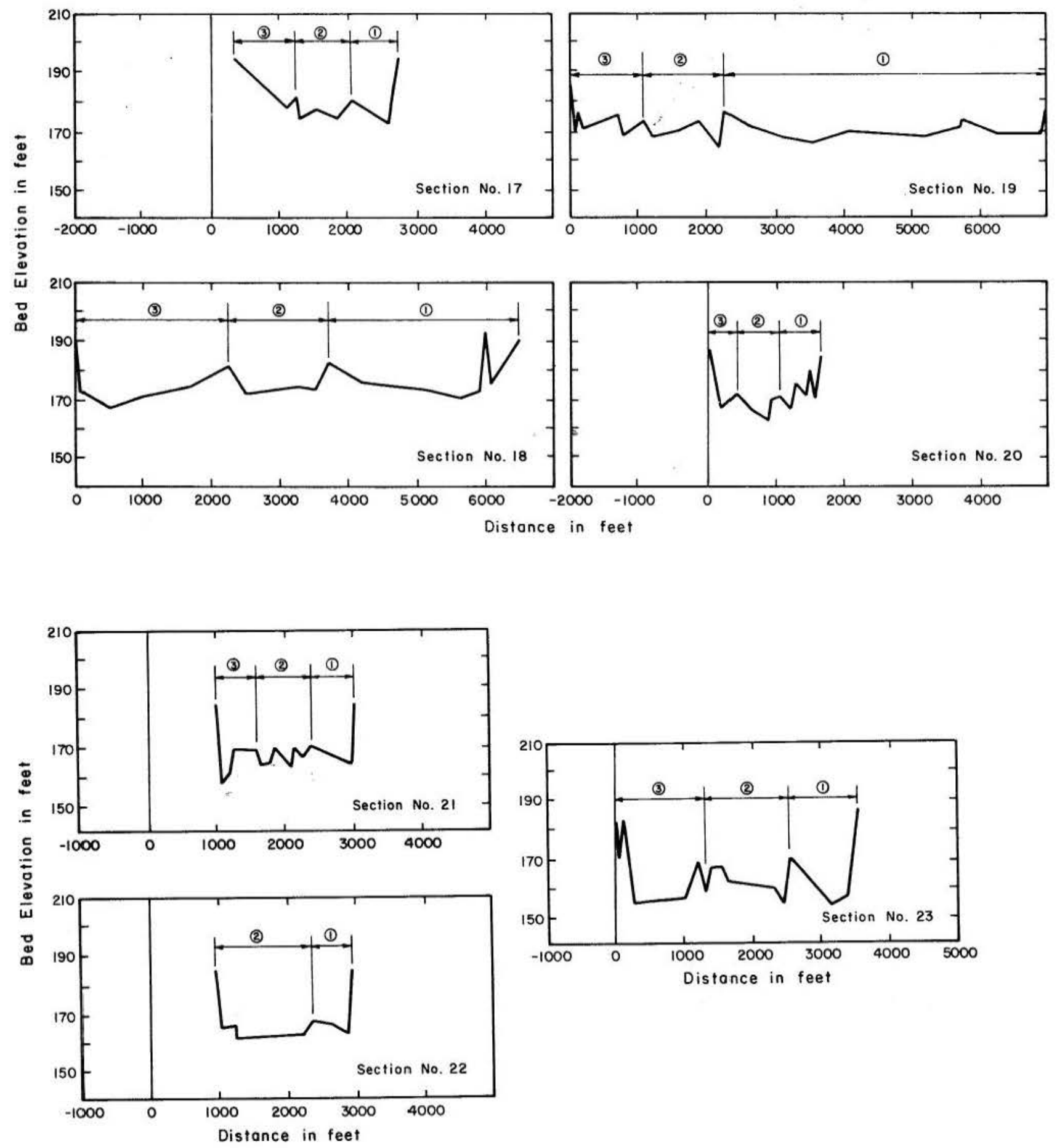

Fig. 5.12 (continued) 
Table 5.3. Location of Cross Sections in the Study Reach

\begin{tabular}{|c|c|c|}
\hline Section & $\begin{array}{l}\text { Miles Below } \\
\text { Parker Dam }\end{array}$ & $\stackrel{\Delta x}{(M i l e s)}$ \\
\hline 1 & 86.4 & 10.10 \\
\hline 2 & 96.5 & 5.80 \\
\hline 3 & 102.3 & 6.60 \\
\hline 4 & 108.9 & 1.70 \\
\hline 5 & 110.6 & 2.00 \\
\hline 6 & 112.6 & 1.90 \\
\hline 7 & 114.5 & 1.70 \\
\hline 8 & 116.2 & 2.30 \\
\hline 9 & 118.5 & 2.30 \\
\hline 10 & 120.8 & 1.40 \\
\hline 11 & 122.2 & 2.30 \\
\hline 12 & 124.5 & 1.80 \\
\hline 13 & 126.3 & 2.00 \\
\hline 14 & 128.3 & 2.20 \\
\hline 15 & 130.5 & 2.00 \\
\hline 16 & 132.5 & 2.10 \\
\hline 17 & 134.6 & 1.80 \\
\hline 18 & 136.4 & 2.10 \\
\hline 19 & 138.5 & 2.00 \\
\hline 20 & 140.5 & 2.30 \\
\hline 21 & 142.8 & 2.60 \\
\hline 22 & 145.4 & 1.20 \\
\hline 23 & 146.6 & - \\
\hline
\end{tabular}

Table 5.4. Geometric Properties at Each Subsection between Taylors Ferry and Imperial Dam in the Colorado River

\begin{tabular}{|c|c|c|c|}
\hline $\begin{array}{l}\text { STAGE } \\
\text { (FT) }\end{array}$ & $\begin{array}{l}\text { FLow } \\
\text { DEPTH } \\
\text { (FT) }\end{array}$ & $\begin{array}{l}\text { AREA } \\
\text { (FTXFT) }\end{array}$ & $\begin{array}{l}\text { TOP WIDTH } \\
\text { (FT) }\end{array}$ \\
\hline \multicolumn{4}{|c|}{ CROSS SECTION 1 SUBSECTION 2} \\
\hline $\begin{array}{l}237.00 \\
239.00 \\
241.00 \\
243.00 \\
245.00\end{array}$ & $\begin{array}{l}0.00 \\
2.00 \\
4.00 \\
6.00 \\
8.00\end{array}$ & $\begin{array}{r}0.00 \\
899.07 \\
2058.52 \\
3281.26 \\
4567.27\end{array}$ & $\begin{array}{r}0.00 \\
563.91 \\
595.55 \\
627.19 \\
658.83\end{array}$ \\
\hline \multicolumn{4}{|c|}{ CROSS SECTION 2 SUBSECTION 2} \\
\hline $\begin{array}{l}221.97 \\
223.97 \\
225.97 \\
227.97 \\
229.97\end{array}$ & $\begin{array}{l}0.00 \\
2.00 \\
4.00 \\
6.00 \\
8.00\end{array}$ & $\begin{array}{r}0.00 \\
855.73 \\
2244.03 \\
6201.40 \\
11076.28\end{array}$ & $\begin{array}{r}0.00 \\
518.52 \\
1530.19 \\
2294.55 \\
2476.28\end{array}$ \\
\hline \multicolumn{4}{|c|}{ CROSS SECTION 3 SUBSECTION 2} \\
\hline $\begin{array}{l}214.59 \\
216.59 \\
218.59 \\
220.59\end{array}$ & $\begin{array}{r}0.00 \\
2.00 \\
4.00 \\
6.00 \\
8.00 \\
10.00\end{array}$ & $\begin{array}{r}0.00 \\
553.38 \\
1695.26 \\
2987.29 \\
4420.55 \\
6298.06\end{array}$ & $\begin{array}{r}0.00 \\
495.67 \\
626.21 \\
665.82 \\
813.07 \\
1028.51\end{array}$ \\
\hline
\end{tabular}

Table 5.4. (continued)

\begin{tabular}{|c|c|c|c|}
\hline STAGE & $\begin{array}{l}\text { FLow } \\
\text { OEPTH } \\
\text { (FT) }\end{array}$ & $\begin{array}{l}\text { AREA } \\
\text { (FTXFT) }\end{array}$ & $\begin{array}{l}\text { TOP WID:- } \\
\text { (FT) }\end{array}$ \\
\hline \multicolumn{4}{|c|}{ CROSS SECTION 4 SUBSECTION } \\
\hline $\begin{array}{l}206.80 \\
208.80 \\
210.80 \\
212.80 \\
214.80 \\
216.80\end{array}$ & $\begin{array}{l}0.00 \\
2.00 \\
4.00 \\
6.00 \\
8.00 \\
10.00\end{array}$ & $\begin{array}{r}0.00 \\
804.46 \\
3406.17 \\
7276.19 \\
11236.33 \\
15290.69\end{array}$ & $\begin{array}{r}0.00 \\
804.46 \\
1916.67 \\
1957.51 \\
2003.62 \\
2049.73\end{array}$ \\
\hline \multicolumn{4}{|c|}{ CROSS SECTION 4 SUBSECTION 2} \\
\hline $\begin{array}{l}202.49 \\
204.49 \\
206.49 \\
208.49 \\
210.49 \\
212.49 \\
214.49\end{array}$ & $\begin{array}{l}0.00 \\
2.00 \\
4.00 \\
6.00 \\
8.00 \\
10.00 \\
12.00\end{array}$ & $\begin{array}{r}0.00 \\
473.90 \\
1710.16 \\
3309.17 \\
506.27 \\
6895.14 \\
8779.14\end{array}$ & $\begin{array}{r}0.00 \\
473.90 \\
723.02 \\
344.34 \\
902.30 \\
923.72 \\
954.63\end{array}$ \\
\hline
\end{tabular}

$\begin{array}{rrrr}211.39 & 0.00 & 0.00 & 0.00 \\ 213.39 & 2.00 & 2587.28 & 1448.09 \\ 215.39 & 4.00 & 5725.73 & 1683.94 \\ 217.39 & 6.00 & 9272.80 & 1954.33 \\ 219.39 & 8.00 & 13659.10 & 2431.98 \\ 221.39 & 10.00 & 18705.40 & 2614.32 \\ 223.39 & 12.00 & 24116.38 & 2796.67\end{array}$

CROSS SECTION 5 SUBSECTION ।

$\begin{array}{rrrr}206.48 & 0.00 & 0.00 & 0.00 \\ 208.49 & 2.00 & 224.19 & 224.19 \\ 210.48 & 4.00 & 899.77 & 448.39 \\ 212.48 & 6.00 & 2009.31 & 642.50 \\ 214.48 & 8.00 & 3394.94 & 717.30 \\ 216.48 & 10.00 & 4337.28 & 725.04 \\ 218.48 & 12.00 & 6295.10 & 732.78\end{array}$

CROSS SECTION 5 SUBSECTION 2

$\begin{array}{rrrr}197.10 & 0.00 & 0.00 & 0.00 \\ 199.10 & 2.00 & 88.22 & 88.22 \\ 201.10 & 4.00 & 352.89 & 176.44 \\ 203.10 & 6.00 & 793.99 & 264.66 \\ 205.10 & 8.00 & 2015.78 & 1536.12 \\ 207.10 & 10.00 & 5118.02 & 1566.12 \\ 209.10 & 12.00 & 8280.24 & 1596.11\end{array}$

CROSS SECTION 5 SUBSECTION 3

$\begin{array}{rrrr}201.68 & 0.00 & 0.00 & 00.00 \\ 203.68 & 2.00 & 177.04 & 177.04 \\ 205.68 & 4.00 & 708.18 & 354.09 \\ 207.68 & 6.00 & 1596.80 & 576.46 \\ 209.68 & 8.00 & 353.1 .07 & 1357.82 \\ 211.68 & 10.00 & 6599.49 & 1563.90 \\ 213.68 & 12.00 & 9736.48 & 1573.09\end{array}$

CROSS SECTION 6 SUBSECTION 1

$\begin{array}{rrrr}205.58 & 0.00 & 0.00 & 0.00 \\ 207.58 & 2.00 & 819.44 & 732.50 \\ 209.58 & 4.00 & 271.88 & 1159.94 \\ 211.58 & 6.00 & 5170.43 & 1237.37 \\ 213.58 & 8.00 & 7654.36 & 1240.56 \\ 215.58 & 10.00 & 10132.66 & 1243.75 \\ 217.58 & 12.00 & 12623.34 & 1246.94\end{array}$

CROSS SECT1ON 6 SUBSECTION 2

$\begin{array}{rrrr}196.87 & 0.00 & 0.00 & 0.00 \\ 198.87 & 2.00 & 253.76 & 253.76 \\ 200.87 & 4.00 & 101.75 & 507.53 \\ 202.87 & 6.00 & 2283.88 & 751.29 \\ 204.87 & 8.00 & 3894.38 & 824.42 \\ 206.87 & 10.00 & 5577.84 & 859.05 \\ 208.87 & 12.00 & 7330.58 & 393.69\end{array}$

CROSS SECTION 6 SUBSECTION 3

$\begin{array}{rrrr}206.00 & 0.00 & 0.00 & \\ 208.00 & 2.00 & 111.47 & 1090 \\ 210.00 & 4.00 & 439.32 & 218.02 \\ 212.00 & 6.00 & 893.57 & 230.99 \\ 214.00 & 8.00 & 1362.98 & 238.42 \\ 216.00 & 10.00 & 1847.24 & 245.85 \\ 218.00 & 12.00 & 2346.36 & 253.27\end{array}$

cross SEction 7 SUasection 1

\begin{tabular}{|c|c|c|c|}
\hline 202.77 & 0.00 & 0.00 & 0.00 \\
\hline & 2.00 & 141.92 & 141.92 \\
\hline & 4.00 & & 283.85 \\
\hline 3.77 & 6.00 & 1198.80 & $\begin{array}{r}344.83 \\
376.47\end{array}$ \\
\hline & 8.00 & $\begin{array}{r}1922.78 \\
2704.40\end{array}$ & $\begin{array}{l}376.47 \\
405,14\end{array}$ \\
\hline 214.77 & 12.00 & 3543.34 & $\begin{array}{l}4053.81 \\
431\end{array}$ \\
\hline & & & \\
\hline & & & \\
\hline & & . 493.20 & 388.71 \\
\hline & & $\begin{array}{l}1305.32 \\
217\end{array}$ & 418.42 \\
\hline & $\begin{array}{l}6.00 \\
8.00\end{array}$ & 3097.82 & $\begin{array}{l}448.12 \\
47.83\end{array}$ \\
\hline & 10.00 & 4083.18 & 507.54 \\
\hline & & & \\
\hline
\end{tabular}


Table 5.4. (continued)

\begin{tabular}{|c|c|c|c|}
\hline $\begin{array}{l}\text { STAGE } \\
\text { (FT) }\end{array}$ & $\begin{array}{l}\text { FLON } \\
\text { OEPTH } \\
\text { (FT) }\end{array}$ & $\begin{array}{l}\text { AREA } \\
\text { (FTXFT) }\end{array}$ & $\begin{array}{l}\text { TOP N1DTH } \\
\text { (FT) }\end{array}$ \\
\hline \multicolumn{4}{|c|}{ CROSS SECTION 7 SUBSECTION 3} \\
\hline $\begin{array}{l}208.33 \\
210.33 \\
212.33 \\
214.33 \\
216.33\end{array}$ & $\begin{array}{l}0.00 \\
2.00 \\
4.00 \\
6.00 \\
8.00\end{array}$ & $\begin{array}{r}0.00 \\
1049.47 \\
2422.59 \\
3307.64 \\
5204.63\end{array}$ & $\begin{array}{r}0.00 \\
683.57 \\
639.57 \\
693.51 \\
701.45\end{array}$ \\
\hline \multicolumn{4}{|c|}{ CROSS SECTION \& SUBSECTION 1} \\
\hline $\begin{array}{l}201.33 \\
203.33 \\
205.33 \\
207.33 \\
209.33 \\
211.33 \\
213.33\end{array}$ & $\begin{array}{l}0.00 \\
2.00 \\
4.00 \\
6.00 \\
8.00 \\
10.00 \\
12.00\end{array}$ & $\begin{array}{r}0.00 \\
126.17 \\
50.67 \\
1239.75 \\
3630.01 \\
6049.64 \\
9699.50\end{array}$ & $\begin{array}{r}0.00 \\
126.17 \\
252.33 \\
991.72 \\
1207.26 \\
1212.37 \\
127 \%\end{array}$ \\
\hline
\end{tabular}

CROSS SECT:OH a SUESEETiGa 2

$\begin{array}{lrrr}190.63 & 0.00 & 0.00 & \\ 192.63 & 2.00 & 124.78 & 0.00 \\ 194.63 & 4.00 & 499.12 & 249.73 \\ 196.63 & 6.00 & 1123.03 & 374.34 \\ 196.63 & 8.00 & 1996.48 & 497.77 \\ 198.63 & 8.00 & 3026.23 & 531.99 \\ 200.63 & 10.00 & 300 \\ 202.63 & 12.00 & 4124.42 & 566.21\end{array}$

CROSS SECTION B SUBSECTION 3

$\begin{array}{rrrr}208.49 & 0.00 & 0.00 & 0.00 \\ 210.49 & 2.00 & 402.65 & 411.29 \\ 212.49 & 4.00 & 1516.84 & 599.67 \\ 214.49 & 6.00 & 2721.86 & 605.34 \\ 216.49 & 8.00 & 3938.21 & 611.01 \\ 218.49 & 10.00 & 5165.91 & 616.66 \\ 220.49 & 12.00 & 6404.95 & 622.35\end{array}$

CROSS SECTION 9 SUBSECTION ।

$\begin{array}{rrrr}205.79 & 0.00 & 0.00 & 0.00 \\ 207.79 & 2.00 & 486.73 & 288.47 \\ 209.79 & 4.00 & 1068.93 & 293.72 \\ 211.79 & 6.00 & 1661.63 & 298.97 \\ 213.79 & 8.00 & 2264.82 & 304.22 \\ 215.79 & 10.00 & 2878.52 & 309.47 \\ 217.79 & 12.00 & 3502.71 & 314.72\end{array}$

CROSS SEction 9 SUBSection 2

$\begin{array}{llll}190.87 & 0.00 & 0.00 & 0.00 \\ 192.87 & 2.00 & 456.66 & 535.51 \\ 194.87 & 4.00 & 1896.54 & 768.99 \\ 196.87 & 6.00 & 3468.41 & 801.83 \\ 198.87 & 8.00 & 5105.08 & 834.79 \\ 200.87 & 10.00 & 5807.55 & 867.69 \\ 202.87 & 12.00 & 8575.82 & 900.59\end{array}$

CROSS SECTION 9 SUBSECTION 3

$\begin{array}{lrrr}203.79 & 0.00 & 0.00 & \\ 205.79 & 2.00 & 1298.93 & 799.40 \\ 207.79 & 4.00 & 2904.55 & 806.17 \\ 209.79 & 6.00 & 4523.50 & 812.81 \\ 211.79 & 8.00 & 6155.80 & 819.44 \\ 213.79 & 10.00 & 7801.43 & 826.15 \\ 215.79 & 12.00 & 9460.41 & 832.82\end{array}$

CROSS SECTION 10 SUBSECTION ,

$\begin{array}{rrrr}202.42 & 0.00 & 0.00 & \\ 204.42 & 2.00 & 2012.22 & 12.00 \\ 206.42 & 4.00 & 4662.24 & 1403.97 \\ 208.42 & 6.00 & 7472.80 & 105.59 \\ 210.42 & 8.00 & 10288.59 & 10909.21\end{array}$

CROSS SECTION 10 SUBSECTION 2

$\begin{array}{rrrr}179.70 & 0.00 & 0.00 & \\ 181.70 & 2.00 & 79.66 & 79.00 \\ 183.70 & 4.00 & 265.24 & 105.35 \\ 185.70 & 6.00 & 501.16 & 130.55 \\ 187.70 & 8.00 & 787.43 & 155.72 \\ 189.70 & 10.00 & 1296.23 & 358.41 \\ 191.70 & 12.00 & 2465.05 & 667.45\end{array}$

CROSS SECTION 11 SUBSECTION ।

$\begin{array}{rrrr}195.27 & 0.00 & 0.00 & \\ 197.27 & 2.00 & 1304.42 & 0.00 \\ 199.27 & 4.00 & 3574.42 & 119.27 \\ 201.27 & 6.00 & 5969.80 & 1203.89 \\ 203.27 & 8.00 & 83899.94 & 127.25 \\ 205.27 & 10.00 & 10934.80 & 1228.61 \\ 207.27 & 12.00 & 13304.39 & 1240.97\end{array}$

CROSS SECTION 11 SUBSECTION 2

$\begin{array}{rrrr}184.13 & 0.00 & 0.00 & 0.00 \\ 186.13 & 2.00 & 37.84 & 367.22 \\ 188.13 & 4.00 & 1503.18 & 872.66 \\ 190.13 & 6.00 & 3535.61 & 1063.24 \\ 192.13 & 8.00 & 5732.28 & 1133.43 \\ 194.13 & 10.00 & 8069.33 & 1203.62 \\ 196.13 & 12.00 & 10546.75 & 1273.52\end{array}$

Table 5.4. (continued)

\begin{tabular}{|c|c|c|c|}
\hline $\begin{array}{l}\text { STAGE } \\
\text { (FT) }\end{array}$ & $\begin{array}{l}\text { FLOW } \\
\text { DEFTH } \\
\text { (FT) }\end{array}$ & $\begin{array}{l}\text { AREA } \\
\text { (FTXF) }\end{array}$ & $\begin{array}{l}\text { TOP AlDTH } \\
\text { (F) }\end{array}$ \\
\hline \multicolumn{4}{|c|}{ CROSS SECTION 12 SUBSECTION 1} \\
\hline $\begin{array}{l}190.74 \\
192.74 \\
194.74 \\
196.74 \\
198.74 \\
200.74 \\
202.74 \\
204.74 \\
206.74\end{array}$ & $\begin{array}{l}0.00 \\
2.00 \\
4.00 \\
6.00 \\
8.00 \\
10.00 \\
12.00 \\
14.00 \\
16.00\end{array}$ & $\begin{array}{r}0.00 \\
1717.29 \\
5590.16 \\
10927.65 \\
17057.01 \\
23935.30 \\
31370.09 \\
38912.73 \\
46531.66\end{array}$ & $\begin{array}{r}0.00 \\
1484.94 \\
2330.26 \\
2877.45 \\
3251.91 \\
3626.37 \\
3752.25 \\
3790.39 \\
3828.53\end{array}$ \\
\hline
\end{tabular}

CROSS SECTION 12 SUBSECTION 2

$\begin{array}{rrrr}177.52 & 0.00 & 0.00 & \\ 17.52 & 2.00 & 181.01 & 181.00 \\ 181.52 & 4.00 & 724.04 & 362.02 \\ 133.52 & 6.00 & 1629.10 & 543.03 \\ 185.52 & 8.00 & 2847.02 & 645.39 \\ 18.52 & 10.00 & 492.98 & 700.57 \\ 189.52 & 12.00 & 5649.29 & 755.74 \\ 191.52 & 14.00 & 7215.94 & 810.91 \\ 193.52 & 16.00 & 8892.93 & 866.03\end{array}$

CROSS SECTION 13 SUBSECTION

$\begin{array}{rrrr}185.78 & 0.00 & 0.00 & \\ 18.78 & 2.00 & 72.72 & 72.72 \\ 189.78 & 4.00 & 290.88 & 145.44 \\ 19.78 & 6.00 & 653.75 & 211.40 \\ 191.78 & 8.00 & 1088.51 & 223.29 \\ 193.78 & 8.00 & 1546.90 & 233.11 \\ 195.78 & 10.00 & 2028.94 & 246.93 \\ 197.78 & 12.00 & 2028.94 & 255.75 \\ 199.78 & 14.00 & 2534.62 & 275.57 \\ 201.78 & 16.00 & 3063.94 & 27.57\end{array}$

CROSS SECTION 13 SUBSECTION 2

\begin{tabular}{|c|c|c|c|}
\hline & 0.00 & & \\
\hline & & 181. & \\
\hline 180.71 & 4.00 & 725.91 & 362.9 \\
\hline 182.71 & 6.00 & 1633.30 & 544.43 \\
\hline 184.71 & 8.00 & 3086.19 & 1051.88 \\
\hline 186.71 & 10.00 & 5691.83 & 1383.82 \\
\hline 188.71 & 12.00 & 8523.84 & $14: 5.19$ \\
\hline 190.71 & 14.00 & 11476.51 & $\begin{array}{r}1505.35 \\
\end{array}$ \\
\hline 192.71 & & 14515.95 & \\
\hline
\end{tabular}

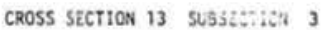

$\begin{array}{rrrr}190.57 & 0.00 & 0.00 & \\ 192.57 & 2.00 & 1477.90 & 891.00 \\ 194.57 & 4.00 & 3269.58 & 925.41 \\ 196.57 & 6.00 & 5079.54 & 909.55 \\ 198.57 & 8.00 & 6907.77 & 913.68 \\ 200.57 & 10.00 & 8754.26 & 927.82 \\ 202.57 & 12.00 & 10619.03 & 936.95 \\ 204.57 & 14.00 & 12502.07 & 996.90 \\ 206.57 & 16.00 & 14403.38 & 955.22\end{array}$

CROSS SECTION 14 SUBSECTION ।

$\begin{array}{rrrr}181.12 & 0.00 & 0.00 & \\ 18.12 & 2.00 & 460.87 & 27900 \\ 13.12 & 4.00 & 1162.51 & 435.15 \\ 185.12 & 6.00 & 2204.20 & 606.54 \\ 187.12 & 6.00 & 3479.71 & 646.06 \\ 189.12 & 8.00 & 12.00 \\ 191.12 & 10.00 & 4782.67 & 656.90 \\ 193.12 & 12.00 & 6107.30 & 667.73 \\ 195.12 & 14.00 & 7453.60 & 67.57 \\ 197.12 & 16.00 & 8821.56 & 689.40\end{array}$

CROSS SECTION 14 SUBSECTION ?

\begin{tabular}{|c|c|c|c|}
\hline 177.43 & 0.00 & 0.00 & \\
\hline & 2.00 & 208.89 & \\
\hline 181.43 & 4.00 & 824,81 & \\
\hline & $\begin{array}{l}6.00 \\
8.00\end{array}$ & 1716.52 & $\begin{array}{l}505.10 \\
623.5\end{array}$ \\
\hline $\begin{array}{l}185.43 \\
187.43\end{array}$ & 10.00 & $\begin{aligned} 2845.23 \\
4210.94\end{aligned}$ & 742.11 \\
\hline 189.43 & 12.00 & 5798.41 & \\
\hline & 14.00 & 7542.59 & 899 . \\
\hline & 16.00 & 9341.39 & 899. \\
\hline
\end{tabular}

CROSS SECTION 14 SUBSECTION 3

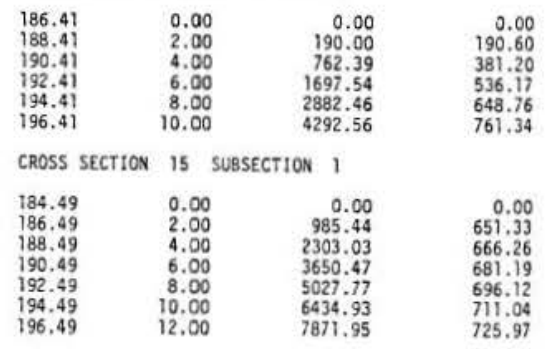


Table 5.4. (continued)

\begin{tabular}{llcc}
$\begin{array}{l}\text { STAGE } \\
\text { (FT) }\end{array}$ & $\begin{array}{l}\text { FLPTH } \\
\text { (FT) }\end{array}$ & $\begin{array}{c}\text { AREA } \\
\text { (FTXFT) }\end{array}$ & $\begin{array}{c}\text { TOP WIDTH } \\
\text { (FT) }\end{array}$ \\
\hline
\end{tabular}

CROSS SECTION 15 SUBSECTION ?

$\begin{array}{rrrr}173.15 & 0.00 & 0.00 & 0.00 \\ 175.15 & 2.00 & 179.28 & 192.33 \\ 177.15 & 4.00 & 858.00 & 485.30 \\ 179.15 & 6.00 & 2116.99 & 745.21 \\ 181.75 & 8.00 & 3639.47 & 777.27 \\ 183.15 & 10.00 & 5226.05 & 809.32 \\ 185.15 & 12.00 & 6876.75 & 841.38 \\ 187.15 & 14.00 & 8574.48 & 853.45 \\ 189.15 & 16.00 & 10296.12 & 868.44\end{array}$

CROSS SECTION 16 SUBSECTION 1

$\begin{array}{rrrr}179.45 & 0.00 & 0.00 & \\ 181.45 & 2.00 & 120.50 & 120.00 \\ 183.45 & 4.00 & 482.00 & 241.00 \\ 185.45 & 6.00 & 972.20 & 246.33 \\ 187.45 & 8.00 & 1467.01 & 248.70 \\ 189.45 & 10.00 & 1967.01 & 251.08 \\ 191.45 & 12.00 & 2471.55 & 253.45\end{array}$

CROSS SECTION 16 SUBSECTION ?

\begin{tabular}{|c|c|c|c|}
\hline 170.38 & 0.00 & & \\
\hline 172.38 & 2.00 & 73.00 & 73.00 \\
\hline $\begin{array}{l}1 / 4.38 \\
176\end{array}$ & $\begin{array}{l}4.00 \\
6.00\end{array}$ & $\begin{array}{r}398.20 \\
3275\end{array}$ & 329.12 \\
\hline 178.38 & $\begin{array}{l}6.00 \\
8.00\end{array}$ & $\begin{array}{l}1275.96 \\
2245.74\end{array}$ & $\begin{array}{l}470.83 \\
498.95\end{array}$ \\
\hline 180.38 & 10.00 & 3271.74 & 527.06 \\
\hline $\begin{array}{l}182.38 \\
184.38\end{array}$ & 12.00 & $\begin{array}{l}4353.98 \\
G 407\end{array}$ & 555.18 \\
\hline $\begin{array}{r}186.38 \\
186,8\end{array}$ & 16.00 & 6630.97 & 572.37 \\
\hline
\end{tabular}

CROSS SECTION 17 SUBSECTION ।

\begin{tabular}{|c|c|c|c|}
\hline 172.43 & & & \\
\hline 174.43 & 2.00 & 143.47 & 143.47 \\
\hline & & 573.83 & 286.94 \\
\hline & 6.00 & 1291.23 & 430.41 \\
\hline 180.43 & 8.00 & 2295.51 & 0.00 \\
\hline $\begin{array}{l}182.43 \\
184.43\end{array}$ & 10.00 & 3454.44 & 585.91 \\
\hline $\begin{array}{l}184.43 \\
186.43 \\
186\end{array}$ & 12.00 & $\begin{array}{l}4640.60 \\
585 .\end{array}$ & 600.25 \\
\hline $\begin{array}{l}186.43 \\
188.43\end{array}$ & 14.00 & $\begin{array}{r}5855.46 \\
7099\end{array}$ & $\begin{array}{l}614.60 \\
620\end{array}$ \\
\hline & & & \\
\hline CROSS S & 517 & $100 \% 2$ & \\
\hline 176.14 & 0.00 & & \\
\hline $\begin{array}{l}176.14 \\
178.14\end{array}$ & $\begin{array}{l}2.00 \\
4,00\end{array}$ & $\begin{array}{r}356.63 \\
\end{array}$ & 377.88 \\
\hline 70.4 & $\begin{array}{l}8.00 \\
6.00\end{array}$ & 2979.09 & $\begin{array}{l}699.18 \\
786.59\end{array}$ \\
\hline & 8.00 & 4583.70 & $\begin{array}{l}170.59 \\
807.60\end{array}$ \\
\hline & 10.00 & 6198,90 & 80.60 \\
\hline 86. & 12.00 & 7814.10 & 807.60 \\
\hline 38. & 14.00 & 9429.30 & 807.60 \\
\hline & & & \\
\hline
\end{tabular}

CROSS SECTION 17 SUBSECTION 3

$\begin{array}{llrl}178.21 & 0.00 & 0.00 & \\ 180.21 & 2.00 & 175.58 & 17.00 \\ 182.21 & 4.00 & 700.91 & 340.31 \\ 184.21 & 6.00 & 1473.90 & 432.47 \\ 186.21 & 8.00 & 2430.80 & 524.63 \\ 188.21 & 10.00 & 3572.21 & 616.79 \\ 190.21 & 12.00 & 4897.94 & 708.94\end{array}$

CROSS SECTION 18 SUESECTION ।

$\begin{array}{rrrr}170.00 & 0.00 & 0.00 & 0.00 \\ 172.00 & 2.00 & 641.11 & 654.20 \\ 174.00 & 4.00 & 2513.99 & 1250.80 \\ 176.00 & 6.00 & 5755.59 & 1818.32 \\ 178.00 & 8.00 & 9604.33 & 2030.42 \\ 180.00 & 10.00 & 13877.28 & 2242.52 \\ 182.00 & 12.00 & 18574.42 & 2452.62 \\ 184.00 & 14.00 & 2357.62 & 2539.10 \\ 186.00 & 16.00 & 28729.69 & 2610.95\end{array}$

CROSS SECTION 18 SUBSECTION 2

$\begin{array}{rrrr}171.13 & 0.00 & 0.00 & 0.00 \\ 173.13 & 2.00 & 727.70 & 786.18 \\ 175.13 & 4.00 & 2890.58 & 1175.75 \\ 177.13 & 6.00 & 5336.11 & 1269.79 \\ 179.13 & 8.00 & 7969.74 & 1363.84 \\ 181.13 & 10.00 & 1075.86 & 1440.65 \\ 183.13 & 12.00 & 13698.95 & 1462.20 \\ 185.13 & 14.00 & 1662.35 & 1462.20 \\ 187.13 & 16.00 & 19547.75 & 1462.20\end{array}$

CROSS SECTION 18 SUBSECTION 3

\begin{tabular}{|c|c|c|c|}
\hline 166.16 & 0.00 & 0.00 & 0.00 \\
\hline 168. & 2.00 & $\begin{array}{r}383.60 \\
\end{array}$ & 383.60 \\
\hline $\begin{array}{l}170.1 \\
172.16\end{array}$ & $\begin{array}{l}4.00 \\
6.00\end{array}$ & 1534.40 & 767.20 \\
\hline $\begin{array}{l}172.16 \\
174.16\end{array}$ & $\begin{array}{l}6.00 \\
8.00\end{array}$ & $\begin{array}{l}35773.62 \\
6527.33\end{array}$ & $\begin{array}{l}1272.82 \\
1642.03\end{array}$ \\
\hline 176.16 & 10.00 & 9991.06 & 1821.69 \\
\hline 178.16 & 12.00 & 13814.10 & 2001.35 \\
\hline 180.16 & 14.00 & 17996.47 & 2181.02 \\
\hline 182.16 & 16,00 & 22416.67 & 2216,04 \\
\hline
\end{tabular}

Table 5.4. (continued)

\begin{tabular}{|c|c|c|c|}
\hline $\begin{array}{l}\text { STAGE } \\
\text { (FT) }\end{array}$ & $\begin{array}{l}\text { FLCW } \\
\text { OEPTH } \\
\text { (FT) }\end{array}$ & $\begin{array}{l}\text { AREA } \\
\text { (FTXFT) }\end{array}$ & $\begin{array}{c}T 00 \text { NIDTA } \\
\text { (FT) }\end{array}$ \\
\hline CROSS SECTIOA & $419=$ & $c+1081$ & \\
\hline $\begin{array}{l}165.56 \\
167.56 \\
169.56 \\
171.56 \\
173.56 \\
175.56 \\
177.56 \\
179.56 \\
181.56\end{array}$ & $\begin{array}{r}0.00 \\
2.00 \\
4.00 \\
6.00 \\
8.00 \\
10.00 \\
12.00 \\
14.00 \\
16.00\end{array}$ & $\begin{array}{r}0.00 \\
728.92 \\
4362.33 \\
13373.62 \\
20970.83 \\
30085.00 \\
39459.02 \\
49880.81 \\
58331.55\end{array}$ & $\begin{array}{r}0.03 \\
726.93 \\
3368.09 \\
4093.69 \\
4177.26 \\
4636.91 \\
4703.65 \\
4718.13 \\
4732.61\end{array}$ \\
\hline CROSS SECTION & 19 & ection 2 & \\
\hline $\begin{array}{l}164.00 \\
166.00 \\
168.00 \\
170.00 \\
172.00 \\
174.00 \\
176.00 \\
178.00 \\
180.00\end{array}$ & $\begin{array}{r}0.00 \\
2.00 \\
4.00 \\
6.00 \\
8.00 \\
10.00 \\
12.00 \\
14.00 \\
16.00\end{array}$ & $\begin{array}{r}0.00 \\
77.59 \\
326.47 \\
1479.45 \\
3646.11 \\
6582.12 \\
9674.05 \\
12788.63 \\
15903.43\end{array}$ & $\begin{array}{r}0.00 \\
76.44 \\
257.57 \\
862.66 \\
1324.00 \\
1530.68 \\
1555.83 \\
1557.40 \\
1557.40\end{array}$ \\
\hline
\end{tabular}

$\begin{array}{llrl}169.41 & 0.00 & 0.00 & \\ 171.41 & 2.00 & 84.09 & 10.00 \\ 173.41 & 4.00 & 620.94 & 394.71 \\ 175.41 & 6.00 & 1661.17 & 62.74 \\ 177.41 & 8.00 & 2946.08 & 64.64 \\ 179.41 & 10.00 & 453.64 & 65.18 \\ 181.41 & 12.00 & 5599.59 & 65.38 \\ 183.71 & 14.00 & 6963.33 & 676.77\end{array}$

CROSS SECTION 20 SUBSECTION 1

\begin{tabular}{|c|c|c|c|}
\hline $\begin{array}{l}165.52 \\
168.52\end{array}$ & $\begin{array}{l}0.00 \\
2.00\end{array}$ & $\begin{array}{l}0.00 \\
95.93\end{array}$ & $\begin{array}{l}0.00 \\
95.93\end{array}$ \\
\hline $\begin{array}{l}168.52 \\
170.52\end{array}$ & 20 & $\begin{array}{l}95.93 \\
386.38\end{array}$ & 199.83 \\
\hline 172.52 & 6.00 & 920.15 & 325.92 \\
\hline 174.52 & 8.00 & 1688.81 & 442.74 \\
\hline 176,52 & 10.00 & 2660.01 & 508.98 \\
\hline $\begin{array}{l}178.52 \\
180.52\end{array}$ & $\begin{array}{l}12.00 \\
14.00\end{array}$ & $\begin{array}{l}3712.53 \\
4833.15\end{array}$ & $\begin{array}{l}533.55 \\
573.06\end{array}$ \\
\hline $\begin{array}{r}80.52 \\
182.52\end{array}$ & 16.00 & 5989.17 & 582.97 \\
\hline
\end{tabular}

CROSS SECTION 20 SUBSECTION 2

$\begin{array}{lrrr}162.00 & 0.00 & 0.00 & \\ 164.00 & 2.00 & 142.70 & 147.12 \\ 166.00 & 4.00 & 570.28 & 266.35 \\ 168.00 & 6.00 & 1197.24 & 360.61 \\ 170.00 & 8.00 & 20013.61 & 469.60 \\ 172.00 & 10.00 & 3179.45 & 615.00 \\ 17.00 & 12.00 & 4490.45 & 615.00 \\ 176.00 & 14.00 & 563.45 & 615.00 \\ 178.00 & 16.00 & 6869.45 & 615.00\end{array}$

CROSS SECTION 20 SUBSECTION 3

$\begin{array}{rrrr}166.12 & 0.00 & 0.00 & 0.00 \\ 168.12 & 2.00 & 11.09 & 111.09 \\ 170.12 & 4.00 & 444.35 & 222.18 \\ 172.12 & 6.00 & 975.65 & 234.93 \\ 174.12 & 8.00 & 1560.15 & 299.51 \\ 176.12 & 10.00 & 217.71 & 314.04 \\ 178.12 & 12.00 & 2816.32 & 328.57 \\ 180.12 & 14.00 & 3487.98 & 343.10 \\ 182.12 & 16.00 & 4188.70 & 357.63\end{array}$

CROSS SECTION 21 SUBSECTION 1

$\begin{array}{lrrr}164.50 & 0.00 & 0.00 & 0.00 \\ 166.50 & 2.00 & 199.69 & 199.69 \\ 168.50 & 4.00 & 798.75 & 399.33 \\ 170.50 & 6.00 & 1797.20 & 599.07 \\ 172.50 & 8.00 & 3025.76 & 616.75 \\ 174.50 & 10.00 & 4263.25 & 620.74 \\ 176.50 & 12.00 & 5508.72 & 624.73 \\ 178.50 & 14.00 & 6762.17 & 628.72 \\ 180.50 & 16.00 & 8023.59 & 632.71\end{array}$

CROSS SECTION 21 SUBSECTION 2

$\begin{array}{lrrr}162.86 & 0.00 & 0.00 & \\ 164.88 & 2.00 & 205.44 & 0.00 \\ 166.88 & 4.00 & 826.19 & 43.13 \\ 168.88 & 6.00 & 1906.30 & 67.16 \\ 170.88 & 8.00 & 3453.53 & 82.94 \\ 172.88 & 10.00 & 5098.73 & 82.60 \\ 174.88 & 12.00 & 6743.93 & 82.60 \\ 176.88 & 14.00 & 8389.13 & 822.60 \\ 178.88 & 16.00 & 10034.33 & 822.60\end{array}$

CROSS SECTION 21 SUASECTION

$\begin{array}{lrrr}157.42 & 0.00 & 0.00 & \\ 159.42 & 2.00 & 67.55 & 0.00 \\ 156.42 & 4.00 & 270.20 & 135.10 \\ 163.42 & 6.00 & 567.48 & 159.83 \\ 165.42 & 8.00 & 909.37 & 182.06 \\ 16.42 & 10.00 & 1295.73 & 200.30 \\ 169.42 & 12.00 & 1773.27 & 509.50 \\ 17.42 & 14.00 & 1849.22 & 550.76 \\ 173.42 & 16.00 & 3935.90 & 545.92\end{array}$ 
Table 5.4. (continued)

\begin{tabular}{lllc}
\hline STAGE & FLOW & AREA & TOP WIOTH \\
(FT) & (FEPTH & (FIXFT) & (FT) \\
\hline
\end{tabular}

CROSS SECTION 22 SUBSECTION 1

$\begin{array}{rrrr}162.65 & 0.00 & 0.00 & 0.00 \\ 164.65 & 2.00 & 141.29 & 141.29 \\ 166.65 & 4.00 & 615.21 & 391.42 \\ 168.65 & 6.00 & 1616.61 & 526.04 \\ 170.65 & 8.00 & 2675.18 & 532.52 \\ 172.65 & 10.00 & 3746.71 & 539.01 \\ 174.65 & 12.00 & 4831.20 & 545.49 \\ 176.65 & 14.00 & 5928.66 & 551.97 \\ 178.65 & 16.00 & 7039.07 & 558.45\end{array}$

CROSS SECTION 22 SUBSECTION 2

$\begin{array}{lrrr}161.33 & 0.00 & 0.00 & 0.00 \\ 163.33 & 2.00 & 1391.80 & 1009.37 \\ 165.33 & 4.00 & 3498.95 & 1175.50 \\ 167.33 & 6.00 & 6122.68 & 1362.23 \\ 169.33 & 8.00 & 8853.62 & 1368.41 \\ 171.33 & 10.00 & 11596.33 & 1374.30 \\ 173.33 & 12.00 & 14350.81 & 1350.18 \\ 175.33 & 14.00 & 17117.06 & 1336.07 \\ 177.33 & 16.00 & 19895.08 & 1391.95\end{array}$

CROSS SECTION 23 SUBSECTION 1

$\begin{array}{rrrr}152.10 & 0.00 & 0.00 & 0.00 \\ 154.10 & 2.00 & 243.57 & 243.57 \\ 156.10 & 4.00 & 905.12 & 381.55 \\ 158.10 & 6.00 & 1750.59 & 463.92 \\ 160.10 & 8.00 & 2760.80 & 546.29 \\ 162.10 & 10.00 & 3935.75 & 628.66 \\ 164.10 & 12.00 & 5275.44 & 711.03 \\ 166.10 & 14.00 & 6779.86 & 793.40 \\ 168.10 & 16.00 & 8449.02 & 875.77\end{array}$

CROSS SECTION 23 SUBSECTION 2

$\begin{array}{rrrr}152.90 & 0.00 & 0.00 & 0.00 \\ 154.90 & 2.00 & 64.66 & 64.65 \\ 156.90 & 4.00 & 258.64 & 129.32 \\ 158.90 & 6.00 & 648.99 & 390.35 \\ 160.90 & 8.00 & 2051.19 & 924.15 \\ 162.90 & 10.00 & 3988.91 & 1013.57 \\ 164.90 & 12.00 & 6105.46 & 1102.98 \\ 166.90 & 14.00 & 8518.73 & 1312.67 \\ 168.90 & 16.00 & 11173.49 & 1337.00\end{array}$

CROSS SECTION 23 SUBSECTION 3

$\begin{array}{lrrr}154.21 & 0.00 & 0.00 & \\ 156.21 & 2.00 & 955.49 & 758.00 \\ 158.2 & 4.00 & 2514.88 & 801.23 \\ 160.21 & 6.00 & 4160.43 & 844.31 \\ 162.21 & 8.00 & 5892.12 & 887.38 \\ 164.21 & 10.00 & 7709.95 & 930.45 \\ 166.21 & 12.00 & 9613.93 & 973.53 \\ 168.21 & 14.00 & 11603.94 & 1014.56 \\ 170.21 & 16.00 & 13642.10 & 1024.24\end{array}$

The sequence of flows selected in the model as the upstream boundary condition was the average monthly discharge. A histogram of inflows into Imperial Reservoir for the period 1938-1943 is indicated in Fig. 5.13 .

The downstream boundary condition is a stage hydrograph obtained from the river cross sectioning at section No. 23, just above Imperial Dam. The variations of water elevations with time for the period in consideration are indicated in Fig. 5.14.

The inflowing sediment load was separated into four grain size classes: silt, fine sand, mean sand and coarse sand. Particle sizes for each class are shown in Table 5.5 .

Table 5.5 Grain Size Classes for the Inflowing Sediment Load

\begin{tabular}{lcll}
\hline Grain Class & $\begin{array}{c}\text { Size Fraction } \\
(\mathrm{mm})\end{array}$ & \multicolumn{1}{c}{$\begin{array}{c}\text { Geometric } \\
(\mathrm{mm})\end{array}$} & $\begin{array}{c}\text { Mean Size } \\
(\mathrm{ft})\end{array}$ \\
\hline Silt & $<0.0625$ & 0.0625 & 0.000205 \\
Fine Sand & $0.0625-0.25$ & 0.125 & 0.00041 \\
Mean Sand & $0.25-0.50$ & 0.35 & 0.0012 \\
Coarse Sand & $0.50-2.0$ & 1.0 & 0.0033 \\
\hline
\end{tabular}

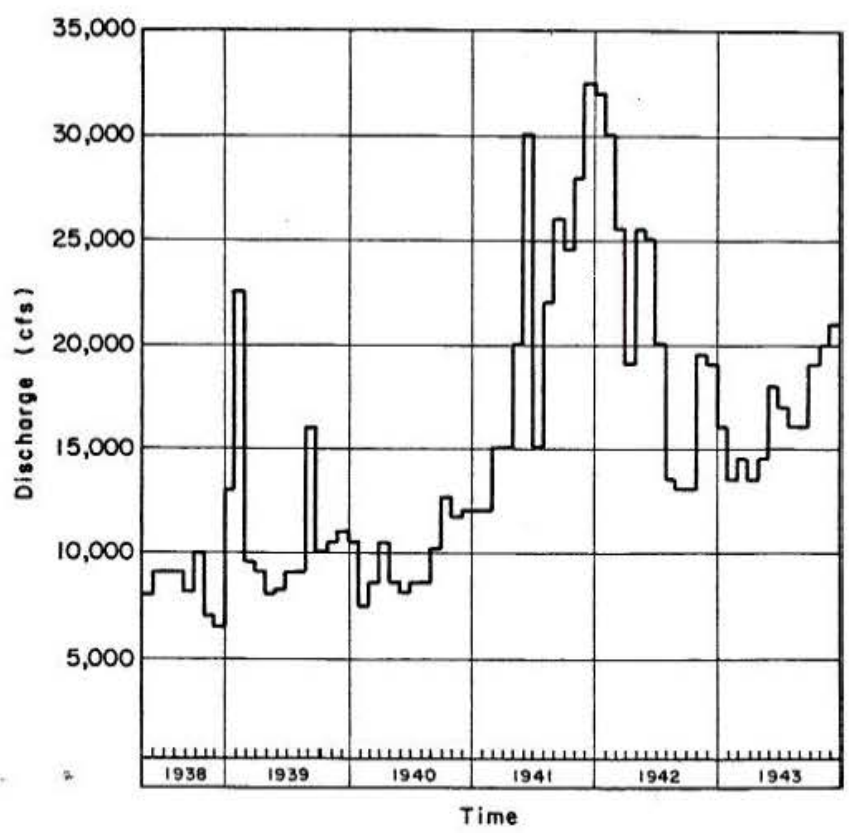

Fig. 5.13 - Average Monthly Discharge at Taylors Ferry Station for the Period 1938-1943

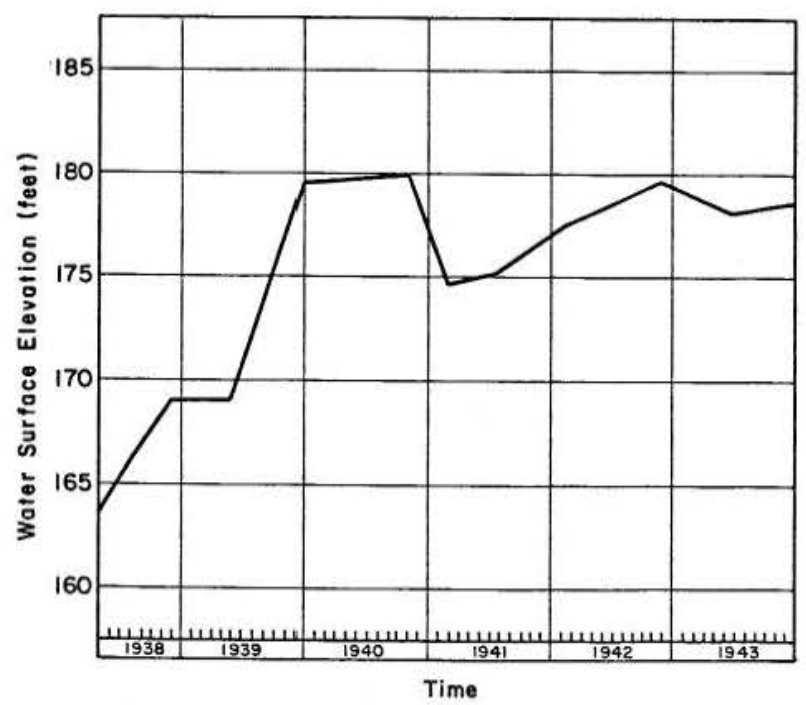

Fig. 5.14 - Stage Hydrograph at Imperial Dam for the Period 1938-1943

After examining the available sediment data in the last section, it can be seen that changes in size of the sediment material resulting from the upstream control works are taking place in the study river reach. When Hoover Dam and Parker Dam were closed, the suspended material from upstream sources was trapped in the reservoirs and the suspended material in the lower reaches consisted of recharge from the bed and banks. As the finer material was carried away, with no upstream source of replenishment, the sediment material carried by the stream became coarser until a new equilibrium condition was reached. This change in sediment size distribution could have had a significant impact on channel behavior and needs to be accounted for in the mathematical model if a realistic simulation is to be carried out. 
Bed sediment transport curves for the different fractions of the sediment material are shown in Fig. 5.15 for the Colorado River at Taylors Ferry. These curves represent the total sediment discharge and were obtained from suspended sediment samples taken on the river in 1939 and by applying the Modified Einstein Method as given by the computer program MODEIN2 (Ponce et al., 1976).

The term Q' represents the sediment load per fraction of bed material and is given by:

$$
Q_{s}^{\prime}=\frac{Q_{s}}{F_{b}}
$$

in which $Q_{S}$ is the sediment discharge in tons per day and $F_{b}$ is the class fraction of bed material.

At the beginning of the simulation period, the values for these fractions can be obtained from Fig. 5.11 as:

$$
\begin{aligned}
& F_{b_{1}}=0.02 \\
& F_{b_{2}}=0.78 \\
& F_{b_{3}}=0.18 \\
& F_{b_{4}}=0.02
\end{aligned}
$$

in which $F_{b_{1}}$ is the silt fraction of bed material; $\mathrm{F}_{\mathrm{b}_{2}}$ is the fine sand fraction of bed material; $\mathrm{F}_{\mathrm{b}_{3}}$ is the mean sand fraction; and $\mathrm{F}_{\mathrm{b}_{4}}$ is the coarse sand fraction of bed material.

Since the value of these fractions changes as sediment is being deposited in the reservoir, this formulation attempts to account for the change in bed material distribution with time and its effect on the sediment transport capability of the stream.

The data in Fig. 5.15 can be fitted roughly by power relations of the form:

$$
Q_{S}^{\prime}=m V^{n}
$$

that are straight lines on logarithmic papers.

Straight lines were fitted to the data of these figures in the range of velocities for which observed data were available. The coefficients and exponents for the four grain sizes are given in the following table.

Table 5.6. Parameters for the Sediment Transport Equations

\begin{tabular}{lrl}
\hline Grain Class & \multicolumn{1}{c}{$\mathrm{m}$} & $\mathrm{n}$ \\
\hline Silt & 2941.50 & 4.0 \\
F.S. & 150.86 & 4.0 \\
M.S. & 326.83 & 2.74 \\
C.S. & 1002.50 & 1.82 \\
\hline
\end{tabular}

The inflowing sediment load entering the upstream end of the model is determined also as a function of the mean velocity for the whole study period. The data in Fig. 5.16 is fitted by the following relationship:

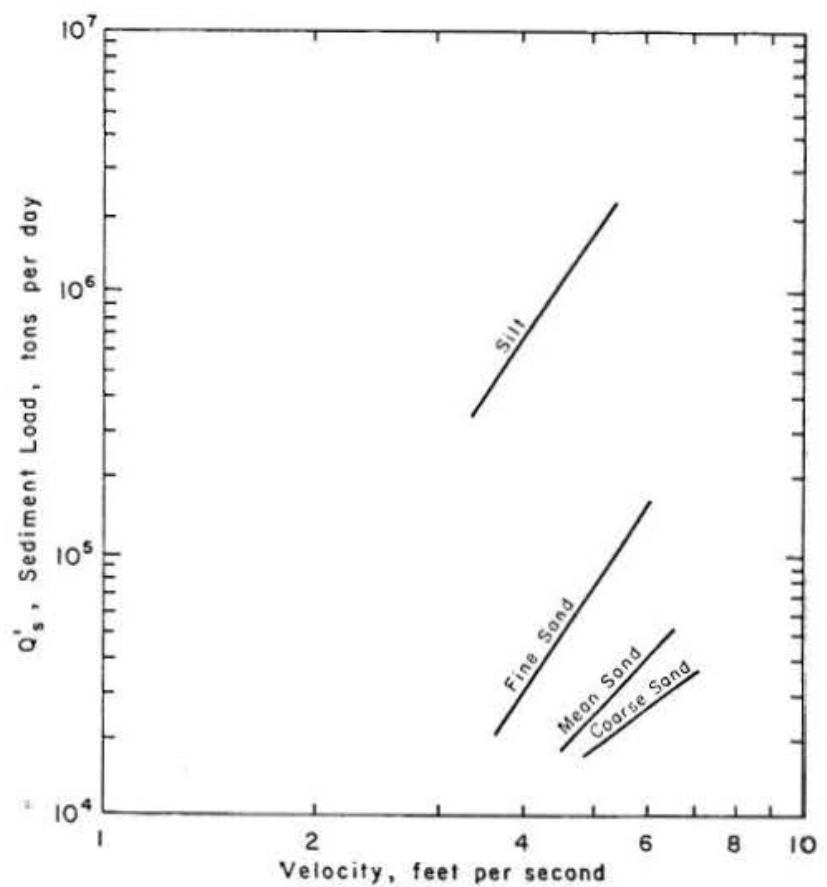

Fig. 5.15 - Sediment Transport Curves for Different Fractions of the Bed Material at Taylors Ferry

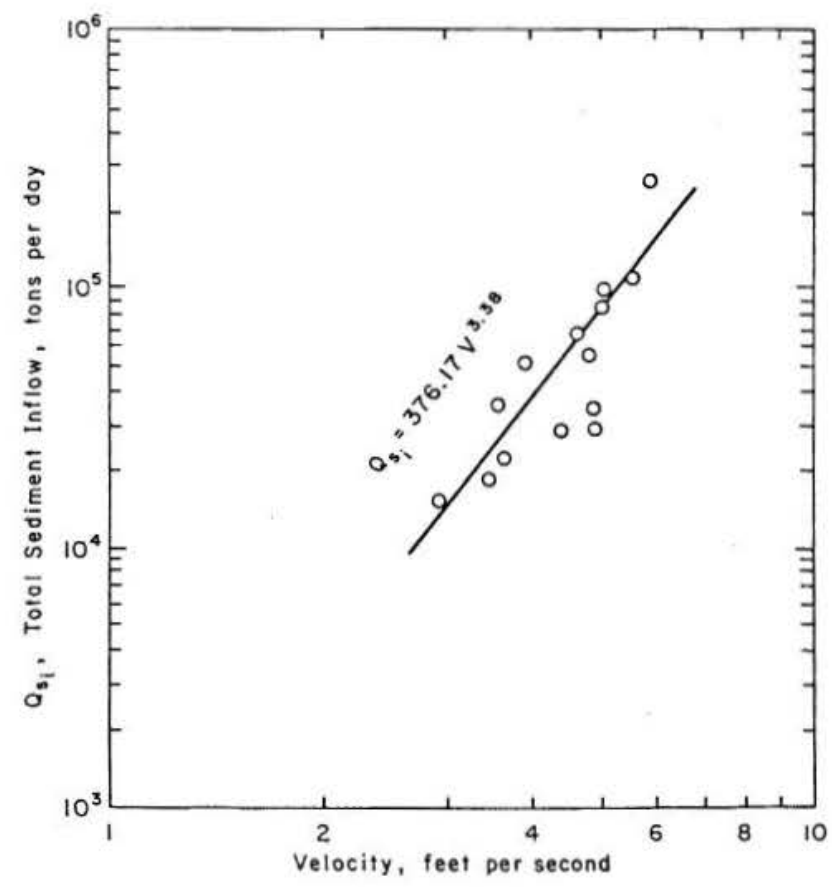

Fig. 5.16 - Total Sediment Inflow at Taylors Ferry as a Function of the Mean Velocity

$$
Q_{s_{i}}=376.16 v^{3.38}
$$

in which $Q_{s_{i}}$ represents the total inflowing sediment load at Taylors Ferry in tons per day.

Since the inflowing sediment is composed of a range of grain sizes and the size distribution is 
itself changing with time, the following factors were obtained from the application of the Modified Einstein Method for each individual fraction of sediment material: in which $\mathrm{F}_{\mathrm{s}_{1}}$ is the silt fraction of the inflowing sediment load; $\mathrm{F}_{\mathrm{S}_{2}}$ is the fine sand fraction; $\mathrm{F}_{\mathrm{S}_{3}}$ is the mean sand fraction and $\mathrm{F}_{\mathrm{S}_{4}}$ is the coarse sand fraction of the inflowing sediment load.

The inflowing sediment load per individual size fraction is then given by:

$$
Q_{s_{i_{n}}}=376.16 F_{s_{n}} v^{3.38} \text {, for } n=1,4
$$

Table 5.7. Factors for the Inflowing Sediment Load

\begin{tabular}{ccccc}
\hline & $F_{S_{1}}$ & $F_{S_{2}}$ & $F_{S_{3}}$ & $F_{S_{4}}$ \\
\hline 1939 & 0.31 & 0.62 & 0.06 & 0.01 \\
1942 & 0.22 & 0.60 & 0.12 & 0.06 \\
1945 & 0.15 & 0.47 & 0.23 & 0.15 \\
\hline
\end{tabular}

\subsubsection{Model Calibration}

The usual approach in calibrating a flow and sediment routing model is to select two points in time when channel geometry and water and bed elevations of a specific prototype are known. The information at the earlier point in time provides the initial conditions for the simulation period and the information at the second time act as a check. The goal of the model calibration is to simulate the response of the prototype by adjusting resistance coefficients and sediment parameters.

For the mathematical model described in this study, model calibration means the proper adjustment of the following parameters:

1. The Manning coefficients at all subsections in the system.

2. The value of the jet width constant at sections where jet corrections are required.

3. The sediment transport parameters $m$ and $n$ for each one of the sediment fractions.

Since the physical system is represented by 57 subsections, attempts to adjust all of the parameters at the same time becomes a difficult task. Thus, in order to overcome this difficulty, the calibration procedure is carried out in three steps.

Step 1--A fixed bed condition without sediment movement is used to adjust the Manning $n$ values by reconstituting observed water elevation variations at different sections along the river reach. Since these water elevations will undoubtedly be affected by the deposition of sediment at the head of the reservoir, they must be taken as a first estimation needing further adjustment after completion of Step 3.

Step 2--After Step 1 is completed, the sediment inflow is reteased and the sediment parameters $m$ and $\mathrm{n}$ in the sediment transport equations are adjusted by comparing the sediment deposition patterns with observed bed profiles.
Step 3--The distribution of sediment deposits at the different sections and subsections in the system is further adjusted by the proper selection of the jet width constant, "a".

Imperial Dam was closed in 1938 . Then the time period selected for the calibration of this model was 1938-1940. Before starting the computer simulation, one important aspect of the model calibration requires that the selection of the proper initial flow conditions be made. It means that initial estimations are needed for Manning's coefficients and water and bed elevations.

To establish the n-values, the Manning's equation is applied at the ends of the reach as:

$$
n=\frac{1.486 T h^{5 / 3} S_{0} 1 / 2}{Q}
$$

An average channel bed slope $S_{0}$ was computed based on the bed elevations of the river at Taylors Ferry and Imperial Dam:

$$
S_{0}=2.35 \times 10^{-4}
$$

An arbitrary flow distribution for $Q$ was assumed at the ends of the reach and initial estimations for the n-values were made. The Manning's roughness coefficients at the interior section were then obtained by linear interpolation.

With this information and average bed and water elevations obtained from the cross-sectioning measurements, a steady state case in a fixed bed model was run through the system in order to obtain a water surface profile for the dominant discharge of $Q=$ $10,000 \mathrm{cfs}$. A water surface profile at the dominant discharge computed by the Bureau of Reclamation in 1938 was used as a check point to obtain the proper initial conditions. After several runs for adjusting the model, an equilibrium profile was obtained and these conditions were recorded as the initial conditions prevailing in the river in 1938, at the beginning of the simulation period. Figure 5-17 shows the water surface profiles in the Colorado River between Taylors Ferry and Imperial Dam as computed by the Bureau and by the model, and Table 5.8 indicates the initial water and bed elevations for the different sections in the system.

An estimate of the time interval to be used in the computer model can be made, based on Fig. 4.5. The celerity of the bed wave is first obtained by using Equation (4.7.16) and the initial flow conditions existent at Taylors Ferry (computer section No. 1) at the beginning of the routing period:

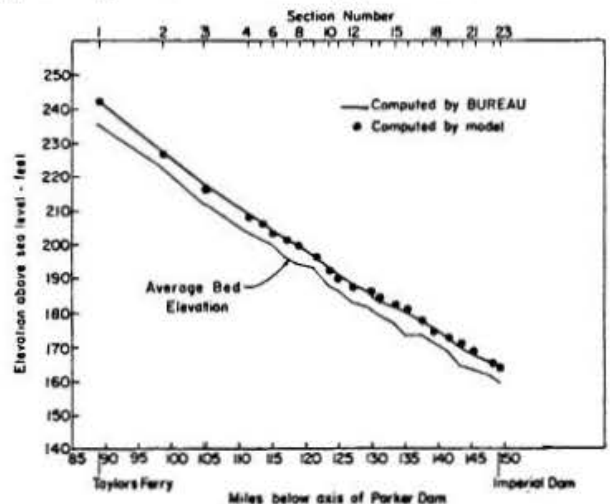

Fig. 5.17 - Water Surface Profile (1938) at the Dominant Discharge between Taylors Ferry and Imperial Dam 
Table 5.8. Initial Flow Conditions in the Colorado River between Taylors Ferry and Imperial Dam in 1938

\begin{tabular}{|c|c|c|c|c|}
\hline Section & Subsection & Manning's a & $\begin{array}{l}\text { Bed Elevation } \\
\text { (ft) }\end{array}$ & $\begin{array}{c}\text { Water Elevation } \\
\text { (ft) }\end{array}$ \\
\hline 1 & 2 & 0.016 & 237.50 & 242.03 \\
\hline 2 & 2 & 0.016 & 224.58 & 226.35 \\
\hline 3 & 2 & 0.016 & 212.94 & 215.68 \\
\hline 4 & 1 & 0.045 & 211.0 & 207.86 \\
\hline 4 & 2 & 0.016 & 204.78 & 201.86 \\
\hline 4 & 3 & 0.035 & 215.0 & 207.86 \\
\hline 5 & 1 & 0.040 & 210.0 & 205.93 \\
\hline 5 & 2 & 0.016 & 202.51 & 205.93 \\
\hline 5 & 3 & 0.040 & 208.0 & 205.93 \\
\hline 6 & 1 & 0.025 & 208.0 & 203.03 \\
\hline 6 & 2 & 0.016 & 199.06 & 203.03 \\
\hline 6 & 3 & 0.035 & 210.0 & 203.03 \\
\hline 7 & 1 & 0.018 & 208.0 & 201.22 \\
\hline 7 & 2 & 0.016 & 196.28 & 201,22 \\
\hline 7 & 3 & 0.018 & 208.0 & 201.22 \\
\hline a & 1 & 0.018 & 205.0 & 199.41 \\
\hline 8 & 2 & 0.016 & 193.33 & 199.41 \\
\hline 8 & 3 & 0.018 & 210.0 & 199.41 \\
\hline 9 & 1 & 0.018 & 205.0 & 195.74 \\
\hline 9 & 2 & 0.018 & 192.78 & 195.74 \\
\hline 9 & 3 & 0.018 & 204.0 & 195.74 \\
\hline 10 & 1 & 0.018 & 202.0 & 191.92 \\
\hline 10 & 2 & 0.018 & 187.49 & 191.92 \\
\hline 11 & 1 & 0.018 & 197.0 & 189.10 \\
\hline 11 & 2 & 0.018 & 187.95 & 189.10 \\
\hline 12 & 1 & 0.018 & 196.0 & 186.38 \\
\hline 12 & 2 & 0.018 & 182.61 & 186.38 \\
\hline 13 & 1 & 0.018 & 191.0 & 185.66 \\
\hline 13 & 2 & 0.018 & 182.00 & 185.66 \\
\hline 13 & 3 & 0.018 & 191.0 & 185.66 \\
\hline 14 & 1 & 0.026 & 185.00 & 183.83 \\
\hline 14 & 2 & 0.018 & 179.12 & 183.83 \\
\hline 14 & 3 & 0.030 & 190.0 & 183.83 \\
\hline 15 & 1 & 0.018 & 186.0 & 182.04 \\
\hline 15 & 2 & 0.018 & 177.10 & 182.04 \\
\hline 16 & 1 & 0.040 & 183.0 & 181.62 \\
\hline 16 & 2 & 0.018 & 173.93 & 181.62 \\
\hline 17 & 1 & 0.018 & 176.62 & 17.51 \\
\hline 17 & 2 & 0.018 & 174.76 & 177.51 \\
\hline 17 & 3 & 0.018 & 182.0 & 177.51 \\
\hline 18 & 1 & 0.045 & 173.12 & 173.55 \\
\hline 18 & 2 & 0.018 & 174.09 & 173.55 \\
\hline 18 & 3 & 0.045 & 175.79 & 173.55 \\
\hline 19 & 1 & 0.045 & 168.68 & 172.68 \\
\hline 19 & 2 & 0.022 & 168.66 & 172.68 \\
\hline 19 & 3 & 0.045 & 170.95 & 172.68 \\
\hline 20 & 1 & 0.040 & 166.94 & 171.78 \\
\hline 20 & 2 & 0.027 & 164.78 & 171.78 \\
\hline 20 & 3 & 0.045 & 167.04 & 171.78 \\
\hline 21 & 1 & 0.040 & $165.60 \quad$. & 169.38 \\
\hline 21 & 2 & 0.027 & 164.39 & 169.30 \\
\hline 21 & 3 & 0.040 & 161,83 & 169.39 \\
\hline 22 & 1 & 0.040 & 163.36 & 165.25 \\
\hline$n$ & 2 & 0.027 & 161.81 & 165.25 \\
\hline 23 & 1 & 0.040 & 156.43 & 164.10 \\
\hline 23 & 2 & 0.030 & 159.51 & 164.10 \\
\hline 23 & 3 & 0.040 & 157.59 & 164.10 \\
\hline
\end{tabular}

$$
C=2.33\left(\frac{n Q_{s}}{\gamma_{s}^{T y}}\right)^{0.96}=0.012 \mathrm{ft} / \mathrm{sec}
$$

in which

$$
\begin{aligned}
Q_{S} & =500.0 \mathrm{lb} / \mathrm{sec} \\
\gamma_{S} & =165.54 \mathrm{lb} / \mathrm{ft}^{3} \\
T & =500.0 \mathrm{ft}, \\
y & =6.0 \mathrm{ft}, \\
n & =4.0 .
\end{aligned}
$$

From Fig. 4.5 the critical value of $\Delta x / \Delta t$ is obtained directly as:

$$
\frac{\Delta x}{\Delta t}=0.022 \mathrm{ft} / \mathrm{sec}
$$

An estimate for the time step $\Delta t$ is then obtained by assuming an average space interval of $\Delta x=2$ miles. Thus,

$$
\Delta t=5 \text { days. }
$$

The topography of the Colorado River from Adobe Ruin to Imperial Dam requires an additional consideration as far as the application of the jet theory is concerned. The river in this reach is in a confined section being hemmed in on both sides by mountains. Some sections of the river are narrow as they are confined by the canyon walls while others are wider forming pools and lakes. Thus the ideal situation described in the model formulation of a river entering a wide basin is not present in this case. The jet theory is incorporated into the Colorado River model by comparing the theoretical jet width given by equation (3.2.2.5) with the cross-sectional top width at all sections along the river reach. Individual corrections for the jet effect at a section are then made if the top width is greater than the corresponding width of the expanding jet at that section. Otherwise, no jet corrections are needed. Since the cross-sectional area and top width of the river are a function of the stage, this procedure permits the change of hydrautic conditions to be incorporated into the application of the jet model. Thus, during high flows a river section may become wider making it necessary to apply corrections for jet effect, whereas, for low flows this correction may be unnecessary.

Two years of simulation were employed for calibration of the mathematical model. The observed water stages and the measured bed elevations in 1940 for the reach in consideration are compared to the generated water and bed profiles. After several runs were made it was realized that the sediment inflow entering at Taylors Ferry was not great enough to produce the expected changes in bed profiles. The inflowing sediment load was then increased by 30 percent and the computed results showed a better agreement with the observed data. The transport parameters in the sediment transport equation were also increased to accormodate the corresponding increase in sediment inflow.

The values obtained for the sediment parameters following calibration of the model are indicated in Table 5.9 where the value of the sediment load is given in pounds per second. The jet constant "a" turned out to be $a=1.40$.

By increasing the sediment load the rate of deposition was accelerated requiring a reduction in the time interval of the numerical scheme from 5 days to 2.5 days. Figure 5.18 indicates the agreement between computed and observed water surface profiles, and Fig. 5.19 shows the average bed elevations at different sections in the system.

Table 5.9. Sediment Parameters after Calibration of the Mathematical Model

\begin{tabular}{cccccc}
\hline & $\begin{array}{c}\text { Sediment } \\
\text { Inflow }\end{array}$ & $\begin{array}{c}\text { Silt } \\
\text { Fraction }\end{array}$ & $\begin{array}{c}\text { Fine Sand } \\
\text { Fraction }\end{array}$ & $\begin{array}{c}\text { Mean Sand } \\
\text { Fraction }\end{array}$ & $\begin{array}{c}\text { Coarse Sand } \\
\text { Fraction }\end{array}$ \\
\hline m & 15.0 & 200.0 & 5.50 & 13.0 & 150.0 \\
$\mathrm{n}$ & 3.38 & 4.0 & 4.0 & 2.74 & 1.48 \\
\hline
\end{tabular}

\subsubsection{Model Verification}

After calibration, the next step in the validation of the mathematical model is to check the calibrated parameters by using a different set of observed data. The same river reach in the Colorado River 


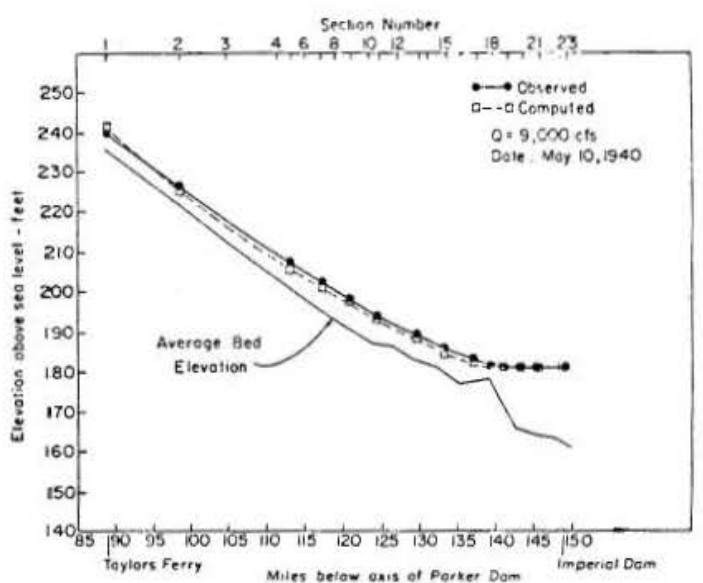

Fig. 5.18 - Water Surface Profile between Taylors Ferry and Imperial Dam in the Colorado River after Two Years of Simulation

between Taylors Ferry and Imperial Dam was used in the model verification. The period of time considered in this part of the analysis was 1940-1943.

The calculated water surface profiles in the reach under consideration are plotted and compared to the measured water surface elevations in Figs. 5.20 and 5.21 . The first figure corresponds to a mean flow discharge of $Q=13,000 \mathrm{cfs}$ whereas the second one corresponds to a high flow rate of $Q=32,000 \mathrm{cfs}$. Even though in both cases the mathematical model predicts lower stages than what was actually observed, the results can be considered to be within the margin of error acceptable for these cases.
Cross sections along the river reach are shown in Fig. 5.22. The 1938 initial conditions, the 1943 observed sections and the 1943 calculated sections are all shown. The dash line indicates the average bed elevation computed by the mathematical model. It is given by:

$$
\bar{z}=Y_{0}-\frac{A_{0}}{T_{0}}+\Sigma \Delta Z
$$

where $\bar{Z}$ is the average bed elevation at any time $t$; $Y_{0}, A_{0}$, and $T_{0}$ are the initial water elevation, flow area and top width at time $=0$; and $\Sigma \Delta Z$ is the accumulated change in bed elevation after $t$ years of sediment routing. Whereas the shape of the actual cross section changes between 1938 and 1943, horizontal lines indicating the mean value of the bed elevation describe the computed sections. The overall crosssectional changes are reasonably close to the observed sections. In some regions, as in sections 14,15 and 16 , smaller depositions of sediment on the main channel and greater depositions on the lateral channels were predicted by the mathematical model, but in general the extent and the distribution of the deposits seems to be in reasonable agreement with the observed data.

\subsubsection{Discussion of Results}

For the sections in the river farthest downstrean (see sections 22 and 23 in Fig. 5.22) the mathematical model seems to predict less deposition than what actually occurred in the reservoir. This difference between measured and computed deposition can be attributed to the fact that the mathematical model does not consider the effect of density currents on the sedimentation process. The finer material carried by the stream may not settle out as the velocity of the.

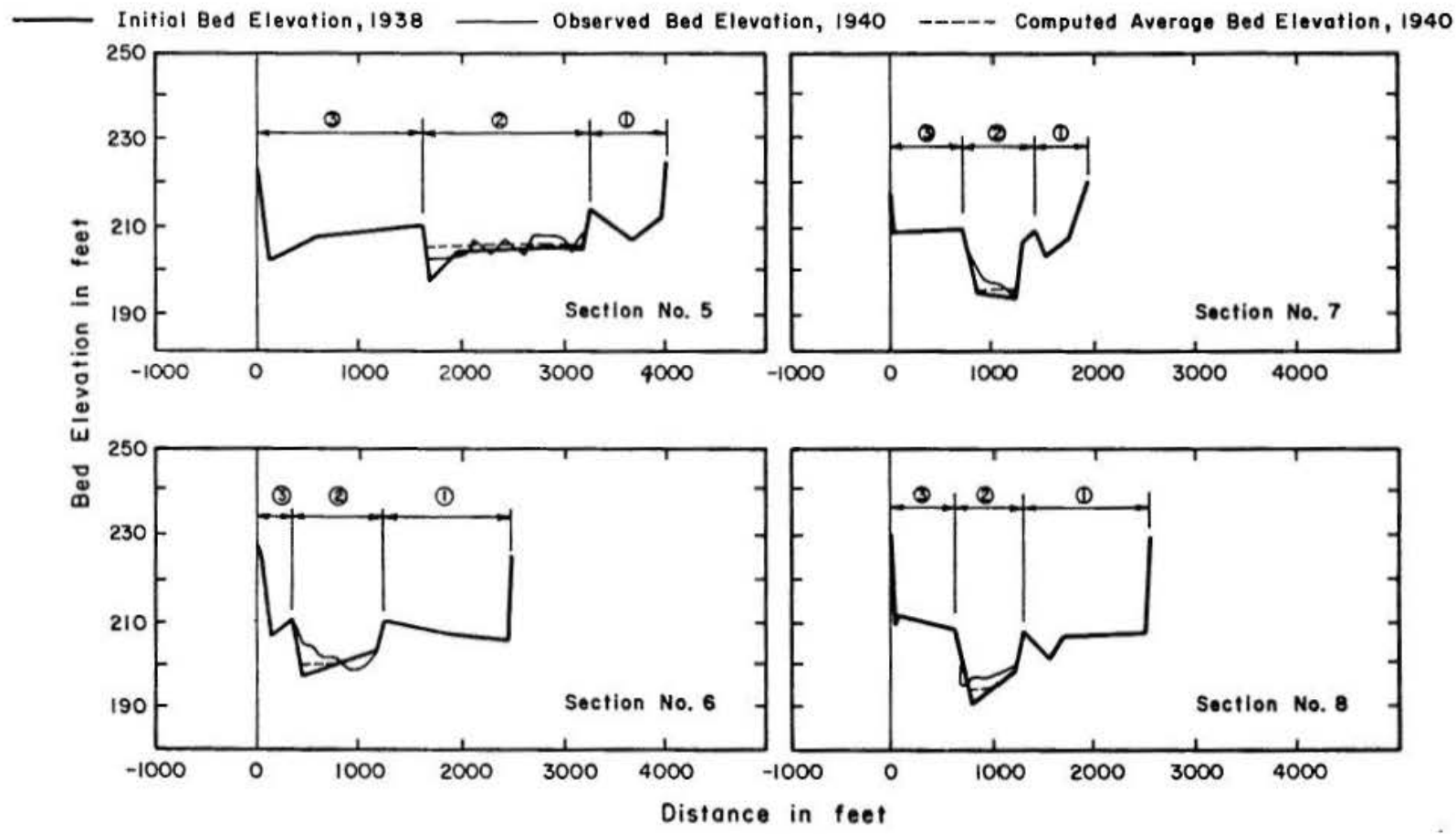

Fig. 5.19 - Cross Section Changes between Taylors Ferry and Imperial Dam in the Colorado River after Two Years of Simulation 


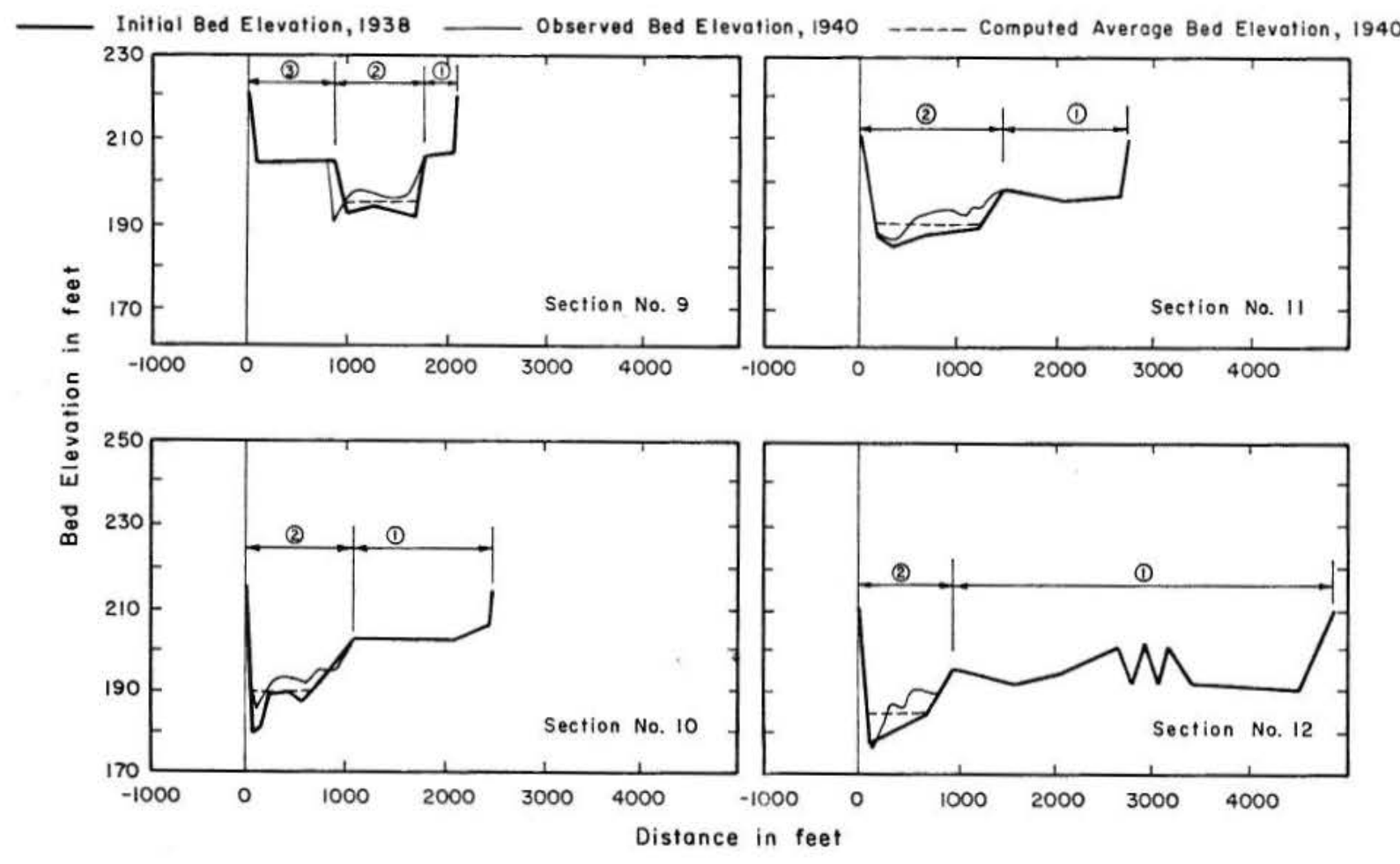

Fig. 5.19 (continued)

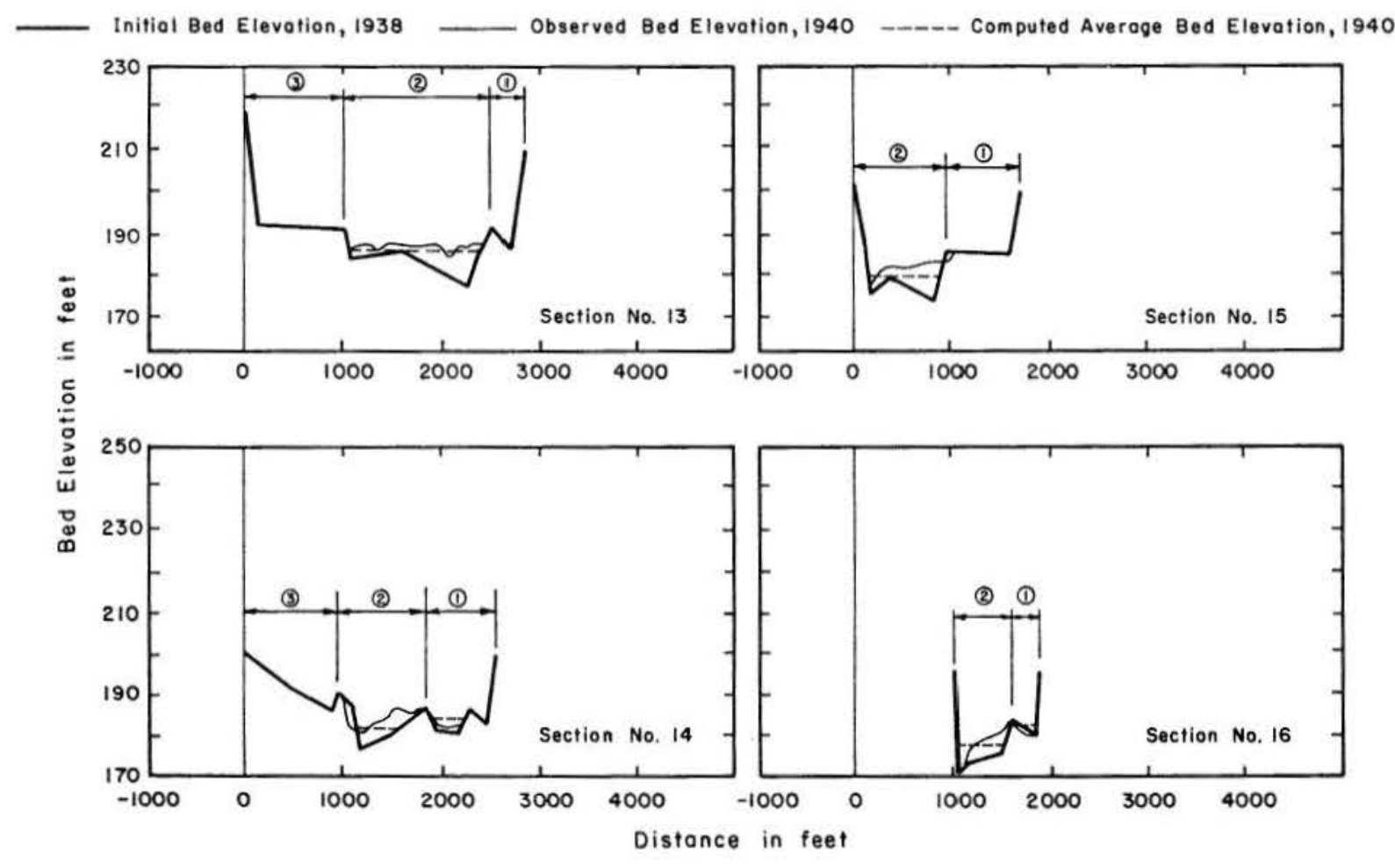

Fig. 5.19 (continued) 


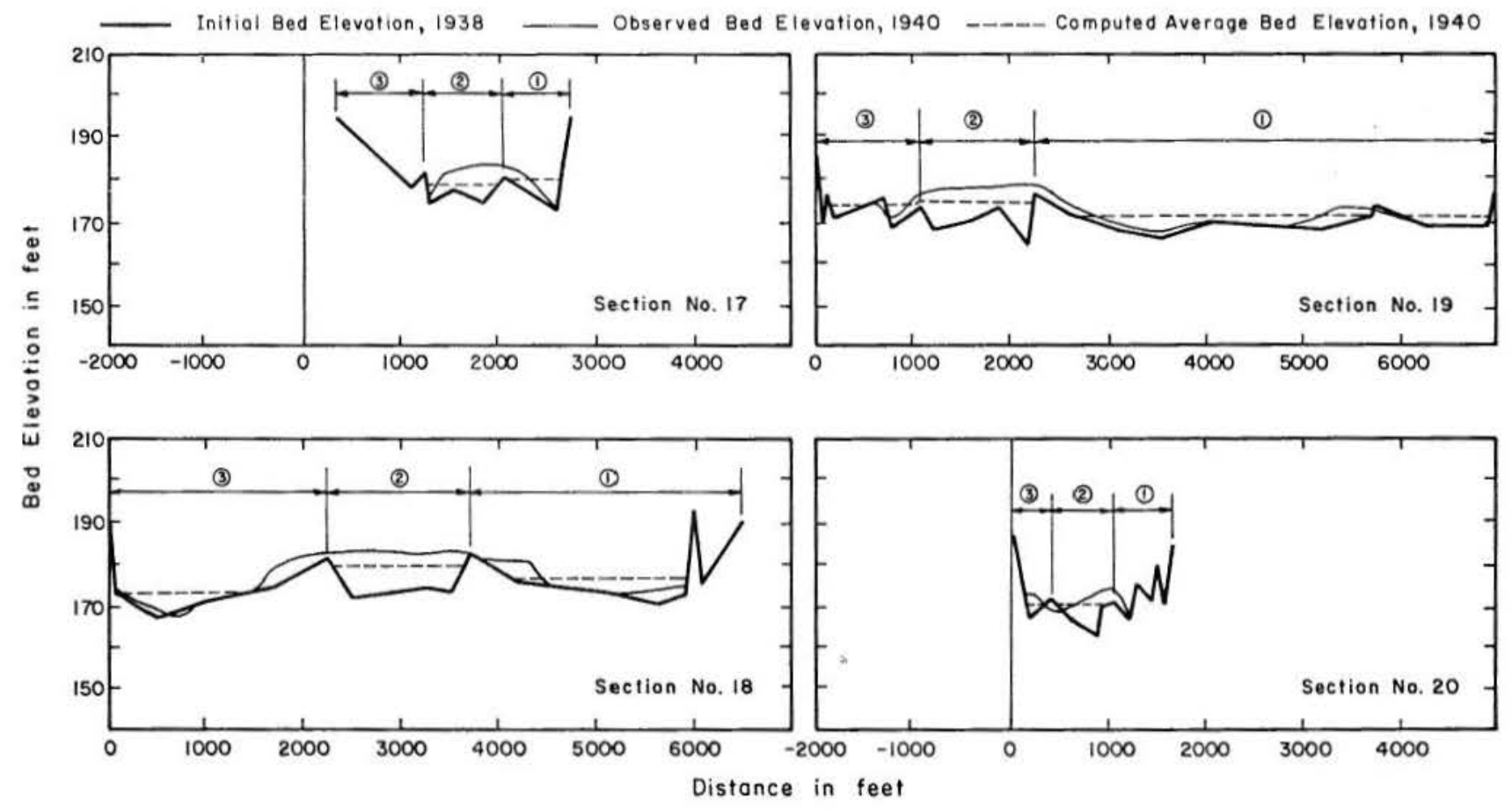

Fig. 5.19 (continued)

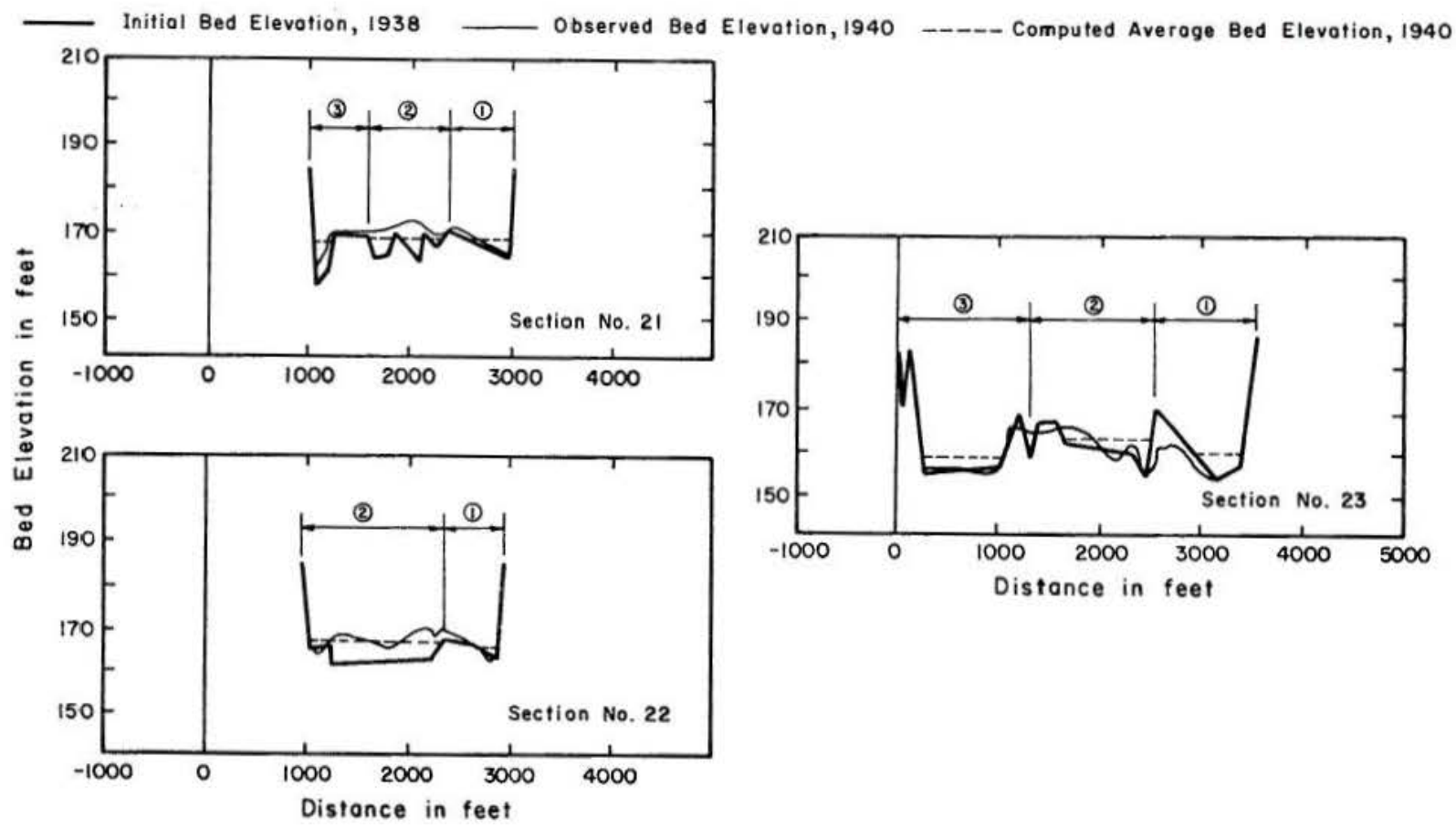

Fig. 5.19 (continued) 


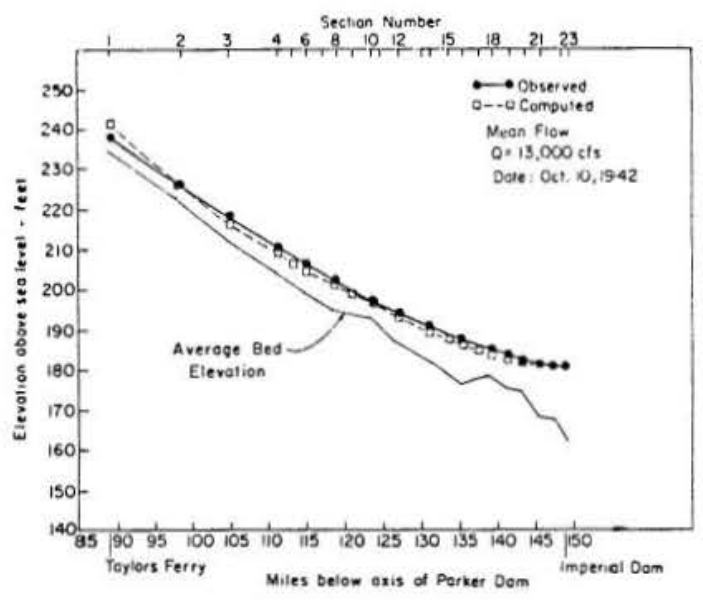

Fig. 5.20 - Water Surface Profile between Taylors Ferry and Imperial Dam in the Colorado River (Mean Flow Condition)

flow is decreased and, because of its difference in specific gravity with the clear water of the reservoir, a gravity underflow may result with the consequent motion of this material to the deepest part of the reservoir. There is no satisfactory explanation for the absence of sediment deposits in section 23, subsection 1, as indicated by the measured data. The computer model on the other hand predicts a deposition which amounts approximately to 10 feet. Perhaps this material was removed from the bed by dredging or by sluicing through the gates.

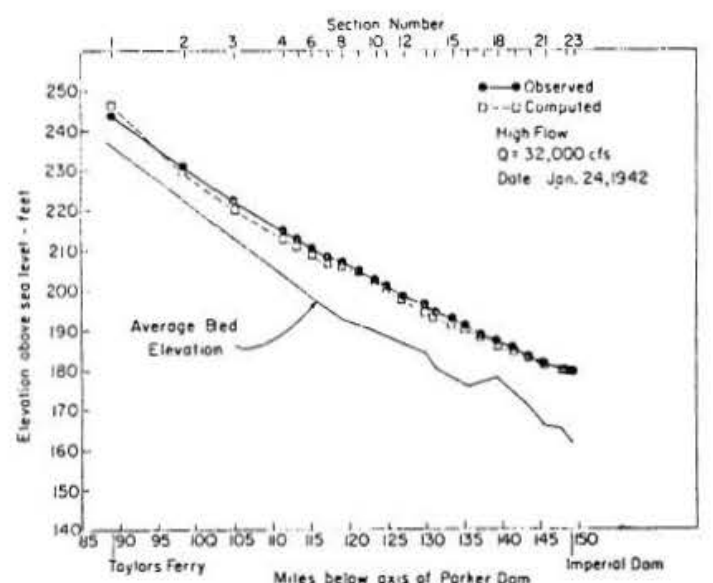

Fig. 5.21 - Nater Surface Profile between Taylors Ferry and Imperial Dam in the Colorado River (High Flow Condition)

The computer model is not only able to predict the volume of sediment deposition but also estimates the sedimentation rates for all sections in the system. Figure 5.23 indicates the longitudinal bed profiles on the main channel between Taylors Ferry and Imperial Dam as predicted by the mathematical model for the years 1940 and 1943. Degradation took place in sections 1 through 4 but it was so slight that it was not depicted in the figure. The reach of the river between section 5 and Imperial Dam constitutes the diversion pool and associated backwater areas

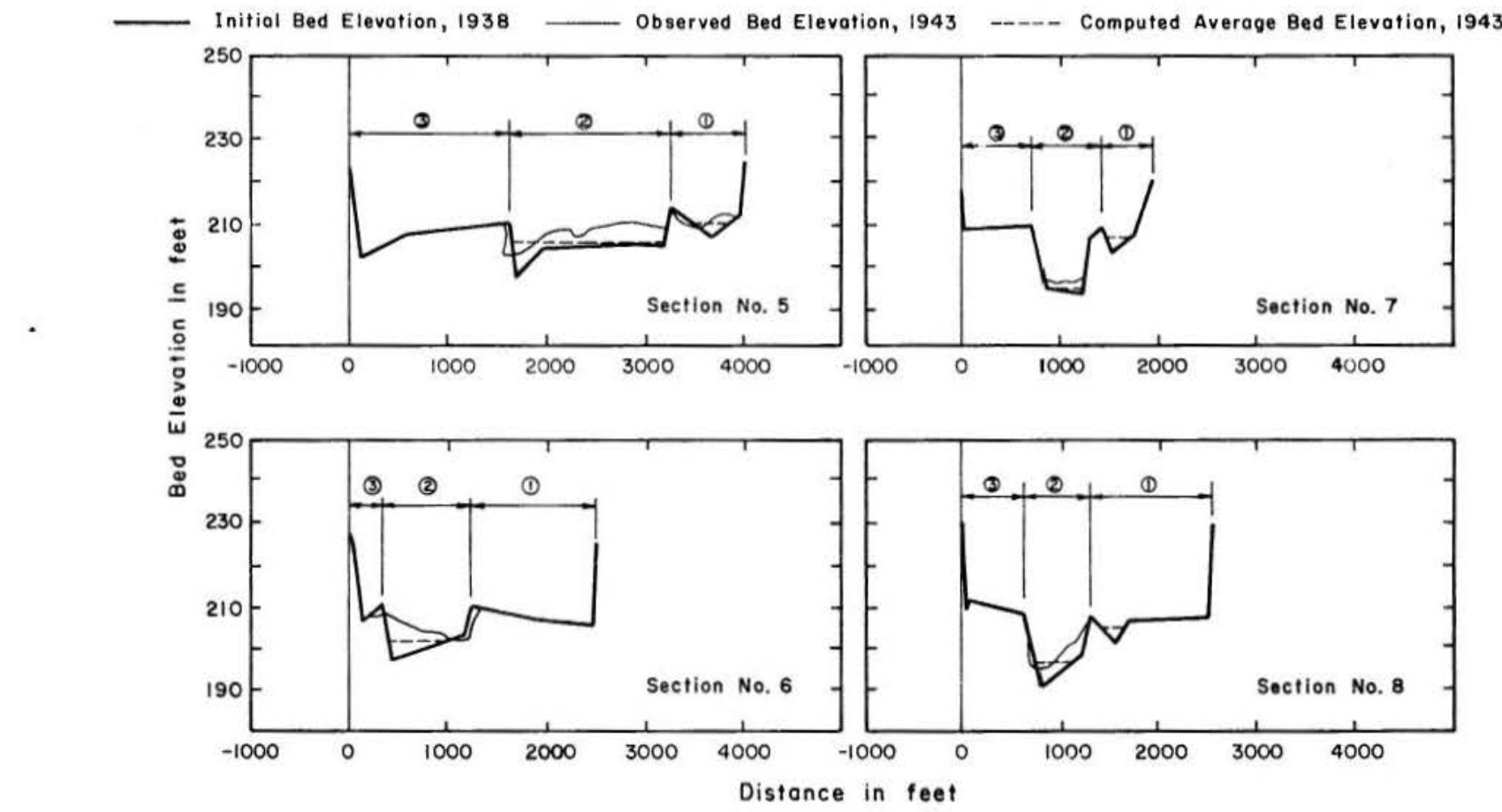

Fig. 5.22 - Cross Section Changes between Taylors Ferry and Imperial Dam in the Colorado River after Five Years of Simulation 


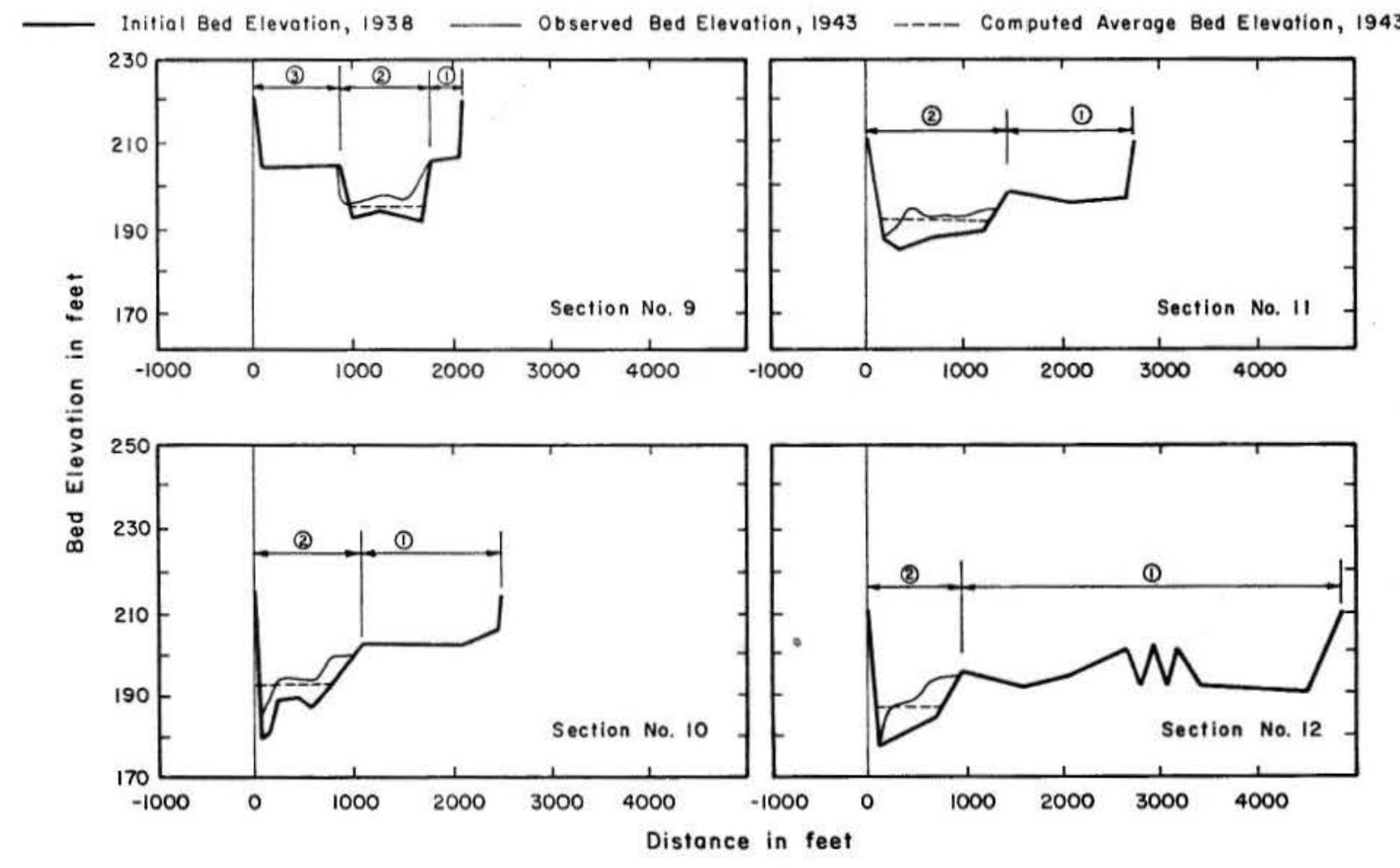

Fig. 5.22 (continued)

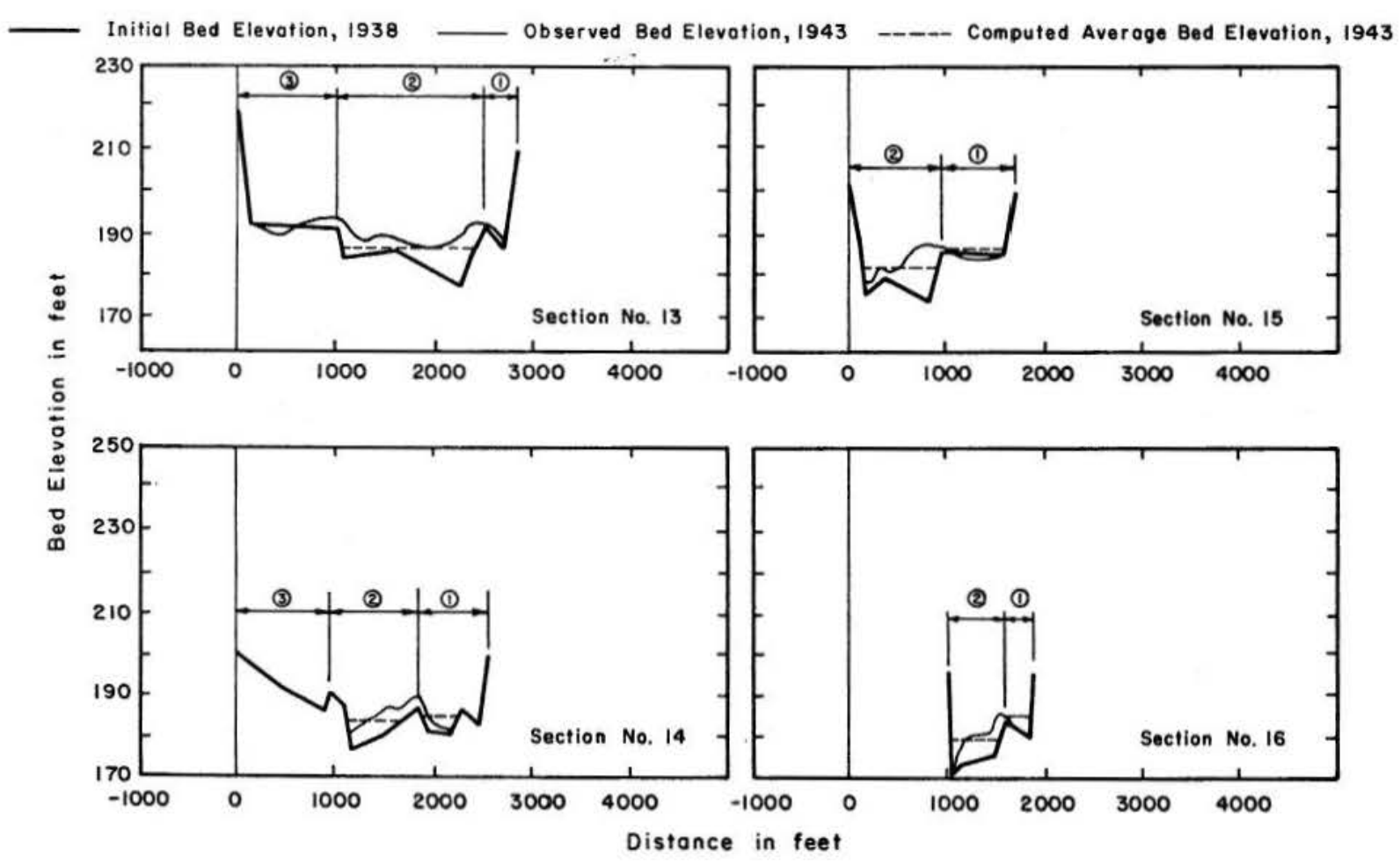

Fig. 5.22 (continued) 


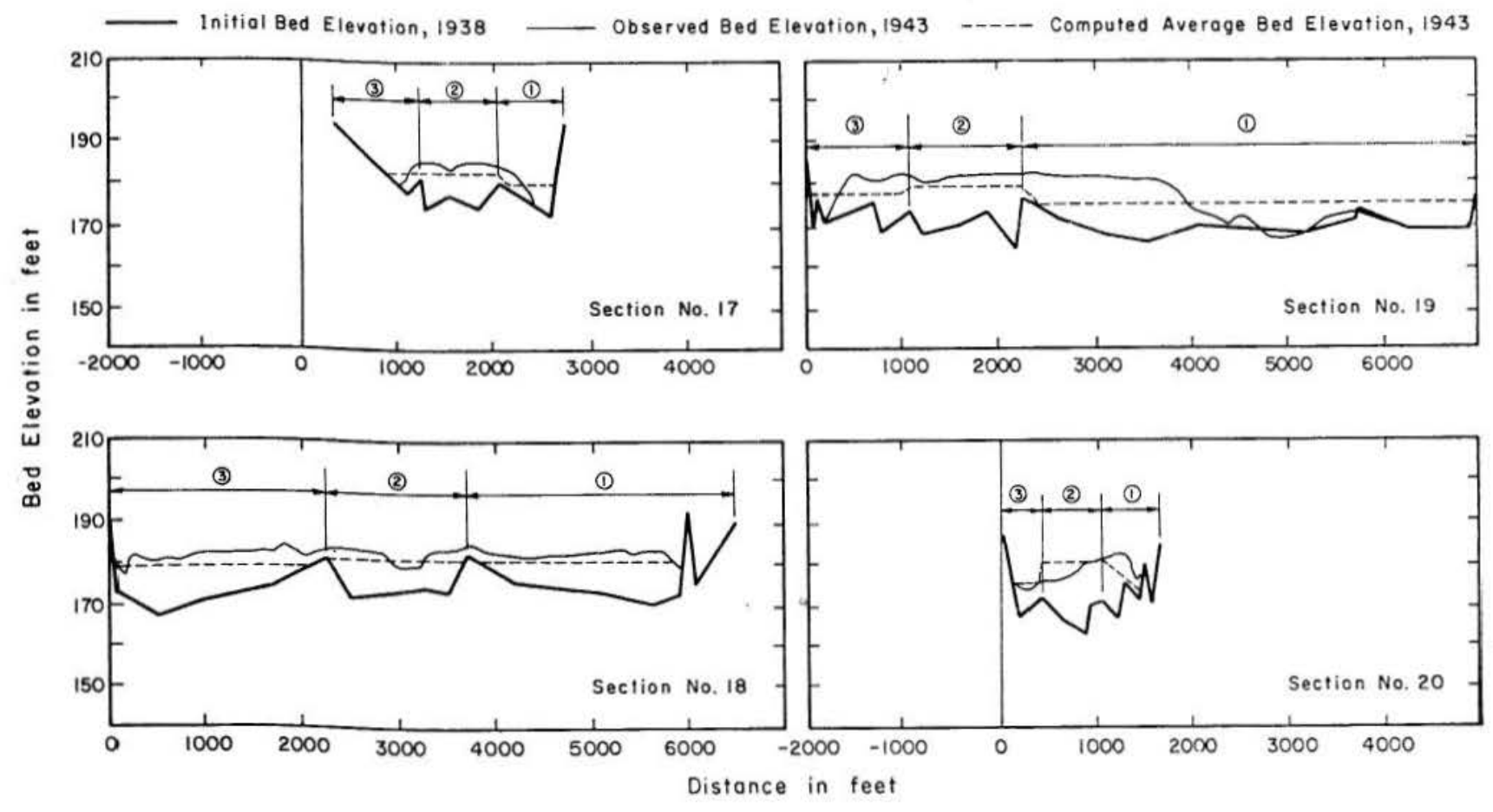

Fig. 5.22 (continued)
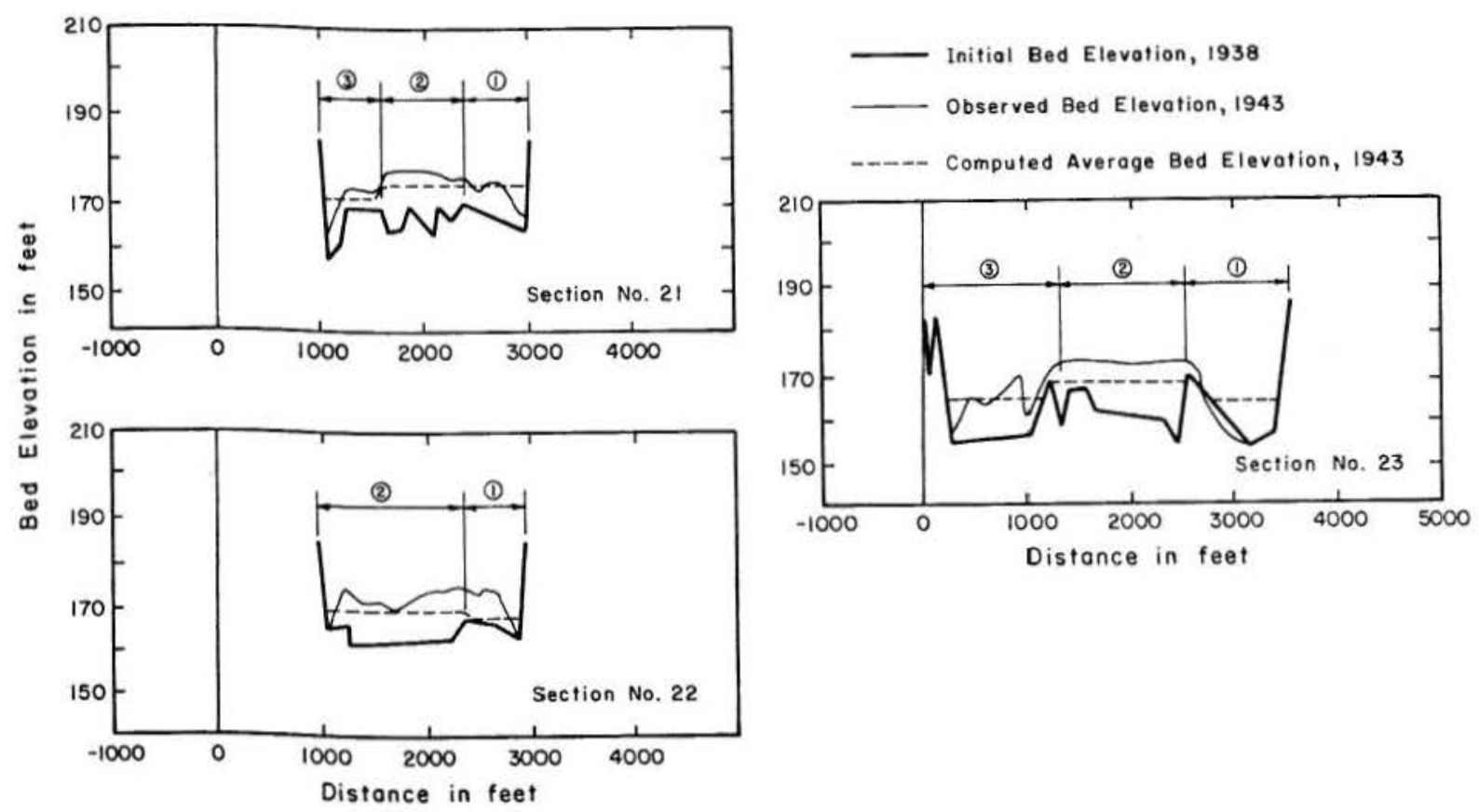

Fig. 5.22 (continued) 


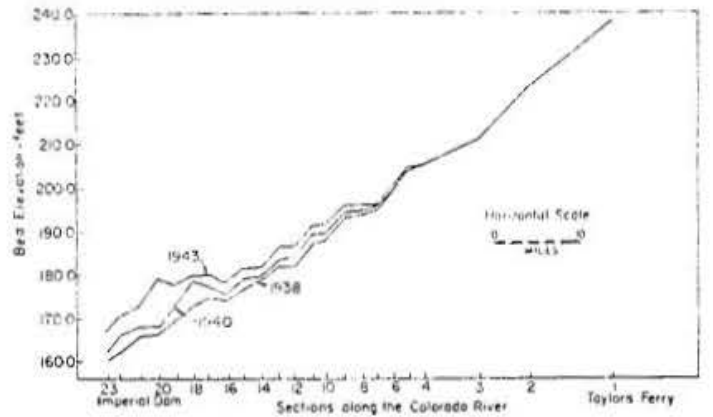

Fig. 5.23 - Computed Bed Profiles along Channel 2 in the Colorado River above Imperial Dam

of Imperial Dam. As can be seen in the figure, most of the incoming sediment is deposited within this reach.

To visualize, in more detail, the sediment deposition patterns in the reservoir, the bed profiles between sections 12 and 23 are shown in expanded scale in Fig. 5.24 for five different years. One year after the closure of the dam, aggradation above Imperial Dam was taking place in an orderly manner. Actually, because of a diversion dam (Laguna Dam) located six miles downstream of Imperial, the river in this reach was aggrading during the years previous to Imperial closure. The completion of Imperial Dam in 1938 continued aggradation at a more rapid rate throughout this reach.

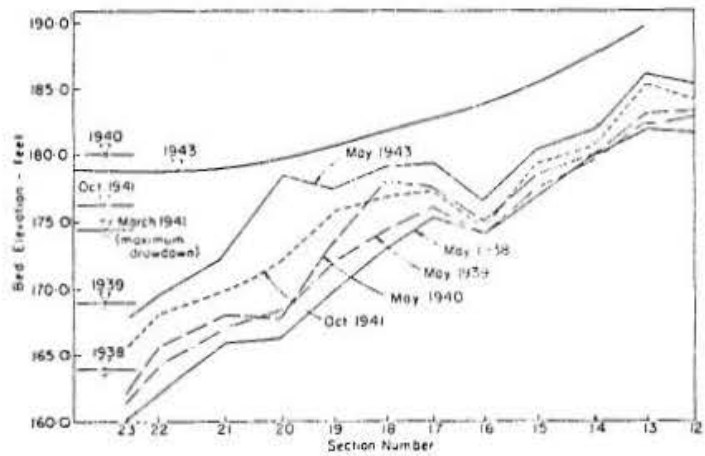

Fig. 5.24 - Computed Bed Profiles along the Colorado River above Imperial Dam

With the increase of water surface in the lake to an elevation of $180.0 \mathrm{ft}$, a delta began forming between sections 17 and 18 . This is indicated by the line corresponding to the 1940 bed condition. Lowering the water level in the lake by five feet produced a flattening of the delta and a subsequent motion downstream toward the dam. Actually the sediment deposition pattern indicated by the dash line, corresponding to the 1941 bed elevation condition, was produced by a combined effect of reservoir drawdown and high flow discharges. Sediment material was moved to deeper parts into the reservoir but also more sediment inflow came into the reservoir being deposited into the pool and backwater areas of Imperial Dam. The computed profile for the year 1943 indicates the final conditions prevailing in the system after the fiveyear simulation period were completed and the water level in the lake had been reestablished to its normal operating level of 179.50.

A close look at these bed profiles indicates that multiple delta fronts were developed in the system during the study period. The first delta was formed at the head of the reservoir and moved progressively down into the lake while the top-set beds were formed progressively upstream. The second delta was developed near the point of lowest drawdown, between sections 19 and 20, and after the normal water surface elevation in the reservoir was reestablished. A new delta front started developing at the head of the reservoir. Multiple delta formations are common in many irrigation and multipurpose reservoirs if they are subject to frequent seasonal drawdowns.

Figure 5.25 shows the sedimentation rates for some specific sections above Imperial Dam. It is possible to observe that, even though the general trend in the system is to build up the bed, alternate periods of aggradation and degradation were taking place in the river. A negative slope in this figure indicates that the bed was degrading, while a positive slope indicates aggradation. The explanation for this phenomena can be found by examining this figure in conjunction with the flow discharge hydrograph (Fig. 5.13) and the reservoir operating rules (Fig. 5.14). As a flood wave was passing through the system, the velocity of the flow was increased and the bed material was picked up and carried down to be deposited at a lower elevation. Then, in general, bed degradation took place when the flow discharge in the system was increased. On the other hand, in the recession part of the hydrograph the velocity of the flow was decreased causing a corresponding deposition of the sediment material.

With reference to sections 18 and 21 , it can be seen that initially the sedimentation rates seem to be greater on the lateral channels than on the main channel. In contrast to the behavior of the main channel, the lateral channels are subject to little degradation. This phenomena seems to be in agreement with field observations. When the water elevation is increased in the system, the flood water goes overbank from the main channel to the lateral channels, and the sediment material which is supported within the water goes with it. Since the flow velocity of this water mass is reduced significantly on the floodplain, it can no longer support the sediment load it is carrying in suspension and most of this sediment drops down on the floodplain. With the falling water stage, the water on the floodplain starts flowing back to the main channel. The small flow velocities on the floodplains can no longer transport the sediment back to the main channel and then the sediment, deposited previously by the flood, remains there.

The drawdown that occurred in the reservoir at the end of 1940 and the beginning of 1941 seems to have had no appreciable effect on the lateral channels (subsections 1 and 3 ). The slope of the line, which indicates the change in bed elevation per unit time, was slightly decreased during the years 1940 and 1941 but it remained approximately uniform during the rest of the period. On the contrary, the sedimentation rates in subsection 2 reflect the effect of the reservoir drawdown of this period. Degradation took place in the channel bed and the sediment deposits were moved farther downstream.

It can be said, in general, that the excess of sediment load carried by the stream during the high flows of 1941 was deposited mostly on the lateral 
channels and that the reservoir drawdown only affected the sediment deposits located on the main channel.

Lowering the water elevation in the lake suggests a method to control sediment deposition in the reservoir. The purpose would be to move the sediment from critical reaches into the deeper part of the pool
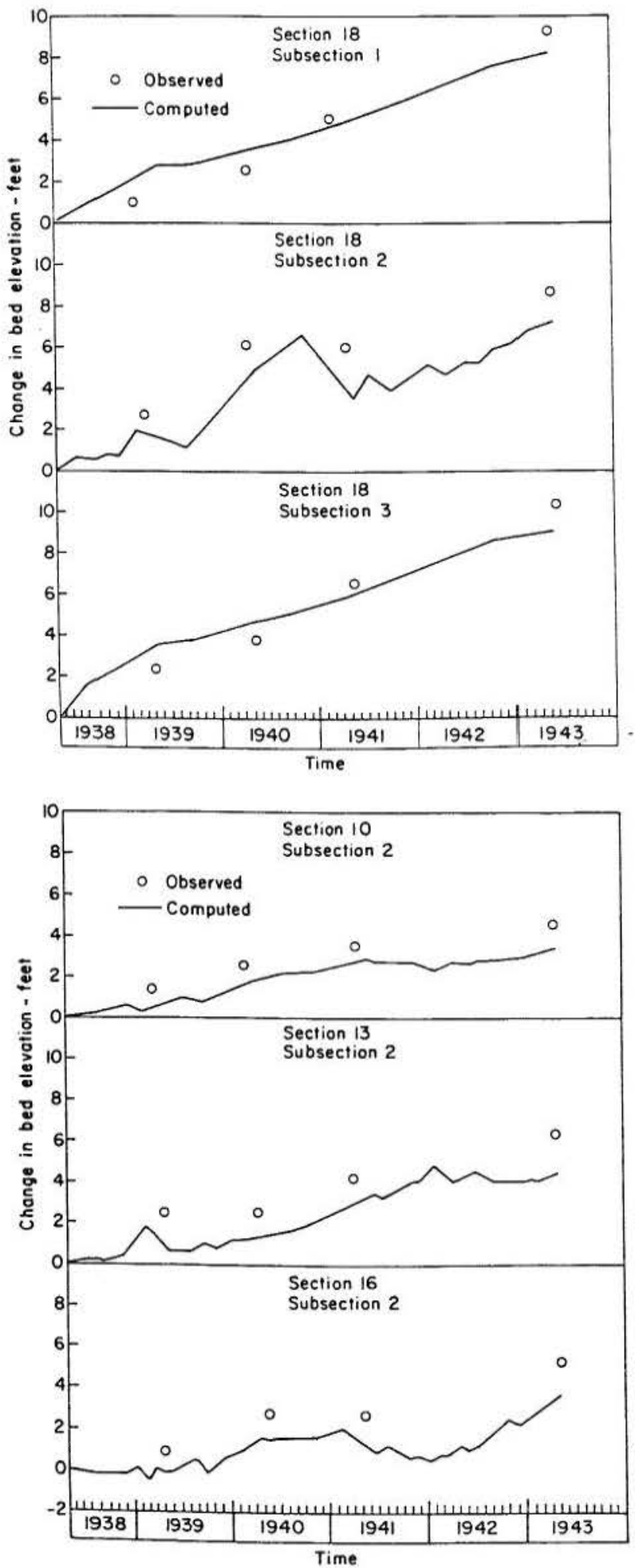

Fig. 5.25 - Sedimentation Rates along the Colorado River above Imperial Dam

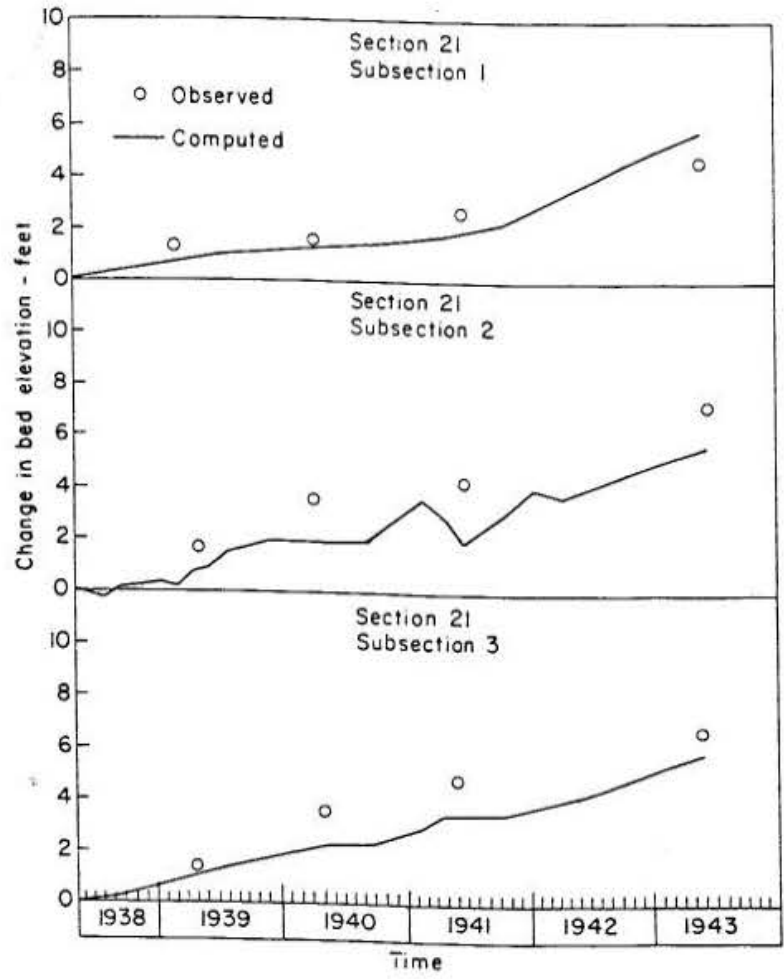

Fig. 5.25 (continued)

where maintenance dredging would not be necessary, or where the sediment could be sluiced down through the gates.

The distribution of sediment below the delta area depends to a great extent upon the size distribution characteristics of the sediment load. The changes in bed material size distribution with time for two sections in the river (sections 2 and 10) and three sections in the reservoir (sections 18, 22, and 23) are shown in Fig. 5.26. That the bed material is becoming coarser with time in the upstream sections, and finer in the downstream sections is easily realized by inspection of these charts. The median grain size of the bed material in section 2 was increased from $0.16 \mathrm{~mm}$ in 1938 to $0.2 \mathrm{~mm}$ in 1943 . This coarsening of the bed material at the upstream sections was caused mainly by an increase in the coarse fractions of the inflowing sediment load. An intermediate section in the reach, such as section 10, changed very little its composition of grain sizes.

Sections located near the reservoir, as sections 18 and 22, gradually increased the proportion of fine material in the bed. This is indicated by the shifting of the gradation curve towards the left side. The response of the system to the reservoir drawdown of 1940-1941 was to transport the finer parts of the sediment to a new location farther downstream. Then, even though the mean diameter is drastically reduced at these sections, there is a slight increase in size of bed material in 1943, compared to the conditions existent in 1941. For the lateral channels, a similar reduction in bed material size is observed. The median grain size of the deposition in section 23 , subsection 3 , after the five-year study was about $0.07 \mathrm{~mm}$. Of the entire amount of deposition, about 40 percent was in the silt sizes and 50 percent was in the range of fine sands. Subsections 1 and 2 in section 23 presented also similar changes. 

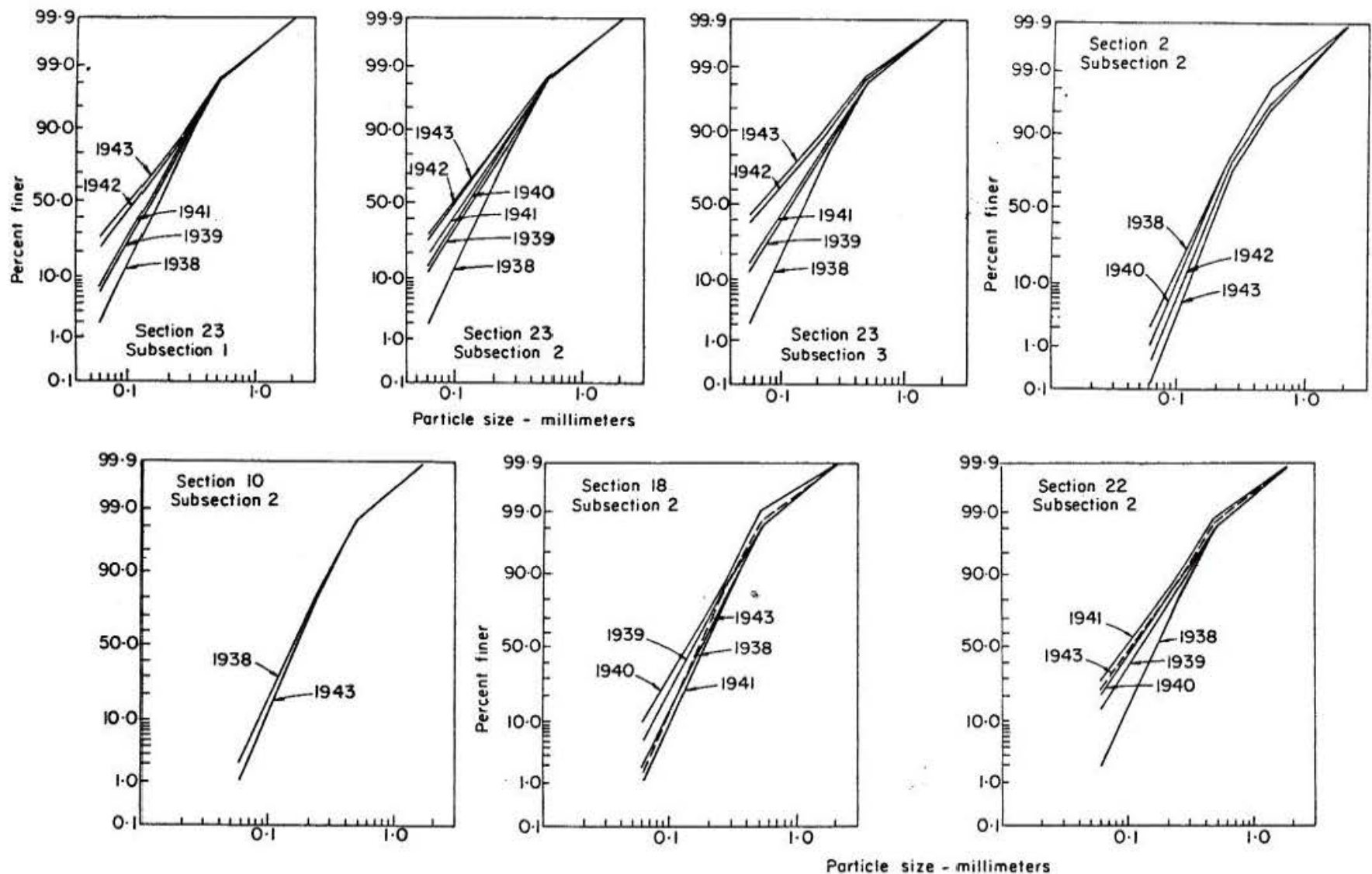

Fig. 5.26 - Computed Gradation Curves of Deposition for Different Sections in the Colorado River (Temporal Variation)

Figure 5.27 shows computed gradation curves for the deposits in different sections along the river and for three different times: 1938, 1940 and 1943. The 1938 grain size distribution corresponds to the initial condition imposed at all sections in the system. Again the same conclusions can be drawn regarding the fining of the bed. Figure 5.28 indicates the bed material gradation curve between Taylors Ferry and Imperial Dam after the five-year simulation period was completed.

The bed material gradation curves depicted in the last figures seem not to reproduce adequately the sorting of the coarser fractions. This was basically because the sediment continuity equation could not properly simulate the final deposition of the coarser sands. The coarser sands tend to deposit immediately upon the river entering the reservoir, but the mathematical model predicts that some fraction of this material is transported deep into the reservoir. This problem could be avoided by introducing into the analysis a critical motion condition in order to control the sediment deposition of the larger grains. This idea is proposed as a recommendation for improving the mathematical model and is discussed in more detail in the next chapter.

The initial specific weight of the sediment deposits was computed by the method developed by Lara and Pemberton (1963). The sediment was considered to be always submerged or nearly submerged during the whole study period and corrections for change in bed material size distribution were made at each time step. The computer results after five years of simulation showed a slight increase in the specific weight of the sediment deposit in the upstream sections from $96.46 \mathrm{lb} / \mathrm{ft}^{3}$ to $97.0 \mathrm{lb} / \mathrm{ft}^{3}$. For the most downstream sections the specific weight varied from $96.46 \mathrm{lb} / \mathrm{ft}^{3}$ to $89.93 \mathrm{ib} / \mathrm{ft}^{3}$. This is due to the accumulation of fine sands and silts which increased the proportion of fine materials while decreasing the proportion of coarser grains. Actually, the sediment which is deposited is subject to a certain amount of compaction and consolidation. No account was taken in the mathematical model for consolidation of the deposits with time. The model could be improved to take such phenomena into account by defining a rate of consolidation for each fractional sediment size.

The results obtained from the mathematical model can be used directly to estimate the trap efficiency of Imperial Dam. The computer simulation carried out for the study period gives information about sediment loads at all sections in the system. Under the assumption that the sediment arriving at the last section of the reservoir will pass through the gates and tunnels, a direct estimation of the reservoir trap efficiency can be made based on the differences between sediment outflows at Imperial and sediment inflows at Taylors Ferry. Figure 5.29 shows the trap efficiency of Imperial Dam as computed by the mathematical model for the period 1938-1943. The filling of the reservoir in 1938 is reflected by the rapid increase in the trap efficiency of the reservoir. The 1941 drawdown affected the trap efficiency by decreasing the capacity of the reservoir to arrest the sediment. The overall trap efficiency varied from 78 percent (for the highest inflow year) to 99.6 percent (for very low flow periods). 

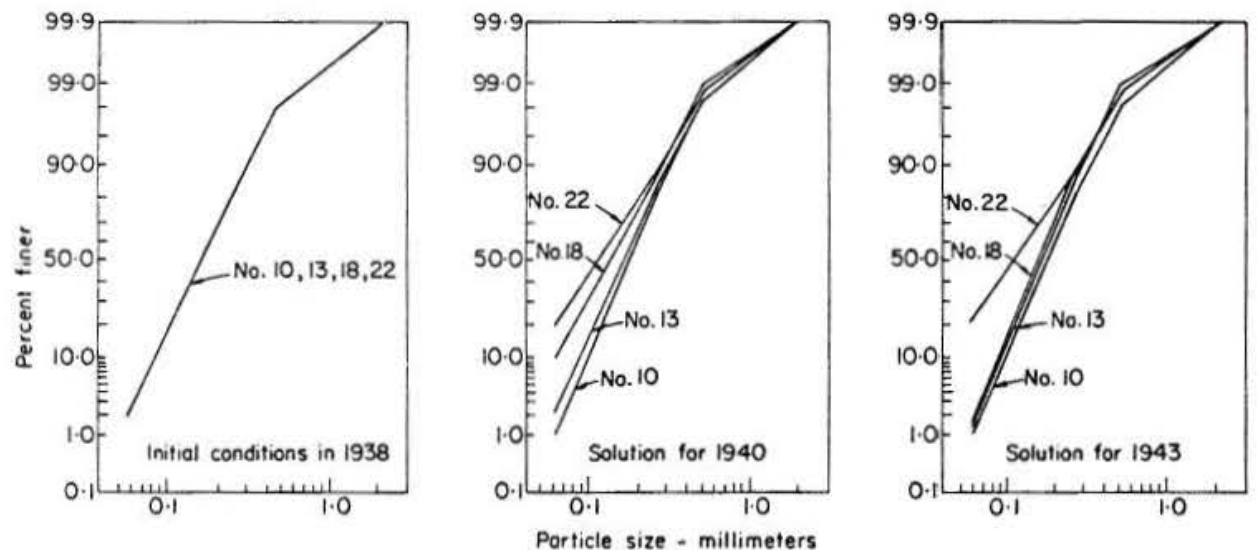

Fig. 5.27 - Computed Gradation Curves of Deposition for Different Sections in the Colorado River (Spatial Variation)

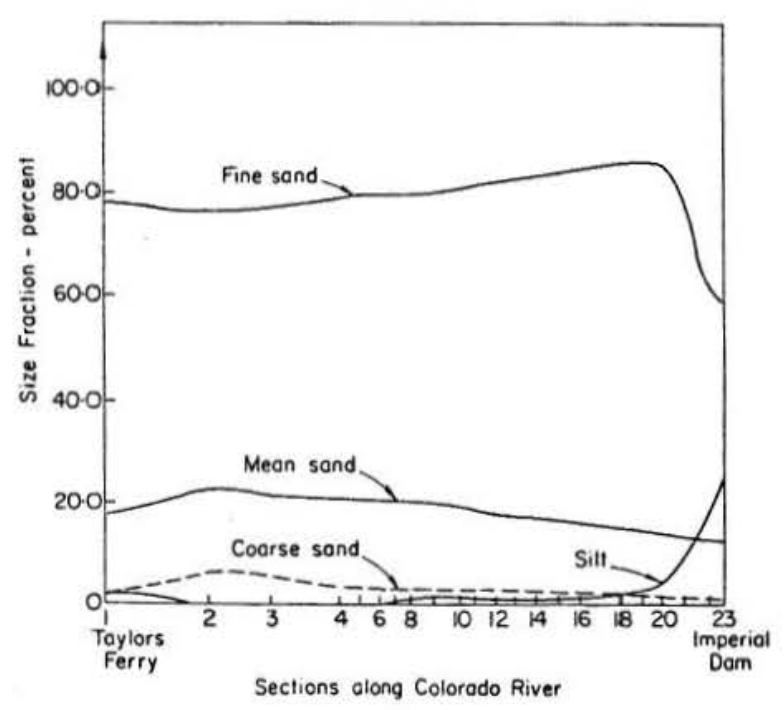

Fig. 5.28 - Computed Bed Material Gradation Curve in 1943

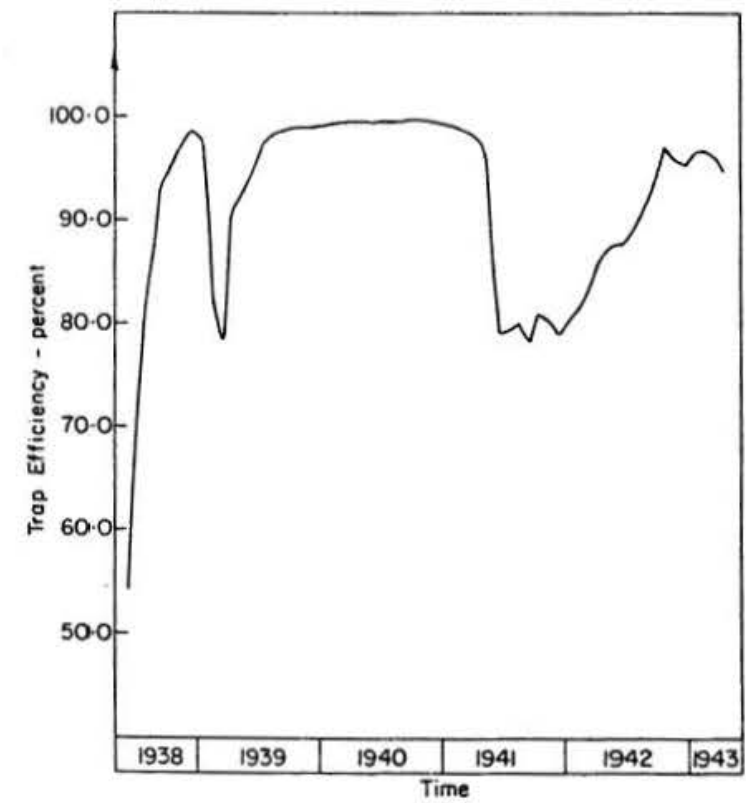

Fig. 5.29 - Trap Efficiency of Imperial Dam for the Period 1938-1943
Theoretically, no reservoir can have a trap efficiency of 100 percent until its capacity reaches an infinite quantity or the sediment inflow reaches zero. However in practice, if the water and sediment inflows are small enough so there will be no water or sediment losses over the spillway or through the outlets, the sediment may settle down and the trap efficiency may be considered to be 100 percent.

The data on trap efficiencies of reservoirs presented by Brune (1953) listed the Imperial Dam Reservoir as a "Normal Ponded Reservoir" with a trap efficiency of 90.2 percent for the period 1938-1942. This data seems to be in agreement with the overall trap efficiency computed by the mathematical model in this study.

In general, estimations of trap efficiencies in reservoirs is a problem which requires a careful study of all the factors affecting the process of sediment deposition for the particular case in consideration. It is clear that the specific conditions which apply to Imperial Reservoir do not apply to any other reservoir. During the study period 1938-1943, the Lower Colorado River was adjusting to a new regime brought about by construction and operation of new dams, reservoirs and diversion structures. The coarse nature of the sediment material and the manner in which the reservoir was operated are also two specific characteristics of this system. Under these circumstances, it is quite unlikely that capacity-inflow ratios or capacity-watershed ratios bear the same relationships to trap efficiency for Imperial Dam, as they would do for any other reservoir.

This study shows the rapid rate of deposition that occurred above Imperial Dam on the Colorado River. Five years after completion of the dam, sediment deposition was taking place for a distance over 40 miles upstream, even though the level pool above the dam originally extended only about 15 miles. The magnitude and rate of deposition would have been greater and extended farther upstream, if the flow of the river had not been regulated by Parker Dam, which also arrested the natural sediment load of the stream.

The mathematical model developed in this study provides a means for better and more accurate estimations of trap efficiencies in reservoirs. It can also be used to determine more precisely capacity curves and outlet elevations. Additional potential applications of the model include a) estimation of the useful life of the reservoir, b) evaluation of construction conditions and increased sediment load projections, c) determination of the response of the river upstream of the reservoir, and d) control of sediment aggradation through reservoir operation criteria. 


\section{Chapter 6 \\ SUMMARY AND CONCLUSIONS}

A flow and sediment routing mathematical model for reservoirs has been developed. A summary of the main findings and conclusions of this study are presented in this chapter.

\subsection{Summary and Discussion}

The main features of this study are summarized and discussed.

\section{Relating to the Mathematical Model Formulation}

1. A description of the flow phenomena of sediment deposition in reservoirs and related aspects is first given to help define the various assumptions required to efficiently model the physical process.

2. The mathematical model considers the riverreservoir system divided into three zones, differing in the hydraulic characteristics; a) the River, extending upstream from the mouth of the reservoir, comprising that part of the river which may be or may not be affected by the backwater effect; b) the Transition Zone, connecting the river-reservoir system in which the flow pattern may become markedly twodimensional; and c) the Reservoir extending downstream from the transition zone up to the dam.

3. Routing the flow of water and sediment through the river-reservoir system is carried out in a sequential mode. Initially the flow conditions are determined by assuming no sediment movement and secondly the backwater profile is assumed to remain unchanged during the calculations made for the sediment deposition.

4. For routing the flow through the riverreservoir system, the following approach is used: a) the flow in the river is considered to be onedimensional and the hydraulic characteristics are described only in the longitudinal direction of the flow, b) in the transition region, the flow phenomena is simulated by comparing the river to a twodimensional plane jet discharging into a fluid of the same density and c) a compound model approach is used to determine the flow characteristics in the reservoir. If the reservoir and the transition zone are divided into a set of subchannels, this approach allows for the determination of the flow distribution in the reservoir.

5. The formulation of the flow routing model is based on the numerical solution of the following equations: a) The Flow Continuity Equation, b) the Flow Momentum Equation, c) the Jet Equation, d) the Conveyance Equation and e) the Flow Resistance Equation.

6. The compound model approach is based on a modified form of the basic one-dimensional unsteady flow equations and thus avoids the use of the more complex two-dimensional flow equations. The main difficulties associated with the application of twodimensional models to study river problems are due to their very complex formulation and the excessive computer time required in their operations. Since the sedimentation phenomena in the reservoir is a very slow process, the use of two-dimensional models to study long-term responses in the reservoir is not feasible at the present time. On the other hand, the compound model is less complex in the formulation and does not require extensive computational effort. However, the compound model developed here must be further modified to better account for the lateral transfer of momentum between subsections.

7. The formulation of the sediment routing model is based on the following equations: a) the Sediment Continuity Equation and b) the equation for the lateral transfer of sediment. The solution for the sediment routing is obtained by applying these two equations to each individual subchannel in the discretized river-reservoir system. In this way the bed elevation changes are determined in the longitudinal and transversal direction of the flow.

8. The nonuniform grain size distribution is treated by carrying out the sediment routing for different fractions of the bed material. Variation in bed elevations are then obtained by superimposing the results obtained for each sediment fraction. In this way the larger sediment sizes are allowed to deposit before the smaller ones. Thus, the sorting process and its effect on the delta formation can be investigated.

9. A method of taking into account the grain size distribution of bed material is described. Sediment size fractions present on the bed are computed by assuming that sediment deposition takes place in parallel layers. This in turn allows for the correction of the specific weight of the sediment deposits at each time step.

10. The sediment transport function is given in terms of a power function of the mean flow velocity and the size fraction of bed material. This formulation attempts to account for the effect of sediment sorting on the transport capability of the stream.

11. Under the assumptions of parabolic jet boundary, triangular velocity distribution and no flow entrainment, a jet theory is developed to determine the flow field in wide reservoirs. Despite the simplicity of the jet model, it is observed that the predicted behavior of the delta is in good judgement. with laboratory and field observations.

\section{Relating to the Numerical Analysis and Computer Model}

1. The numerical solution of the flow routing model is developed by using the fully implicit scheme $(\theta=1.0)$ of finite differences with discretization intervals in space and time. For sediment routing purposes, an explicit scheme of finite differences is used. This scheme uses a four-point solution to approximate any function $f(x, t)$ and its derivative $\partial f / \partial x$, whereas, in order to improve the stability of the scheme, a two-point solution is used to approximate the time derivative af/at.

2. There is no existing theory for analyzing the stability and convergence of numerical schemes for nonlinear partial differential equations. The experience of some authors indicates that the system of linearized partial differential equations can be assessed in terms of stability and convergence by using the small perturbation analys is technique. The main findings of several authors are described and discussed in this study. The range of applicability of the numerical scheme used herein is obtained by numerical experiments and thus a proper value of 
$\Delta x / \Delta t$ is selected in order to insure the stability of the scheme.

3. Three boundary conditions are needed in the numerical model, two for the water and one for the sediment. The upstream boundary conditions can be a stage or discharge hydrograph and a sediment hydrograph. At the downstream boundary, the reservoir operating rules or a rating curve can be utilized.

4. The main output from the computer model includes water surface elevations, water and sediment discharges, bed elevations and gradation of bed material at all sections and subsections in the riverreservoir system and at each time interval in the routing period.

5. The time and space intervals for the numerical model must be carefully selected since they can significantly affect the numerical results. If the space increment $\Delta x$ is fixed for topographic or geometric reasons, an estimation of the maximum value of $\Delta t$ to be used in the routing calculations can be made based on the procedure explained in section 4.7.

6. The simulation is restricted to the cases in which the changes in the flow variables are small enough so that the linearization of the governing equations is valid.

7. The time intervals should be selected small enough so that changes in bed elevation due to scour or deposition during that time interval do not significantly influence the flow conditions and the sediment transport capacity by the end of the time interval. This problem arises from the sequential mode of solving the governing equations (uncoupled solution) because the transport capacity is calculated for the bed elevation at the beginning of the time interval and it is not recalculated during that interval.

\section{Relating to the Flume Study}

1. To test the feasibility of the model an experiment was conducted in a laboratory flume. The computed bed profiles show a reasonably good agreement with the measured bed profiles. The results suggest that the model is capable of simulating the formation of levees and mouth bars which are shown to occur in nature.

2. The flume study shows the importance of considering the jet effect when studying the sediment deposition patterns of wide basins. Different delta patterns are obtained for different values of the jet coefficient "a". By reducing the lateral extent of the jet boundary, i.e., decreasing the coefficient "a", more flow is concentrated into the main channel and the delta is forced to move downstream. The best results are obtained when the value of the jet coefficient is $a=0.30$.

\section{Relating to the Colorado River Study}

1. By incorporating seasonal variations in the flow of water and sediment the model can be applied to study long-term responses in the river-reservoir system and can be used as a predictive tool for reservoir sedimentation.

2. Validation of the mathematical madel for real data is accomplished by studying the bed aggradation upstream from Imperial Dam in the Colorado River. This is carried out in two steps: a) model calibration, in which the resistance functions and sediment parameters are adjusted in order to reproduce a set of observed data and, b) model verification, in which the calibrated parameters are checked by reconstituting an independent event or period of record. The period 1938-1940 was selected for the model calibration and the period 1940-1943 for the model verification.

3. The validation of the mathematical model using the observed field data required a great amount of time and effort. Many computer runs were needed for the proper calibration of the unknown parameters in the mathematical model. Two main difficulties encountered during the calibration of the mathematical model are briefly discussed: (1) The simultaneous application of the jet and compound models to a particular section may create instability problems in the computational procedure. This occurs because the flow distribution at a computational section, depending on the flow conditions, may be computed based on the jet model or the compound model. The change in one time step from one set of calculations (jet model) to another set (compound model) may cause too rapid variations in the flow and sediment characteristics and may induce the instability of the numerical scheme. This problem can be solved by the proper adjustment of resistance coefficients and jet parameters in order to avoid discontinuities in the solution methods. (2) The sediment transport equations are very sensitive to the gradation of the bed material. If the size distribution of bed material changes rapidly, a corresponding change in sediment material transported by the stream takes place, and excessive areas of erosion or deposition may occur in the channel bed. Consequently, the parameters in the sediment transport formulation must be carefully selected so that smooth changes take place in the river reach in consideration. The same recommendation can be made in relation to the selection of the Manning coefficients.

4. Computer results from the mathematical model compares well with observed data. Thus, it is believed that the model described in this study can predict with reasonable accuracy the location, extent and gradation of the sediment deposits.

5. The use of the mathematical model permits better estimations for trap efficiencies, capacity curves and outlet elevations.

\subsection{Conclusions}

A summary of the main conclusions of the study follows:

1. A mathematical model for flow and sediment routing applicable for reservoir sedimentation study has been developed. The model incorporates a jet theory to a compound stream model to predict the extent and location of the sediment deposition in the longitudinal and transversal flow directions of the reservoir.

2. The shape and movement of the delta formation are shown to be in close agreement with laboratory and field observations. The study shows that the transitional zone connecting the river-reservoir system must be properly accounted for when studying the sediment deposition patterns of wide basins. The jet theory which simulates the incoming river flow as a two-dimensional plane jet is shown to properly describe the delta formation pattern at this zone.

3. Nonuniform grain size distribution is considered in the mathematical model by routing the 
sediment flow for different fractions of the bed material. Application of the model to real data shows that it can adequately simulate sediment sorting phenomena in the reservoir.

4. A method is developed to account for the change in grain size distribution of the bed material. The computed gradation curves of deposition at Imperial Dam seem to properly represent the behavior that is physically observed to occur in many existing reservoirs. However, more specific field information on bed material changes with time and distance must be obtained in order to quantitatively compare with the results from the mathematical model.

5. Given a river-reservoir system with specific geometric, hydraulic and sediment characteristics, the mathematical model can be used to determine water elevations, sediment distribution patterns and specific weight and gradation of the sediment deposits. Application of the numerical model to a river system requires a careful selection of resistance coefficients and sediment parameters. The interpretation and analysis of results requires a thorough understanding of the behavior of river processes.

6. The model can be used to study long-term responses in the river-reservoir system. The determination of trap efficiency and useful life of the structure as well as better estimation of the capacity curves and outlet elevations is made possible by the use of the mathematical model. Additional potential applications of the model include the study of the upstream backwater effect and the control of sediment aggradation through reservoir operation criteria.

\subsection{Topics for Further Research} section.

Areas of future research are included in this

1. The mathematical model could be improved if a critical motion condition to control the deposition of the larger grains is introduced into the formulation. The Shield's criteria describing the beginning of sediment motion in alluvial channels can be used to obtain a relationship between the critical diameter (maximum size that will be transported by the stream) and the flow conditions in the system. By comparing the different fractional sizes of bed material with the critical diameter, a procedure for sorting the grain sizes can be carried out. If a representative grain size for any size fraction is at a given time and location greater than the corresponding critical diameter, that sediment fraction can no longer be transported by the stream and can be excluded from the sediment routing calculations at that section. Thus, this procedure, coupled with the sediment continuity equation, could provide a mean to more effectively account for the deposition of the coarser material.
2. The jet theory described in this study assumes that the boundary of the jet spreads parabolically from the inlet section of a wide reservoir. The coefficient for this boundary, i.e., the jet constant "a", must be obtained by calibration procedures. More real data must be analyzed and more research must be done in order to precisely estimate the value of this parameter for different geometric and hydraulic conditions. For the case of reservoirs with multiple inlets, the interaction between the various jets must al so be studied.

3. Additional research must be done for the determination of the lateral transfer of flow between subsections. The compound model computes the flow distribution based only on the conveyance equation. Further improvement of this model is required to account for the lateral transfer of momentum. The jet theory must also be improved to avoid problems of discontinuities that arise when the compound and jet models are used simultaneously. The determination of the diffusion coefficients requires also additional studies.

4. Secondary flows and density currents affect the sdistribution of the sediment deposits in reservoirs. A more realistic simulation can be obtained if these phenomena are considered in the formulation of the problem.

5. Finally, the model should be extended to study the downstream river response to dam construction. Determination of anticipated bed elevation changes within the downstream river reaches may be estimated from the water-sediment routing model, as used for the river upstream of the reservoir. The basic unsteady flow equations can be used with the average sediment concentration, $c_{s}$, at the upstream section equal to or approaching zero. The jet model may be applicable depending upon operational criteria of the outlet works and whether top or bottom withdrawal releases are used. The distribution of bed material sizes can be obtained again by routing the sediment for individual fractions. However, further research is recommended to consider the occurrence of extensive armouring.

It is clear that, with each step of improvement in the model the assumptions would become less severe, leading to the fact that the results predicted by the model can be considered more realistic and comparable with field data. On the other hand, there is a great amount of field data in the literature with information on sedimentation in reservoirs. The problem arises because the data is presently dispersed. Efforts must be made in collecting and analyzing field data with proper information on the hydraulic and sediment characteristics of river-reservoir systems. Further verification of the mathematical model for other types of reservoirs is needed before it becomes really applicable to design purposes in practical cases. 
Agricultural Research Service, 1975. "Present and Prospective Technology for Predicting Sediment Yields and Sources," U.S. Department of Agriculture, ARS-S-40, June 1975.

Albertson, M. L., Dai, Y. B., Jensen, R. A., and Rouse, H., 1950. "Diffusion of Submerged Jets," Trans. Am. Soc. Civil Engrs., V. 115, pp. 639-664.

Asada, H., 1973. "Some Examples of Bed Profile Calculations of Sedimentation in Reservoirs in Mountainous Regions," Proc. IAHR, V. 1., 15th Congress, Istanbul.

Bates, C. C. and Freeman, J. C., 1953. "Interrelations between Jet Behavior and Hydraulic Processes Observed at Deltaic River Mouths and Tidal Inlets," Proc. 3rd Conference Coastal Eng., Council on Wave Research, Berkeley, Cal ifornia.

Bates, C. C., 1953. "Rational Theory of Delta Formation," Bulletin of the American Association of Petroleum Geologists, V. 37, No. 9, pp. 2119-2162.

Berard, W., 1943. "Sedimentation in Reservoirs," Proceedings, ASCE, June, p. 793.

Borland, W. M. and Miller, C. R., 1960. "Sediment Problems of the Lower Colorado River," Journal of the Hydraulics Division, ASCE, V. 86 , No. HY4, April.

Borland, W. M. and Miller, C. R., 1958. "Distribution of Sediment in Large Reservoirs," Journal of the Hydraulics Division, ASCE, V. 84, No. HY2, Proceedings Paper No. 1587, pp. 1587-1 to 1587-18.

Bonham-Carter, G. F. and Sutherland, A. J., 1968. "Mathematical Model and Fortran IV Program for Computer Simulation of Deltaic Sedimentation," Computer Contribution 24, Kansas Geological Survey.

Brown, C. B., 1943. "The Control of Reservoir Silting," Miscellaneous Publication No. 521, USDA, August.

Brune, G. M., 1953. "Trap Efficiency of Reservoirs," Transactions, American Geophysical Union, V. 34, No. 3 , pp. 407-418.

Buttling, S. and Shaw, T. L., 1973. "Predicting the Rate and Pattern of Storage Loss in Reservoirs," Eleventh International Congress on Large Dams, Madrid, Spain, V. 1, Question No. 40.

Chang, F. F. M. and Richards, D. L., 1971. "Deposition of Sediment in Transient Flow, "Journal of the Hydraulics Division, ASCE, V. 97, No. HY6, June.

Chang, H. Y., 1967. "Hydraulics of Rivers and Deltas," Ph.D. Dissertation, Department of Civil Engineering, Colorado State University, Fort Collins, Colorado.

Chen, Y. H. and Simons, D. B., 1975. "Mathematical Modeling of Alluvial Channels," Symposium on Modeling Techniques. Proceedings, 2nd Annual Symposium of the Waterways, Harbors and Coastal Engineering Division of ASCE, V. 1, pp. 466-483.
Chen, Y. H., 1973. "Mathematical Modeling of Water and Sediment Routing in Natural Channels," Ph.D. Dissertation, Department of Civil Engineering, Colorado State University, Fort Collins, Colorado.

Chow, V. T., 1959. "Open Channel Hydraulics," McGrawHill Book Company, Civil Engineering Series, New York.

Churchi11, M. A., 1947. Discussion of "Analysis and Use of Reservoir Sedimentation Data," by L. C. Gottschalk, Proceedings of the Federal Interagency Sedimentation Conference, Denver, Colorado, pp. 139-140.

Combs, P. G. and Thomas, W. A., 1977. "Application of Flow-Sediment Model to Red River," Journal of the Hydraulics Division, ASCE, V. 103, No. HY1, January.

Dass, P. and Simons, D. B., 1976. "Mathematical Model to Simulate Channel Deformation," Proceedings, 3rd Annual Symposium of the Waterways, Harbors and Coastal Engineering Division, ASCE, p. 1-15.

Dass, P., 1975. "Water and Sediment Routing in Nonuniform Channels," Ph.D. Dissertation, Department of Civit Engineering, Colorado State University, Fort Collins, Colorado.

DeVries, M., 1965. "Considerations about Non-Steady Bed-Load Transport in Open Channels," Proceedings, 11 th Congress of IAHR, V. 3 .

Fread, D. L., 1974. "Numerical Properties of Implicit Four-Point Finite Difference Equations of Unsteady Flow," NOAA Technical Memorandum NWS HYDRO-18.

Garde, R. J. and Swamee, P. K., 1973. "Analys is of Aggradation Upstream of a Dam," Proceedings, IAHR, International Symposium on River Mechanics, V. I, Bangkok.

Gessler, J., 1971. "Aggradation and Degradation," Chapter 8 in River Mechanics, H. W. Shen, ed., Water Resources Publications, Fort Collins, Colorado.

Graf, W. H., 1971. "Hydraulics of Sediment Transport," McGraw-Hill Book Company, Series in Water Resources and Environmental Engineering.

Henderson, F. M., 1966. Open Channel Flow, McMillan Company, New York.

Horton, R., 1941. Discussion by Robert Horton of "Dynamics of Water Erosion on Land Surfaces," by Leonard Schiff and Robert E. Yoday. Transactions, American Geophysical Union, pp. 287-302.

Hurst, A. J. and Chao, P. C., 1975. "Sediment Deposition Model for Tarbela Reservoir," Symposium on Modeling Techniques--2nd Annual Symposium of the Waterways, Harbors, and Coastal Engineering Division, V. 1, pp. 501-520.

Karaki, S., Mahmood, K., Richardson, E. V., Simons, D. B., and Stevens, M.A., 1974. "Highways in the River Environment, Hydraulic and Environmental Design Considerations," prepared by Engineering Research Center, Colorado State University, Fort Collins, Colorado. 
Karaushev, A. V., 1966. "The Silting of Sma11 Reservoirs and Ponds Theory and Calculation Methods," American Geophysical Union, Soviet Hydrology No. 1.

Kaser, R. F., 1960. "Trap Efficiency of Reservoirs, Debris Basins and Debris Dams," discussion by Kaser, R. F., Journal of the Hydraulics Division, ASCE, No. HY5, May.

Koelzer, V. A. and Lara, J., 1958. "Densities and Compaction Rates of Deposited Sediments," Journal of the Hydraulic Division, ASCE, V. 84, No. HY2, April.

Lane, E. W. and Koelzer, V. A., 1943. "Density of Sediment Deposited in Reservoirs," Report No. 9, U.S. Interdepartmental Committee, St. Paul District, Corps of Engineers, St. Paul, Minnesota.

Lara, J. M. and Pemberton, E. L., 1963. "Initial Unit Weight of Deposited Sediments," Federal Interagency Sedimentation Conference, Jackson, Wyoming.

Lara, J. M., 1962a. "Revision of the Procedure to Compute Sediment Distribution in Large Reservoirs," U.S. Department of the Interior, Bureau of Reclamation, 7 p., 2 tables, 9 figures.

Liggett, J. A. and Cunge, J. A., 1974. "Numerical Methods of Solution of the Unsteady Flow Equations," presented as Chapter 4 in the Institute on Unsteady Flow in Open Channels, held at Colorado State University, Fort Collins, Colorado.

Mahmood, K. and Ponce, V. M., 1976. "Mathematical Modeling of Sedimentation Transients in Sand Bed Channels," Report No. CER75-76KM-VMP28, Engineering Research Center, Colorado State University, Fort Collins, Colorado.

Miller, C. R., 1953. "Determination of the Unit Weight of Sediment for Use in Sediment Volume Computations," U.S. Bureau of Reclamation Memorandum, February 17.

Moore, C. M., Wood, W. J., and Renfro, G. W., 1960. "Trap Efficiency of Reservoirs, Debris Basins, and Debris Dams," Journal of the Hydraulics Division, ASCE, V. 86 , No. HY2, February.

Moser, T. H. and Sears, W. D., 1976. "Sediment Control . at Imperial Dam," Proceedings, Third Federal Interagency Sedimentation Conference, March 2225, Denver, Colorado.

Ponce, V. M., Lopez-Garcia, J., and Simons, D. B. "MODEIN2 and Colby: Computer Codes for Sediment Transport Computations," Report No. CER76-77VMPJL-DBS19, Engineering Research Center, Colorado State University, Fort Collins, Colorado.

Ponce, V. M., Indlekofer, H., and Simons, D. B., 1978. "The Convergence of Implicit Bed Transient Models, "Approved for publication in the Journal of the Hydraulics Division, ASCE, February.

Ponce, V. M. and Simons, D. B., 1978. "Shallow Wave Propagation in Open Channel Flow," Submitted for publication in the Journal of the Hydraulics Division, V. 103, HY12, pp. 1461-1476.
Price, R. K., 1974. "Comparison of Four Numerical Methods for Flood Routing," Journal of the Hydraulics Division, ASCE, V. 100, No. HY7, pp. 879-899.

Rana, S. A., 1971. "Sediment Sorting in Alluvial Channels," M.S. Thesis, Department of Civil Engineering, Colorado State University, Fort Collins, Colorado.

Richardson, E. V. and Christian, H., 1976. "Channel Improvements of the Missouri River," Proceedings, Third Federal Interagency Sedimentation Conference, March 22-25, Denver, Colorado.

Richardson, E. V. and Simons, D. B., 1976. "River Response to Development," Proceedings, 3rd Annual Symposium of the Waterways, Harbors and Coastal Engineering Division, ASCE, Colorado State University, Fort Collins, Colorado.

Simons, D. B. and Sentürk, F., 1977. "Sediment Transport Technology," Water Resources Publication, Fort Collins, Coloardo.

Simons, D. B., et a1., 1977. "Flood Flows, Stages and Damages," Colorado State University, CER7778DBS-VMP-RML-YHC-JG-TJW-ND9, Engineering Research Center, Fort Collins, Colorado.

Strelkoff, T., 1970. "Numerical Solution of SaintVenant Equations," Journal of the Hydraulics Division, ASCE, No. HY1, pp. 223-252.

Suryanarayana, B., 1969. "Mechanics of Degradation and Aggradation in a Laboratory Flume," Ph.D. Dissertation, Department of Civil Engineering, Colorado State University, Fort Collins, Colorado.

Thomas, W. A., 1970. "A Digital Model for Simulating Sediment Movement in a Shallow Reservoir," Proceedings of a Seminar on Sediment Transport in Rivers and Reservoirs, the Hydrologic Engineering Center, U.S. Army Corps of Engineers.

U.S. Bureau of Reclamation, 1973. "Design of Small Dams," 2nd Edition.

U.S. Bureau of Reclamation, 1966. "Examination of Colorado River Font Work and Levee System," Report of Examination by W. M. Borland and T. W. Goddard, Denver, Colorado.

U.S. Bureau of Reclamation, 1969. "Report on River Control Work and Investigations, Lower Colorado River Basin," Boulder City, Nevada.

U.S. Bureau of Reclamation, 1969. "Sediment Studies for the California Sluiceway-Imperial Dam," Lower Colorado River Project and Yuma Project, Denver, Colorado.

Vanoni, V., ed., 1975. "Sedimentation Engineering," prepared by the Task Committee for the preparation of the Manual on Sedimentation of the Sedimentation Committee of the Hydraulics Division, ASCE.

Yalin, M. S., 1972. "Mechanics of Sediment Transport." Pergamon Press, Ltd., Headington Hill Hall, Oxford.

Yuce1, 0. and Graft, W., 1973. "Bed Load Deposition and Delta Formation: A Mathematical Model," Lehigh University, Fritz Engineering Laboratory Report No. 384.1 . 
Key words: Sedimentation, Sediment Deposition, Reservoirs, Dams, Water Supply, Mathematical Models.

Abstract: A mathematical model for the prediction of the extent, locations and gradation of the sediment deposits in reservoirs was and is described in this paper. The model considers the reservoir as a set of multiple channels and uses a compound stream model approach together with a two-dimensional jet theory to route the flow of water and sediment. Upstream from the reservoir a one-dimensional single channel approach is used to simulate the river flow.

Validation of the mathematical model was made by utilizing data developed in a study of the sediment
Key words: Sedimentation, Sediment Deposition, Reservoirs, Dams, Water Supply, Mathematical Models.

Abstract: A mathematical model for the prediction of the extent, locations and gradation of the sediment deposits in reservoirs was and is described in this paper. The model considers the reservoir as a set of multiple channels and uses a compound stream model approach together with a two-dimensional jet theory to route the flow of water and sediment. Upstream from the reservoir a one-dimensional single channel approach is used to simulate the river flow.

Validation of the mathematical model was made by utilizing data developed in a study of the sediment
Key words: Sedimentation, Sediment Deposition, Reservoirs, Dams, Water Supply, Mathematical Models.

Abstract: A mathematical model for the prediction of the extent, locations and gradation of the sediment deposits in reservoirs was and is described in this paper. The model considers the reservoir as a set of multiple channels and uses a compound stream model approach together with a two-dimensional jet theory to route the flow of water and sediment. Upstream from the reservoir a one-dimensional single channel approach is used to simulate the river flow.

Validation of the mathematical model was made by utilizing data developed in a study of the sediment
Key words: Sedimentation, Sediment Deposition, Reservoirs, Dams, Water Supply, Mathematical Models.

Abstract: A mathematical model for the prediction of the extent, locations and gradation of the sediment deposits in reservoirs was and is described in this paper. The model considers the reservoir as a set of multiple channels and uses a compound stream model approach together with a two-dimensional jet theory to route the flow of water and sediment. Upstream from the reservoir a one-dimensional single channel approach is used to simulate the river flow.

Validation of the mathematical model was made by utilizing data developed in a study of the sediment 
deposition pattern in a sudden expansion in a laboratory flume, and utilizing available data from the

Lower Colorado River above Imperial Dam. The actual data were compared with generated bed profiles from the mathematical model. The flume study showed the importance of considering the jet model when studying the deposition pattern of wide basins. The extent and the distribution of the sediment deposits above Imperial Dam were in reasonable agreement with the observed data. The model also effectively accounted for sediment sorting and change in gradation of bed material with time.

Reference: Lopez S., Jose Luis; Colorado State University, Hydrology Paper No. 95 (July 1978), Mathematical Modeling of Sediment Deposition in Reservoirs. deposition pattern in a sudden expansion in a laboratory flume, and utilizing available data from the Lower Colorado River above Imperial Dam. The actua data were compared with generated bed profiles from the mathematical model. The flume study showed the importance of considering the jet model when studying the deposition pattern of wide basins. The extent and the distribution of the sediment deposits above Imperial Dam were in reasonable agreement with the observed data. The model also effectively accounted for sediment sorting and change in gradation of bed material with time.

Reference: Lopez S., Jose Luis; Colorado State University, Hydrology Paper No. 95 (July 1978), Mathematical Modeling of Sediment Deposition in Reservoirs. deposition pattern in a sudden expansion in a laboratory flume, and utilizing available data from the Lower Colorado River above Imperial Dam. The actual data were compared with generated bed profiles from the mathematical model. The flume study showed the importance of considering the jet model when studying the deposition pattern of wide basins. The extent and the distribution of the sediment deposits above Imperial Dam were in reasonable agreement with the observed data. The model also effectively accounted for sediment sorting and change in gradation of bed material with time.

Reference: Lopez S., Jose Luis; Colorado State University, Hydrology Paper No. 95 (July 1978), Mathematical Modeling of Sediment Deposition in Reservoirs. deposition pattern in a sudden expansion in a laboratory flume, and utilizing available data from the Lower Colorado River above Imperial Dam. The actual data were compared with generated bed profiles from the mathematical model. The flume study showed the importance of considering the jet model when studying the deposition pattern of wide basins. The extent and the distribution of the sediment deposits above Imperial Dam were in reasonable agreement with the observed data. The model also effectively accounted for sediment sorting and change in gradation of bed material with time.

Reference: Lopez S., Jose Luis; Colorado State University, Hydrology Paper No. 95 (July 1978), Mathematical Modeling of Sediment Deposition in Reservoirs. 


\section{LIST OF PREVIOUS 25 PAPERS}

No. 70 Regional Water Exchange for Drought Alleviation, by Kuniyoshi Takeuchi, November 1974.

No. 71 Determination of Urban Watershed Response Time, by E. F. Schulz, December 1974.

No. 72 generation of Hydrologic Samples, Case Study of the Great Lakes, by V. Yevjevich, May 1975.

No. 73 Extraction of Information on Inorganic Water Quality, by William L. Lane, August 1975.

No. 74 Numerical Model of Flow in Stream-Aquifer System, by Catherine E. Kraeger Rovey, August 1975.

No. 75 Dispersion of Mass in Open-Channel Flow, by William W. Sayre, August 1975.

No. 76 Analysis and Synthesis of Flood Control Measures, by Kon Chin Tai, September 1975.

No. 77 Methodology for the Selection and Timing of Water Resources Projects to Promote National Economic Development, by Wendim-Agegnehu Lemma, August 1975.

No. 78 Two-Dimensional Mass Dispersion in Rivers, by Forrest M. Holly, Jr., September 1975.

No. 79 Range and Deficit Analysis Using Markov Chains, by Francisco Gomide, October 1975.

No. 80 Analysis of Drought Characteristics by the Theory of Run, by Pedro Guerrero-Salazar and Vujica Yevjevich, October 1975.

No. 81 Influence of Simplifications in Watershed Geometry in Simulation of Surface Runoff, by L. J. Lane, D. A. Woolhiser and V. Yevjevich, January 1976.

No. 82 Distributions of Hydrologic Independent Stochastic Components, by Pen-chih Tao, V. Yevjevich and N. Kottegoda, January 1976.

No. 83 Optimal Operation of Physically Coupled Surface and Underground Storage Capacities, by Dragoslav Isailovic, January 1976.

No. 84 A Salinity Management Strategy for Stream-Aquifer Systems, by Otto J. Helweg, and J. Labadie, February 1976.

No. 85 Urban Drainage and Flood Control Projects Economic, Legal and Financial Aspects, by Neil S. Grigg, Leslie H. Botham, Leonard Rice, W. J. Shoemaker, and L. Scott Tucker, February 1976.

No. 86 Reservoir Capacity for Periodic-Stochastic Input and Periodic Output, by Kedar Nath Mutreja, September 1976.

No. 87 Area-Deficit-Intensity Characteristics of Droughts, by Norio Tase, October 1976.

No. 88 Effect of Misestimating Harmonics in Periodic Hydrologic Parameters, by K. L. Bullard, V. Yevjevich, and N. Kottegoda, November 1976.

No. 89 Stochastic Modeling of Hydrologic, Intermittent Daily Processes, by Jerson Kelman, February 1977.

No. 90 Experimental Study of Drainage Basin Evolution and Its Hydrologic Implications, by Randolph S. Parker, June 1977.

No. 91 A Model of Stochastic Structure of Daily Precipitation Series Over an Area, by C. W. Richardson, July 1977.

No. 92 Effects of Forest and Agricultural Land Use on Flood Unit Hydrographs, by Wiroj Sangvaree and Vujica Yevjevich, July 1977.

No. 93 A Distributed Kinematic Model of Upland Watersheds, by Edward W. Rovey, David A. Woolhiser and Roger E. Smith, July 1977.

No. 94 Fluctuations of Wet and Dry Years, an Analysis by Variance Spectrum, by Vujica Yevjevich, August 1977. 